Dimensionen der Sorge

Thorsten Benkel | Matthias Meitzler | Dirk Preuß

\title{
Autonomie der Trauer
}

Zur Ambivalenz des sozialen Wandels 


\section{Dimensionen der Sorge}

herausgegeben von

Anna Henkel,

Universität Passau

Isolde Karle,

Ruhr-Universität Bochum

Gesa Lindemann,

Carl von Ossietzky Universität Oldenburg

Micha Werner,

Ernst Moritz Arndt Universität Greifswald

Band 4 
Thorsten Benkel | Matthias Meitzler | Dirk Preuß

\section{Autonomie der Trauer}

Zur Ambivalenz des sozialen Wandels

\section{Nomos}




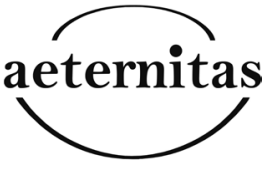

Aeternitas e.V., die gemeinnützige Verbraucherinitiative Bestattungskultur, informiert und berät in allen organisatorischen, rechtlichen und finanziellen Angelegenheiten rund um den Trauerfall und fördert eine zeitgemäße, bürgerfreundliche Bestattungskultur.

Publiziert mit Unterstützung durch die Universitätsbibliothek Passau.

Die Deutsche Nationalbibliothek verzeichnet diese Publikation in der Deutschen Nationalbibliografie; detaillierte bibliografische Daten sind im Internet über http://dnb.d-nb.de abrufbar.

1. Auflage 2019

(c) Thorsten Benkel, Matthias Meitzler, Dirk Preuß

Publiziert von

Nomos Verlagsgesellschaft $\mathrm{mbH} \& \mathrm{Co}$. KG Waldseestraße 3-5 | 76530 Baden-Baden www.nomos.de

Gesamtherstellung:

Nomos Verlagsgesellschaft mbH \& Co. KG Waldseestraße 3-5 | 76530 Baden-Baden

Gedruckt in Deutschland auf alterungsbeständigem Papier.

ISBN (Print): 978-3-8487-6032-9

ISBN (ePDF): 978-3-7489-0152-5

DOI: https://doi.org/10.5771/9783748901525

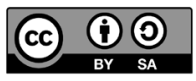

Dieses Werk ist lizenziert unter einer Creative Commons Namensnennung Weitergabe unter gleichen Bedingungen 3.0 Deutschland Lizenz. 


\section{Inhalt}

Einleitung - Trauer in Zeiten gesellschaftlicher Transformation

Thorsten Benkel, Matthias Meitzler \& Dirk Preuß

Mitbestimmte Trauer. Soziologie einer Sinnkonstruktion

Thorsten Benkel

Keine Angst vor echten Tränen. Die Erforschung von Trauer als methodologische Herausforderung

Matthias Meitzler

Zur Rekonstruktion von Trauererfahrungen.

Einstellungsäußerungen im Interviewkontext

Thorsten Benkel \& Matthias Meitzler

Normen im Umgang mit Trauernden. Ethische Überlegungen

Dirk Preuß

Nachwort - Wie die Theorie zur Praxis kommt. Acht Vorschläge

Thorsten Benkel, Matthias Meitzler \& Dirk Preuß

Literaturverzeichnis

Die Autoren

Abbildungen 


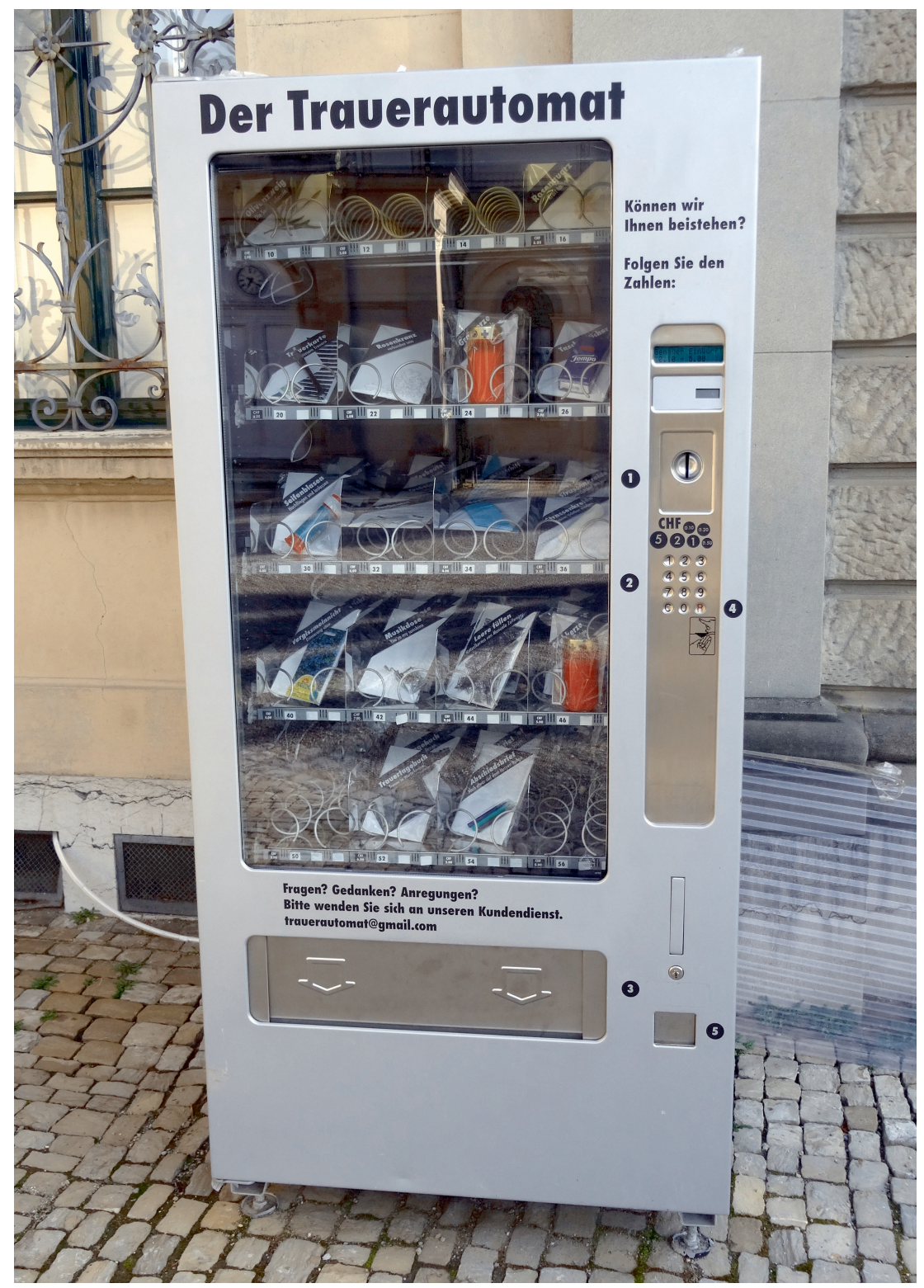




\title{
Einleitung- \\ Trauer in Zeiten gesellschaftlicher Transformation
}

\author{
Thorsten Benkel, Matthias Meitzler \& Dirk Preuß
}

»Was ist denn eigentlich Trauer? Ich weiß das gar nicht. Ich weiß auch gar nicht so genau, wie ich eigentlich trauere und ich hab' festgestellt, dass das so 'ne ganz komische Sache ist, die von einem erwartet wird, von der man aber selber gar nicht weiß, wie das geht."

(Interview M8, 6:52)

\section{Die Gegenwart und Zukunft von Trauer und Bestattung}

Ein wenig sind wir Wissenschaftler ja mitschuldig. ${ }^{1}$ Dass es beinahe schon zu einem Gemeinplatz geworden ist, vom 'Wandel der Bestattungskultur< zu sprechen, dürfte einerseits der Permanenz gesellschaftlicher Veränderungen geschuldet sein - und verdankt sich andererseits wohl auch der in den letzten Jahren gestiegenen Aufmerksamkeit vonseiten zuständiger Disziplinen.

Es wäre nun ja auch seltsam, würde sich die Welt bewegen, würde sich Gesellschaft verändern und würden alleine die sepulkrale Sphäre, die Art und Weise, in der Trauer ihren Ausdruck findet, im gegebenen Zustand verharren. Danach sieht es ganz und gar nicht aus, und deshalb ist die Frage interessant, wohin und mit welchem Tempo sich die Trauer- und Bestattungsrituale entwickeln, was dies für den Friedhof, die Bestatterbranche, die Zuliefererindustrie, die Steinmetze und Friedhofsgärtner etc. bedeutet. Virulent ist für die Gewerbetreibenden allzumal die Frage, ob dieser Wandel in Form leichter Verschiebungen stattfinden oder ob es zu tiefgreifenden Umbrüchen kommen wird. Fachleute wissen aus eigener, nicht selten leidvoller Erfahrung, dass die seismische Bestimmung entsprechender Ver-

1 Aus Gründen der besseren Lesbarkeit wird in diesem Band auf die gleichzeitige Verwendung männlicher und weiblicher Sprachform verzichtet. Alle Personenbezeichnungen gelten - wenn nicht ausdrücklich anders gekennzeichnet - gleichwohl für sämtliche Geschlechter. 
änderungen im Vergleich zum tatsächlichen Beben manchmal ganz anders ausfällt, als prognostiziert wurde; ein wenig Überraschungspotenzial ist also immer mit dabei.

Durchaus merkliche, wenn auch nicht umstürzende Veränderungen konnten in der Vergangenheit etwa durch das Aufkommen der Waldbestattungen festgestellt werden. Sie führten und führen zu einer Abwanderung von den bis dato snormalen Friedhöfen hin in die sogenannten Ruheforste und Friedwälder, und auf diesen Zug werden gewiss noch andere Anbieter aufspringen. Die Friedhöfe verloren so an Bestattungszahlen, reagierten aber ihrerseits mit einer erweiterten Angebotspalette, zu der Baumbeisetzungen oder pflegeleichte Gemeinschaftsgrabflächen gehören. Ob dies langfristig eine zielführende Taktik ist, um den Friedhof als primäre Raumanordnung im Kontext von Gedenkhandlungen festzuschreiben, ist ebenso offen wie die Frage, ob die genannten Naturbestattungsmodelle ihren Charme auf lange Sicht werden bewahren können - erst recht dann, wenn die nächste große Innovation kommt, die Angehörigen als echte Alternative zum Althergebrachten präsentiert wird.

Zweifellos kommt es bereits jetzt zu ökonomischen Verlusten und Unternehmensschließungen; soweit wir sehen, werden die bisherigen Geschäftsmodelle aber (noch?) nicht per se in Frage gestellt. Die Situation scheint eher die einer Ergänzung um Konkurrenzkonzepte zu sein, mit denen vor Jahrzehnten noch niemand rechnen wollte - und die gegenwärtig, mehr oder weniger diskret, allemal aber selbstbewusst das Ende antiquierter Abschieds- und Erinnerungsmodelle beschwören. Könnten sich auch Verwerfungen in der Sepulkralkultur einstellen - etwa so, wie die Digitalfotografie das faktische Aus für ihre analogen Vorläufer bedeutete?2 Im Raum steht u.a. die Befürchtung, dass in Deutschland eine Aufhebung der sogenannten Friedhofspflicht droht - jenes juristischen Vorschriftenkanons,

2 Der geneigte Friedhofsbesucher dürfte ahnen, dass der Vergleich nicht ganz deplatziert wirkt, wo doch die Digitalfotografie aktuell einen der größten Transformationsfaktoren in deutschen Grablandschaften darstellt. Seit gut 20 Jahren wird mit dem Anbringen von Fotos an der Ruhestätte der Toten eine alte Tradition wiederbelebt, die bereits Mitte des 19. Jahrhunderts mit dem Aufkommen der fotografischen Technik ihren Anfang nahm, im Zuge der nationalsozialistischen Herrschaft und lange Zeit danach indes eine (auch juristisch gesteuerte) Unterbrechung erfuhr. Die omnipräsente Einsatzbereitschaft von (Digital-)Kameras forciert heutzutage nicht nur im sozialen Alltag eine regelrechte >Bilderflut‘, sondern trägt nicht zuletzt auch dazu bei, dass Fotografien auf Grabsteinen gegenwärtig so vielfältig und so weit verbreitet sind wie nie zuvor (Benkel/Meitzler 2014a; dies. 2016a). 
der den Friedhof zum (fast ${ }^{3}$ ) einzig legitimen Bestattungsort menschlicher Körperüberreste adelt. ${ }^{4}$ Vorstöße in diese Richtung gibt es an verschiedenen Fronten, mit durchaus unterschiedlichen Effekten. Auch wenn die Friedhofspflicht angeschlagen ist, steht sie noch; aber wie lange? Nichts bleibt ewig bestehen, auch nicht eine etablierte Rechtsauffassung. Drohen Steinmetz- und Friedhofsgärtnerbranche zu den nekropolitischen Gegenstücken von Kodak und Agfa zu werden?

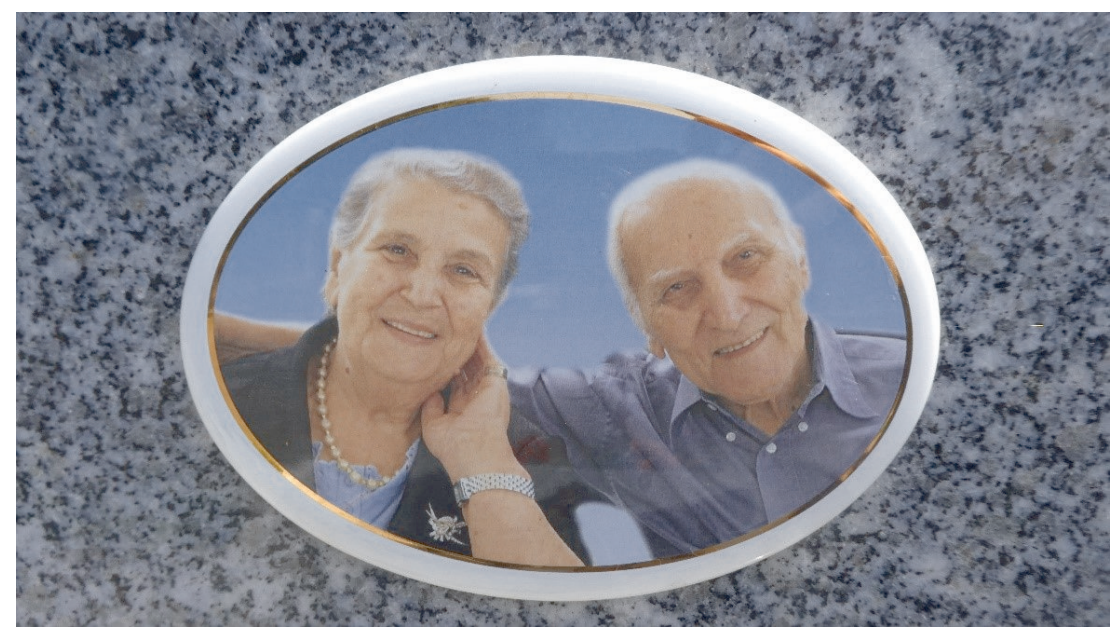

Was nicht selten von den Stakeholdern diskutiert und verständlicherweise auf die eigene Geschäftswelt hin reflektiert wird, stellt sich noch einmal anders akzentuiert mit Blick auf und aus Perspektive von unmittelbar Betroffenen dar. Während sich die einen angesichts der verschiedenen Angebote auf dem Markt die Augen reiben und fragen, nach welchen Kriterien wohl die Wahl zwischen Landschaftsgräberfeld, Gemeinschaftsgrab, Ko-

3 Ausnahmen bilden die Seebestattung, die erwähnten Beisetzungen auf einer speziell dafür gewidmeten Waldfläche oder in einem Kirchenkolumbarium.

4 Ursprünglich geht diese Verpflichtung auf das Preußische Allgemeine Landesrecht zurück und wurde im deutschen Feuerbestattungsgesetz von 1934 erneut aufgegriffen. Dort heißt es: „Die Aschenreste jeder Leiche sind in ein amtlich zu verschließendes Behältnis aufzunehmen und in einer Urnenhalle, einem Urnenhain, einer Urnengrabstelle oder in einem Grabe beizusetzen. ( $\$ 9$ Abs. 1 FBestattG) Mittlerweile sind in den verschiedenen Bundesländern unterschiedliche Bestattungsgesetze gültig, die aber ganz überwiegend im Geiste der zitierte Normpassage stehen; dazu weiter unten mehr. 
lumbarium, anonymer Beisetzung, Rasengrab, Erdwahlgrab oder Urnenhain zu treffen sei, erleben andere die Bestattungsgesetze, Friedhofsordnungen und überhaupt die Erwartungen im sozialen Umfeld als hochreglementiert bzw. einengend und wünschen sich größere Freiheiten, wie man sie längst schon aus den allermeisten EU-Nachbarländern kennt. ${ }^{5} \mathrm{Zu}$ den naheliegenden, weil im Trauerkontext evident funktionalen Wünschen gehört das Anliegen, die Asche des Verstorbenen im Krematorium ausgehändigt zu bekommen und mit nach Hause zu nehmen, oder sie einem anderen Schicksal - jedenfalls: einem selbstbestimmten Umgang - zuzuführen, sei es im Sinne der Verstorbenen oder derer, die sich ihnen über den Tod hinaus verbunden fühlen.

Über die Mitnahme der Asche ist in der Vergangenheit viel diskutiert worden - in Gesetzgebungsverfahren, auf Bestattungs- und Friedhofsfachmessen, in der Presse, im Ad-hoc-Gespräch. Die einen sind aufgeschlossener; die anderen zeigen sich ablehnender. Wenn auch manche Bundesländer (etwa Nordrhein-Westfalen) in gewisser Hinsicht Lockerungen zulassen, so ist Bremen doch bislang das einzige Bundesland, das mit der Friedhofspflicht bricht, unter bestimmten Bedingungen. ${ }^{6}$ Manche anderen sehen in einer Liberalisierung der Praxis eine Gefahr für ihr Geschäftsmodell, wenn nicht gleich für das christliche Abendland. Wieder andere sehnen die liberaleren niederländischen, französischen, schweizerischen oder amerikanischen Verhältnisse herbei, weil sie gerade in dem dadurch erhofften Schub eine überfällige Erneuerung der Modi des Trauerns angelegt sehen.

Viel wurde auch darüber spekuliert, welche Auswirkungen es auf die Angehörigen, auf die engeren und ferneren Bekannten haben könnte, gäbe es kein öffentlich zugängliches Grab mehr, sondern einen Platz für die Urne im Wohnzimmer. Vielleicht wird die Asche aber auch im Garten vergraben, aufgeteilt oder ausgestreut. Genau genommen handelt es sich nur be-

5 Neben Deutschland gilt die Friedhofspflicht auch in Österreich und Italien. In anderen Staaten wie der Schweiz, Frankreich, Spanien, den Niederlanden oder in Teilen von Tschechien ist sie zumindest für Kremationsasche aufgehoben.

6 Hierzu muss die betroffene Person ihren letzten Wohnsitz im Bundesland Bremen gemeldet und über die Beisetzung außerhalb des Friedhofs schriftlich verfügt sowie einen Totenfürsorgeberechtigten benannt haben. Ferner muss sich der Beisetzungsort in privatem Eigentum befinden, der Grundstückseigentümer seine $\mathrm{Zu}$ stimmung erklärt haben und benachbarte Grundstücke dürfen durch die Beisetzung nicht beeinträchtigt werden (Gesetz über das Friedhofs- und Bestattungswesen in der Freien Hansestadt Bremen, $\mathbb{S} 4$, Abs. 1a). Diese Sonderregelung ermöglicht insgesamt einen flexibleren Umgang mit Kremationsasche, eine faktische Abschaffung der Friedhofspflicht ist damit allerdings nicht vollzogen. 
dingt um Spekulationen, denn tatsächlich geschieht all dies bereits in deutschen Wohnstätten, Grund- und Waldstücken, und an zahlreichen weiteren Orten, die genügend Diskretion für den kurzen Augenblick ihrer oft unsichtbaren Veränderung geben.

Gewiss können viele Friedhofsmitarbeiter und zahlreiche Bestatter (wir reihen uns ebenfalls ein) Anekdoten und Gerüchte über den einen oder den anderen Fall preisgeben, bei welchem jeweils eine der folgenden Aussichten realisiert wurde: etwa Aschekapseln, die angeblich im Müll entsorgt werden; Trauernde, denen der Zugang zur privat verwahrten Asche verwehrt ist; Urnen, die Teil der Erbmasse mittlerweile verstorbener Angehöriger sind, usw. Zu hören sind aber ebenso Geschichten von Menschen, denen die Urne zuhause Trost und Hilfe bei der Trauer bietet. In einer moralisch disparat gewordenen Gesellschaft sind nicht nur die Narrative unterschiedlich - sondern auch ihre Bewertung.

Was in der Debatte bisher weitgehend fehlte, war die Auskunft derer und eine systematische und breit angelegte Erhebung zu denen, die die Angelegenheit im Kern betrifft. Gemeint sind, schon dies war einmal ein Paradigmenwechsel und ist heute weitgehend common sense, nicht die Toten, sondern die Hinterbliebenen. Betroffen sind sowohl diejenigen, die sich tatsächlich für die Mitnahme der Asche entschieden haben und diese Praxis zu verwirklichen wussten, ${ }^{7}$ als auch solche Angehörigen, die diesen Weg nicht gewählt haben, gleichwohl aber starke Vorbehalte gegenüber der normativen Konstruktion des Trauerns hegen. Das vorliegende Buch ist ein Versuch, den Fokus in diese Blickrichtung zu justieren und die Diskussion damit aus dem bloßen Expertenkontext dorthin zu rücken, wo sie wahrhaftig von lebens-, und eben nicht von todesweltlicher Relevanz ist.

7 Wird die Kremation im Ausland vorgenommen bzw. die Urne von einem ausländischen Krematorium angefordert und dorthin gebracht, so unterliegt die Totenasche fortan nicht mehr deutschem Recht, sondern den Bestattungsverordnungen des jeweiligen Landes - die überwiegend liberaler sind als die Vorschriften in Deutschland. (Ggf. verlangen deutsche Behörden den formalen Nachweis über die Miete einer Grabstätte auf ausländischem Boden; nur selten kommt es vor, dass eine Behörde von dem Vorhaben der Ascheaneignung erfährt und es mit Verwaltungsmaßnahmen unterbinden will.) Nach Ablauf einer bestimmten Frist kann die Urne über den Postweg zurück nach Deutschland versendet oder vor Ort von Angehörigen abgeholt werden. 


\section{Forschungsleitende Fragestellungen und Erkenntnisinteresse}

Im Zentrum unserer Forschung stehen die mit den Handlungen der Angehörigen verbundenen Motive, Erwartungen und Versprechungen. Was verbinden Menschen damit, was erhoffen sie und was antizipieren sie, wenn sie sich die Asche ihres Verstorbenen aushändigen lassen, sei es, um sie zuhause aufzubewahren oder an einem Ort ihrer Wahl auszustreuen oder beizusetzen? Hinsichtlich der (größeren) Gruppe derer, die Kritik äußern bzw. Renovierungsbedarf an den Regularien sehen, ohne diese anzugreifen, wollten wir wissen, ob und inwiefern das Problem ein normatives und/oder ein individuelles, biografisches ist; ob damit persönliche Erfahrungen tangiert werden, oder eine generelle Kritik ausgesprochen werden soll; ob die Bewertung für unterschiedliche Menschen (nahes/weiteres Umfeld, Fremde...) unterschiedlich ausfält, und vieles mehr. Generell interessiert uns, welches Verständnis und welche Konzepte von Trauer und Trauerprozessen sich in den Aussagen von Menschen widerspiegeln, die also und dies ist die thematisch umfassende Klammer - über Erfahrungen im Umgang mit dem Verlust einer nahestehenden Person verfügen.

Konkret gefragt: Geht die Entscheidung gegen den Friedhof, wo sie denn vorliegt, auf den zu Lebzeiten geäußerten Wunsch des Verstorbenen zurück oder wurde sie allein von den Angehörigen gefällt? Wie muss man sich die Aushandlungsprozesse in den Familien vorstellen (wenn es sie überhaupt gegeben hat)? Welche Vorzüge werden dem Vorgehen zugeschrieben? Und ebenso wichtig: Inwieweit haben sich daran geknüpfte Erwartungen, Hoffnungen oder Befürchtungen im Nachhinein erfüllt? Aus welchen Gründen wurde das Angebot des Friedhofs, immerhin der kulturell dominante Beisetzungs- und Trauerort, abgelehnt? Speziell mit Blick auf gesellschaftliche Wandlungsprozesse ist zu fragen: Wie stark ist Trauern zu einer Angelegenheit geworden, die individualistisch >betrieben< wird wodurch kollektive Rahmenbedingungen verständlicherweise an Attraktivität verlieren?

Ferner sollte mit der Studie in Erfahrung gebracht werden, über welche Wissensquellen speziell diejenigen, die sich die Asche aneigneten, bei ihrer Entscheidungsfindung verfügten. Stand ihr Entschluss vvon vornherein< fest, wurde er saus dem Bauch heraus getroffen oder erst nach reiflicher Abwägung aller bekannten Optionen? Welche Rolle spielt dabei das Bewusstsein, streng genommen etwas Illegales zu tun bzw. getan zu haben wenn auch die Strafverfolgungsquote, nach unserem Informationsstand, gering ist? Wird der selbstbestimmte Umgang mit den Ascheresten gegenüber anderen Personen thematisiert? Wie reagieren diese; kam es zu Konflikten? Unsere Untersuchung blickt zudem auf den Stellenwert von 
Räumlichkeit, Körperlichkeit und Zeitlichkeit. Benötigt Trauer aus Sicht der Betroffenen einen festen Ort? Bedeutet die räumliche Nähe zur Kremationsasche (etwa im Falle der häuslichen Urnenaufbewahrung) zugleich eine größere subjektive Nähe zum Verstorbenen? Inwieweit wird die eher abstrakte und nicht unmittelbar sinnlich wahrnehmbare Asche - die noch dazu morphologisch dem verstorbenen Menschen völlig unähnlich ist überhaupt mit dem Toten in Verbindung gebracht? Hat der Umgang mit der Asche heute noch den gleichen Stellenwert für das persönliche Trauermanagement wie zu der Zeit unmittelbar nach dem Verlust?

Viele dieser Fragen erlauben eine Übertragung hin in die Gruppe derjenigen, die zu einer Art >Reflexionselite r geworden sind: Ihre Erfahrung im Zusammenhang von Sterben, Tod und Trauer hat sich ihnen eingeschrieben, sie sind, ohne dies gewollt zu haben, Experten der Verabschiedung einer oder mehrerer Personen geworden, und im Lichte dieser Erfahrung haben sich Nachdenkprozesse, Irritationen, aber auch Trost und Orientierung ergeben. Unseren (weiter unten näher thematisierten) Aufrufen zur Teilnahme an unserer Studie folgten aus dieser quantitativ sehr großen Gruppe wohl vor allem Menschen, die die Gelegenheit nutzen wollten, endlich einmal ihre Perspektive kund zu tun. Im wissenschaftlichen Interview besteht noch dazu die Möglichkeit, eine Haltung sozusagen >offizielk zu machen - das ist gerade dann reizvoll, wenn man Ansichten vertritt, die bislang nicht zum Mainstream gehören und denen die Lobby fehlt bzw. zu fehlen scheint. Wer die Friedhofs- und Bestattungsverhältnisse in Deutschland (und natürlich auch in Österreich und anderen angrenzenden Gebieten) als unproblematisch einschätzt oder sich damit nicht befasst, der wird vermutlich weniger motiviert sein, mit uns zu sprechen, als Menschen, die sich durchaus als Akteure im sepulkralen Feld verorten und aus dieser Akteursposition heraus traditionsabweichende Ansichten gewonnen haben.

$\mathrm{Zu}$ wissen, was wir wissen, nachdem wir mit dieser Untersuchung buchstäblich Wissen geschaffen haben, bedeutet zwangsläufig auch, zu ahnen oder zu spüren, was nicht gewusst wird oder werden kann. Wir können von unserer Erkenntniswarte aus nicht genau ermitteln, wie viele Menschen tatsächlich unzufrieden mit der Realität der gegenwärtigen Bestattungskultur sind und wie viele davon aus einer Betroffenenperspektive die Entscheidung fällen, von der Normerwartung abzuweichen. Und wir wissen kaum, wie viele Menschen negative und positive Erfahrungen gemacht und ihre Wahl (langfristig) bereut haben oder von deren Richtigkeit nicht mehr überzeugt sind. Wir müssen eingestehen, dass wir - wie es bei Fragestellungen hochpersönlichen und intimen Charakters nicht unüblich ist nicht sehen, was wir nicht sehen. 
Während in einem zweijährigen interdisziplinären Forschungsprojekt an den Universitäten Erlangen-Nürnberg und Passau sowie am Kulturwissenschaftlichen Institut Essen ursprünglich die Frage nach dem Umgang mit illegal angeeigneten Aschen im Mittelpunkt stand, wurde unsere Aufmerksamkeit also im Laufe der Zeit erweitert; das Forschungsfeld hat sich vergrößert. Kern der Untersuchung ist nach wie vor das Motiv des geliebten Menschen, der qua Kremation zu Asche wird, und der damit zugleich 'gegenständlich genug geworden ist, dass man um ihn ringen und streiten, und ihn eben auch >mitnehmen kann. Diese Thematik wurde unserer Kenntnis nach im besagten Forschungsprojekt erstmals umfassend wissenschaftlich und insbesondere empirisch untersucht; somit ist das vorliegende Buch das Ergebnis einer Pionierstudie. ${ }^{8}$ Sie sollte, hoffen wir, nicht der letzte Beitrag zur Diskussion sein, aber diese Sorge besteht nicht, denn das Problem drängt sich zunehmend auf - gegenwärtig vor allem für die >Player im sepulkralen Feld, früher oder später wird es aber noch weitere Kreise ziehen. Das mediale Echo auf unser Projekt lässt vermuten, dass hier und da bereits ein öffentliches Bewusstsein für die spezielle Problematik der ’Hoheit< über das eigene, und generell über das kollektive Trauern, und auch für die allgemeinere Frage nach Autonomie im Kontext des Lebensendes besteht.

Wenn unsere Ergebnisse dabei helfen, dass Gespür für die sich wandelnden Bedürfnisse von Menschen zu schärfen, wäre neben dem akademischen auch ein lebensweltlicher Gewinn zu verzeichnen. Schön wäre es. (Noch schöner wäre es, würde beides von vorn herein nicht auseinanderfallen - aber das ist eine andere Debatte.) Eine größere Sensibilität jenen gegenüber, denen die bisherigen offiziellen Angebote und Möglichkeiten der Bestattungskultur nicht ausreichen, und ein unvoreingenommenes Herangehen an ihre Motive, würde letzten Endes, so denken wir, zu einer Versöhnung, und nicht zu einer Vertiefung bestehender Spaltungen führen.

8 Das Desiderat ist bekannt: Vor knapp 20 Jahren konstatierte der Jurist Tade M. Spranger in seinem Plädoyer für die Aufhebung des Friedhofszwangs bei Feuerbestattungen, dass es diesbezüglich einen Wandel in der »Gefühlswelt der Bürger« (BVerwGE $45,230)$ gegeben habe. Nicht ausgeführt wird hier der Mangel an empirischen Daten, weil dieses Defizit im Jahr 2000 augenscheinlich war (Spranger 2000: 158f.). 
Unweigerlich kommt bei all dem die Facette des sozialen Wandels ins Spiel. Alles, was an Üblichkeiten, Regelwerken, Sichtweisen und kulturellen Mustern besteht, ist das Resultat eines "So-und-nicht-anders-gewordenSeins«, wie Max Weber schreibt (1988: 170f.). Es hat nicht von Anfang an existiert, sondern ist entstanden; und was entsteht, kann auch wieder vergehen. Wer Freude an naheliegenden Vergleichen hat, wird zustimmen können: Wie Leben entsteht und durch Sterben verschwindet, so tauchen auch die Produkte des gesellschaftlichen Zusammenlebens irgendwann auf, um sich später wieder zu verabschieden. Die Genealogie des Gewordenen impliziert nun eine Permanenz des Wandels. Mit anderen Worten: Wenn Dinge sich bis zum heutigen Stand hineinentwickelt haben, werden sie sich auch weiterentwickeln. Wenn sie nicht mehr existieren, ist das $\mathrm{Ma}$ ihres Entwicklungspotenzials ausgekostet (vielleicht nicht in einem philosophischen Sinne, aber allemal in empirischer Hinsicht).

Gesellschaftliche Tatsachen sind niemals entkoppelt von der Zeitachse (Elias 1984) und lassen sich erst dann verstehen, wenn man ihre historischen Entstehungs- und Entwicklungsbedingungen berücksichtigt. Unser Untersuchungsfeld scheint uns ein gutes Beispiel zu sein, um das Wirken, vor allem aber die Mehrdeutigkeit des Wandels darzustellen. Die Beschäftigung mit Sterben, Tod und Trauer - mit einem thanatologischen Themenspektrum also - legt zu jedem historischen Zeitpunkt nahe, dass der soziale Wandel sich unabhängig von konkreten Fallkonstellationen auswirkt. Wie ein Mensch verabschiedet, beerdigt, betrauert oder vermisst wird, und sogar, ab wann er als tot gilt (Benkel/Meitzler 2018) - und wie sehr -, ist abhängig von der Zeit, dem Ort, der einrahmenden kulturellen Prägung und, mittlerweile, mehr und mehr von der individuellen Disposition derer, die verabschieden, beerdigen, trauern und vermissen.

Sozialer Wandel steht für die Veränderungen in der menschlichen Mentalität über Sachverhalte, die zuvor anders gehandhabt wurden. Sowohl das Jetzt wie auch das Früher erscheinen zum jeweiligen Geltungszeitpunkt als >richtig oder sangemessen<, und dies nicht, weil entsprechende Definitionen es diktiert haben - sondern vielmehr, weil sich bestimmte Einstellungen aus dem gesellschaftlichen Umgang heraus ergeben haben. Dass Macht, Unterdrückung, Steuerung, Zufall, ja auch Fehler, Katastrophen und Krisen kausal für eigenwillige Richtigkeits- und Angemessenheitsdiskurse gewesen sind bzw. ihren Beitrag zu Veränderungen geleistet haben, ist unbestreitbar. Dennoch ist der soziale Wandel nicht mit Vulkanausbrüchen, Kometeneinschlägen oder Überschwemmungen zu vergleichen: Es geht nicht nur um Unausweichliches, sondern um Entwicklun- 
gen, die Menschen selbst angelegt haben, indem sie mit anderen, für andere und gegen andere Menschen agiert haben bzw. agieren zu müssen glaubten.

Es scheint ein Leichtes, im historischen Rückblick festzuhalten, dass früher >die Verhältnisse geordneter waren, dass es weniger Komplexität gab und mehr Einigkeit; das aber sind trügerische Etikettierungen. Auf unser Thema bezogen heißt das: Keine Bestattungskultur ist immanent >einfach<, denn das Phänomen, das sie anspricht und durch das sie entstanden ist, ist in seiner Komplexität unverändert. Nichtmehrdasein als Zukunftsschicksal ist eine geschichtliche Konstante, wie darüber nachgedacht und was damit angefangen wird, ist hochgradig variabel. Pietätlosigkeit anzuprangern, 'gute Lösungen zu loben, die Vergangenheit zu bedauern oder zu beneiden - im sepulkralen Feld sind das Momentaufnahmen; es sind Perspektiven mit, wie man sagen könnte, zu kurzer Belichtungsdauer. Die wissenschaftliche Expertise hilft weiter, aber auch sie hat nicht das sgroße Ganzer im Blick, auch sie ist nur im Kontext ihrer Zeit und der dominierenden Haltungen verständlich. Wer einwenden möchte, dass doch zumindest naturwissenschaftliche Erkenntnisse eine überzeitliche 'Wahrheit transportieren, möge sich eine Zeitmaschine bauen und entsprechende Weisheiten in jenen Jahren öffentlich kundtun, in denen die westliche Zeitrechnung begann. Es dürfte kein schöner Ausflug werden.

In diesem Band werden Ergebnisse von Wandlungsprozessen beschrieben, von denen wir wissen, dass sie nicht von ewiger Aktualität sein werden, sondern bestenfalls für den Augenblick gelten. Eben dies ist die Ambivalenz des sozialen Wandels. Es kommt die Zeit, da niemand mehr wissen wird, dass es dieses Buch jemals gegeben hat, und auch dann werden Menschen geboren und sterben - es wird so sein wie immer, und doch ganz anders.

\section{Vom Wert der Mitbestimmung}

Zuletzt noch ein Wort zum Titel: Autonomie verstehen wir als einen Aspekt der Mit- bzw. Selbstbestimmung. In einer sozialen Welt, in der individuelle Perspektiven niemals vollständig isoliert von anderen bestehen können, erscheint der Unterschied zwischen beiden Konnotationen gering. Genau genommen blicken wir auf die Handlungen von Menschen, die in Bestattungsangelegenheiten posttraditionell denken und mithin handeln. Sie verwehren sich dagegen, dass Gesetze, Verordnungen und gesellschaftliche Vorgaben ihnen vorschreiben, wie sie die bzw. wie sie schlussendlich ibre >letzten Dinger gestalten. Zugleich verdeutlichen sie hierdurch, dass es 
eben keine unveränderlichen Naturgesetze sind, die uns die Art und Weise vorgeben, wie wir bestatten; der Mensch ist es selbst, der sich Maximen setzt.

Das Handeln in der Trauersituation soll uns als zentrale Figur eines solchen Bestimmungs-, aber auch Besorgungskontextes gelten. Denn mit dem Wunsch nach eigener Entscheidungs- und Aktionsfreiheit geht nahezu immer das dahinter stehende Anliegen einher, sich stellvertretend um die mutmaßlichen oder zu Lebzeiten geäußerten Interessen der Verstorbenen zu kümmern.

Den aus den vielfältigen Facetten von Autonomie entspringenden Fragestellungen rund um das Lebensende möchten wir im Folgenden nachgehen. Zunächst wird Trauer unter den Vorzeichen von Individualisierung und Pluralisierung sowie hinsichtlich ihrer normativen Dimensionen soziologisch diskutiert. Daraufhin werden die methodologischen Möglichkeiten und Probleme sondiert, die sich bei der sozialwissenschaftlichen Erforschung von Trauer als kultureller Praxis ergeben. Welche Befunde die Studie unter diesen Voraussetzungen hervorbrachte, wird sodann anhand von Interviewpassagen veranschaulicht. Danach wird im Sinne angewandter Ethik zu fragen sein, an welchen Normen man sich angesichts der empirischen Befunde bei der Gestaltung der Trauerkultur orientieren sollte und begründet orientieren kann. Zum Abschluss greifen wir die Konsequenzen auf, die sich aus den vorangegangen Kapiteln und aus unserer Forschung für die Praktiker und Fachexperten ableiten lassen - für diejenigen also, die an den vermittelnden, mithin übersetzenden Schnittstellen zwischen dem Einzelnen und gesellschaftlichen Vorgaben positioniert sind.

Unser größter Dank gilt all jenen Menschen, die an unseren Erhebungen teilgenommen, die sich für unser Forschungsanliegen Zeit genommen und die uns ihr Vertrauen geschenkt haben, wenn sie von ihren Trauererfahrungen berichtet, ihren Umgang mit dem Verlust eines geliebten Menschen beschrieben oder uns erkenntnisreiche Einblicke in ihre Arbeit im Kontext von Sterben, Tod und Trauer gewährt haben. Ebenso möchten wir uns bei all denjenigen bedanken, die uns bei der Akquise der Forschungsteilnehmer geholfen haben.

Herzlich bedanken wir uns bei der Verbraucherinitiative Bestattungskultur Aeternitas e.V. (Königswinter) und ihrem Vorsitzenden, Christoph Keldenich, für sein Interesse, sein Engagement und sein Vertrauen.

Den Herausgebern der Schriftenreihe >Dimensionen der Sorge sind wir zu Dank verpflichtet für ihre Bereitschaft, unserem Buch eine publizis- 
tische Heimat zu geben. Dies gilt insbesondere für die freundliche Unterstützung durch Prof. Dr. Anna Henkel.

Ferner danken wir Ida Meyenberg, Alexandra Molnár und Leonie Schmickler, die uns an der Universität Passau in Forschungs- und Organisationsfragen tatkräftig zur Seite standen - gewiss über das Maß hinaus, das ansonsten bei studentischen und wissenschaftlichen Hilfskräften erwartbar wäre.

*x*

Leser dieses Buches werden erkennen, dass es sich in die für Trauerliteratur reservierte Ratgebersparte nicht so recht einordnen lässt. Auf der Ebene der kritischen Beobachtung dessen, was in Ratgebern steht, fühlt sich unser Buch mutmaßlich aber ganz wohl. Denn von dieser Ebene aus ist klar, dass sich Trauer nicht pauschalisieren lässt, sodass jedwede Empfehlung auch wenn, oder gerade wenn sie diese triviale Wahrheit betont - stets nur relativ gültig, d.h. von dem darin eingenommenen Standpunkt abhängig ist. Das gilt auch für unsere Beobachtung. Indem wir Trauer wissenschaftlich betrachten, bringen wir auf Distanz, was realiter nicht auf Distanz geschieht. Anders gesagt, wir setzen auf Abstand, um näher dran zu sein. 


\title{
Mitbestimmte Trauer. Soziologie einer Sinnkonstruktion
}

\author{
Thorsten Benkel
}

»Der Tod eines geliebten Menschen [...] erfüllt mit dem Bewußtsein von Schuld; alles ungewordene Mögliche, alles Versäumte und der kleinste Fehler noch den man sich vorzuwerfen hat tritt zwischen den Gedanken an den Toten und einen selber - und oft war mir zumute, als ob ich ihn ermordet hätte, nur weil ich vielleicht dann gerade, wenn ich ihm hätte helfen können, nicht da war." (Theodor W. Adorno nach dem Tod des Komponisten Alban Bergs an dessen Witwe Helene, 16. April 1934)

Trauer kennt viele Schattierungen. Man kann traurig sein über das Ende einer Liebes- oder Freundschaftsbeziehung, darüber, dass der Urlaub zu Ende geht, man kann den Verlust von (Wert-)Gegenständen betrauern, und man kann in einer melancholischen Stimmung auch darüber traurig sein, dass die schönen Dinge des Lebens nicht so bleiben, wie sie sind, weil permanent das Alte vom Neuen abgelöst wird. Trauer kann sehr unterschiedlich verstanden und unterschiedlich verwendet werden; in diesem Buch steht aber ein spezifisches Trauerverständnis im Vordergrund, das - vermutlich - wohl auch die gängigste Deutungsvariante sein dürfte. Trauer soll hier verstanden werden als gesellschaftlich vermittelte, emotional transportierte Reaktion auf den irreversiblen, weil durch Tod verursachten (oder unmittelbar drohenden) Verlust eines Sozialpartners.

Etwas >gesellschaftlich vermittelt $<$ nennen bedeutet, die Mitwirkung des sozialen Umfeldes zu berücksichtigen; es geht nicht um menschenunabhängige 'Substanzen oder 'Wahrheiten`, die san sich Bestand haben, sondern um Sachverhalte, die erst durch die Beziehung zu anderen real werden. Erst dadurch, dass Personen für, mit oder gegeneinander handeln, entstehen soziale Austauschprozesse, und erst dank solcher Prozesse ist ein Phänomen wie Trauer überhaupt greifbar. Trauer wird erlernt, Trauer wird (mit-)geteilt und Trauer ist ein Indikator für kulturelles Niveau. Es gibt Trauer nicht losgelöst von sozialen Beziehungen, sondern nur eingebettet in eine tragfähige, ordnungs- und gemeinschaftsstiftende Kultur. 
Vor diesem Hintergrund soll nachfolgend konkret der Blick auf die sozialtheoretische und, damit verbunden, auf die handlungspraktische Dimension der Trauergestaltung gelegt werden. Im Sinne der zugrunde liegenden qualitativ-empirischen Forschung ist ein besonderer Schwerpunkt die Frage nach den autonomen Mitwirkungsoptionen einzelner Akteure in der bald mehr, bald weniger stark so empfundenen, aber in dieser Hinsicht eben doch individualisierten Welt.

\section{Theorie und Traner}

$Z u$ trauern bedeutet heute, sich einen Weg zu suchen. Einerseits brauchen Trauernde einen Weg, der sie in einem Tempo, das sie selbst vorgeben, wieder aus der Trauersituation herausführt. Ohne einen solchen Weg würde die Trauer um eine geliebte Person sie permanent überwältigen, und sie wären auch auf lange Sicht nicht imstande, ihrem Leben eine Alltagsroutine zu verleihen, in der der Verlust nicht das zentrale Thema ist. In der Trauer gefangen, würden sich die Gefühle derjenigen Menschen, denen der Weg aus dieser Gefangenschaft heraus fehlt, vermutlich durchaus von der betrauerten Person lösen. So paradox es klingen mag: Es ist vollstellbar und kommt auch vor, dass man sich in der Trauer seinnistet und der Tote in der Folge irgendwann nur mehr die Rolle eines >Ausgangsmotivs< spielt, welches die ursprüngliche Trauer ausgelöst hat - mehr nicht. Menschen, die dies betrifft, haben sich gewissermaßen daran gewöhnt, mit und in der Trauer zu leben - und sie können sich von dieser Empfindung nicht mehr lösen. Ihre Trauer gibt ihnen Halt und Orientierung, sie ssteht fest $\iota$, sie wird von Außenstehenden sofort verstanden. Sie wurde über einen längeren Zeitraum hinweg schleichend und unbewusst zur Normalität gemacht. ${ }^{1}$

Die Trauer verwandelt sich in diesen Fällen also in etwas, was die trauernde Person - von außen betrachtet, aber vielleicht auch ihrer eigenen Ansicht nach - definiert; und zwar nicht nur für einen bestimmten Zeitraum, sondern potenziell für immer. Gerade dies ist doch schließlich die

1 Der paradox anmutende Vorteil, den dieser unbewusste Mechanismus mit sich bringt, liegt darin, dass Trauerhaltungen von außen häufig unmittelbar erkennbar und verständlich sind. Man kann an Trauer problemlos sanschließen`; man weiß, dass ein respekt- und pietätvoller Umgang angebracht ist. Verstöße gegen diese soziale Spielregel gelten als immenser Fauxpas. Trauer ist, wenn man diese Schlussfolgerung ziehen möchte, also der Auslöser eines eigenwilligen Kommunikationsmodus' (Winkel 2002; dies. 2008). 
emotionale Erfahrung beim Tode eines nahestehenden Menschen: Wie soll dieser Schmerz jemals vergehen, wie soll es je wieder eine unbeschwerte Alltäglichkeit geben können, nachdem geschehen ist, was geschehen ist? Wer der Trauer in diesem Sinne nachgibt, sich ihr anvertraut, sie umarmt und nicht mehr loslässt, der bedient sich der Trauer in gewisser Hinsicht ungefähr so wie einer Ideologie - denn auch Ideologien geben Nestwärme, sie spenden Trost durch tiefe Vertrautheit, und hat man einmal eine übernommen, wird man sie so rasch nicht mehr los.

Nicht bei allen, aber eben doch bei sehr vielen Toden kommen Trauernde in erzwungener >Passivität $<$ zu ihrer Rolle. Das gilt insbesondere bei Unfällen mit tödlichem Ausgang, bei Umweltkatastrophen mit menschlichen Opfern, bei Straftaten mit Todesfolge usw. Wer in diesen Zusammenhängen einen geliebten Menschen verliert, kann sich häufig nicht verabschieden, kann das Ende der sozialen Beziehung nicht vorab reflektieren, deshalb ist die damit verknüpfte Erfahrung, in Todesnähe zu gelangen, ein durch und durch passives Geschehen. Man hat es nicht gewollt - und doch ist es so gekommen.

Die Aufgabe, den Weg zu finden aus dieser tiefempfundenen, die ganze Lebenswelt fest einschnürenden Gefühlswelt wirkt wie eine aktive Handlung. Dieser Weg stößt Betroffenen, so scheint es zumindest, nicht schlichtweg zu - jedenfalls bei weitem nicht in dem Maße, in dem vielen Menschen die Konfrontation mit dem Tod zustößt. Inmitten der aufwühlenden Unübersichtlichkeit, in die Trauernde sich gestoßen fühlen, werden indes gesellschaftliche Mechanismen aktiviert, die auf lange Sicht das Heraustreten aus der Trauersphäre antreiben. Die Aktivität kommt vonseiten der Gesellschaft - während das betroffene Individuum dies wohl häufig als einen 'wie von selbst< ablaufenden Prozess erlebt. (Er wird also nur scheinbar durch eigene Handlungen selbst erzeugt.) Es gibt Rituale und andere Umgangsformen, die man selbst umsetzt, und die den Durchschlag der gesellschaftlichen Spielregeln begünstigen; aber es gibt keine von der Gesellschaft unabhängige und ihr vollständig entzogene Trauer.

An dieser Stelle lässt sich der Sinnbegriff ins Spiel bringen. In der Soziologie gibt es die Vorstellung, dass es eine >oberste Wirklichkeit ‘ gibt, nämlich die Alltagswelt. Neben ihr haben noch weitere Erfahrungsformen und -felder Platz. Ergänzend zur Alltäglichkeit gibt es also, mit anderen Worten, noch weitere Sinnwelten. Die Alltagswelt muss man sich vorstellen als den Inbegriff wiederkehrender Routinen, sie ist die Sphäre bekannter Abläufe und geteilter Vorstellungen, sie ist also jener Bereich, in der wir uns auch mit Fremden gut verständigen können, weil ‘wir alle das Konzept der Alltäglichkeit teilen und weil ’wir alle`verstehen, was gemeint ist, 
wenn von alltäglichen Dingen die Rede ist. ${ }^{2}$ Genau betrachtet, ist die Alltagswelt - die natürlich in unterschiedlichen Kulturen sehr unterschiedlich aufgebaut ist; bleiben wir daher beim Alltagsverständnis in Zentraleuropa - eine Zone, in der für sehr viele Menschen dieselben Sachverhalte, Geschehnisse, Gegen- und Umstände Sinn ergeben. Das gilt auch in die Gegenrichtung: Auf dem Territorium der Alltäglichkeit würden sich sehr viele Menschen, auch solche, die sich nicht vorab verständigt haben müssen, rasch darüber einig werden können, wenn blanker Unsinn vorläge. ${ }^{3}$

Der Begriff >Alltagswelt $<$ ist bewusst gewählt. Welt meint immer auch: Sinn-Welt; denn ohne ein geteiltes Verständnis oder Wissen darüber, was in dieser oder jener Situation Sinn ergibt (was also sinnhaft ist), kann auch keine plausible, über die subjektive Ansicht hinausgehende Vorstellung von 'Welt< etabliert werden (Berger/Luckmann 2004). Darüber nachzudenken, wirkt auf den ersten Blick sehr akademisch, denn tatsächlich leben swir alle ja nun in einer solchen Welt - einem Lebensbereich, der für uns ganz überwiegend sinnhaft aufgebaut ist. Oder anders formuliert: Unsere Erfahrung von (>der $<$ ) Welt ist eine von Sinnkonzepten gestützte. Wir erfahren die Welt nicht als ungeordnetes Chaos, sondern wir finden sie (übrigens schon im Augenblick der Geburt) als eine sinnhaft aufgebaute vor. ${ }^{4}$ Die Welt muss von uns nicht selbstständig mit Sinn gefüllt werden, weil

2 »Wir alle«steht dabei in Anführungsstrichen, weil sich im Alltag bekanntlich eben doch Abweichungen, Missverständnisse, Bewertungsunterschiede usw. einschleichen - und Menschen sich ja ohnehin niemals so sehr gleichen, dass sie die Dinge absolut identisch bewerten. (Dann müsste man schon identisch sein; vgl. Schütz 1972: 14.) Allerdings sind diese Reibungen in der Alltagswelt geringer als in Spezialkontexten, schon deshalb, weil an Spezialkontexten nicht jeder gleichermaßen partizipiert und nicht jeder über Mitwirkungskompetenzen verfügt. An das Konzept Alltag können hingegen sehr viele Menschen ohne größeren Aufwand und ohne größere Irritationen anschließen.

3 Das muss natürlich noch nicht mit einer Wertung einhergehen - vielleicht ist das, was als Unsinn gilt, ja in Wahrheit ein belebendes Element, das etablierte Sinnmuster in Frage stellt und schon insofern selbst ssinnhaft ist. Der Philosoph Odo Marquard (1996: 33) jedenfalls meint: »Der Sinn - und dieser Satz steht fest - ist stets der Unsinn, den man lässt.«.

4 In gewisser Hinsicht ist die Welt gleichwohl recht chaotisch, zumindest im Lichte einer bestimmten Betrachtungsweise. Bei Max Weber taucht dieser Gedanke zu Beginn des 20. Jahrhunderts als "heterogene Mannigfaltigkeit« auf - ein Begriff, den der Philosoph Heinrich Rickert geprägt hatte. Laut Weber wird dieses real existierende Durcheinander dadurch abgemildert, dass aus diesem Malstrom der Unübersichtlichkeit heraus Menschen aktiv Sachverhalte mit "Kulturbedeutung« aufladen und sie dadurch gedanklich alleine stellen (vgl. Weber 1988: 174). Deshalb wirkt die Welt auf den ersten Blick nicht chaotisch, sondern geordnet: Verinnerlicht und 
andere dies bereits für uns getan haben. Wir müssen allerdings lernen, und das ist schon kompliziert genug, diese Sinnkonzepte zu verstehen und mit ihnen so umzugehen, als seien sie die Wahrheit<, als seien sie 'Tatsachen<. Das erfolgt während des Prozesses, der gemeinhin Sozialisation genannt wird.

Es war der österreichische Soziologe Alfred Schütz, der die Ansicht vertrat, dass der Alltag die »ausgezeichnete Wirklichkeit « sei - das meint: die oberste, die Haupt-Wirklichkeit der Menschen (Schütz 1971a: 372).5 Daneben verortete Schütz sogenannte "Sub-Universa« (Schütz 1971b: 263ff.). Gemeint sind Felder, in denen sich Menschen zwar auch bewegen und miteinander, füreinander, vielleicht sogar gegeneinander agieren, mit dem Unterschied jedoch, dass in diesen *kleineren Welten ganz andere Sinnbestimmungen vorherrschen als im Alltag. Hier machen also buchstäblich ganz andere Dinge Sinn; und es gibt daher auch ganz andere Verständnisse von Unsinn. Schütz geht davon aus, dass die Alltagswelt nicht über allen gesellschaftlichen Bereichen steht und auch nicht jeder Umgangsweise von Menschen übergestülpt ist, sondern dass es außeralltägliche Felder gibt, deren Außeralltäglichkeit gerade darin zum Ausdruck kommt, dass in ihnen alternative Sinnvorstellungen existieren.

Darunter fallen Schütz zufolge solche unterschiedlichen Bereiche wie die Wissenschaft (wo Dinge geschehen, die - zumindest auf den ersten Blick - nur für Wissenschaftler, nicht aber für Außenstehende sSinn ergeben $<$ ), die Welt spielender Kinder (die um sich herum die Zeit vergessen und ganz in ihrem Spiel aufgehen - was viele erwachsene Beobachter nicht nachvollziehen können) oder auch solche innerräumlichen< Areale wie etwa die starke Konzentration eines Menschen, der innbrünstig betet. Auch dies ist nicht für jeden Alltagsmenschen ssinnhaft<, sondern nur für manche, und auch für sie erschließt sich dieser spezifische Sinn der Gebetshandlung wohl dann am besten (vielleicht sogar nur dann), wenn sie selbst schon ähnliche Erfahrungen gemacht haben. ${ }^{6}$ Schütz ${ }^{6}$ Überlegungen wurden von zwei Soziologen der Folgegeneration, die sich stark an seinem

kennengelernt werden zunächst vor allem diejenigen Partien der Welt, die von kulturellem Wert sind, eine gewisse Ordnung bzw. Struktur zugewiesen bekommen haben und weitgehend zweifelsfrei als >sinnträchtig angesehen werden.

5 Schütz floh vor den Nationalsozialisten in die USA und schrieb von da an seine Texte auf Englisch; im Original ist daher vom Alltag als der »paramount reality« die Rede.

6 Ganz zu schweigen von denjenigen, die zwar - äußerlich betrachtet - beten, die also die körperliche Haltung einnehmen, die notwendigen Gesten durchführen usw., aber innerlich nichts von dieser alternativen Sinnbestimmung spüren. Sinn 
Werk orientiert und zum Teil bei ihm studiert haben, erweitert und verfeinert. Peter L. Berger und Thomas Luckmann, auch sie Emigranten, haben sich 1966 in ihrem Buch The Social Construction of Reality intensiv mit dem Spannungsverhältnis von Alltag und, wie sie schreiben, den »Subsinnwelten « befasst, in denen andere Bedingungen herrschen. Bemerkenswert ist, dass man sich in einer solchen Sinnwelt auch dann befinden kann, wenn hinsichtlich der Rahmenbedingungen (Umfeld, Ort usw.) alles ist 'wie immer<, also alles so ist, wie es normalerweise im Alltag ist. Das mag überraschen, ist aber durchaus plausibel: Wissenschaft betreiben, spielen, beten usw. kann ich weitgehend ortsunabhängig, solange nur mein Bewusstsein entsprechend justiert ist.

In dieser soziologischen Traditionslinie, einer von vielen, und noch dazu einer, die nicht ohne Kritik geblieben ist, weil sie das Bewusstsein so stark in den Vordergrund rückt - und den vermeintlichen Zentralgegenstand der Soziologie, die Gesellschaft, zu vernachlässigen scheint -, sind durchaus philosophische bzw. phänomenologische Elemente eingearbeitet. Wer seine Gesellschaftsanalyse lieber als Ansammlung statistischer Werte betreibt, könnte vor dieser, wie manchmal formuliert wird, sozialphänomenologischen Sichtweise zurückschrecken. Für Untersuchungen zu Phänomenen, die zwar von großer gesellschaftlicher Tragweite sind, die sich aber zugleich vorrangig im Bewusstsein abspielen (oder dort abzuspielen scheinen), ist dieser theoretische Zugriff jedoch überaus brauchbar. Er geht letztlich zurück auf Edmund Husserl, der zu Beginn des 20. Jahrhunderts Überlegungen zum Wesen des Bewusstseins anstellte und zu der Erkenntnis kam, dass Menschen nicht schlichtweg ein Bewusstsein haben sondern immerzu über ein Bewusstsein von etwas verfügen (Husserl 1993; vgl. näher Ogawa 1991). Es ist unmöglich, den Geist einfach schweifen zu lassen - er greift sich immerzu Inhalte, er verarbeitet Material, er bedient sich der Impulse aus der sozialen Umwelt. Man kann Menschen zwar bekanntlich nicht in den Kopf schauen, aber man kann wissen, dass das Bewusstsein, und daraus abgeleitet das Denken und das Wissen, so funktioniert.

ist, wie dieses Beispiel zeigt, nicht einfach eine Angelegenheit des Tuns, sondern auch und gerade eine Sache der inneren Einstellung. 


\section{Tragische Aktivitäten}

Neben dem Alltag stehen, wie gesagt, andere Wirklichkeiten. Lässt sich nicht auch die Trauer als eine solche Subsinnwelt verstehen? Ist nicht das Trauern mehr als nur ein >Umstand ? Ist es nicht eine Situation, ein Prozess, ein Handlungszusammenhang, bei dem das, was im Alltag sinnvoll war, nicht mehr gilt - oder zumindest in stark abgeschwächter Form? Und ergeben sich nicht umgekehrt im Trauern andere Sinnhaftigkeiten, die zuvor undenkbar waren oder die nicht thematisiert worden sind, weil sie eben - auf dem Boden der >obersten Wirklichkeit< des Alltags - buchstäblich bislang ’keinen Sinn « gemacht haben? Mit Schütz und Berger/Luckmann kann diese Auffassung zweifellos vertreten werden. Das gilt umso mehr, als Schütz, u.a. in Anlehnung an den berühmten dänischen Religionsphilosophen im 19. Jahrhundert, Søren Kierkegaard (dessen Name im Dänischen übrigens 'Kirchhof bedeutet), davon spricht, dass die Alltagswelt in Richtung Subsinnwelt auf zwei Wegen verlassen wird: durch einen Sprung oder durch einen Schock.

Üblicherweise werden Subsinnwelten, wenn sie einmal >betreten den (das sollte, wie gesagt, nicht wörtlich verstanden werden), auch wieder verlassen, weil man früher oder später wieder zurück in die Alltagswelt gleitet. Ein Beispiel: Egal, wie lange oder hart das Party-Wochenende gewesen sein mag, für sehr viele derjenigen, die sich in diesem Kontext gezielt eigenwilligen Sinnbestimmungen ausgesetzt haben, um der >Normalität< zu entfliehen, beginnt am Montagmorgen eben doch wieder die Alltagsroutine - mit ihrem Trott, aber eben auch mit ihrer inneren Ordnung und Stabilität. Man muss die Alltagswelt wieder zulassen; es bleibt einem ja kaum eine Wahl. Die Party mag zwar durch Musik und Tanzen, durch eine gute Zeit mit Freunden, durch neue Bekanntschaften und nicht selten durch den Konsum von Alkohol und anderen Drogen sehr anders sein als der Alltag, die Übergänge sind dennoch fließend. Es liegt kein Kulturschock vor, wenn man freitags abends, nach einem Tag im Büro, an der Uni oder in der Schule, den abgedunkelten, mit lauter Musik durchschallten Club-Raum betritt und mit den seltsamen Körperregungen der oft alltagsuntypisch gekleideten Diskobesucher konfrontiert wird. ${ }^{7}$ Denn das, was einen dort erwartet, kennt man. Man kann die eigenwillige Sinnstruk-

7 So denkt man allenfalls beim allerersten Mal; und selbst das ist unwahrscheinlich, schließlich geht dem ersten Besuch meistens eine nähere Beschäftigung mit der Idee der Disko voraus, und außerdem bereiten mediale Erfahrungen darauf vor, was man erwarten darf. Der tatsächliche erste Diskobesuch wird dann zum Initiationsmoment, zu einer Art `Einweihung < - die einen von den Uneingeweihten, noch 
tur des Clubs aufgrund früherer Erfahrungen und dank der Planung und des Austauschs mit anderen voraussehen. Üblicherweise ist man entsprechend auf ungewohnte, aber eben nicht ganz fremde sSinnangebote< vorbereitet. Das gelingt vor allem deshalb, weil klar ist, dass auch die schönste Party einmal endet. Kein Club der Welt feiert ewig, deshalb bleibt der Alltag Sieger. Es wäre wohl selbst für die begeisterungsfähigsten Besucher ein Horrorszenario, Teilnehmer einer unaufhörlichen Party zu sein (und spätestens dann wäre Drogenkonsum mehr als verständlich!). Tatsächlich aber fordert der Alltag schon deshalb seinen Tribut, weil das Prinzip der gesellschaftlichen Ordnung nicht aufrechterhalten werden könnte, wäre diese Subsinnwelt nicht in einem relativ engen zeitlichen Raster verortet. Damit ist nicht gemeint, dass Clubs nur zu bestimmten Zeiten geöffnet haben, sondern vielmehr, dass entsprechende Veranstaltungen und Räumlichkeiten von einzelnen Besuchern eben nur zu bestimmten (Lebens-)Zeiten aufgesucht werden.

Und mehr noch: Der Alltag ist eigentlich immer mit dabei. Solche zentralen gesellschaftlichen Einrichtungen wie die Sprache oder die Geltung von Institutionen bleiben auch dann erhalten, wenn die Sinnwelt des Alltags weicht und die besondere Sinnwelt der Diskothek sich um einen schließt. Denn auch in der Subsinnwelt wird (für gewöhnlich) jene Sprache verwendet, mit der man sich im Alltag verständigt; dieselben Vokabeln stehen hier für dieselben Dinge. ${ }^{8}$ Das erleichtert es, von der einen in die andere Sphäre zu gleiten - und es erleichtert sukzessive auch die Rückkehr in die Routine. Und auch in Subsinnwelten wie eben der Diskothek sind institutionelle Ansprüche noch gültig, d.h. der Personalausweis ist nach wie vor ein Identitätsbeleg, die Bestimmungen von Ämtern und Behörden gelten in diesem Rahmen unvermindert, und die Polizei hat auch dann, wenn eine alternative Sinnkonstruktion vorliegt, das Durchgriffsrecht, das sie im Alltag besitzt. So gesehen, ist die Subsinnwelt mit dem Alltag recht

Ahnungslosen, noch Erfahrungslosen (etwa jüngeren Geschwistern) abgrenzt. Das Lachen über deren Unwissenheit ist da, wo es vorkommt, letztlich ein Ausdruck der Erleichterung darüber, dass man das eigene vormalige Nichtwissen durch Erfahrungen und leibhaftigen Wissenserwerb einzutauschen wusste.

8 Es gibt natürlich durchaus Spezialvokabular, Geheimsprache usw., z.B. in der Sinnwelt des Sado-Masochismus, des Gefängnisses, in Jugendcliquen oder in hochspezialisierten Nischenfeldern. Entsprechende Codierungen werden dort im Sinne einer Stellvertretung bzw. einer situationsnahen Präzisierung der seigentlichen< Sprache verwendet, also nicht als Ersatz, sondern eingebettet in den verinnerlichten Sprachwissensbestand. 
eng verbunden. Sie ist jedenfalls nicht etwas gänzlich anderes; sie ist kein von den Spielregeln der Gesellschaft isolierter Planet.

Diejenigen Subsinnwelten, die durch einen Sprung betreten bzw. verlassen werden können, müssen - dies legt schon die Begriffswahl nahe - als Alternativen zur Alltagswelt angesehen werden, welche man bewusst und gezielt aufsucht. Wie bei einem Sprung vom Drei-Meter-Brett im Schwimmbad oder einem Sprung im sportlichen Kontext sind diese Sprünge Aktivitäten. Bei diversen Subsinnwelten sind die Sprünge eingerahmt von konkreten Übergangshandlungen (im Fall der Diskothek: durch die Kleiderwahl, den Eintritt in die Location, das Akzeptieren der clubeigenen Regularien, etwa das geordnete Warten auf den Einlass, das Sich-Taxieren-Lassen durch die Türsteher usw.). Ähnliches gilt für die genannten Beispiele von Schütz: In den Wissenschaftskontext sspringt man sicherlich nicht ohne Absicht, das Spielen wird gezielt vorgenommen, und auch ein Gebet erfolgt fraglos intentional. Ein Schock hingegen muss als passives Geschehen gedeutet werden. Der alltägliche Sprachgebrauch legt bereits nahe, dass es nicht um beabsichtigte Ausnahmen vom Alltag geht, sondern um erlittene Situationsumbrüche.

Vor diesem Hintergrund soll die Erfahrung des Verlustes einer nahestehenden, einer geliebten Person als Aufenthalt in einer Subsinnwelt bezeichnet werden, die häufig (wenn auch gewiss nicht in jedem Fall) durch eine Schockerfahrung erlebt und die gemeinhin als Trauer umschrieben wird. Trauer findet da statt, wo das Lebensende sich als Grenzüberschreitung heraus gestellt hat. Nicht man selbst macht diese Erfahrung; sondern man bezeugt das Geschehen an anderen. Es sind also Konfrontationen mit »räumlichen und zeitlichen Schranken" für eigene Erfahrungen, die die Trauer kennzeichnen (Schütz/Luckmann 2003: 625). Die Erfahrung des Sterbens und Gestorbenseins >gehört jemand anderem. Gewiss: Wenn ein Mensch nach langer Krankheit verstirbt, kann dieses Ende etwas Erlösendes haben. Die emotionale Einstellung der Hinterbliebenen dürfte dennoch Trauer sein, diese Trauer ist aber nicht unbedingt sschockartig<, weil es eine Frist der emotionalen Vorbereitung gegeben hat. Dennoch kann selbst ein antizipiertes Lebensende dann, wenn es erfolgt ist, einen Schock auslösen. Es gibt für diesen Vorgang keine verbindlichen, stets wiederkehrenden Muster. ${ }^{9}$

9 Besonders deutlich zeigt sich dies an Fällen >irrtümlicher Trauer; etwa dann, wenn ein lange vermisster, tot geglaubter und vielleicht sogar für tot erklärter Mensch sich als lebendig herausstellt. Die empirischen Fälle dürften selten sein, prominente Beispiele wie der Entführungsfall Natascha Kampusch fallen einem rasch ein. 
Viele der Umstände und Orientierungspunkte, die im Alltag wie selbstverständlich funktioniert haben, sind auch dann noch vorhanden und identifizierbar, wenn man trauert. Aber sie können diese Funktion nicht mehr übernehmen, weil die emotionale Überwältigung zu groß ist, was letztlich das oben Angesprochene bedeutet - nämlich, dass sie nunmehr im wahrsten Sinne des Wortes skeinen Sinn mehr machen<. Etwas genauer betrachtet ist der Verlust eines Menschen womöglich auch der Verlust eines konkreten >Sinnankers〈, insofern dieser Mensch eine Stütze zur Alltagsbewältigung gewesen sein mag. Sein Tod ist dann ganz unmittelbar ein Alltagseinsturz. Es ist ein schwacher, vermutlich sogar überhaupt kein Trost, zu erfahren, dass die Sinnwelt der Trauer - wie (fast) alle Sinnwelten - irgendwann einmal überleiten wird zur Rückkehr in den Alltag. ${ }^{10}$ Selbst das oben beschriebene Einnisten in die Trauer ist hiergegen kein Widerspruch, weil die Option der Alltagsrückkehr ja - wenigstens von außen betrachtet - nach einem gewissen Zeitraum durchaus besteht. Die schwierige Aufgabe liegt darin, zu klären, wann dieser Punkt im Einzelfall vorliegt pauschale Vorschläge zu den Zeitstrukturen des Trauerns helfen hier nicht weiter.

Argumentiert man, dass Trauer bewältigt werden muss, hört sich das wiederum nach eigenen Aktivitäten an, um den - in der Metapher gespro-

Trauer kann auch losgelöst von einem Todesfall, genauer: vom Vorliegen einer Leiche erfolgen. Die über 240 Fluggäste und Crewmitglieder von MH 370, einem seit März 2014 verschollenen Flugzeug der Malaysia Airlines, befinden sich hinsichtlich der Trauer ihrer Angehörigen im Stadium des Verschwundenseins. Die Hoffnung auf ein Wiedersehen dürfte gering sein, ist aber (noch) nicht ausgeschlossen (Benkel 2018a). Solche Beispiele werfen die - hier aber nicht näher verfolgte - Frage auf, ab wann in der gesellschaftlichen Sichtweise legitim getrauert werden >darf $<$ und, im Kontrast dazu, getrauert werden ssolk

10 Die Einschränkung, dass sie lediglich für `fast`alle Sinnwelten gilt, muss deshalb gemacht werden, weil es schon im Kanon der Sinnwelten von Schütz Beispiele gibt, die von länger anhaltender Dauer sind. Schütz spricht beispielsweise vom Wahnsinn (vgl. Schütz 1971b: 266). Einmal davon abgesehen, dass dies heutzutage nicht mehr dem adäquaten Sprachgebrauch entspricht: Ein Mensch in einer psychologischen Ausnahmesituation kann darin über einen langen Zeitraum verharren; und dann hat die Sinnwelt gewissermaßen den Stellenwert der Alltagswelt übernommen, indem sie sie verdrängt hat. Ähnliche Mechanismen sind vorstellbar beim Eintritt in neue religiöse Bewegungen, die beispielsweise Weber noch Sekten nannte: Auch dabei kann eine hochspezifische, mit vergleichsweise wenigen Menschen geteilte, aber für viele sehr salltagsuntaugliche Lebenssituation auf Dauer gestellt werden (mit dem Unterschied, dass dies in diesem Zusammenhang absichtsvoll geschieht). Die interessante Frage ist, welchen Einfluss in diesen beiden Fällen das hintergründige >Lauern`der Alltäglichkeit dennoch ausübt. 
chen - >Rück-Sprung in die Alltagswirklichkeit zu schaffen. Mein Vorschlag ist, in diesem Zusammenhang von tragischer Aktivität zu sprechen, weil es einerseits schmerzhaft und problematisch ist, aus der Trauer-Situation wieder heraus zu springen in eine nicht immer besonders tröstliche, nicht immer verständnisvolle Alltagsumwelt. Andererseits läutet diese Aktivität ein Weitermachen in der Gesellschaft der Lebenden ein, der tragischerweise die verstorbene Person - der man in der Trauer unzählbar viele Gedanken gewidmet hat - nicht mehr angehört. Und schließlich ist die Aktivität tragisch, weil sie tatsächlich weniger Aktivität und mehr Passivität beinhaltet, als vielen Menschen klar sein dürfte.

Wie schon gesagt: Dass Trauer überleitet in Alltäglichkeit, ist für Trauernde keine einfache Vorstellung. Denn in dem Moment, in dem Trauer empfunden wird, ist sie die allerrealste Wirklichkeit, und kaum ein Bestandteil der Alltagswelt scheint gewichtig genug, diese Wirklichkeit an die Seite zu verdrängen. Vermutlich geschieht dies am schnellsten in jenen Fällen, in denen Menschen in Trauer ältere Menschen oder Kinder zu versorgen haben, insbesondere kleine Kinder. Diesen Kindern fehlt das Eigenverständnis für das Verhältnis von Alltag und Subsinnwelt, über das erwachsene bzw. herangewachsene Menschen implizit verfügen, weil Letztere dieses Verhältnis in unzähligen Situationen serlebt haben - auch wenn sie sich dessen häufig nicht bewusst sind. ${ }^{11}$ Wer andere Personen zu versorgen und zu betreuen hat, ist in der schwierigen Lage, einen in seiner Routiniertheit ungebrochenen Alltag raufzuführen<, ohne subjektiv Alltäglichkeit empfinden zu können. Im herkömmlichen Sprachgebrauch heißt es dann, man müsse eben >funktionieren .

\section{Gemeinschaft, Individualität und Destabilisierung}

Das Wort sunktionieren deutet an, worauf es auf dem Boden der Alltagswelt ankommt. In einer Gesellschaft und Kultur, die auf Pluralität und Individualität aufbaut, erfüllen Menschen sehr unterschiedliche Aufgaben und Funktionen. Kaum jemand kann alle Aspekte und Elemente seines Lebens überschauen oder organisieren. Die Lebensmittel kommen aus dem Supermarkt, in dem man selbst nicht arbeitet, die Wäsche wird von einer Maschine gereinigt, die man selbst nicht gebaut hat, das Geld kommt von einer Einrichtung, die man selbst nicht gegründet hat, und die Strafe

11 Berger und Luckmann (2004: 16) formulieren es so: »Wenige befassen sich mit der theoretischen Interpretation der Welt, aber alle leben in einer Welt.«. 
für Fehlverhalten im gesetzlichen Sinne wird von Personen ausgesprochen bzw. durchgesetzt, die man selbst nicht in ihr Amt gesetzt hat. Einzelne Akteure üben vor dem Hintergrund dieser funktionalen Differenzierung diverse Funktionen aus: Sie können Staatsbürger sein (das sind sehr viele), Steuerzahler (schon weniger), sie können zur aktiven oder passiven politischen Wahl befähigt sein, sie sind Konsumenten, Partner, Kollegen und Familienmitglieder, sie gestalten im Kleinen Gesellschaft mit und werden ihrerseits von der Gesellschaft 'gestaltet<. Besonders exponiert sind diejenigen Funktionen, die mit dem Beruf einhergehen. Einen Beruf ausüben bedeutet mehr, als schlichtweg seine Arbeitskraft und Lebenszeit zu verkaufen. Welchen Beruf jemand ausübt, ist weder Zufall, noch zwingende Notwendigkeit. Die Berufswahl ist abhängig von einem komplexen Geflecht aus Bedingungen und Möglichkeiten, und das gilt noch stärker für Faktoren wie den Berufserfolg, für das erwirtschaftete Gehalt, für das mit der Berufstätigkeit verbundene Prestige und für einige weitere Aspekte. Eine funktional differenzierte Gesellschaft bringt für bestimmte Berufsbereiche eine große Nachfrage mit sich - etwa in den Feldern Behörden/Angestelltenwesen/Bürokratie und Verwaltung. Andere Berufe muten dagegen geradezu exotisch an, weil auf den ersten Blick unklar ist, wofür die Gesellschaft sie >braucht $<$ - wozu, beispielsweise, braucht man Byzantisten? (Und ja, manche fragen natürlich auch: Wofür braucht man Soziologen?) Es dürfte nicht überraschen, dass eine sehr persönliche Berufswahl - eine, die den eigenen Interessen entgegenkommt - in einer funktional differenzierten Gesellschaft geradezu wie ein luxuriöser Anspruch wirkt. Emile Durkheim, einer der Gründerväter der Soziologie, bevorzugte es, statt von Interessen von `Leidenschaften zu sprechen. Mit diesem Begriff wird der Kontrast in seiner Schärfe deutlich. In einer Gesellschaft wie der zentraleuropäischen Gegenwartsgesellschaft muss die soziale Architektur, muss der Aufbau des gemeinschaftlichen Zusammenlebens gesichert werden, und dies funktioniert umso schlechter, je persönlicher - man könnte auch sagen: je egoistischer - die Berufsentscheidung jedes einzelnen ausfällt. Wenn alle einzig und allein das täten, was sie sich in ihrem Inneren wünschen, wohin also ihre persönliche Leidenschaft sie treibt, wären sehr viele Posten, die zum Funktionieren der Gesellschaft notwendig sind, unbesetzt. Einige Berufstätigkeiten wären nach wie vor begehrt, andere gar nicht mehr. Und viele würden das Heil für ihre Leidenschaft ohnehin gewiss anderswo suchen, als im Bereich der Arbeit.

Eine derart radikalindividualisierte Gesellschaft würde nicht funktionieren. Sie wird auf dem politischen Parkett von niemandem versprochen, und sie scheint auch nicht von vielen Menschen angestrebt zu werden. Das ist zunächst einmal erstaunlich: Wer würde schließlich nicht gerne die ei- 
genen Leidenschaften ins Zentrum seiner Aktivitäten stellen wollen? Offenkundig gibt es eine recht starke Übereinkunft - aller Individualisierung und allen unterschiedlichen Werthaltungen zum Trotz -, dass das Zusammenleben in einer komplexen Gesellschaft den Menschen Zugeständnisse abverlangt. Für diejenigen, denen diese Einsicht von selbst nicht kommt (wobei >von selbst< stets meint: indoktriniert durch Sozialisation und Erziehung, also vermittelt durch die Gesellschaft), gibt es mehrere Steuerungsinstrumente, um sie zumindest auf der beruflichen Ebene dazu zu bewegen, eine Funktion zu übernehmen, die - mehr oder weniger - dem Erhalt der Gesellschaft dient (auch wenn die konkrete Tätigkeit möglicherweise nicht den Eindruck macht, als täte sie das). Diese Instrumente wären nicht notwendig, hätte sich an verschiedenen historischen Punkten nicht immer wieder gezeigt, dass der Mensch ein Kollektivwesen ist (schon Aristoteles nennt ihn im 4. Jahrhundert vor der modernen Zeitrechnung in seiner Politik ein szoon politikon<, ein Gemeinschaftswesen). Soziologisch relevant ist, dass sich Gemeinschaft und Gesellschaft unterschiedlich fassen lassen. Die Differenzierung geht auf das 19. Jahrhundert zurück und beschreibt, kurzgefasst, den Unterschied zwischen eher zweckmäßigen, notgedrungenen, mechanischen Abläufen und eher solidarischen, organischen Zusammenhängen (vgl. Tönnies 2017, erstmals 1887). Gesellschaftlich sind beispielsweise Konsumsituationen oder eben berufliche Kontexte (man kann sie sich mitunter nicht aussuchen; man kann oft selbst nicht steuern, was zu tun ist, und schon gar nicht, wer einem vorgesetzt ist oder wer die Kollegen sind). Gemeinschaften sind Familien, Partnerschaften usw., die wesentlich stärker eigenständig mitgestaltet sind und deren Zusammenhalt auf ganz anderen Prinzipien beruht als etwa die Arbeitsteilung im Berufsalltag. In der Realität überlagern sich diese beiden Formen häufig. Essenziell ist, dass es in beiden Fällen um Kollektivität geht - das autonome, vereinzelte Ich ist folglich eine Gestalt, die nur inmitten dieser stabilen kollektiven Rahmungen zum Vorschein kommen kann.

Nun lässt sich leicht einwenden, dass es Menschen gibt, die zurückgezogen leben und deren Gemeinschaftsinteressen gering ausgeprägt sind (während sie, im Sinne der eben vorgestellten Unterscheidung, vermutlich durchaus Gesellschaftsinteressen haben dürften, schließlich müssen auch sie konsumieren, Einnahmen generieren, usw.). Doch deren Ich-Verständnis, dass sie, sei es absichtlich oder durch Umstände verschuldet, von anderen Personen trennt, ist gleichfalls etwas sozial Vermitteltes. Ganz und gar 
losgelöst von Mitmenschen operiert niemand. ${ }^{12}$ Und eben deshalb gibt es Prämissen, die für die Funktionsweise des Gemeinschaftswesens notwendig sind. Das Berufswesen mit seiner Melange aus Wahlfreiheit und Zwangsmechanismen gehört dazu; es soll aber an dieser Stelle nur als Beispiel für das Verhältnis von Kollektiv und Individuum fungieren.

$\mathrm{Ab}$ und $\mathrm{zu}$, das mag häufig situationsspezifisch sein, sind Menschen innerhalb des Kollektivs auf eine andere Weise nicht sonderlich >gesellig dann nämlich, wenn sie inmitten funktionierender Strukturen auf eigene Vorteile bedacht sind. Egoisten sind nicht automatisch Einzelgänger, sie verfolgen aber - in bestimmten Momenten - eine subjektive Agenda. Vermutlich sind alle Menschen mehr oder weniger egoistisch. Egoismus ist mit Individualität schon insofern verbunden, als egoistische Bestrebungen immerzu spezifisch sind; sie hängen von Gelegenheiten und Ausgangslagen, vor allem aber von Durchsetzungschancen ab. Durkheim spricht (wie andere auch) mit einer etwas anderen Akzentuierung von >Individualismuš. Aber auch egoistische Einstellungen sind sozial angelegt. Sie mussten im Laufe von Jahrhunderten überhaupt erst entwickelt werden, denn das autonome Ich und das mündige Selbst sind im Wesentlichen neuzeitliche Erfindungen. Sie sind sozusagen Scheinfiguren des modernen Alltagslebens: Vollständige Eigenständigkeit gibt es empirisch nicht, aber als Ideal ist der Gedanke populär.

Die Erfindung des Ichs bzw. die Erfindung der Autonomie lässt sich übrigens am Beispiel der Bestattungskultur demonstrieren. Im späten Mittelalter nimmt die Kultur der individualisierten Sterbe- und Begräbnisszenarien - inklusive persönlich gefärbter Leichenpredigten - an Fahrt auf. Die Rede ist von >Sterbekünsten<, von artes bene moriendi - in den zweifelhaften Genuss dieser Wertschätzungsrituale kommen jedoch nur Leichen von Rang und Namen. »Trauer wird zum Element höfischer Zeremonie«, und für Gräber bedeutet dieser Wandel, dass sie »eine prunkvolle Zelebration von Memoria « betreiben, um der Erinnerung an diesen einen besonderen Menschen willen (Kiening 2003: 295). Wesen und Charakter, oder deren

12 Max Scheler, auch er einer der frühesten Exponenten der Soziologie, hat einmal notiert, dass selbst Robinson Crusoe, der auf einer verlassenen Insel gestrandete Romanheld, nicht außerhalb gemeinschaftlicher Bezüge steht - schon deshalb nicht, weil er von bestimmten Menschen vermisst wird, und insbesondere deshalb, weil er in der Erinnerung die Gemeinschaft nach wie vor sbei sich trägt<. Selbst wenn Robinson nie in einer Gemeinschaft gelebt hätte (was kaum vorstellbar ist), wäre sein davon also vollständig unabhängiges Ich doch nur denkbar, wenn man die Gemeinschaft als Gegenpol miteinbezöge (vgl. Michalski 1997: $54)$. 
Anschein, wurden von nun an mit dem schicksalhaften Todesgeschehen als solchem zusammengedacht und -gebracht. Diese etwa im 15. Jahrhundert entstehende Tradition lässt den Durchschnittssterblichen jedoch außen vor. (Noch Wolfgang Amadeus Mozart wurde etwa dreihundert Jahre später in einem Massengrab verscharrt.) Wer nicht mit einer herausragenden Adels- oder Klerikalfunktion gesegnet war, war in dieser Zeit vor allem 'Gattungsangehöriger: Mensch ja, aber eben kein spezifischer. ${ }^{13}$ Man war in Gemeinschaft und Gesellschaft verstrickt, stach aber nicht durch individualistische Haltungen hervor; man lebte vielmehr ganz im Sinne kollektiver Richtlinien, die den meisten Menschen - bis auf die wenigen Privilegierten an der Spitze der Hierarchie - Vorgaben jenseits ihrer individuellen Person machten.

Es ist aufschlussreich, diesbezüglich die Einstellungen archaischer Kulturen zu recherchieren. Die Vorstellung, dass ein von der Gruppe unabhängiges Ich existiere, das zudem in jedem einzelnen Gruppenmitglied hause, gilt hier als eine geradezu übergeschnappte. Dennoch: »Der Tod eines Menschen verursacht für alle Eingeborenen der Ostküste Neuguineas eine große und lang währende Gleichgewichtsstörung «, schreibt der berühmte Anthropologe Bronislaw Malinowski über seinen Aufenthalt beim Volk der Trobriander im westlichen Pazifik. Dies aber vor allem deshalb, weil dieser Tod eine »ungeheure Erschütterung der wirtschaftlichen Verhältnisse der Gesellschaft « mit sich bringt (Malinowski 1922: 490). Mitglieder dieser Gesellschaft, und gerade solche, die sich um den Erhalt des Lebens- und Glaubensstandards auch angesichts äußerer Bedrohungen verdient gemacht haben - in diesem Zusammenhang vorrangig erwachsene Männer -, werden also selbst in einer weitgehend individualitätsfreien Welt betrauert. Ihre Leistungen waren im Rückblick allerdings keine individuellen. Der französische Ethnologe Lucien Lévy-Bruhl bescheinigt sogenannten Urvölkern Folgendes: »Das Individuum gilt bei ihnen als solches viel weniger als bei den höher stehenden Völkerschaften, und doch scheint

13 Der französische Autor Michel Foucault hat die Entdeckung der Individualität entgegen populärer Vorstellungen vom Sieg der persönlichen Freiheit, der sich darin ausdrücke - als eher ambivalenten Fortschritt bezeichnet. Wer Individuum ist, so Foucault, dem können Verfehlungen und Abweichungen persönlich zugerechnet werden. Am Beispiel eines Kriminalfalles aus dem 19. Jahrhundert demonstriert er, dass im extremsten Fall eine Straftat somit von ihren sozialen Begleitumständen losgelöst werden kann: ganz so, als sei das Individuum, vereinzelt und dadurch losgelöst von gemeinschaftlichen Bindungen, für sein Schicksal folglich ganz alleine verantwortlich (Foucault 1975). Individualität steht jedoch nicht für die Auslöschung sozialer Bindungen, sondern allenfalls für neue Betrachtungsweisen, die auf diese Bindung angelegt werden können. 
der Tod eines Erwachsenen ihnen ein viel wichtigeres Ereignis zu sein und eine viel tiefere Ergriffenheit auszulösen als bei uns. [...] Es ist das Fortbestehen der ganzen Gruppe, das bedroht und gefährdet erscheint. [...] Der Todesfall hat ihr einen Teil ihrer Substanz geraubt.« (Lévy-Bruhl 1956: 234f.) Das betrauerte Individuum ist hier also lediglich eine Stellvertretungsfigur für die Gemeinschaft selbst. Man kann für diese archaische, früher primitiv und vorzivilisatorisch genannte Welt, zumindest für viele der näher untersuchten Volksgruppen, also festhalten: Wenn ein Mensch stirbt, »trifft der Tod nicht nur seine Angehörigen, sondern die ganze Gesellschaft.« (Lévi-Strauss 1979: 225)

Es dauert nur einen Gedankensprung, um wieder zurück in der Gegenwart zu landen. In den individualisierten Gesellschaften der westlichen Welt wird anders getrauert und anders erinnert (Benkel 2017a). Es gehört heute zum guten Ton und zur Ritualerwartung dazu, dass Leichenpredigten, wenn es nicht bereits Abschiedsworte eines säkularen Trauerredners sind, Leben und Denken der verstorbenen Person angemessen würdigen (oder zumindest so tun). Dank sozialer Wandlungsprozesse hat die Vorstellung vom persönlichen Sterben, Totsein und Bestattetwerden Allgemeingültigkeitscharakter angenommen. Die Idee der gegenseitigen Abhängigkeit von Mitgliedern innerhalb einer Gemeinschaft zum Zweck der Garantie dieser Gemeinschaft ist damit aber nicht ausgestorben. Die erwähnten Steuerungsmechanismen beweisen es - und erst recht die Üblichkeiten des Trauerns. Wäre es nämlich anders, würde im Todesfall ein kurzes Abschiedsritual ausreichen, um die Verstorbenen aus der Gemeinschaft rauszutreiben < - und die Leichen könnten wie Abfall behandelt werden. Trauer, die über den Tag hinaus reicht, wäre ein Hindernis beim Verfolgen der individualistischen Ziele jedes isolierten Einzelnen, d.h. also: beim Ausleben subjektiver Leidenschaften. Und tatsächlich ist Trauer ja auch Blockade; sie hält den Fortgang des alltäglichen >Immer-so-weiter für eine gewisse Frist spürbar auf. Dass die gesamte Gesellschaft, soweit überschaubar, um einen Menschen trauert, ist selten geworden - umso seltener, je größer und komplexer Gesellschaften sind. (In Gemeinschaften, in solidarischen Sozialkontexten also, sieht es anders aus - also beispielweise im Familienkreis, im dörflichen Kollektiv, im Verein, usw.) Dennoch versteht jeder, ob nun persönlich betroffen oder nicht, was es bedeutet, wenn jemand trauert. Jeder könnte, wenn er wollte, sich an die Stelle des Trauernden denken und eigene Verlusterfahrungen erinnern bzw. sie als künftige Geschehnisse imaginieren. Diese Austauschbarkeit der Perspektiven - in der Soziologie ist die Rede vom »taking the role of the other" (George Herbert Mead) ist nur denkbar in einer gesellschaftlichen Umgebung, die Trauer als Signal einer nicht nur individuellen, sondern kollektiven Destabilisierung deutet. 
Einerseits gilt Individualität als kaum zu überschätzender Wert; andererseits brauchen moderne Gesellschaften die sich selbst einschränkende Individualität, um jenes $\mathrm{Ma}$ an Ordnung stabil zu halten, das stabil zu halten in der Idee der Gemeinschaft implizit versprochen wird. Das Verhältnis von Individuum und Kollektiv ist insofern von einer delikaten Balance geprägt. Rollenzuweisungen und Rollenübernahmen sind in stark von sozialer Ungleichheit geprägten Gesellschaften zwar keine vollkommen überzeugenden Regulative mehr. Aber in ihnen lebt der Geist des geordneten Zusammenlebens fort, und damit auch die Vision einer durch Moral verbundenen Gemeinschaft - um die es gleich näher gehen wird.

Hier zeichnet sich vorsichtig ab, was es heißt, wenn Menschen trotz Trauer funktionieren sollen, funktionieren wollen oder glauben, funktionieren zu müssen. Sie wollen diejenigen Aufgaben, die ihnen zur Unterstützung des Kollektivs auferlegt sind bzw. denen sie sich selbst verpflichtet fühlen, erfüllen. Beziehungsweise sie fühlen sich unwohl, wenn sie nicht mehr so arbeiten und sich in das soziale Umfeld einbringen können, wie sie bislang funktioniert haben, und wie man sie bislang kannte. Manche Menschen sind jedoch so tief in die Sinnwelt der Trauer verstrickt (in ihre je eigene), dass entsprechende Ansprüche - berufliche ebenso wie familiäre, partnerschaftliche, nachbarschaftliche, freundschaftliche usw. - an ihnen geradezu abprallen. Sie sind kognitiv und häufig auch körperlich nicht im Stande, jene Aufgaben wieder anzupacken, die sie zuvor - mehr oder minder gemäß eigener Wahl - innerhalb des Gesellschaftslebens ausgeübt haben. Andere hingegen scheinen sich regelrecht zu schämen, dass sie nicht können, aber eigentlich doch wollen. ${ }^{14}$ Wieder andere scheinen sich in das ihnen altbekannte Tätigkeitsfeld zu stürzen, jedoch vermutlich

14 Eine aufschlussreiche Parallele lässt sich zum Zustand der Krankheit ziehen. Es spricht einiges dafür, auch Krankheiten als Subsinnwelten zu verstehen - und ebenso gibt es gute Argumente dafür, Trauer mitunter wie einen krankheitsähnlichen Zustand zu behandeln. (Gemeint ist nicht, dass Trauernde erkrankt sind gemeint ist, dass es Ähnlichkeiten hinsichtlich ihrer sozialen Position gibt. Die Debatte darüber, ab welchem Punkt intensive Trauer tatsächlich pathologisch ist, soll hier nicht geführt werden. Der Vorschlag von medizinischer Seite, diese Grenze bei 14 Tagen Trauerzeit zu ziehen [vgl. Lanzerath 2014: 66], hat einige Kritik nach sich gezogen). Kranke dürfen in modernen Gesellschaften üblicherweise auf Verständnis für ihre Lage hoffen, und auch in sozialökonomischer Hinsicht gibt es üblicherweise Abfederungsmechanismen, die das Erkranken von Arbeitnehmern usw. für alle beteiligten Seiten kompensieren. (Dies wird näher im Kontext der Gesundheitssoziologie bzw. der Public Health-Forschung thematisiert.) Der amerikanische Soziologe Talcott Parsons schreibt, dass Menschen in Krankheit, nüchtern betrachtet, gesellschaftliche Instrumente in Anspruch nehmen, zugleich 


\section{Thorsten Benkel}

nicht, weil ihr Verantwortungsgefühl sie >Alltagsmensch` sein lässt, sondern häufig genug, um sich von der Trauer abzulenken. Insbesondere der Berufsbereich bietet sich dafür an, verlangt er einem doch gerade nicht emotionale Anteilnahme, sondern häufig genug lediglich ablauforientiertes Funktionieren $\mathrm{ab}$ - ohne dass das Innenleben dabei angesprochen würde. Die Trauer kann somit still gestellt werden. Die Empfindung dürfte dabei wohl nicht verschwinden, sondern sie wird psychologisch nur verlagert, ungefähr so wie Gerümpel im Haushalt, den man nicht wegwerfen möchte, für den man aber auch keine akute Verwendung hat. Er wird in die Abstellkammer verbannt, um früher oder später doch wieder Thema zu sein. Es sind nur >Pausen`, in denen das Gerümpel nicht stört - aber es löst sich in diesen Pausen nicht auf.

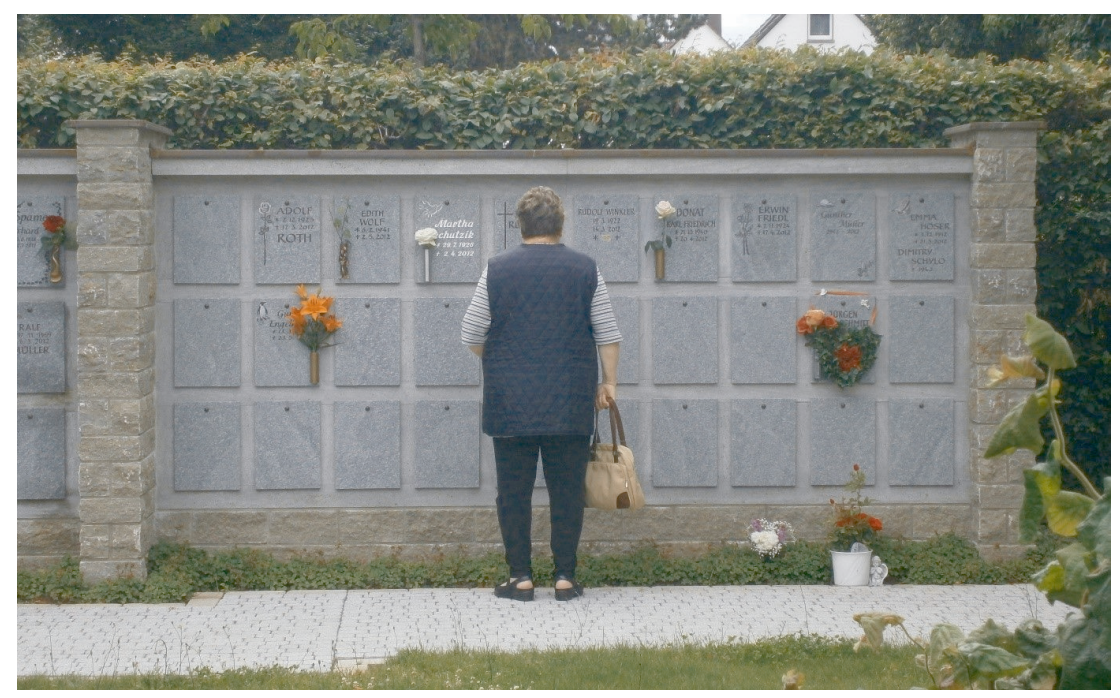

Stellt Trauern für die Gesellschaft heute vielleicht eine Art dysfunktionale Phase dar, die von je unterschiedlichen Individuen unterschiedlich erlebt wird - von manchen eben auch derart, dass sie ihre unbedingte Funktions-

aber ihre Aufgaben (als Berufstätige, als Familienmitglieder, als Partner usw.) nicht erfüllen (vgl. Feldmann 1995: 145ff.). Dieses Kalkül mag befremdlich wirken. Aber es gibt fraglos Menschen, die eigene Erkrankungen genauso betrachten und versuchen, gewissermaßen saus eigener Kraft heraus< das Funktionieren ihres Aufgabenzusammenhangs zu bewerkstelligen. Ohne Zweifel gilt dies auch für manche Personen, die sich in Trauer befinden. 
tüchtigkeit unter Beweis stellen wollen? Nur wenige werden diesen Standpunkt laut aussprechen. Er wirkt pietätlos, und vor allem ist er falsch. Denn Trauer hat eine soziale Funktion.

\section{Soziale Funktionen der Trauer}

Soziologie ist diejenige Wissenschaft, die sich von ihren Anfängen - die im letzten Viertel des 19. Jahrhunderts liegen - bis heute im Kern immer wieder dieselbe Frage gestellt hat: Wie ist gesellschaftliche Ordnung möglich? (Vgl. Simmel 1999: 42ff.) Im Wesentlichen zielt diese Frage darauf ab, wie es kommt, dass Menschen mit zum Teil sehr unterschiedlichen Lebenseinstellungen, Werthaltungen, Existenzbedingungen usw. zusammenleben können. Nicht nur parallel nebeneinander her, sondern tatsächlich auch miteinander, im nahen Austausch, arbeitsteilig, sich respektierend, sich liebend, sich verachtend. Menschen sind offenkundig trotz ihrer Leidenschaften (oder vielleicht sogar deswegen?) gesellige Wesen. Anders als bestimmte Tierarten fühlen sie sich nicht nur aus pragmatischen Gründen zueinander hingezogen. Wenn sie sich in gegenseitige Abhängigkeitsverhältnisse begeben (und dies ist in der modernen Gesellschaft der Normalzustand), dann nicht lediglich deshalb, weil dies dem persönlichen Weiterkommen dient, oder weil hormonelle Überflutungen des Bewusstseins sie in Paarungsperioden dazu zwingen (auch wenn mancher Zeitgenosse genau diesen Eindruck macht). Die Menschen haben sich über verschiedene Entwicklungsstadien hinweg Ordnungen gegeben, die das Zusammenleben regulieren. Norbert Elias (1994) vertritt die Ansicht, dass sich diese Stadien in Richtung Zivilisation zugespitzt haben; demnach sind historisch frühe Ordnungskonzepte (zum Beispiel die erwähnten archaischen Kulturen) einfacher, dadurch aber in Sachen Selbsterhalt weniger effizient als spätere. Insbesondere $\mathrm{ab}$ der frühen Neuzeit seien Modelle für das Zusammenleben etabliert worden, bei denen zuvor für die Oberschicht (Adel, Klerus) reservierte Privilegien und Gestaltungsspielräume allmählich auch für die Gesamtbevölkerung verfügbar wurden. Damit erklärt Elias sowohl den Fortschritt in der Gesellschaftsentwicklung wie auch die enge Verzahnung des individuellen, scheinbar ganz eigenständigen Denkens mit den Rahmenbedingungen, innerhalb derer sich dieses Denken überhaupt erst entfaltet.

Ordnungen sind also, das lässt sich bei Elias lernen, wandelbar - so wie sich Gesellschaft insgesamt permanent im Wandel befindet. Was hat dies nun aber mit Trauer zu tun? Etwas früher als Elias hat sich der bereits erwähnte französische Soziologe Emile Durkheim diese Frage gestellt. Ge- 
nau genommen, hat Durkheim sich, wenn auch nur am Rande, mit der Kollektivität des Trauerns befasst. In seinem Buch über die Elementaren Formen des religiösen Lebens kommt er $1912 \mathrm{zu}$ folgendem kontroversen Schluss: »In der Trauer fügt man sich Leid zu, um zu beweisen, daß man leidet.« Denn Trauer, so Durkheim weiter, sei letztendlich eine »Pflicht, die von der Gruppe auferlegt wird « und somit »eine rituelle Haltung«, welche »unabhängig ist vom Gefühlszustand des Individuums «, also auch unabhängig davon, ob »der ausgedrückte Kummer wirklich gefühlt wird « (Durkheim 1984: 532). Durkheim geht mit der Trauer hart ins Gericht. Sie ist für ihn eine Art Inszenierung, die nicht um der Toten, sondern um der Lebenden willen aufgeführt wird. Trauern hat demnach vorrangig eine nach außen geleitete Funktion: Sie adressiert das soziale Umfeld, also die Mitmenschen, die registrieren können (und nach Durkheim ausdrücklich registrieren sollen), dass es Grund gibt zu trauern. Getrauert wird deshalb, weil dies den in der Sozialisation vermittelten Werten zum Thema Lebensende einer nahestehenden Person entspricht. ${ }^{15}$ Die Spuren des archaischen Trauerns, des Trauerns wegen gemeinschaftsgefährdender Ressourcenverluste, treten dabei nur noch sehr versteckt auf. Einen wirklichen Grund benötigen Traueraufführungen nicht mehr, so sehr sind sie als Üblichkeiten festgeschrieben, die sich überdies nur in wenigen Details unterscheiden. Es sei, dies meint Durkheim sinngemäß, gar nicht entscheidend, ob folglich beim Todesfall in der Familie tatsächlich Trauer empfunden wird. Womöglich war der verstorbene Großvater tyrannisch, die Mutter gefühlskalt usw., sodass die Angehörigen so recht nicht zu trauern vermögen. Entscheidend ist daher, laut Durkheim, dass so getan wird, als $o b$ - dann ist dem sozialen Anspruch, dass dieser Tod betrauert werden soll, ja muss, Genüge getan. Wie es im Kopf der Trauernden wirklich aussieht, muss nicht thematisiert werden, im Gegenteil, es wäre am Schluss sogar hinderlich für einen reibungslosen Ablauf der die Trauerphase begleitenden Rituale (wie Gedenkgottesdienst, Beerdigungsfeier, Kondolenzsituationen, usw.). Der Ausdruck

15 Unter Umständen bezieht sich Trauer auch auf Personen, die verehrt, ja geliebt wurden, die einem aber weitgehend unbekannt geblieben sind. Ein Beispiel hierfür ist der Tod einer prominenten Persönlichkeit, die ihre trauernden Anhänger in Form ihrer >Medienrepräsentation kannten, jedoch nicht als Interaktionspartner im alltäglichen Leben. Der Trauer tut das keinen Abbruch. Die Abläufe des Trauergeschehens werden außerdem zunehmend auf Todesfälle im Heimtierkontext übertragen. Aufgrund veränderter Strukturen im Mensch-Tier-Verhältnis fungieren Hund und Katze offenkundig zunehmend als Sozialpartner; dabei steht nicht das, was Mensch und Tier trennt im Vordergrund, sondern konstruierte $\mathrm{Zu}$ sammengehörigkeit. Dies schlägt sich entsprechend in einer um animalische Elemente erweiterten Bestattungskultur nieder (Meitzler 2017c; Preuß 2016). 
von Trauer kann durch eine Art `Gefühlsmanagement< erzeugt werden was die Trauer in eine Reihe mit anderen emotionalen Zuständen stellt, die nicht nur innerlich empfunden, sondern auch (und manchmal: ausschließlich) 'nach außen p präsentiert werden (Russell Hochschild 2006).

Betrachtet man den Gedankengang etwas näher, so wird erkennbar, dass Durkheim keineswegs bestreitet, dass mit dem Tod Verlustschmerzen oder eine angstbesetzte Zukunftsunsicherheit einhergehen können (vgl. Benkel 2012: 61). Es soll auch nicht in Frage gestellt werden, dass der Verlust in den allermeisten Fällen etwas faktisch Betrauernswertes ist, also ein spürbarer, Anschlussprobleme auslösender Negativeffekt für das trauernde Umfeld. Worum es Durkheim vorrangig geht, ist die Idee der Ordnung, die im Trauerhandeln Ausdruck findet.

Um dies zu verstehen, muss man sich klarmachen, dass >der Mensch, wie es immer heißt, wenn es in kulturellen Angelegenheiten um das große Ganze geht, nicht vereinzelt, sondern - wie gesagt - in Großgruppen lebt. (Ob und inwiefern diese Lebensform nicht zugleich psychologische Vereinsamung zulässt, soll hier nicht diskutiert werden - vermutlich dürften aber die meisten Leserinnen und Leser verstehen, wie ich das meine.) Es gab eine Zeit, da hat es unter den Menschen, die zusammenlebten, nur wenige Differenzierungen gegeben. Die genannten archaischen Kulturen gehören dazu. Es bedarf aber keiner Reise in ferne Länder, um diese Vergangenheit zu erkunden - sie war in Europa gelebte Realität. Entscheidend waren damals, vor Jahrhunderten, sagen wir: in einer Dorfgemeinschaft, Unterscheidungen wie die zwischen Mann und Frau, zwischen Priester und Nicht-Priester, eventuell noch zwischen Krieger und Nicht-Krieger, usw. Es gab aber bei weitem nicht so viele Differenzierungen wie in Gegenwartsgesellschaften. ${ }^{16}$ In dieser Zeit waren die Menschen untereinander auch deshalb solidarisch, weil sie einander stark ähnelten. Wenn das Kollektiv angesprochen war, konnte sich auch jedes, oder nahezu jedes Mitglied des Kollektivs betroffen füblen. Auch dies ist ein Grund, warum der Tod eines Gruppenmitglieds die anderen in Schrecken und Agonie versetzt - sie fühlten sich mitbetroffen, weil da wirklich jemand starb, der genauso war

16 Eine zentrale Unterscheidung, die heute nicht mehr wegzudenken ist und verführerisch >natürlich zu sein scheint, ist die zwischen Erwachsenen und Kindern. Sie ist eine neuzeitliche Erfindung, wie der französische Sozialhistoriker Philippe Ariès - übrigens auch Autor einer umfassenden Darstellung zur Geschichte des Todes (Ariès 2002) - anhand von Quellenmaterial nachgewiesen hat (Ariès 2000). In diesem Lichte lässt sich besser verstehen, weshalb es auch heute noch Kulturen gibt, in denen Kinder arbeiten müssen bzw. verheiratet werden. Ihnen fehlt eine in der westlichen Welt vor Jahrhunderten erfolgreich etablierte Differenzierung. 
wie sie. Dies war die Zeit der segmentären Differenzierung, und Durkheim nennt den Zusammenhalt, der damals zwischen den Menschen vorherrschte, mechanische Solidarität (Durkheim 1988). In seinem Buch mit dem Titel Über soziale Arbeitsteilung (genau genommen war dies eine seiner beiden Dissertationsschriften, verfasst im Jahr 1893) legt Durkheim dar, dass diese Variante des Zusammenlebens eine Art "Kollektivbewusstsein" (ebd.: 128) mit sich brachte. Die meisten Mitglieder dieser Gemeinschaft konnten auch die meisten relevanten Aufgaben übernehmen. Es gab keinen Grund, komplexe Aufträge gezielt zu verteilen. Alle zogen am gleichen Strang - bewusst und gewollt. Die Individualität des Menschen war hier "gleich Null« (ebd.: 182).

Im Laufe der Zeit aber kommt es zu erheblichen gesellschaftlichen Veränderungen. Aus Dörfern werden kleine, schließlich große Städte. Politisch getrennte, aber geografisch nahe Gebiete wachsen allmählich zusammen. Die Gruppengrößen des Zusammenlebens nehmen zu - Durkheim spricht konkret von einem Anstieg des »sozialen Volumens (ebd.: 319). In dieser nun komplexer und daher unübersichtlicher gewordenen Welt kennt nicht mehr jeder jeden, sodass Institutionen errichtet werden müssen, die stellvertretend Aufgaben erfüllen, welche zuvor vom Kollektiv selbst übernommen werden konnten. Vor allem aber kommt es zum Phänomen der Arbeitsteilung. In der nun funktional differenzierten Gesellschaft kann nicht mehr jeder sämtliche anspruchsvolle Tätigkeiten vollbringen, die eine erfolg- und ertragreiche Lebensführung einem abverlangen. Man muss mit anderen Menschen kooperieren - weil es andere sind, die einem Waren und Lebensmittel bringen oder ab einem bestimmten Kindesalter Erziehungsaufgaben übernehmen. Wer sich mit dem Nachbarn um Rechtsansprüche streitet, braucht ebenso professionelle Unterstützung wie derjenige, der erkrankt ist und Heilung anstrebt. Dies sind nur einige von vielen Anforderungen, die in der modernen Gesellschaft ständig erfüllt werden müssen. Der Einzelne übernimmt nur einige wenige dieser Aufgaben, und zumindest die berufliche Rolle, die man spielt, kommt dabei mal unmittelbar und mal über Umwege anderen Gesellschaftsmitgliedern zugute - auch solchen, die man persönlich gar nicht kennt. Auf diese Weise wird Solidarität erzeugt, wenn auch eine Solidarität, die auf rationalem Egoismus aufbaut. Gemeint ist damit, dass Menschen schon deshalb nicht radikal egoistisch bzw. individualistisch sind, weil sie ahnen können, dass sie in einer solchen Welt ihre eigenen Ziele nicht länger erreichen können. Die Vernunft flüstert einem also ein, dass es sinnvoller ist, anderen Personen gegenüber unterstützend zu agieren, als stets bloß dem eigenen Vorteil zu folgen. Die Gefahr, sich zu isolieren, ist nach Durkheim umso größer, je individueller Menschen denken. In einer funktional differenzierten Gesell- 
schaft ist das individuelle Bewusstsein nun aber für gewöhnlich recht stark ausgeprägt. Alleine schon aufgrund der subjektiven Rolle, die man inmitten eines ziemlich heterogenen, in vielerlei Hinsicht durchaus anonymen Kollektivs spielt, empfinden sich Menschen verständlicherweise nicht mehr als gleichberechtigte, aber individualitätsarme Gruppenmitglieder, sondern eben als Individuen, die sich inmitten der sozialen Welt ihren eigenen Weg bahnen müssen, bahnen sollen oder bahnen wollen.

Durkheim nennt dies die Welt der organischen Solidarität (vgl. ebd.: 200ff.). Wie in einem menschlichen Körper, sind die einzelnen Organe der Gesellschaft zwar nicht gleichberechtigt - aber sie werden eben doch alle benötigt, um den Körper funktionsfähig zu halten. Es ist also notwendig, dass die Gesellschaftsmitglieder ihren Egoismus - wie gesagt: ihre >Leidenschaften $<$ - im Zaum halten, sonst verliert der Gemeinschaftsgedanke endgültig seine Substanz und es bleiben egoistische Beutegreifer auf sonderbaren Märkten zurück, die nur auf den eigenen Vorteil bedacht sind. Durkheim weiß, welches Mittel der funktional differenzierten Gesellschaft auf die Sprünge hilft und das Auseinanderbrechen in eine zersplitterte soziale Wirklichkeit vermeidet. Er ist der Überzeugung, dass Zwang, also etwa: gesetzliche Regelungen, nicht helfen würden, denn in einer solchen Welt wäre der Solidaritätsgedanke nicht deshalb lebendig, weil die Menschen an ihn glauben - sondern in erster Linie deshalb, weil sie Angst vor der Strafe haben. Die zentrale Methode, den Zusammenbruch zu vermeiden, ist laut Durkheim vielmehr die Moral.

Moralische Einsichten werden, dies ist der Gedanke dahinter, nicht respektiert, weil man ansonsten bestraft wird, sondern deshalb, weil man einsieht, dass sie richtig sind. In diesem Sinne sind liberale Gesellschaften so strukturiert, dass moralische Fragestellungen nicht über rechtliche Regelungen, sondern überwiegend über soziale Aushandlungen geklärt werden. Der Unterschied zwischen mechanischer und organischer Solidarität lässt sich vor diesem Hintergrund nachvollziehen: In der segmentär differenzierten Welt von früher gab es wenig Notwendigkeit, bei Bestrafungen von Fehlverhalten nähere Nachforschungen zu den Handlungsmotiven für dieses Fehlverhalten anzustellen. Schließlich waren die Menschen weitgehend gleich, und was für alle falsch sein sollte, konnte im Einzelfall schwerlich entschuldigt werden - erst recht nicht durch individuelle< Tatumstände, denn Individualität war zu dieser Zeit, wie erwähnt, keine besonders relevante Größe. Was Regeln und Regelbrüche angeht, waren die Gesellschaften dieser Epoche bzw. dieses Entwicklungsstandes also tatsächlich sgleich‘; zwischen einzelnen Personen wurde kaum differenziert. In der funktional differenzierten Welt ist der entscheidende Gedanke hingegen der, dass die Stabilität des Zusammenlebens gewährleistet werden 
muss. Es geht, mit anderen Worten, vorrangig um die Ordnung und erst in zweiter Linie um persönliche Interessen. Bei strafbaren Verhaltensweisen wird daher nicht pauschal und mit stets gleicher Konsequenz bestraft, sondern es werden die genauen Hintergründe ermittelt und es wird evaluiert, welcher Umgang mit der Tat dem Ziel des Ordnungserhalts am besten dient - inklusive der Berücksichtigung individueller Lebenslagen. Wie gesagt: Wenn Menschen sich alleine aus Angst vor Strafe den vorherrschenden gesellschaftlichen Normen unterwerfen, ist das offenkundig etwas ganz anderes, als wenn sie diese Normen aus moralischer Einsicht heraus gutheißen. Eine moderne und komplexe Gesellschaft braucht diese Einsicht; sie braucht moralische Substanz, um zu funktionieren. Ein Schema, bei dem auf eine Handlung pauschal eine (immer gleiche) Reaktion folgt, ist dem gegenüber ungeeignet, um heute noch soziale Leitlinien zu vermitteln.

Durkheims Buch über die Religion, das seine Überlegungen zur Trauer enthält, entstand knapp zwanzig Jahre später als seine Überlegungen zum Kollektivbewusstsein bzw. zur Arbeitsteilung. Beide Werke sind mittlerweile Klassiker, die mehr als 100 Jahre Rezeptionsgeschichte hinter sich haben, die aber immer noch konsultiert werden - nicht nur von Soziologiehistorikern, sondern auch und gerade von einem Leserkreis, der sich fragt, wie der gesellschaftliche Zusammenhang damals, zu Durkheims Lebzeiten, interpretiert wurde und was sich schlussfolgernd für die heutige Gesellschaft daraus lernen lässt. Auf den ersten Blick könnten die Befunde, die Durkheim getroffen hat, veraltet wirken: Ist nicht die Gegenwartsgesellschaft längst zu sehr individualisiert? Sind nicht die Egoismen, die Durkheim als negative Bedrohung eines solidarisch-moralischen Zusammenlebens auszumachen glaubte, längst als Alltagsnormalität etabliert? Oben habe ich diesen Punkt bereits kurz angesprochen. Eine verbindliche Antwort fällt schwer, denn diesen - wohl eher rhetorischen - Fragen kann mit Pro- wie auch mit Contra-Argumenten entgegnet werden. Vielleicht lautet die richtige Antwort: vielleicht bohrt, desto deutlicher zeigt sich jedenfalls, wie aufschlussreich und überzeitgemäß Durkheims Konzept in Wahrheit ist. Und schließlich hilft seine Analyse auch heute noch beim Verständnis des Phänomens Trauer und der Umbrüche, die sich in diesem Kontext abzeichnen.

Was Durkheim deutlich macht, ist, dass Gesellschaft nicht ohne Ordnung funktionieren kann. Die Ordnung kann als eine Art Kraft oder 'Energier gedeutet werden, die von gesellschaftlichen Institutionen angestoßen bzw. hergestellt wird, um den sozialen Zusammenhalt zu gewährleisten. Diese Institutionen sind jedoch selbst das Produkt von ordnungsgenerierenden Interessen. Man könnte sagen: Das gesellschaftlich organisierte $\mathrm{Zu}$ - 
sammenleben ist eine Reaktion darauf, dass Menschen zusammenleben. Es ist aber nicht bewusst so entstanden - es hat sich vielmehr ergeben. Hätte es Gesellschaft irgendwann nicht gegeben, schreibt Niklas Luhmann, der Querdenker unter den bekannten deutschsprachigen Soziologen, wie hätte jemand sie sich ausdenken können, um sie sodann gezielt zu erfinden? Ordnung gibt dem Zusammenleben Kontur, Ordnung verspricht, sich selbst zu garantieren - und Ordnung ist, entgegen dem oberflächlichen Anschein, zugleich nichts, was sich von selbst trägt. Es braucht alltägliche Anstrengungen, Ordnung zu bestätigen, zu stabilisieren bzw. zu renovieren. Das gilt heute nicht weniger als zu Durkheims Zeiten - sondern vielleicht sogar mehr.

Die Individualisierung ist von heute aus betrachtet massiv vorangeschritten. An anderer Stelle habe ich gemeinsam mit Matthias Meitzler zu zeigen versucht, dass insbesondere die zeitgenössische Bestattungskultur stark (und zunehmend) von Individualisierungsschüben geprägt ist (Benkel/ Meitzler 2013; Benkel 2016; Meitzler 2016). Individualisierung zeigt sich aber auch, und noch wesentlich deutlicher, in anderen Lebensbereichen. Schlagworte wie Selbstverwirklichung und das persönliche Streben nach Sinngebung sind in einer von der Individualisierung durchdrungenen sozialen Welt erwartbar. Dagegen sind die schon zu Durkheims Zeit schwachen Bezüge zum Kollektivbewusstsein heute, in einer nochmals ausdifferenzierteren Arbeitsteilung, die sich sogar so sehr aufteilt, dass manche Menschen vollständig herausfallen, kaum mehr auffindbar. Auch über Moral muss heute anders berichtet werden als zu Lebzeiten Durkheims. ${ }^{17}$

Mit diesem Vorlauf lässt sich nun besser nachvollziehen, wie Durkheim zu seiner Ansicht zur Trauer gelangen konnte. Umeinander trauern, den

17 Luhmann beispielsweise vertritt die Ansicht, dass Moral das Gegenstück zur Arbeitsteilung sei (vgl. Luhmann 2002: 192). Zugleich könne sie heutzutage (dem Heute der 1990er Jahre) nicht mehr als `Kollektivphänomen existieren. Abgesehen von der Ebene des unmittelbaren zwischenmenschlichen Kontakts, wo Moral im Sinne von Respektsbezeugungen usw. noch Bedeutung habe, lässt sich von allgemeinverbindlichen moralischen Regeln laut Luhmann nicht mehr sprechen. Einzelne Moralappelle seien heute folgenlos; somit kommen konkrete Moralangebote, die über situative Kontexte hinausragen, allenfalls noch vom Fernsehen, der zentralen Moralinstanz, an die sich aber niemand gebunden fühlen muss. Andere Instanzen sind noch weniger durchsetzungsfähig. Die Folge: Moral wurde im Laufe der Zeit mehr und mehr simplifiziert zu einer »Kommunikation, die Hinweise auf Achtung oder Missachtung mitführt«; dies spitzte sich so sehr zu, dass nun mehr gelte, sie habe »etwas leicht Pathologisches an sich « (Luhmann 1990: 18). Vom Impuls, das Gemeinschaftsleben zu verbessern, ist somit für Luhmann nicht mehr viel zu sehen. 
Verlust bedauern, einander unterstützen - plakativ nach außen gerichtet, oder mit ehrlicher Empfindung von innen heraus -, dies alles sind Einzelbestandteile der organischen Solidarität. Trauer symbolisiert Solidarität. Trauer steht für Werte des Gemeinschaftslebens jenseits der Person des Toten. Trauer drückt aus, dass wir - die Überlebenden - weiterhin gewillt sind, das Prinzip der gesellschaftlichen Ordnung hoch zu halten. Trauer ist, im Lichte dieser Deutung, immerzu etwas soziales, und Trauer benötigt somit also nicht unbedingt eine korrespondierende innere Erfahrung, um zu >wirken‘. Soziologisch interpretiert - gemäß der Soziologie Durkheims, der ich mich hier anschließe - sind die Verstorbenen die letzthin austauschbaren Auslöser für Rituale, bei denen die Hinterbliebenen sich gegenseitig ihr Engagement im Dienste des Ordnungserhalts vorführen. Die Toten profitieren von all dem, was sich bei der Bestattungsfeier, beim Gottesdienst, bei Momenten des Gedenkens usw. abspielt, nicht - wohl aber die Lebenden.

Dies ist die soziale Funktion der Trauer. Dass sich reales Trauern tatsächlich ganz anders anfühlt, und dass diese gesellschaftliche Komponente nur einen schwachen, für viele wohl überhaupt keinen Trost mit sich bringt, steht dem nicht entgegen. Vielmehr zeigt die Tatsache, dass Menschen in Trauer den Verlust personenbezogen empfinden - eben nicht mit Blick auf das soziale Umfeld, sondern vor allem mit einem sehnsüchtigen Blick in Richtung des Verstorbenen -, wie gut das Konzept Trauer als ordnungsstabilisierendes Prinzip in die Gegenwartsgesellschaft eingeschrieben ist. Über Wege des sozialen Lernens verinnerlichen die Mitglieder der Gesellschaft die Regeln dieser Gesellschaft, und dieser Vermittlungsprozess ist gerade dann erfolgreich, wenn er zu dem Resultat führt, dass Menschen spezifische Werthaltungen, Einstellungen, Verhaltensregeln usf. sozusagen als sobjektive< Tatsache empfinden. In dem Moment, in dem eine von der Gesellschaft konstruierte Umgangsweise (wie hier beispielhaft der Umgang mit dem Tod in Form von Trauer) so angenommen und reproduziert wird, dass sich kaum je die Frage nach dem Ursprung und der Legitimität dieser Umgangsweise stellt, ist der Beleg für die sobjektivierender Kraft des menschlichen Zusammenlebens erbracht. Trauern wird fraglos erlernt; Neugeborene haben keinen Sinn für die Trauer. Und Trauer wird gleichwohl so behandelt, als gehöre sie zum 'Wesen des Menschen $<$ - ungeachtet der Tatsache, dass es andere Kulturen (und natürlich auch einzelne Personen in der eigenen kulturellen Sphäre) gibt, die damit völlig anders umgehen. 


\section{Die institutionelle Geltungsdauer sozialer Konzepte}

Trauern ist ein Bestandteil der gesellschaftlichen Wirklichkeit - und nicht allein eine Facette der psychologischen Disposition. ${ }^{18}$ Etwas einfacher formuliert: Der Ursprung der Trauer ist nicht das individuelle Bewusstsein, sondern eine Gesellschaft, die dieses Bewusstsein fundamental prägt und ihm >vormacht $<$, dass es individuell entscheidet und empfindet - auch dann (und vielleicht gerade dann!), wenn dies tatsächlich nicht der Fall ist. Was wirklich, richtig oder normal ist, wird in der Gesellschaft ausgehandelt. Es wird nicht schlichtweg vorgefunden (Benkel/Meitzler 2019a). Wirklich, richtig oder normal sind folglich keine unabänderlichen, ewig feststehenden Begriffe. Sie halten für eine Weile an - und dann kommt der Wandel. Diese Phase, bis die Veränderung eintritt, möchte ich an dieser Stelle die institutionelle Geltungsdauer sozialer Konzepte nennen. Die Geltung von Überzeugungen im Bereich des zwischenmenschlichen Umgangs, und damit auch Vorstellungen von der >Angemessenheit< trauerspezifischer Umgangsweisen, sind offenkundig beschränkt - sie haben gewissermaßen eine Art unsichtbares Haltbarkeitsdatum. Deutlich wird dies am Beispiel solcher aussterbenden Ritualformen wie der Trauerkleidung, dem Trauerjahr oder der Aufbahrung. Im Laufe der Zeit haben sie anderen Ausgestaltungen Platz gemacht; manche kulturell etablierten Traditionen sind sogar ersatzlos gestrichen worden. Wenn man will, könnte man von einem Design der Trauer sprechen, das für einen bestimmten Zeitraum nicht nur innerhalb konkreter Gruppen von Hinterbliebenen gilt, sondern auch hinsichtlich seiner Anerkennung durch Institutionen. Ämter, Behörden, Bestatter, die Gewerke usw. kennen dieses Design und agieren entsprechend. Aber sie müssen sich selbstverständlich ebenso wie die Personen, die damit in ihrer Alltäglichkeit hin und wieder konfrontiert werden, darauf einstellen, dass das Design der Trauer von Transformationsvorgängen ergriffen wird und sich verändert.

Wie wird dieses konkrete Design nun erlernt - angesichts der institutionellen Geltungsdauer sozialer Konzepte, wie eben der gesellschaftlichen

18 Das zeigt schon der Ursprung der Trauerpsychologie. Folgt man den Spuren der einflussreichen Arbeit von Sigmund Freud über Trauer und Melancholie von 1917 (Freud 1982), lässt sich erkennen, dass von der dort angeratenen Trauerarbeit als Bewältigungsstrategie gegen das Trauma des Verlustes eine Abstammungslinie überleitet zum eher medizinischen Diskurs über den krankhaften Charakter von Trauer (Granek 2010, vgl. ferner Horn 1998: 8ff.). Die Pathologisierung überdeckt, dass Trauerempfindungen auf sozialen Bezugsrahmen aufbauen, die entsprechende sStandpunkte erst ermöglicht haben - als Option, nicht als Störung. 
Umgangsweisen mit Trauer? Man könnte einwenden, dass diese Geltungsdauer sich doch wohl schlecht bemessen lasse, weil Wandel sich unmerklich immerzu abspielt. Das klingt gut und stimmt wohl auch - aber es gibt andererseits durchaus Phasen, es muss sie sogar geben, in denen innergesellschaftlich über den Wandel reflektiert und er in die sozialen Prozeduren ’hineingedacht wird. ${ }^{19}$ Die zuvor bereits erwähnten Berger und Luckmann sprechen bezüglich dieser Reflexion von einem Dreischritt, über den man die "gesellschaftliche Konstruktion der Wirklichkeit" verinnerlicht (Berger/Luckmann 2004: 139). Im ersten Schritt, der Internalisierung, geht es darum, dass die äußere Welt Inhalte/Wahrheiten/Wissen, mithin also: ein bestimmtes >Image der Wirklichkeit, weitergibt - und zwar an die nachwachsende Generation, die dieses Realitätsverständnis nach und nach kennenlernen muss. ${ }^{20}$ Die Wirklichkeit wird über Erziehungsinstanzen weitergegeben (Schule, Kindergarten, entsprechende Medieninhalte), sowie - umfangreicher - über Sozialisationsagenturen. Darunter fallen sämtliche soziale Kontakte und Interaktionen, die Menschen zeitlebens wahrnehmbar erfahren (also auch die durchlebten Erziehungskontexte). Jede noch so triviale Kommunikation überliefert zwischen den Zeilen jene Wirklichkeitsimages, die in dieser Kultur dominant sind. ${ }^{21}$ Man kann der gesellschaftlichen Konstruktion der Wirklichkeit nicht entgehen.

Im zweiten Schritt, der Objektivation, werden die Realitätsannahmen, die einem also durch Erziehung zeitweilig bzw. durch Sozialisation perma-

19 Pierre Bourdieu spricht beispielsweise von einem Verzögerungseffekt, der greift, wenn »Dispositionen [...] schlecht an die objektiven Möglichkeiten angepaßt sind «, wenn also Sachverhalte in einem Bereich (noch) zu weit von einem anderen entfernt sind. Eine solche Begegnung ist eine Art »Vorwegnahme der $\mathrm{Zu}$ kunft«, denn eine potenzielle Anpassung ist durchaus möglich - später, verzögert (Bourdieu 1993: 116).

20 Denn die Gesellschaft ist, wie Heinrich Popitz schreibt, "nach unten offen« (Popitz 2006: 73). Damit ist gemeint, dass Kinder nur sehr wenige eigene Ansprüche artikulieren können, aber dafür die Ansprüche anderer - der Erwachsenen - übernehmen ssollen können ausdrücklich durch Lern- und Imitationsprozesse verinnerlichen; und sie sollen so ein Verständnis für die vorherrschenden Selbstverständlichkeiten entwickeln.

21 Es gibt allerdings auch Ausnahmen, beispielsweise sogenannte neue religiöse Bewegungen, die einer anderen Weltsicht anhängen und diese gruppenintern weitergeben, etwa an die Kinder von Gruppenmitgliedern. Ein anderes Beispiel wäre ein Terrorist, der sich undercover in einer Gesellschaft bewegt, die er eigentlich als feindlich ansieht und bekämpfen will; um seine geheime Mission nicht zu stören, verdeckt er diese abweichende Wirklichkeitssicht jedoch und sspielt mit<. Für diese und andere mögliche Konstellationen benutzen Berger/Luckmann (2004: 123) den Begriff der »alternativen Wirklichkeitsbestimmungen«. 
nent vermittelt werden, durch den eigenständigen Austausch mit anderen bestätigt. Die anderen gehen offenkundig von gleichen Wirklichkeits- und damit auch Ordnungsvorstellungen aus wie ich selbst. Es gibt natürlich hin und wieder Widersprüche, Missverständnisse und abweichende Meinungen; im Großen und Ganzen aber spasst ‘ das kommunikativ vermittelte Schema der Realität, das man selbst kennt/weiß, mit dem überein, was andere - Bekannte, aber auch Fremde - wissen und kennen (solange man nicht kulturelle Demarkationslinien überschreitet - dann sieht es womöglich rasch ganz anders aus!). Objektivation bedeutet also, dass der internalisierte Input sich als stimmig entpuppt. Man erlebt die Welt, die einen umgibt, als weitgehend durchschaut`.

Der letzte Schritt heißt Externalisierung. Nun wird das internalisierte und objektivierte Wirklichkeitsbild durch eigene Sozialisations- bzw. Erziehungstätigkeiten an andere Menschen weitergegeben. Dies geschieht in unzähligen alltäglichen Interaktionsmomenten. Die Wirklichkeit wird dabei für gewöhnlich nicht so behandelt, als steckten hinter ihrer Geltung Kommunikations- und Lernvorgänge. Sie wird vielmehr ganz so zum Ausdruck gebracht, als sei dieses Ergebnis sozialer Austauschprozesse tatsächlich etwas san sich Geltendes‘, etwas außerhalb der Gesellschaft Liegendes. Die Wirklichkeit, eigentlich ein Produkt menschlichen Wirkens, wird also so thematisiert, als sei sie eine unumstößliche Faktizität. Metaphorisch formuliert, könnte man auch sagen, dass die gesellschaftliche Wirklichkeit einer Art Drehbuch folgt, das die Mitglieder einer Kultur kennen und das sie sich voreinander immer wieder aufs Neue sdurchspielen - mit wenigen, vergleichsweise seltenen Schritten auf die Hinterbühne, also dorthin, wo man die Inhalte des Skriptes nachlesen kann.22

Aufgrund der erwähnten institutionellen Geltungsdauer sozialer Konzepte sind die Inhalte von Internalisierung, Objektivation und Externalisierung aber eben nicht per se >richtig«, und schon gar nicht immerzu gültig. Die Zeiten ändern sich, und deshalb ist es auch nicht überraschend, dass Kinder, spätestens sobald sie alt genug sind, sich selbstständig und mit einem gewissen Komplexitätsanspruch mit anderen auszutauschen, rasch in manchen Einzelheiten sehr andere Ansichten als ihre Eltern entwickeln.

22 Vielleicht ist auch dies, die Bewegung hinter den Vorhang und damit auf die Meta-Ebene der gesellschaftlichen Wirklichkeit (eine Bewegung, die der vorliegende Text durchzuführen versucht) ein Teil des Skripts? Bei dem kanadischen Soziologen Erving Goffman heißt es recht unbarmherzig: "Wir alle spielen Theater" - so der deutsche Titel seines bekanntesten Buches, The Presentation of Self in EverydayLife von 1956 (Goffman 2006). Seine eigene Zunft würde Goffman davon sicherlich nicht ausnehmen. 
Die Welt, in der sie das Internalisierte objektivieren wollen, hat sich verändert, seit ihre Eltern sich erstmals ihr angelerntes Weltbild von der sozialen Außenwelt haben bestätigen lassen. Mit diesem zwischenzeitlichen gesellschaftlichen Wandel sind neue Elemente ins Spiel gekommen, die immer wieder einmal dafür sorgen, dass sich zwischen den Generationen Konflikte ergeben - die Weltbilder sind zu unterschiedlich. ${ }^{23}$ Der Ablauf von Internalisierung, Objektivation und Externalisierung ist ein von Mensch durchgeführter Mechanismus, und dadurch treten immer wieder neue Elemente hinzu, während andere verschwinden. Man könnte hier von unbestimmten, womöglich unbewussten Interventionen bzw. 'Selbstreflexionen< der Gesellschaft sprechen, die sich darin abbilden und die (vorläufig) bleibende Eindrücke hinterlassen.

Nun dürfte etwas deutlicher geworden sein, inwiefern Trauer so snatürlich wirkt, sich so erbarmungslos aufdrängt, weshalb dabei häufig echte Tränen fließen und echte Emotionen empfunden werden, obwohl es keine Wirklichkeit der Trauer jenseits gesellschaftlicher Vermittlungsarbeit gibt. ${ }^{24}$ Alleine deshalb, weil ein Sachverhalt sozial konstruiert, d.h. also: im Zuge des Umgangs von Menschen mit anderen Menschen entstanden ist und nicht, wie Sonne, Mond und Sterne, unabhängig davon Bestand hat auch nicht als snatürlicher Bestandteil des Menschen, also auch nicht aufgrund biologischer oder medizinischer `Anlagen $<-$, ist dieser Sachverhalt im Empfinden und in den Reaktionen der Menschen nicht weniger swirklich als eben Sonne, Mond und Sterne und all jene weiteren natürlichen Tatsächlichkeiten, die sich auffinden lassen, wie menschliche und tierische Körper, Gewächse, Bakterien, Viren, DNA. Es wäre sogar überaus fahrlässig, die Geburt der Trauer aus dem Geist der sozialen Ordnung als Relativierung zu deuten. Was Soziologen wie Durkheim aussagen wollen, ist, dass Trauer ein Kulturphänomen ist, das sich verändert - so wie sich andere Kulturphänomene ebenfalls verändern, man denke nur an die sich wandelnden und in diesem Wandel gut untersuchten Umgangsweisen der Menschen mit Religion, politischen Haltungen, Sexualität, Zahlungsmitteln, usw.

23 Die gute Nachricht für alle Eltern von Teenagern: Das legt sich mit der Zeit. Nach einer gewissen Frist innerhalb der Gesellschaft (bei gleichzeitig gewachsener Autonomie) kommt meistens auf beiden Seiten die Einsicht, dass Einstellungsunterschiede nicht immerzu ausgefochten werden müssen.

24 Dem Sachverhalt wird emotionssoziologisch intensiver und facettenreicher nachgegangen, als hier skizziert werden kann. Interessierte wenden sich an Gerhards (1988), Schützeichel (2006) und Senge/Schützeichel (2013). 
Den Zusammenhang von Trauer und gesellschaftlicher Ordnung kann man noch weiterdenken. Pierre Bourdieu, wohl der prominenteste französische Soziologe nach Durkheim, hat beispielsweise in einem kurzen Text - eigentlich eine im Jahr 2000 gehaltene Rede, die von den meisten Experten wenig beachtet wird -, die Behauptung aufgestellt, dass die »völlig[] verzweifelten Gesten « Trauernder letztlich jenseits von Sinn und Zweck angesiedelt sind (Bourdieu 2010: 429). Auch eine solche Äußerung kann leicht missverstanden werden. Bourdieu will damit keineswegs zum Ausdruck bringen, dass es sinnlos ist, am Grab Blumen abzulegen oder sich zuhause, am gemeinsamen Urlaubsort, oder überhaupt irgendwo seiner geliebten Verstorbenen zu erinnern. Im Gegenteil, an gleicher Stelle betont er, dass diese Gesten nicht nur verzweifelt, sondern "gleichermaßen psychologisch notwendig[]《 seien (ebd.). Nur ist eben die Trauer um eine verstorbene Person keine Handlung, die geeignet wäre, den Verlustschmerz zu verarzten. Verzweiflung, Tränen und tief empfundenes Unglück sind keine Möglichkeiten, die Leiche wieder zurück ins Leben zu führen. Und wenn die Toten nicht zurückkehren, sind Gefühlsausbrüche, die diese Rückkehr ausdrücklich oder sinngemäß zum Inhalt haben, zwangsläufig rzwecklos‘. Es macht keinen Sinn, »am Grab einer geliebten Person« darauf zu setzen, dass mithilfe »bestimmter ritueller oder kultischer Praktiken" (ebd.) unmittelbar etwas getan werden könne, was die Trauer ad hoc abmildert. In gewisser Hinsicht haben diese Gesten aber doch einen verborgenen Sinn. Sie transportieren, wie beschrieben, das Gefühl der Ordnungsunterbrechung; sie signalisieren, dass man die Rolle als trauernde Person kennt und aufrichtig empfindet; sie machen klar, dass der Verlust eines Menschen, den ja nicht dieser Mensch, sondern die Hinterbliebenen stellvertretend für die Gemeinschaft - erleiden, nichts ist, was schlichtweg stoisch hingenommen werden kann.

Man könnte mit einem von Bourdieu an anderer Stelle aufgeworfenen Begriff vom "Sinnüberschuss" der Trauerhandlung sprechen (Bourdieu 1993: 127): In den Gesten der Verzweiflung kommt insgeheim das Wissen über die Regeln des gemeinschaftlichen Zusammenlebens zum Ausdruck. Sie stacheln Solidarität und Unterstützung an und schaffen auf diese Weise soziale Konstruktionen außeralltäglicher Gemeinschaftserfahrungen. Jeder versteht, was es bedeutet, wenn ein Mensch trauert; und schon dieses Verständnis legt nahe, dass die soziale Welt keine radikal egoistische ist. Mit dem Verständnis gehen im näheren sozialen Umfeld traditionell Gesten alltagsuntypischer Zuneigung einher: Unterstützung über das snormale< freundschaftliche Maß hinaus, tief empfundene Anteilnahme (auch wenn man sich sonst nicht gerne in fremde Angelegenheiten< einmischt), sogar Geldgeschenke. Noch dazu sind alle (temporären) Ausfälle der Trauernden 
verständlich; etwaige Gefühlsausbrüche werden mit Verständnis registriert. Indem Trauernde sozialen Support erhalten, werden die im Alltag als stabil empfundenen Rahmenbedingungen des Gemeinschaftslebens symbolisch gestützt; bzw. sie werden neu errichtet, nachdem das Verlusterlebnis sie in Frage gestellt hat.

\section{Nach der Trauer}

Die Trauer loslassen können bedeutet, für die Gesellschaft und nicht für sich selbst zu funktionieren. Wenn die Trauer irgendwann abklingt, wenn die schmerzhaften Gefühle abnehmen, wenn Alltäglichkeit wieder mehr Platz im Leben von Hinterbliebenen verlangt, dann steht die mit der Trauer verbundene, aber eben verborgene Ordnungsvorstellung wieder im Vordergrund. Wie lange dieser Prozess dauert, oder gar zu dauern hat, lässt sich zumindest mit soziologischen Mitteln nicht bestimmen. Es gibt keine Formel, mit der sich berechnen lässt, wann ein Mensch zu viel oder zu wenig getrauert hat. Wie gesagt: Man kann Menschen nicht in den Kopf schauen. Man kann authentisches Empfinden nicht vernünftigく regulieren. Man kann ein Ende der Trauer nicht erzwingen.

Sehr vielen Menschen, die eine Trauererfahrung gemacht haben - wobei selbstverständlich bedacht werden muss, dass die Grade der Betroffenheit stark divergieren und Einzelfälle nie deckungsgleich sind -, finden sich nach einer gewissen Weile in der Lage, gesellschaftlich wieder zu funktionieren. Sie übernehmen, wie zuvor dargestellt, wieder die Rollen, die ihnen zugewiesen sind. Oder sie haben andere Rollen übernommen. Wie auch immer, sie spielen das Spiel namens Gesellschaft wieder mit - bald mehr, bald weniger intensiv. Es wirkt in manchen Fällen, als versteckten sie ihre Gefühle; als seien sie insgeheim geprägt von einer 'maskierten Trauer<, die öffentlich nicht gezeigt wird. Das Verlusterlebnis ist dadurch nicht gestrichen. Die Erfahrung, in Todesnähe gewesen zu sein (wie ich diese Situation nenne; vgl. Benkel 2017b: 277), prägt insgeheim wohl die allermeisten Menschen ihr Leben lang, denn Trauer hat ein Echo, das immer wieder nachhallt. Die Momente, in denen dieses "Grundrauschen der Trauer « sich bemerkbar macht, sind gewiss nicht nach sachlichen Kriterien bestimmbar. Vermutlich kommen sie innerhalb von bestimmten »sozio-lokalen $\mathrm{Zu}$ sammenhängen « stärker zum Tragen - beispielsweise dann, wenn die Trauer ein gezieltes, im akuten Kontext passendes Gesprächsthema ist (Häußler 2019: 251f.). Allerdings können emotionale Rückgriffe auf die Trauer, und damit auf den Verlust sozialer Nähe, auch in anderen Situationen auftre- 
ten; sowohl als aktives Handeln (d.h. als gezieltes Gedenkenwollen), wie auch als ungeplantes passives Erleben.

Dies ist die subjektive Facette der Trauer. Sobald Trauernde wieder 'funktionieren<, ist schließlich die Phase vorbei, in der sie vermeintlich >objektiv (in Wahrheit aber innerhalb eines entsprechend justierten intersubjektiven Rahmens) ausdrücklich im Modus der Trauer agierten. Man könnte auch sagen, dass die Gesellschaft sich durchgesetzt hat. Ohne dies bewerten zu wollen: Trauer ist, mal mehr, mal weniger ausgeprägt, eine Empfindung oder Situation, die einen vermeintlich auf sich selbst zurückwirft. Dies scheint einen von der Gesellschaft zu entfernen, aber das ist nur der äußere Anschein; in Wahrheit bedeutet Trauern, voll und ganz Teil der Gesellschaft zu sein, denn die Gesellschaft hat einen gelehrt, dass, wieso und in welcher Form Trauer sinnhaft ist. Im Trauerzustand liegt ein hochspezifisches Spannungsverhältnis zwischen Individualität und Kollektivität vor: Hier bekommt die menschliche Subjektivität von der Gesellschaft die Ausnahmeposition zugesprochen, sich selbst auf die Vorderbühne zu stellen. ${ }^{25}$ 'Nach der Trauer soll die subjektive Empfindung gegenüber dem Todesfall langsam wieder in den Hintergrund treten, um einer adäquaten Rollenübernahme Platz zu machen. Kein Wunder, dass ein Begriff wie `Trauerarbeit` den Zusammenhang zwischen einem Gefühlszustand und beruflichen Pflichten impliziert (während korrespondierende Ausdrücke wie >Liebesarbeit $<$ oder $>$ Freundschaftsarbeit $<$ fehlen).

Liegt die Trauer in der Hand des Einzelnen? Oder befindet sich der Einzelne in der Hand der Trauer? Womöglich agieren Trauernde und die Trauer Hand in Hand. Denn schließlich treffen sich die gesellschaftlich vermit-

25 Helmuth Plessner, der sich zwischen philosophischer Anthropologie und Soziologie bewegt, vertritt die Ansicht, dass im Lachen und im Weinen - in Momenten also, die überaus subjektiv wirken - ein kurzfristiger Kontrollverlust durchbricht, der aber durchaus eine Funktion erfüllt. Denn Lachen und Weinen sind Vorgänge, die dann ins Spiel kommen, wenn zwischen »Mensch und physischer Existenz«, also: zwischen Person und Körper kein Einklang mehr besteht; dieser »Verlust an Beherrschung « kann dadurch bewältigt werden, dass Tränen fließen, die Stimme versagt, die Körperkontrolle unterbleibt (Plessner 1950: 86). Dann wird der Kontrollverlust für einen kurzen Augenblick nämlich ein totaler, er wird somit eingestanden, und danach kann es wieder weiter gehen. Lachen und Weinen gehören damit zu den »antirationalen, aber doch sinnbezogenen Phänomene[n]« (Fischer 2013: 274). Insofern wäre die Trauer wohl zu unterscheiden von massiven Äußerungen der Betroffenheit (wie etwa einem Zusammenbruch aufgrund seelischer Überwältigung). Sie müsste gedacht werden als Haltung, die durchaus reflexive Momente beinhaltet - wie eben Erinnerung und Gedenken, welche nicht für Kontrollverlust stehen, sondern (wenigstens teilweise) intendiert sind. 
telte, individuell erlebte Gefühlsregung und ihre ganz persönliche Ausgestaltung im Gesicht, in den Worten und in der körperlichen Haltung einer Person. Es ist ein Handschlag, auf den viele verzichten könnten. In Zeiten, da der Tod noch etwas weniger verschämt besprochen wurde als heute, erschien es passend, ihn symbolisch als Sensenmann bzw. Skelett auftreten zu lassen, nicht selten übrigens in weiblicher Erscheinung (Guthke 1998), um diesen >Begegnungsgedanken< bildhaft zu verdeutlichen. Die Knochengestalt symbolisierte damals auch visuell etwas (übrigens kulturübergreifend) Fremdes, Ungewolltes. Mittlerweile ranken sich um diese fremde Sphäre Professionalisierungs- und andere, ziemlich weltliche Bewältigungsstrategien (Schützeichel 2017). Wenn nun aber individuelle Trauerberatungen, zeitgenössische Seelsorge als »religion on demand « (ebd.: 127), Online-Foren, Ratgeberbücher, Volkshochschulkurse und vieles mehr das altmodische Konzept der solidarischen Gemeinschaft ergänzen (noch scheinen sie es nicht zu ersetzen), wie sollte der Tod da aussehen? Er wird gesichtsloser, je gründlicher und professioneller er aufgearbeitet werden kann. Auch das ist Trauerarbeit.

Die Zeit nach der Trauer ist auch die Zeit einer ungewohnten Übergangserfahrung. Die verstorbene Person hat ihren Übergang gemacht; sie hat, wie das Arnold van Gennep (2005) zu Beginn des 20. Jahrhunderts in seinem einflussreichen Buch zu Übergangsriten nennt, die drei Phasen Ablösung, Zwischenstadium und Integration (das meint hier: in andere Zugehörigkeitssphären) schon durchlaufen. Der Abschied aus den irdischen sozialen Bezügen ist vollzogen; das schwierige Stadium zwischen klar geltenden Zuständen (wie lebendig/tot), das etwa bei der Aufbahrung virulent ist, ist überwunden, und die Person hat, dies ist abhängig von den Überzeugungen der Hinterbliebenen, neue Existenzkontexte erfahren (oder, wie man streng materialistisch wohl annehmen müsste, die Integration ins Nichtsein vollzogen). Die Angehörigen gehen diese Passagen nicht mit, die meisten von ihnen werden aber zumindest einen zentralen Übergang, nämlich die Abtrennung von der Trauer erleben - und eine (Wieder-)Aufnahme in eine Lebenswelt, in der Trauer nicht mehr die dominante Empfindung ist. Es kommt der Punkt, an dem sich Pflichtbewusstsein und Aufgabensensibilität, oder der Impuls zum Weitermachen, zum Fortleben trotz allem, stärker aufdrängen, als der immanente Schmerz des Verlusts. Dann ist man paradoxerweise wieder spürbar das, was man ohnehin die ganze Zeit war: ein Teil der Gesellschaft. Letztlich geht es bei den Formen der Trauer, die gesellschaftlich etabliert sind, immer auch um den Erhalt der Gesellschaft, innerhalb derer sie etabliert worden sind. 


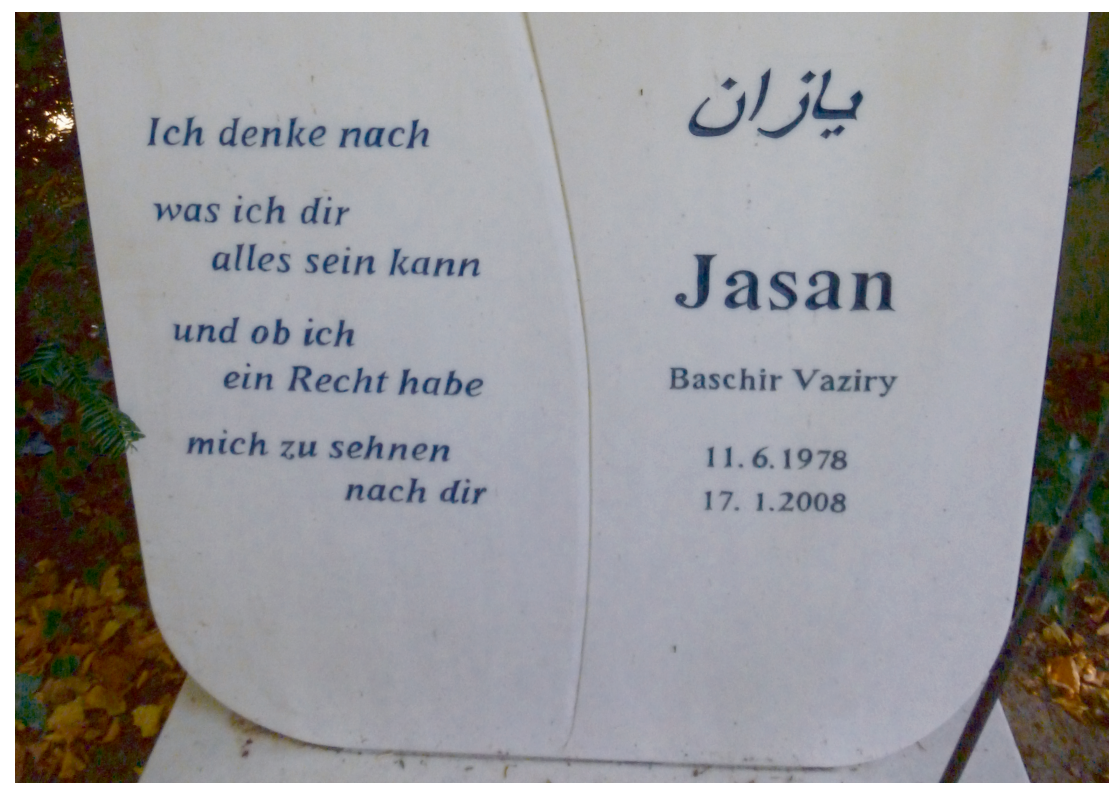

\section{Autonomie und Abschied}

Das vorliegende Buch trägt den Titel Autonomie der Trauer. Autonomie steht dem buchstäblichen Wortsinn nach für >Selbst-Gesetzgebung<. Ein autonomes Leben scheint eines zu sein, das sich in maßgeblichen Punkten von anderen Lebensentwürfen dadurch unterscheidet - so zumindest der Anspruch -, dass nicht kollektive Maßstäbe ausschlaggebend sind, dass also nicht im Mainstream oder beim Durchschnittswert Orientierung gesucht wird. Es geht in der Autonomie auch nicht darum, gesellschaftliche Interessen in den Fokus zu nehmen (erst recht nicht das, was angeblich der Gesellschaft dient), und es ist somit auch nicht das vorrangige Ziel autonomer Entscheidungen, den vorherrschenden Status quo zu gewährleisten. ${ }^{26}$

26 Will man diese Unterschiede überhaupt noch treffen, so wäre hinsichtlich der einem näherstehenden Gemeinschaftsumfelder zu klären, ob dort autonome Interessen nicht sogar einen konstituierenden Anteil am Gesamtkontext haben, schließlich wäre eine organisch-solidarische Gemeinschaft nicht pauschal daran interessiert, >individualistische< Anliegen abzuwehren - solange sie sich mit bestimmten Wertvorstellungen verbinden lassen, und das ist ja grundsätzlich möglich. 
Ordnungsanliegen jenseits der eigenen, d.h. subjektiven Sichtweise - also Ordnungsanliegen in dem Sinne, wie ich sie oben beschrieben habe - sind selten der Gegenstand betont autonomer Aktivitäten. Wer im Zeichen dieser Selbst-Gesetzgebung agiert, dürfte es in Kauf nehmen, dass die damit verfolgten Ziele von anderen nicht geteilt werden können und vielleicht sogar auf Kritik stoßen. Autonom sein bedeutet also im Sinne der genannten Studie, dass zahlreiche gesellschaftlich kursierende Haltungen, Einstellungen und Werte ausdrücklich nicht Einfluss auf eigene Entscheidungen nehmen - zumindest nicht allein deshalb, weil dies die Haltungen, Einstellungen und Werte anderer sind.

Die Karriere des Autonomie-Begriffs lässt sich in zahlreichen, überwiegend (sozial-)philosophischen Darstellungen näher recherchieren (Leu/ Krappmann 1999). Aktuell scheint der Terminus sogar besonders populär zu sein (Guinebert 2018; Pauen/Welzer 2015; Quante 2014; Rössler 2017; spezifisch akzentuiert: Ehrenberg 2012). Um eine genaue Begriffsdarstellung geht es an dieser Stelle aber nicht. Autonomie ist im Rahmen der vorliegenden Darstellung eine Chiffre für eine überwiegend individuelle, allenfalls im engsten Familien- und Freundeskreis getroffene Entscheidung von Menschen, die eine geliebten Person verloren haben, die sich also in Trauer befanden (bzw. noch immer befinden) und die durch diese Verlustsituation in Todesnähe geraten sind. Es geht diesen Menschen nicht um die lang gehegte, anlasslose und nüchtern geplante Entscheidung, mithilfe autonomen Handelns bestimmten strukturellen Anforderungen zu entkommen. Im Gegenteil: Viele haben sogar erst aufgrund des Todesfalls in ihrem Umfeld von den Strukturen erfahren, die sie mit ihren autonomen Handlungen in der Folge konkret einzelfallbezogen zu umgehen versuchen. Diese Variante der Autonomie ist also in einer großen Anzahl der untersuchten Fallkonstellationen erst aufgrund einer ungewollten Konfrontation mit institutionellen, juristischen bzw. moralischen Regularien überhaupt raufgeweckt $<$ worden.

Es bedarf keiner Diskussion, dass jedwede betont autonome Entscheidung eingebettet ist in eine Vielzahl weiterer Entscheidungen, Einstellungsbekundungen und Aktivitäten, die - mehr oder weniger ausdrücklich - nicht autonom ablaufen, sondern die auf Kompromissen, Zwängen, Einsichten und Notwendigkeiten beruhen. Das gilt auch, und vielleicht sogar in besonderem Maße, für den Kontext Tod. Meine These lautet: Gerade weil die Umgangsweisen mit Sterben, Tod und Trauer so stark reguliert und lange weitgehend sübersubjektiv betrieben worden sind, haben sich hier Selbstbestimmungsansprüche regen können. Sie haben sich in einem lang andauernden, im Prinzip von außen wenig durchsichtigen Prozess verstetigt, und sie scheinen sich mehr und mehr durchzusetzen. Entschei- 
dend dafür ist die beschriebene Erweckung; sie entsteht aus einem konkreten Anlass heraus, der in den allermeisten Fällen ein vollendeter Sterbeprozess ist, und aus der somit notwendigen Auseinandersetzung mit zuvor unberücksichtigten, oft völlig unbekannten Vorschriften. Eine wirklich nachdrückliche Artikulation von Autonomie wäre in diesem Zusammenhang nicht möglich, würde nicht das System der legitimen Bestattungs- und Trauerhandlungen auf eine Menge Menschen den Eindruck machen, dass dabei Autonomie von vorn herein ignoriert wird.

Wenn ein Mensch stirbt, gibt es bekanntlich diverse Entscheidungen zu treffen. Nicht zuletzt steht die Frage im Raum, wann und wo er bestattet werden soll. Professionelle Akteure, allen voran die Bestattungsunternehmen, sind für gewöhnlich an der Schaltstelle der Koordination. Hier gestalten kreative (und weniger kreative) Köpfe die Feinheiten, die mit den Entscheidungen der Hinterbliebenen einhergehen sollen. Individuelle Betroffenheit und überindividuelle Expertise treffen und ergänzen einander. Beratungs- und Gestaltungskompetenzen stülpen sich über die lebensweltliche Katastrophe und `depersonalisieren « sie. In den Händen der Experten spielt die Identität der Verstorbenen kaum eine Rolle; auf dieser Ebene geht es zuallererst um die möglichst reibungslose Anwendung des Regelwerks. Die Kunst in diesem Metier besteht allerdings darin, den singulären Fall so zu thematisieren und zu handhaben, dass im Ergebnis Individualität im Vordergrund steht (oder zu stehen scheint) - und eben nicht ein routiniertes Durchlaufen der Ablaufschritte (zur Problematik jedweder scheinselbstständigen `Fallgeschichte` vgl. Bergmann/Dausendschön-Gay/ Oberzaucher 2014). Dass aktuell innovative und salternative< Bestatter besonders gefragt sind, hängt mit der schlechten Reputation der Routine ab. Jeder möchte sich selbst, und selbstverständlich auch geliebte Menschen im Umfeld, als unvergleichbares Einzelwesen sehen, und diese Erwartung muss das im funeralkulturellen Berufskontext geschulte Personal als Erwartung der Kundschaften erwarten; es muss also Erwartungserwartungen hegen.

Platzhirsche mit lokalem Monopol können es bei den Standardverfahren belassen, sie werden ihre Klientel finden. Je mehr jedoch - auch dank des Internets und der fortschreitenden Digitalisierung - der Gedanke der Auswahl und des Vergleichs auch in dieser Branche sich durchsetzt (gerade in Verbindung mit der Autonomie der Kunden), desto notwendiger wird es auch für die professionellen Akteure, sich unbequemen, weil womöglich jenseits der traditionellen Ausbildung stehenden Ansprüchen und Interessen zu stellen. Sonst kann man die eigene Bestattungsexpertise früher oder später auf die Abwicklung des eigenen Unternehmens anwenden. 
In diesem Buch geht es nicht um eine Beschreibung des >Normalzustandes‘. Die Entscheidung, die diverse Hinterbliebene fällten, mit denen wir (die Autoren des vorliegenden Buches) gesprochen haben, hat sie aus dieser Routiniertheit heraus bugsiert und ihnen - wie gesagt, in vielen Fällen vollkommen unbeabsichtigt - eine Art Vorreiterrolle` verliehen. Mehr noch, ihre Entscheidung hat diese Interviewpartner zum Teil einer kleinen Minderheit gemacht, die als Gruppe kaum je irgendwo in Erscheinung tritt; die sich auch gar nicht als Gruppe wahrnimmt; die fast keine Lobby hat bzw. diesbezüglich vorhandene Angebote oft nicht kennt, und sie häufig auch nicht sucht. Und nicht zuletzt hat diese Entscheidung die Angehörigen, die sie getroffen haben, in eine Grauzone jenseits des gesetzlich erlaubten Handlungsbereiches geführt. Gemeint ist die Entscheidung, mit der Asche der verstorbenen und kremierten Person so zu verfahren, wie sie selbst - autonom - es für richtig empfinden, über bestehende moralische und juristische Regeln hinweg.

Selbstverständlich trifft diese Ausgangslage nur auf einige der Gesprächspartner in den über 120 qualitativen Interviews, in einer umfangreichen Online-Umfrage und in zahlreichen weiteren Kommunikationen zu, um die Matthias Meitzler, Dirk Preuß und ich uns gekümmert haben. Da unser Interesse der Ausdifferenzierung von Trauer im Zeichen des sozialen Wandels gilt - zunächst einmal unabhängig von singulären Fallkonstellationen - wäre alles andere auch überraschend. Dennoch ist die beschriebene Situation hinsichtlich der Autonomiefrage im Trauerkontext aufschlussreich. Daher haben wir ihr einen besonderen Schwerpunkt gewidmet. Uns interessiert in diesem Zusammenhang: Wie gehen Menschen, die sich die Asche ibrer Verstorbenen aushändigen lassen, damit um? Was geschiebt mit ibr? Wem gegenüber wird dieses Handeln offenbart, wem gegenüber wird es verschwiegen? Was sind die Motive für dieses Handeln - und wie verteidigen die Betroffenen es? In anderen Ländern Europas, beispielsweise in den Niederlanden oder in der Schweiz, wo besonders liberale Bestattungsvorschriften existieren, könnte eine entsprechende Studie ebenfalls durchgeführt werden. Dann aber wären die Fragen zur Legitimation bzw. zum Verschweigen schon insofern weitgehend überflüssig, als die Praxis, sich die Asche nach der Kremation heraus geben zu lassen, dort erstens legal und zweitens nicht unüblich ist. Unsere Studie setzt, was diesen Aspekt betrifft, nun aber in Deutschland an und damit in jenem Land, das mitunter die strengsten Bestattungsrichtlinien des europäischen Kontinents aufweist. Nach geltendem deutschen Recht ist es, lässt man Feinheiten außer Acht, verboten, dass Angehörige nach der Kremation (oder nach jeglichen anderen Bestattungsprozeduren, die der tote Körper/Mensch durchläuft) diesen Körper bzw. seine >Überreste` in ihre eigenen Händen übertragen bekom- 
men. In manchen Bundesländern ist es nicht einmal zulässig, dass Hinterbliebene beispielsweise die Urne, die die Asche der verstorbenen Person enthält, selbsttätig an die dafür vorgesehene Begräbnisstätte auf dem Friedhof bringen. Diese Aufgabe müssen die Bestatter bzw. von ihnen beauftragte Dritte übernehmen; die Angehörigen bezahlen diesen Service zwar, sie dürfen ihn dann aber nicht eigenständig ausüben. Der >letzte Gang`zur >letzten Ruhestätte findet also, so will es die formale und juristisch abgesicherte Regelung, auf eine Weise statt, die die Hinterbliebenen auf Abstand zu den menschlichen Überresten hält.

Das Beispiel mag trivial wirken. Wer allerdings einmal die Erfahrung gemacht hat, sich einbringen zu wollen in einzelne Stationen des Bestattungsprozesses, und daraufhin erfahren musste, dass man trotz der engen sozialen Verbindung zu Lebzeiten, trotz der liebevollen Beziehung zur Person, die dieser tote Körper/diese Asche gewesen ist, von entscheidenden Abschnitten des >Lebensabschieds ausgeschlossen ist, wird es nicht als Nebensächlichkeit abtun. Genau hier setzen Autonomiebestrebungen an: Anstelle der Vorschrift sollen Wunsch und Wille der affektiv betroffenen Menschen Berücksichtigung finden. ${ }^{27}$

Nicht unerwähnt bleiben darf, dass es sehr viele Hinterbliebene gibt (sie sind quantitativ vermutlich in der Mehrzahl), denen es durchaus genehm ist, von bestimmten Situationen, Mechanismen und Aufgaben entbunden zu sein. Die Auslagerung der Todesbürokratie an externe Experten (Knopke 2018) reduziert die Komplexität. Sie mindert die emotionale Überlastung in einer angespannten und einen oft zutiefst aus der Bahn werfenden Ausgangslage. Für diese Menschen ergeben sich auf den ersten Blick folglich auch keine Mitbestimmungsdefizite, entspricht es ihrem situativen Autonomieempfinden doch eher, sich von diesen Aufwendungen weitgehend fern halten zu dürfen. In dieser vollkommen verständlichen Haltung gibt es nichts zu kritisieren - schon deshalb nicht, weil die Gesellschaft

27 Nicht näher eingehen kann ich an dieser Stelle auf die Angebotspalette an innovativen Weiter>verarbeitungen $<$ von Kremationsasche, die - anders als in Nachbarländern - in Deutschland nicht bzw. nur unter Vorbehalt und eher verborgen zugänglich sind. Asche kann, neben der Aufbewahrung oder Bestattung an selbstgewählten Orten, benutzt werden, um damit ein Gemälde zu schaffen, um aus ihr einen >Erinnerungsdiamanten zu erzeugen, um damit eine Smaragd- oder Rubinproduktion anzureichern, um daraus eine Schallplatte zu pressen, um sie in Gewehrpatronen abzufüllen, um damit dekorative Schmuckkristalle zu verzieren, und vieles mehr. Eine nähere Auseinandersetzung unter dem Gesichtspunkt des fließenden Übergangs von Sozialität zu Materialität ist aktuell Gegenstand einer Forschungskooperation zwischen den Universitäten Rostock (Praktische Theologie, Thomas Klie) und Passau (Soziologie, Thorsten Benkel). 
sich in genau diese Richtung ausdifferenziert hat und sie in vielerlei Hinsicht funktional für die soziale Ordnung ist. Die Problematik eingeschränkter oder fehlender Autonomie betrifft diejenigen Menschen, die mit Bestattungsabläufen aus konkreter Erfahrungen heraus unzufrieden sind, oder anders gesagt: die mit Reflexionsanforderungen konfrontiert worden sind und sie zum Antrieb subjektiver Bewältigungsstrategien gemacht haben. Etwas unglücklich aus Sicht dieses Personenkreises ist der Umstand, dass ihre Interessen - so subjektiv und einzigartig sie ohnehin sind - für diejenigen, die keine entsprechenden Erfahrungen gemacht haben oder diesen Erfahrungen aus dem Weg gegangen sind, bisweilen unverständlich sind. Was hier für die einen ein brennender Wunsch ist, ist für die anderen extravagant, deplatziert oder egoistisch. Die Forderung nach einem »Recht auf Trauer" (Seeck 2017) erscheint, je nach Adressat, überflüssig, weil doch alles geregelt ist, bzw. dringend geboten, weil Mitbestimmung weitestgehend fehlt und Marginalisierung droht. Es fehlt im buchstäblichen Sinne an einem common sense. Die Situation entspricht gewissermaßen einem starken Auseinanderdriften von Angehörigen in verschiedene Richtungen des Handelns und Reflektierens. Dass es so gekommen ist, ist allgemeinen Tendenzen der Pluralisierung in der Bestattungskultur zu verdanken. Es spricht vieles dafür, dass dieses Auseinanderdriften sich künftig nicht wieder wird einfangen lassen. Die Zeichen stehen weiterhin auf Individualisierung und damit weiterhin auch auf Verringerung kollektivistischer Ansprüche. Das hier beschriebene Szenario ist nur eines von mehreren im Zusammenhang von Sterben, Tod und Trauer, bei denen Deutungshoheiten in Frage gestellt und alternative Hegemonialkonzepte verhandelt werden.

\section{Kritik der institutionellen Vernunft}

Von 1934 an regelte auf deutschem Boden lange Zeit das Feuerbestattungsgesetz die wesentlichen Fragen rund um das Schicksal des Körpers nach dem Tod. Diesem Gesetz nach ist es unzulässig, dass Körperteile an einem anderen Ort als auf einem offiziellen, d.h. institutionell anerkannten Friedhofsgelände bestattet werden. Hinsichtlich der Bestattungsstätte brachte dieses Gesetz gegenüber Vorläufernormen keine besonderen Neuigkeiten mit sich. Innovativ war es vor allem im Hinblick auf die Gleichstellung von Erdbestattung und Kremation, die schon Jahrzehnte zuvor leidenschaftlich diskutiert worden war (ein Beispiel von vielen: Caspari 1914), und von nun an landesweit geltendes Recht war. Auf den ersten Blick finden auch individuelle Anliegen im Feuerbestattungsgesetz Berücksichti- 
gung: $\mathbb{} 2$ regelt ausdrücklich, dass der »Wille des Verstorbenen« im Zentrum stehen müsse. Das bezieht sich aber nicht auf den Bestattungsort oder den Bestattungsmodus, sondern meint an dieser Stelle allein den Wunsch, kremiert zu werden (oder eben nicht) (vgl. Spranger 2014a: 80).

Während das gesellschaftliche Interesse an Kremationen und Urnenbestattungen in dieser Zeit zunahm, antwortet das Feuerbestattungsgesetz auf diesen Trend ausdrücklich und zustimmend. Sollten sich beispielsweise die Angehörigen nicht einigen können, ob eine Kremation umzusetzen sei oder nicht, werde nach $\$ 2$, Abs. 4 notfalls »die Polizeibehörde« aktiv - ausdrücklich im (zu ermittelnden) Sinne der Toten. Dies also ist die Neuerung, die das Feuerbestattungsgesetz auf den Weg brachte und in seinem Namen trägt: eine neue Bestattungsvariante wurde institutionell legitimiert. Mit der generellen Idee einer kollektiv gültigen $>$ Friedhofsreglementierung ‘ wurde nicht gebrochen, im Gegenteil (vgl. Fischer 2014: 28). Insofern ist das Gesetz eben doch vom Geist seiner Zeit bestimmt, jener Zeit nämlich, in der die Vorstellung individualistischer Ausbruchsversuche aus normativen Rahmenrichtlinien als schwierig und spannungsreich angesehen wurde. Es bedurfte zur Realisierung abweichender Ideen wie der Kremation kollektiver Anstrengungen, um angesichts anderer, als antiquiert angesehener Kollektivkonzepte den Beweis` erbringen zu können, dass eine Reformnotwendigkeit vorliegt.

Nun sind Bestattungsrituale per se gar nicht von Gesetzen abhängig und ihnen in der historischen Perspektive auch nicht sunterworfen<. Sie wurden selbstverständlich schon lange zuvor abgehalten, die juristischen Regelungen dazu sind historisch betrachtet wesentlich jünger. Es schadet nicht, sich hin und wieder klar zu machen, dass nicht das Recht der Leitfaden früherer Bestattungspraktiken war. Sie fanden am Leitfaden mystisch-ritueller, allemal entlang religiöser Vorschriften, oder auch gemäß einer notgedrungenen Pragmatik statt.

Das Friedhofsimage, das 1934 festgeschrieben wurde - der Friedhof als Sammlungshort aller menschlichen Überreste; und zwar nur der menschlichen, keinesfalls der tierischen! - offenbart so gesehen eine bestimmte ideologische Sichtweise auf die Aufgabe, die Begräbnisstätten für die Gesellschaft übernehmen. Diese Ideologie fußt zweifellos auf redlichen Absichten, nicht zuletzt auf der oben beschriebenen Idee einer ordnungsstabilisierenden gemeinschaftlichen Übereinkunft. Andererseits spielt, wie gesagt, der Zeitgeist von 1934 eine Rolle; denn auf Basis des Feuerbestattungsgesetzes ergibt sich zwangsläufig ein Bild des Friedhofs als Stätte der Rückvergemeinschaftung. Alle sind sich gleich; keiner ragt mehr heraus. Mag der Grabstein auch noch so pompös sein - wer darunter liegt, kann nichts mehr bewirken. Die Grabreihen heben also die Unterschiede, welche zu 
Lebzeiten bestanden und Menschen voneinander getrennt haben, zumindest auf den ersten Blick auf. Man kann darin eine Art Versöhnung ‘ für die nachlebendige Zeit erblicken, wenn man möchte. Das Feuerbestattungsgesetz hat die Idee einer Gemeinschaft der Toten institutionell tragfähig gemacht und damit lokale Eigenheiten und Mentalitätsunterscheide eingeebnet. Die Gemeinschaft, um die es hier geht, war also von Anfang an ein Zwangskollektiv. Der Zwang, Seit' an Seit' begraben zu sein, neben Fremden, die einem schon zu Lebzeiten nichts bedeuteten, ist gewiss kein Wunsch der Lebenden gewesen. Wer wünscht sich, verglichen damit, nicht vielmehr quasi-aristokratische Bestattungsprinzipien? Die Beerdigung erfolgt am besten im eigenen Garten, wenn vorhanden, oder in einer schönen Anlage, bloß kein Moder ringsum, bloß kein 'Schema Fr. Man wird bevorzugt neben und mit der Familie, dem Partner, der Partnerin, vielleicht sogar neben dem Haustier gebettet, und auch die Urenkel, die man nie kennengelernt haben wird, sind nachträglich willkommen. Genauso wie übrigens die Ahnen, die schon vor langer Zeit verstorben sind. Sie haben sich, als Unbekannte, mit denen einen eine genealogische Linie verbindet (und sonst so gut wie nichts), die Berechtigung zur geteilten Grabstätte redlich verdient. Wer nicht vom selben Blut ist, wie man so sagt, für den gilt, was sonst nur Hinweisschilder am Friedhofsportal in einem gänzlich anderen Zusammenhang verkünden: Wir müssen draußen bleiben.

So wurde früher der Adel begraben. Er lag nicht an beliebiger Stelle, sondern in eigens dafür errichteten Gruften, oder wurde ausdrucksstark in/an der Friedhofsmauer bestattet, wenn nicht gar in einem ästhetisch aufgehübschten Winkel des eigenen Feudalgrundstücks. Die Absicht dahinter war (und ist mitunter immer noch), dass keine zwei Toten das identische Grab haben sollten. Im Leben heraus zu ragen, sollte korrespondieren mit dem Einzigartigsein post mortem. Der individuelle Rang wurde durch möglichst besondere, spezifische Bestattungsvarianten unterstrichen.

Um Missverständnisse zu vermeiden: Es geht denjenigen, die heute für individualisierte Bestattungsmodalitäten streiten (für eigene und wie auch für die nahestehender Personen), nicht darum, soziale Unterschiede auf den Totenacker zu tragen und den Grabsteinen mittelalterliche Klassendifferenzen oder etwas in dieser Art einzuschreiben. Der Adel ist kein Vorbild, sondern nur ein Sinnbild. Der zentrale Wunsch ist vielmehr die autonome Regelung, ja geradezu die >Regierung über das als persönlicher Referenzort verstandene Grab jenseits der als einschränkend und bevormundend empfundenen Realität juristischer bzw. bürokratischer Bestattungsnormen.

Soviel jedenfalls steht fest: Die Ideologie der am selben Ort und möglichst gleichförmig beerdigten Volksgemeinschaft ist das exakte Gegenteil 
subjektiver Bestattungswünsche. Wenn der Lebensverlauf die Menschen auch durch Schicksal, Zufall, durch freie Wahl und soziale Ungleichheit getrennt haben mag, kommt am Ende ein Moment der Emanzipation: Der Tod macht alle gleich. Dies sollte durch das Feuerbestattungsgesetz ab 1934 nicht länger nur eine Weisheit sein, der man nachdenklich zunicken kann, sondern eine Realität aller toten Körper werden. Und sie wurde es. Der Kerngedanke ist auch Jahrzehnte später erhalten geblieben, als die Landesgesetzgeber das Feuerbestattungsgesetz abgelöst und durch spezifisches Länderrecht ersetzt haben. Die einzelnen Landesvorschriften unterscheiden sich in Details, aber nicht in der wesentlichen Tendenz. Viel verändert hat sich dadurch nicht: Über Jahrzehnte hinweg, und auch über diverse Klagen hinweg (rechtliche wie exklamatorische), waren die Friedhöfe sinngemäß von der "Einfallslosigkeit von Reihenhaussiedlungen " geprägt (Büsche 2006: 37). Die landesspezifischen Vorschriftenkataloge haben für konkrete Grabgestaltungsanliegen keine neuen Spielräume der kreativen Freiheit geschaffen. Damit beschneiden sie bis heute auch die Spielräume des subjektiven Erinnerns erheblich (vgl. Spranger 2006: 173; Sörries 2008: 29; Fischer 2011: 128; Benkel 2012: 118). Es wäre zu einfach, für diese Fortführung schlichtweg eine in Amtsstuben und Gerichtssälen grassierende Liebe zur Kontinuität verantwortlich zu machen. Realistischer erscheint mir, von der Muse der reduzierten Komplexität zu sprechen. Das strikte Reglement des Feuerbestattungsgesetzes löste sehr viele potenzielle Anschlussprobleme von vornherein auf. Die Grauzone zwischen Erlaubnis und Abweichung wirkte dadurch überschaubar.

Um der Wahrheit die Ehre zu geben: Das Feuerbestattungsgesetz kannte bereits die Möglichkeit der Ausnahme. Die konkreten Vorschriften zur Bestattung $(\mathbb{9} 9)$ sind in dieser Hinsicht zumindest interpretierbar. Ein zeitgenössischer Rechtskommentar hält 1935 fest: »Daß die Aschereste in allen Fällen in einer öffentlichen Begräbnisstelle beigesetzt werden, wird nicht gefordert. Der Beisetzung in einer privaten Begräbnisstätte, sofern dieselbe polizeilich genehmigt ist, steht nichts im Wege.« (Kahler 1935: 66; zit. nach Spranger 2014b: 90). Dieser rechtlichen Lesart wurde in der Praxis offenkundig selten gefolgt - und wer informiert sich schon über die juristischen Eigenheiten von Vorschriften, die in der gesellschaftlichen Wirklichkeit auf eine Art und Weise durchgesetzt werden, welche zu besagen scheint, dass es Alternativen nicht gibt? Zumindest die juristische Konstruktion der Bestattungsrealität war damals anscheinend liberaler, als es die heutigen Landesgesetze sind.

Nicht repräsentiert war 1934 die - dann wohl doch zu moderne - Vorstellung mitbestimmender Trauer. Die Ländergesetze der Bundesrepublik, die das Feuerbestattungsgesetz vor einigen Jahren abgelöst haben, haben 
dieses Defizit weitergetragen. Gemeinschaftliches Mitbestimmen funktioniert nur, wenn ein für alle Gemeinschaftsmitglieder gültiges Recht von diesen individuell beansprucht und gestaltet werden kann, sonst ist die Mitwirkung doch wieder nur eine symbolische bzw. eine plakative, die wenig bis keine Freiheiten lässt. Tote und ihre Hinterbliebenen treten nun aber nicht als einheitliche Fraktion auf. Getrauert wird zumeist im Zusammenspiel mit direkter Betroffenheit; nur wenige machen sich die Mühe, außerhalb persönlicher Involviertheit einmal nachzuforschen, wie sinnvoll die vorgesehenen Regeln sind und wie gut sie zu gesellschaftlichen Wandlungsvorgängen passen. Die Betroffenen, die es tatsächlich angeht, weil es ihre Trauerrituale und sonstigen Erinnerungshandlungen sind, die durch das Feuerbestattungsgesetz und seine landesspezifischen Ablösungsnormen möglicherweise eingegrenzt werden, vermögen es nicht, sich gemeinschaftlich zu organisieren - dafür ist Trauer viel zu sehr intimisiert, viel zu sehr auf den Einzelfall und auf einen recht engen raffektiven Bezugsraum< beschränkt.

Lange Zeit waren Deutschlands Friedhöfe folglich von einem unausgeglichenen Zwiespalt geprägt: Trauer und Gedenken sollten individuell erfolgen können (und wie sollte man dies auch verhindern?), dieser Inhalt sollte aber in den engen Schranken institutionell vorgegebener Formen verwirklicht werden. Dieser Bürokratisierungsmechanismus deutscher Trauer fand übrigens jenseits ideologischer Verortungen statt: Weder ging es um die Fortsetzung des Nazismus, noch um eine spezifisch bundesdeutsche Befindlichkeit. Ein Blick zurück in die Zeit und auf das Areal der DDR offenbart, dass auch ein sich als antifaschistisch beschreibender Staat nicht ohne Regulierungsfuror im Bestattungskontext ausgekommen ist. Der real existierende Sozialismus war nach Meinung seiner Anhängerschaft anderen Systemen überlegen; im Angesicht des Todes galt aber auch hier die Idee der symbolischen Rückvergemeinschaftung als erstes Prinzip (Schulz 2013).

Die bundesdeutschen Ländergesetze zur Bestattung, die heute gültig sind, haben zur Verbesserung der Lage bislang wenig beigetragen, im Gegenteil. Die oben erwähnten liberalisierenden Elemente des Feuerbestattungsgesetzes wurden mitunter sogar gestrichen (so erging es in mehreren Bundesländern beispielsweise der Erwähnung von Ausnahmeregelungen sie fiel ersatzlos unter den Tisch). Gegenwärtig scheint die Lage geradezu »konfus" zu sein, siehe etwa die widersprüchlichen Elemente im Gesetz über das Friedhofs- und Leichenwesen von Baden-Württemberg (Spranger 2014b: 92). Es gibt in den Landesgesetzen zwar offiziell durchaus Ermes- 
sungsspielräume, die aber in der Praxis nicht gleich Freiheiten sind. ${ }^{28}$ Das Bundesverwaltungsgericht, das in diesen Angelegenheiten die letzte Instanz darstellt, gab 1974 die Marschroute vor, indem es verneinte, dass der Wunsch nach individuellen Bestattungsbedingungen (also losgelöst von der Friedhofspflicht, die letztlich ein Friedhofszwang ist) einem »Freiheitsanspruch des Bürgers« entspricht. Es sei "zweifelhaft«, dass dieser Wunsch als »elementare[] Äußerungsform menschlicher Handlungsfreiheit angenommen werden « könne - denn »der Wunsch nach der individuellen, von der Üblichkeit abweichenden Bestattungsart mag etwa den individuell Gläubigen oder den Einzelgänger auszeichnen und für ihn sogar elementar sein, den Menschen im allgemeinen dürfte er derzeit kaum eigen sein « (BVerwGE 45, 224ff.; zit. nach Spranger 2014c: 237). Bemerkenswert ist die vor nun mehr über vier Jahrzehnten formulierte Betonung des »derzeit«! Das Bundesverwaltungsgericht hat weiterhin sogar die Störung der Totenruhe als Argument ins Spiel gebracht, um allzu individuellen, d.h. von den Normkonzepten abweichenden Trauerformen vorwegnehmend einen Riegel vorzuschieben. Dieser Gedanke sei, heißt es in der Entscheidung, »nicht sachfremd « (zit. nach ebd.: 242) - und es wird resümiert, »daß bei einer grundsätzlichen Freigabe von Bestattungsart und Bestattungsort die Nachteile für andere und für die Allgemeinheit gegenüber der Einbuße des einzelnen an Freiheitsraum überwiegen würden. Diese Einbuße an Freiheitsraum hält sich zudem in grundsätzlich zumutbaren Grenzen.» (Zit. nach ebd.) Auch hier wird betont, dass prinzipiell Ausnahmen denkbar scheinen, wenn für betroffene Hinterbliebene Unzumutbarkeitsgrenzen tangiert werden. Unter welchen Umständen dies der Fall sein könnte, wird nicht näher ausgeführt.

Besonders interessant ist aus einer sozialwissenschaftlichen Sicht in diesem Zusammenhang die im Urteilstext implizierte Behauptung, dass Individualität erst durch Kollektivität hergestellt werde - wodurch also sinngemäß der Wunsch nach einer die Persönlichkeit des Verstorbenen auf besondere Weise betonenden Grabgestaltung ganz im Dienste der dadurch gleichzeitig verschwindenden und, wie auch immer das geschehen soll, aufscheinenden Persönlichkeit unterbunden wird! Immerhin hat eine andere Instanz, das Bundesverfassungsgericht, in einer Entscheidung von 1979, in der es diese Einschränkungen im Wesentlichen bestätigt hat, dann

28 Um ein Beispiel herauszugreifen: "Wenngleich somit Nordrhein-Westfalen eine ganze Fülle individueller Umgangsformen mit der Totenasche bzw. mit der Urne etabliert hat, macht die Praxis jedenfalls von den individuellen Ausnahmemöglichkeiten nur äußerst zurückhaltend Gebrauch. Entsprechende Anträge werden mit sehr haarsträubenden Argumentationen abgelehnt.« (Spranger 2014b: 106) 
doch betont, dass die Möglichkeit eines »besonderen Falls« nicht pauschal ausgeschlossen werden könne. Schließlich sei es dem Gesetzgeber nicht möglich, die »individuellen Vorstellungen und Wünsche[] des Einzelnen" vorab zu erkennen (zit. nach ebd.: 244). An diesem Punkt setzen folglich und seither juristische Auseinandersetzungen um die freie Gestaltung des Bestattungswillens an. ${ }^{29}$ Sie haben grundsätzlich den Nachteil, einerseits bindenden Charakter zu besitzen, während sie andererseits die sozio-emotionale Komponente überwiegend ausblenden. Sachlichkeit aber schließt Betroffenheit nicht aus, sondern mitunter ausdrücklich ein. ${ }^{30}$

Im Jahr 2015 hat sich im Bundesland Bremen eine gewisse Liberalisierung ergeben. Das Gesetz über das Friedhofs- und Bestattungswesen wurde im Dezember des Jahres reformiert - mit für deutsche Verhältnisse ungewohnten Freiheitsoptionen. Es ist seither gestattet, dass Ascheüberreste auch auf Privatgrundstücken beigesetzt werden - sofern diverse Bedingungen nachweisbar erfüllt werden. Der Verstorbene muss über einen Hauptwohnsitz in Bremen verfügt und seinen Bestattungswunsch schriftlich erklärt haben, der Grundstückseigentümer muss zustimmen, u.a. Anderswo sind Versuche, das Bestattungsrecht zu liberalisieren und es damit dem sozialen Wandel anzupassen, hingegen vorläufig gescheitert (zuletzt etwa 2016 in Bayern oder 2018 in Brandenburg und Sachsen-Anhalt). Selbst Verschärfungen der bestehenden Regeln hat es gegeben (Hessen schließt erst seit 2018 trauernde Angehörige ausdrücklich vom Urnentransport aus). Dass Grabsteine, die längst eine globalisierte Handelsware sind, nicht durch Kinderarbeit entstehen sollen und dass vor einer Kremierung eine zweite Leichenschau erfolgen soll, dürfte allgemein einleuchten und wenig Kritik provozieren, nicht zuletzt, weil diese Restriktionen keine Handlungsfreiheiten einschränken. Anders die individuellen Bestattungswünsche Angehöriger bzw. Verstorbener, die zu Lebzeiten geäußert wurden: Viele der faktisch vorkommenden Anliegen sind verboten, mithin entscheidet, wie im Fall Bremen, die Geografie über Ja oder Nein. Es braucht einiges an Dog-

29 Vgl. speziell zu den Möglichkeiten des alternativen Umgangs mit Asche vor diesem Hintergrund Ritter/Keldenich (2010), wo die Haltung vertreten wird: »Kann man die Friedhofspflicht heute nicht mehr auf das sittliche Empfinden der Allgemeinheit stützen, gibt es keine Argumente mehr dafür, sie entgegen dem Grundrecht der Handlungsfreiheit aufrecht zu erhalten. Einzelfragen könnten im Rahmen einer Gesetzesänderung berücksichtigt oder von den zuständigen Behörden durch Auflagen geregelt werden.« (Ebd.: 17)

30 »Es ist daher kein Lapsus, wenn die Richtung >objektive Information nicht eingehalten wurde, denn Tod und Trauer sind ohne die Aura der Betroffenheit nicht denkbar.« (Schmied 1985: 201) 
matismus, um diese Einschränkungen mit Generalkategorien wie der $>$ Menschenwürde< aufrecht zu erhalten, denn dabei schützt man Menschen dadurch vor sich selbst, dass man sie in ihrer Trauer zur Fremdbestimmung und zu einer trügerischen Ordnung zwingt (vgl. Ritter/Keldenich 2010: 84). ${ }^{31}$ Langfristig ist die Veränderung jener Regularien, die exklusiv und ohne konkrete Gefährdung subjektiver Ansprüche die Mitwirkungsund Gestaltungsoptionen der Trauernden betreffen, nicht aufhaltbar. Auf kurze Sicht wirken allerdings viele der einschlägigen Vorschriften dadurch, dass sie nicht reformiert werden, wie Bollwerke gegen Transformationsprozesse, die sich ohnehin nicht stoppen lassen.

So weit, so (relativ) autonomiefrei der sepulkrale Status quo. Die institutionelle Vernunft, die den gegebenen Zustand bewahrt, ohne zu überprüfen, wie notwendig er ordnungserhaltende und gemeinschaftsstiftende Prinzipien überhaupt braucht (dies geht nur über den Weg der wissenschaftlichen Analyse), wird über kurz oder lang immer wieder mit dem Prinzip der Selbstbestimmung konfrontiert werden. Wer an die Autonomie von Trauerprozessen glaubt, wird sich mit den Vorzügen kollektivistischer und damit zwangsmoralisierender Haltungen nicht mehr versöhnen lassen. Anders als bei den Verhaltensregeln im Schwimmbad oder den Beförderungsrichtlinien im öffentlichen Verkehrswesen sind Trauern, Gedenken, Ritualisieren usw. nicht darauf angewiesen, abstrakt so geregelt zu werden, dass einzelne Akteure sich daran werden orientieren können. Die in den Gerichtsurteilen der 1970er Jahre herbeizitierte wechselseitige Rücksichtnahme auf mögliche Anliegen möglicher Dritter ist immer schon ein schwacher Ansporn gewesen. Der gesellschaftliche Wandel durch die Individualisierung und ein dabei mitlaufender Anerkennungszugewinn für subjektive Gefühlshaltungen, so irrational oder eigenwillig sie auch wirken mögen, machen vor der Friedhofspforte nicht halt. Jeder stirbt

31 Künftige Liberalisierungen, von denen ich ausgehe, werden allerdings nicht ohne die Überlegung auskommen, inwiefern ein stabiler »Mindeststandard an Friedhofs- und Bestattungskultur« erhalten bleiben kann (Ritter/Keldenich 2010: 97). In diesen Zusammenhang passt die drastische Geschichte jenes Schweizers, der verfügte, nach seinem Tod kremiert zu werden. Die Asche solle sein Sohn, so der ausdrückliche Wunsch, an sich nehmen - in der Schweiz legale Praxis -, auf den Boden streuen, mit Kehrbesen und -blech einsammeln und in die Mülltonne werfen. Dieser Akt sollte die >Bestattung besiegeln. Das Anliegen ist klar definiert, für die Hinterbliebenen jedoch stand es aus nachvollziehbaren Gründen im Widerspruch zu ihrem Trauerbegehren. Solche Divergenzen lassen sich weder heute noch künftig übergehen. Es wird gerade bei Extremsituationen zu klären sein, welche Ansprüche mit welcher Gewichtung berücksichtigt werden können, sollen, ggf. sogar müssen. 
für sich allein, heißt es in einem Romantitel von Hans Fallada. Obwohl es bei Fallada nicht um das Sterben an sich geht (sondern um zivilen Widerstand im Dritten Reich) ist sein Titel sprichwörtlich geworden, denn er beschreibt eine Situation, die seit Jahrzehnten in den Köpfen verfestigt ist und die, nebenbei bemerkt, u.a. mit dem Erfolg der Hospizbewegung in Verbindung steht: Ein jeder Tod steht für eine eigene Geschichte, die der sterbende Körper ‘zu Ende erzählt‘. Nur wenige Menschen kämen heute auf die Idee, Sterbevorgänge als >Massenphänomene zu deuten, etwa mit dem Hinweis auf gemeinsamer Todesursachen. Sterben ist per se eine Eigenwilligkeit geworden, und der Tod ist ein Schicksal einzelner, die davon direkt oder mittelbar betroffen sind. ${ }^{32}$ Trauer hat sich, aus den oben beschriebenen Gründen, korrespondierend zum individuellen Sterben ebenfalls individualisiert. Die größte Schwierigkeit der individualisierten Trauer ist, dass sich nicht herumspricht, wie individualisiert sie ist.

\section{Exkurs über Trauer und Treue}

Die Gespräche, die die Autoren des vorliegenden Bandes mit Hinterbliebenen geführt haben, haben vor allem ein Ergebnis hervor gebracht: Geht es um die individuelle Haltung zu den juristischen und sozialen Normen, die einen Todesfall begleiten, herrscht heute eine Art neue Unübersichtlichkeit vor. Es gibt nicht dier dominierende Haltung; es gibt oszillierende Positionen, Ambivalenzen, Unsicherheiten und Schwankungen, es gibt Aufklärungs- und Nachforschungsbedarf, es gibt aber auch klare Polarisierungen. Die Traditionalisten haben in Sachen Trauer und Autonomie ebenso viel zu sagen wie die Innovativen, und das sind nur zwei von vielen Fraktionen. Wenn man eine religiös gefärbte Metapher benutzen möchte: Es stehen sich heute überzeugte Atheisten und überzeugte Gläubige gegenüber, und dazwischen sind große agnostische Lager platziert, nicht zu vergessen die Anhänger anderer Glaubensrichtungen und die generell >Suchenden . Kaum eine Einstellung, die sich nicht sgut begründen lässt;

32 Folglich trifft die Kritik nicht zu, die an Falladas (Pseudonym für Rudolf Ditzen) Titel geäußert wurde. Falsch sei »die Vorstellung, die darin anklingt«, weil der Tod eine »eminent soziale Tatsache« sei (Planert/Süß 2015: 7). Wieso dies der Realität widerspricht, in der der Tod immerzu etwas Subjektives ist (und in der er sich oft, wenn auch nicht immer salleine< ereignet), will mir nicht einleuchten: Gemeinschaften zeichnen kulturelle Bilder vom Lebensende gemeinsam; Sterben aber ist keine Erfahrung von Kollektiven. 
kaum eine, die nicht ad hoc mit einer Gegenperspektive konfrontiert werden kann.

Die vorhandene Vielfalt beweist, dass die Zeiten der Gemeinschaftsstiftung über das Medium der umfassenden, in Ritual- und anderen Ausdrucksformen realisierten Ordnung vorüber sind. So betrachtet ist Trauer in gewisser Hinsicht das Gegenteil der partnerschaftlichen Treue.

Das hört sich zunächst einmal absurd an. Ein Rückgriff auf das Werk von Durkheim macht den Vergleich, so hoffe ich, ein wenig klarer. Wie erwähnt, hielt Durkheim um das Jahr 1900 herum allzu individualistische Ausbrüche aus dem Gemeinschaftsleben für eine Gefahr für die soziale Ordnung: Wer sich seinen Leidenschaften hingibt ohne Rücksicht auf die Interessen aller anderen, auch und gerade derer, die ihm beruflich oder familiär nahe stehen, der gefährdet nicht nur für sich selbst, sondern auch für alle anderen die Ordnung. Deshalb auch Durkheims Fokus auf die Moral: sie setzt Grenzen. ${ }^{33}$ Da die Ordnung bei Durkheim somit weniger auf dem Recht, als vielmehr auf Moral basiert - denn das Recht wird, ich hatte es weiter oben erwähnt, aus Furcht vor Strafe respektiert, nicht aus Überzeugung -, müsste Individualismus streng genommen als ein unmoralisches Verhalten zu Ungunsten der Gemeinschaft gedeutet werden. Das ähnelt durchaus dem Rang der (Un-)Treue in einer Partnerschaft. Zu Durkheims Zeiten waren die Spielregeln für die Partnersuche noch wesentlich strikter reglementiert als heute, insbesondere in der Oberschicht. Häufig genug hatten die Väter ein Wörtchen mitzureden bei der Gattenwahl ihrer Töchter - wenn sie nicht gar selbst die sgute Partie aussuchten. Die Tochter aus gutem Hause konnte damit rechnen, dass ihr soziales Umfeld ihre Verheiratung erwartet, sobald sie volljährig war. Die vornehmen Herren, die dafür in Frage kamen, mussten sich hingegen als geeignete Schwiegersöhne beweisen. Sie mussten gesellschaftlich etabliert sein, d.h. einen guten Leumund und eine erfolgreiche Berufslaufbahn in einem angesehenen Tätigkeitsfeld vorweisen können. In der Konsequenz waren die künftigen Bräutigame wesentlich älter als ihre Bräute. Während diese ihre ersten legitimen sexuellen Erfahrungen also mit der Hochzeitsnacht machten und

33 »Überließe der einzelne sich seinen natürlichen Neigungen, so hätte er keinen Grund, sich nicht ohne Rücksicht auf die anderen zu entfalten oder zumindest den Versuch dazu zu machen und sich dabei nicht um die Störungen zu kümmern, die er um sich herum verursacht. Erst die moralische Disziplin setzt ihm Grenzen, sagt ihm, wie sein Verhältnis zu den anderen beschaffen sein soll, wo die Schwelle zu einem unrechtmäßigen Übergriff überschritten ist und welche Leistungen er der Gemeinschaft zu deren Erhaltung schuldet.« (Durkheim 1991: 27f.) 
folglich in einem recht jungen Alter, mussten die Gatten eine sehr viel längere Lebensphase ohne Sexualität aushalten. Das Ergebnis dieser strikten Heirats- und Intimitätspolitik ist bekannt: Für die männlichen Mitglieder bestimmter sozialen Schichten waren der Gang ins Bordell oder die Affäre mit dem Dienstmädchen zwar offiziell illegitime, aber stillschweigend akzeptierte Umgangsformen. (Hinsichtlich der Prostitution und bezogen auf Deutschland hatte das Ganze noch dazu eine juristische Dimension, denn diese war vor 1927 illegal.) Durkheim vertrat sinngemäß die Ansicht, dass es eine Art ssexuelle Anomier wäre, wenn gegen dieses Konzept der ssexuellen Arbeitsteilung verstoßen würde, sobald eine Ehe geschlossen wurde. Gemeint ist also, dass es unmoralischer Individualismus wäre, wenn ein Ehemann auch nach der Heirat noch weiterhin Sex mit anderen Frauen beanspruchen würde. (Erst recht galt dies natürlich für die - damals weitgehend als sexuell interesselos angesehene - Ehefrau!) Die Lösung dieses Bedrohungsszenarios für die moralische Substanz des Zusammenlebens ist partnerschaftliche Treue. Sie setzt dem individualistischen Luststreben Grenzen und lenkt das Begehren in eine gesellschaftlich akzeptierte Richtung.

Rückblickend kann man sehen, dass diese moralische Rechnung weitgehend aufgegangen ist. Es gilt heutzutage in der Tat als stillschweigende Prämisse einer Partnerschaft, dass weder A noch B fremdgehen. Dies muss zu Beginn einer Beziehung nicht ausdrücklich geklärt werden - es steht fest, auch wenn darüber niemals ein Wort verloren worden ist. Die Einschränkung der individuellen Freiheit zugunsten einer shöheren< Qualität - der Beziehungszufriedenheit, hinter der die gesellschaftliche Ordnung steht hat sich bewährt. Menschen in solchen Situationen sind rationale Egoisten. Sie sehen zwar, dass sie sich aus moralischen Gründen einschränken müssen, was zunächst einmal wenig attraktiv wirkt; aber sie verstehen, dass diese Einschränkung dem Erhalt von Rahmenbedingungen dient, ohne die sie nicht, oder zumindest nicht gut existieren könnten. Kurzum: Treue ist einerseits eine Eingrenzung spontaner oder impulsiver individueller Wünsche - aber andererseits, und dies wiegt allgemein schwerer, ein Garant für Stabilität. ${ }^{34}$

34 An dieser Stelle sei außenvorgelassen, dass es einerseits durchaus Alternativkonzepte gibt, etwa sogenannte soffener Beziehungen und/oder die Polyamorie (Boehm 2012) - Partnerschaftsmodelle also, die (sexuelle und/oder emotionale) Treue nicht als Stützpfeiler der Paaridentität verstehen, und die insofern als mehr oder minder stark losgelöst von kollektiven Ordnungsvorstellungen verstanden werden müssen. Andererseits darf nicht übersehen werden, dass Untreue ein weit verbreitetes Phänomen zu sein scheint, auch wenn genaue Daten aus nachvollziehbaren 
Treue ist im Lichte dieser Erfolgsgeschichte das Gegenteil von Trauer. Denn während Letztere sich zunehmend individualisiert, wie ich verschiedentlich nachzuzeichnen versucht habe, insbesondere in Kooperation mit Matthias Meitzler (Benkel/Meitzler 2013; Benkel 2015; ders. 2017b; ders. 2018b), ist sie trotz stürmischer Angriffe weitgehend unverwüstlich. Was Treue ist, kann ich zwar subjektiv definieren bzw. ich kann sogar sehr persönliche Treueverständnisse entwickeln (beispielsweise Haltungen wie: `Es ist keine Untreue, wenn man nicht erwischt wird, oder: 'Es ist kein Vertrauensbruch, wenn keine Gefühle im Spiel sind`, usw.). Ich kann aber nicht damit rechnen, dass mein hochsubjektives (Un-)Treueverständnis bei anderen Menschen auf Gegenliebe stößt; und ich werde damit nicht durchkommen, wenn ich potenziellen Partnern dieses Konzept als festzementierte sTatsache` vorhalte. Dafür ist die Treuekonzeption viel zu stabil und vor allem viel zu eindeutig. Es gibt zwar auch hier Graustufen und Unklarheiten (Ist Küssen bereits Fremdgehen? Ist der erotisierte Gedanke an eine $[\mathrm{n}]$ andere[n] schon Untreue?), im Allgemeinen sind die Spielregeln aber ziemlich eindeutig.

Trauer ist anders. Trauer stößt eben nicht auf dieses unausgesprochene Spontanverständnis, auf das man setzen kann, wenn von Treue die Rede ist. Wer nie trauern musste, kann sich womöglich schlecht in Trauernde hineinversetzen. Und selbst wer eindeutige Erfahrungen gemacht hat, weiß bisweilen nicht (das zeigt auch unser Interviewmaterial), wie er Angehörigen eines sfrischen< Todesfalls begegnen soll. Soll man sie in Ruhe lassen? Oder ausdrücklich Trost und Unterstützung anbieten? Es scheint ausgemacht, dass Trauern nicht gleich Trauern ist. Die einen suchen die Nähe des engsten sozialen Umfeldes, um über die schwere Zeit hinweg zu kommen. Andere ziehen sich zurück. Es geht offensichtlich nicht darum, dass hier jemand `Recht< hat mit der eigenen Einstellung. (Schließlich, was wäre denn dann >Unrecht??) Aber worum geht es stattdessen? Glücklicherweise müssen das Alltagsakteure nicht klären. Sie können Trauerkonfrontationen je nach Einzelkonstellation thematisieren: mal so, mal so. Hinzu kommt, dass Trauerfalle, verglichen mit anderen gewichtigen Sozialsituationen, vergleichsweise selten vorkommen. (Untreue dürfte - dies eine vage Spekulation - empirisch gesehen häufiger sein.) Und außerdem gibt es bei der Begegnung mit Trauernden ja noch jene unverfänglichen, lange

Gründen nicht vorliegen. Die Gründe für das Fremdgehen mögen subjektiv bzw. situativ sein, soziologisch gesehen sind sie aber immerzu abhängig von der gesellschaftlichen Wirklichkeit, in der sie sich als konkrete Handlungsmöglichkeiten (oder eben -unmöglichkeiten) ergeben. 
etablierten Handlungsdirektiven (Kondolenzverhalten usw.), die helfen, das notwendige symbolische Vergemeinschaftungspotenzial, welches in dieser Situation begraben liegt, auszuschöpfen, ohne sich subjektiv allzu sehr ins Spiel bringen zu müssen. Was Trauer konkret ist und wie sie in diesem konkreten Fall gefühlt und ausgelebt wird (bzw. wie gerade nicht), muss somit von Außenstehenden gar nicht erst reflektiert werden. Dies ist das Kennzeichen der Individualisierung von Trauer: Sie hat sich losgelöst von einem starren Gehäuse der Erwartbarkeiten. Sie ist so einzigartig geworden, wie es die Lebenswelt war, um deren Verlust sie empfunden wird.

\section{Individualität im Sterbekontext}

Wie gesagt, es gibt nicht die eine, dominierende Einstellung gegenüber Sterben, Tod und Trauer, oder auch nur zur Angemessenheit des Umgangs mit diesem Themenkreis. Die Zeit eines eng justierten »Kollektivbewusstseins«, wie Durkheim (1988: 128) es formulierte, ist endgültig vorbei; und womöglich hat es im Bereich des Lebensendes nie eine historische Phase gegeben, in der eine generelle, geradezu uniforme Überzeugung aller Bevölkerungsmitglieder existierte. Denn zum Zusammenleben im gesellschaftlichen Kontext gehört immerzu die Gruppe derer, die aus verschiedenen Gründen - medizinischen, psychologischen, aber auch ideologischweltanschaulichen, und ebenfalls aufgrund von Zufällen, Unglücken und Missverständnissen - aus der Masse ausschert (einige spannende geschichtliche Beispiele betrachtet Foucault 2007).

Dank der Individualisierung ist es heutzutage in den westlichen Industrienationen einfacher geworden, sich gegen den Mainstream zu positionieren. Eine deutlich gegen die Mehrheit (oder die empfundene Mehrheit) abweichende, zugleich aber offen kommunizierte Haltung wird nicht mehr automatisch als Provokation oder Skandal verstanden, sondern gilt in erster Linie als Persönlichkeitsattribut, als Ausdruck einer (mitunter hoch-)individuellen Sichtweise. Davon sind nur noch einige wenige Tabus ausgenommen - vor allem solche Bereiche, in denen es um Gewalt oder Repression gegen andere geht. Wer anderen nicht schadet, >darf< eine individualistische Position haben - und er darf sie für gewöhnlich auch äußern. ${ }^{35}$

35 Natürlich können auch durch Äußerungen Rechtsgüter verletzt oder zumindest bedroht werden; und bekanntlich hat Meinungsfreiheit ihre (juristisch definierten) Grenzen. In diesem Diskursfeld gibt es konkrete, wie auch abstrakte Ein- 
Eine Folge der Individualisierung ist nun aber auch, dass ehemals wesentlich verbreitetere, teilweise sogar als verbindlich angesehene Einstellungen mittlerweile als eine Haltung unter vielen angesehen werden. Das naheliegendste Beispiel dürften die religiösen Rituale der Bestattung nach protestantischer bzw. katholischer Vorlage sein. Jahrhundertelang waren sie die Stützpfeiler der in diesen Ritualen symbolisierten Ordnung. Sie waren keineswegs unhinterfragt, sonst hätte es schließlich den Protestantismus nie gegeben, und sonst wäre auch die Säkularisierung nicht in Bewegung gekommen. Dennoch war es für lange Zeit üblich, sich bei Fragen zur Bestattungskultur und überhaupt zum Verhältnis von Tod und Gesellschaft an die Vertreter der sogenannten sgroßen Kirchen $<$ zu wenden. Von dort war ein zuverlässiger Expertenrat aus berufenem Mund zu erwarten; er propagierte neben all den tröstenden und manchmal auch mahnenden Worten allemal ein spezifisches Ordnungskonzept. Die kirchlichen Riten gestalteten den Lebensweltverlust einzelner Gesellschaftsmitglieder nahezu vollständig aus; für die Individualität der Verstorbenen blieb angesichts der strengen Form recht wenig Raum.

Gegenwärtig sind diese kirchlichen Traditionen nur noch Nebenaspekte. Die Verhältnisse haben sich umgekehrt: Anstelle strenger Formen herrschen selbst definierte, eben autonome Direktive vor. Wie eng oder streng diese jeweils gefasst werden, entscheiden diejenigen, die ihnen folgen wollen, mittlerweile selbst; sie sind die Regisseure und zugleich die Rezipienten dieser $>$ Programme .

Und so kommt es, dass im Laufe der Zeit aufschlussreiche Neujustierungen des Trauervorgangs erfolgten. In früheren Zeiten kreiste Bestattungskultur um das jenseitige Wohl der Verstorbenen. Je privilegierter diese zu Lebzeiten waren, desto opulenter hörten sich die Fürbitten für eine angenehme Fortexistenz an. Mit der Zeit, konkret: im Zuge der Säkularisierung und der Demokratisierung trat auch der Alltagsmensch als betrauenswerter Toter in spe auf der gesellschaftlichen Bühne in Erscheinung; eine zweite Verschiebung, die dem gegenüber etwas nachhinkte, galt dem Blickrichtungswechsel weg von der jenseitigen Zukunft hin zur lebensweltlichen Vergangenheit. Und schließlich rücken, auch dies wirkt auf mich wie ein Individualisierungseffekt, die Hinterbliebenen nach vorne, während

schränkungen - und über viele davon lässt sich diskutieren (Hörnle 2005). Für den vorliegenden Themenkontext sind diese Einschränkungen allerdings nicht weiter von Relevanz - was, nebenbei bemerkt, zeigt, dass es sich bei (abstrakten wie konkreten) Grenzüberschreitungen im Zusammenhang mit Bestattungskultur eben nicht (mehr) um Sachverhalte handelt, die unisono zurückgewiesen oder die per se als Schädigung des sozialen Miteinanders angesehen werden. 
die Rollen der Toten im sepulkralen Geschehen reduzierter ausfallen. Diese Tendenz, sofern sie sich in der langfristigen Betrachtung als richtig herausstellen wird, steht selbstverständlich nicht dafür, dass die Menschen ihre Verstorbenen weniger achten oder dass ihnen Lebensverluste weniger ausmachen. Das Gegenteil dürfte der Fall sein: Gerade weil Trauern als Reaktion auf eine individuelle Katastrophe verstanden wird (und eben nicht mehr als Gemeinschaftserschütterung, wie in den erwähnten archaischen Volksgruppen), erscheint es folgerichtig, das Ende eines Lebens als Problem nicht für die Verstorbenen, sondern für ihre weiterlebenden Angehörigen zu verstehen oder es entsprechend einzurahmen. So nämlich wird die Kollektivität des Sterbenmüssens am buchstäblichen Ende doch wieder durch lebendige individuelle Betroffenheit relativiert. Da ein Individuum nie losgelöst ist von seinem sozialen Umfeld, ist der individuelle Tod genauso wie das individuelle Trauern nur scheinbar eine >Privatangelegenheit«. Die Verbindungslinie zwischen Tod und Trauer ist schließlich eine psychosoziale Brücke: der Lebensverlust der einen Person infiziert die anderen Personen, die sich ihr nah fühlen, mit einem Trauerimpuls, als wäre Sterben per se ein sozialer Effekt. In diesem Zusammenhang gibt es nur zwei irgendwie als >beweiskräftig` zu betrachtende Facetten: den toten Körper, den die Gesellschaft rasch unsichtbar macht, und Trauer und Totenfürsorge, die von lebendigen Menschen vollzogen werden, welche sich individuell betroffen fühlen (Benkel/Meitzler 2019b). Sie - die Über-, die Weiterlebenden - sind die Träger der Trauer, und Trauer ist folglich stets >lebendig.

Sie ist es auch deshalb, weil Trauern entgegen gebräuchlicher Vokabeln nicht bedeutet, sich zu verabschieden. In der Fachliteratur ist die Rede von "continuing bonds" (vgl. Jakoby 2014: 184 sowie generell Klaas/Nickman/ Silverman 1996), also von anhaltenden, psychosozialen Bindungen der Lebenden zu den nicht mehr Lebendigen über den Tod hinaus. Das NichtLoslassen-Können oder -Wollen kann ebenso sehr ein Problem, wie ein Trost sein, um die faktische, einseitig nicht überwindbare Kommunikationsunterbrechung zu verarbeiten, die das Lebensende unbarmherzig mit sich bringt. Formen der parasozialen Beziehungspflege, wie ich dieses Phänomen nenne, sind mittlerweile sehr zahlreich - nicht zuletzt das Internet birgt diesbezüglich Optionen, die auf die einen erschreckend und auf die anderen hoffnungsvoll wirken (vgl. Benkel 2018c; Benkel/Meitzler 2018). Auch in dieser Bandbreite zeigt sich die Ausdifferenzierung und Vielfalt der Gegenwartsgesellschaft.

Allemal ist der Tod, wie Norbert Elias in einem Büchlein über Die Einsamkeit der Sterbenden in unseren Tagen schrieb, »ein Problem der Lebenden« (1990: 10). Die Aussage ist auf verschiedenen Ebenen wahr, und eben 
auch auf der Ebene persönlicher Individualität und Autonomie. In einer zunehmend säkular über das Lebensende nachdenkenden Welt ${ }^{36}$ (im Einklang mit allgemeinen Entwicklungslinien; Pollack/Rosta 2015) ist der Tod noch am ehesten dort greifbar und diskutabel, wo er Menschen zu tatsächlichen Handlungen bewegt, die wiederum Anschlusshandlungen auslösen. Die Toten aber sind längst keine Gesprächspartner der Lebenden mehr nicht für sie werden Trauerrituale durchgeführt, sondern für die, die noch leben (Benkel 2015). Alle Handlungen und alle Kommunikationen, die Trauer zu dem machen, was sie in gesellschaftlicher (und nicht bloß subjektiver!) Bewertung heute ist, werden von lebendigen Menschen ausgelöst, weitergetragen, aufbewahrt und wieder storniert. Nur sie denken über den Tod nach, über die Verluste, über Schmerz und das Danach der Trauer. Sterben war noch nie etwas anderes als ein Thema lebendiger Menschen. Für Trauer gilt das gleiche.

Sich autonom einzuschalten in die Debatten über die notwendigen (und unaufhaltsamen) Veränderungen der Bestattungskultur, d.h. Stellung zu beziehen bei der Frage nach rechtlicher Reformnotwendigkeit, oder eine Position einzunehmen in kirchlichen, medizinischen, mitunter auch beruflichen und familiären Kontexten, ist in diesem Sinne nichts weniger als die reflexive Konsequenz aus einer immer schon gegebenen Ausgangssituation (Benkel 2020). Wer, wenn nicht die Angehörigen und Hinterbliebenen, können entscheiden und justieren, was sich aus dem Ensemble denkbarer und praktizierter Trauerhandlungen im individuellen Einzelfall als anschlussfähig herausstellen wird? Wer, wenn nicht diejenigen, die sich der sozialen Konstruktion `Trauer und ihrer hintergründigen, ordnungsgebenden Macht aussetzen, sollen definieren können, was unter den Ritualdesignangeboten überkommen, was noch praktikabel und was zukunftsträchtig ist? Pauschalismen sind fehl am Platz, denn sie lähmen die Trauer: sie nehmen ihr das lebendige Entfaltungs-, Gestaltungs- und auch Verdrängungspotenzial. Starre Regelungen haben durchaus ihre funktionsträchtige historische Phase erlebt; die Permanenz des sozialen Wandels ist jedoch das Gegengift wider die institutionelle Selbstgefälligkeit. Wo sich nichts mehr bewegt, herrscht der Tod. Gesellschaftliche Spielregeln, die die Trauer in Ketten legen, verwandeln sie; aus einer lebendigen Empfindung wird

36 Mir scheint, dass religiöse Fundamentalisten zu Sterben und Tod im Lichte ihrer Ideologie häufig nur wenig zu sagen haben und eher an (Vorschlägen zu) der Gestaltung real existierender Lebenswelten interessiert sind. Wenn nun aber selbst die wahrhaft Überzeugten kaum mehr Zeit auf die Durchdringung dieses gravierenden Statusübergangs verwenden, muss der Tod wohl als ein supersäkulares Phänomen angesehen werden. 
eine pauschale Empfindung. Persönliche Perspektiven auf den angemessenen Umgang mit dem Sterben und dem toten Körper, mit dem Abschied und der Erinnerungsstätte sind selbstverständlich manchmal provokant. Sie mögen auf Beobachter deplatziert wirken, oder unangemessen, oder schlichtweg falsch. Eine unabhängig vom individuellen (und darin eben auch zur Autonomie strebenden) Willen geltende Vorschrift, die dies einschränkt, kann eine Waffe sein, mit der Unbedingtheitsansprüche durchgefochten werden können. So unbedingt aber, dass selbst höchstprivate Empfindungen sich ihr formelhaft unterwerfen müssen, sollte in einer individualitätsgeprägten Gesellschaft keine Norm mehr sein. Ihre Leistung ist ansonsten nicht die Lösung von Problemen, sondern die Erschaffung derselben; sie verdinglicht. Damit will ich sagen: Ohne Autonomie der Trauer ist die Trauer selbst ein Symptom fehlender Lebendigkeit. Dass Trauer nichts Totes, sondern etwas Lebendiges ist, muss in der deutschen Gesellschaft noch gelernt werden. 


\section{Keine Angst vor echten Tränen. Die Erforschung von Trauer als methodologische Herausforderung}

Matthias Meitzler

"Es gibt Eingeweihte auf dem Feld der Tränen,
die nie tatsächlich geweint haben."

(Cioran 1988: 32)

Die nachfolgenden Ausführungen bieten eine Darstellung und Reflexion der methodischen Vorgehensweise, die der vorliegenden Forschungsarbeit zugrunde liegt. Neben einer Auseinandersetzung mit der empirischen Ergründbarkeit von Trauer im Allgemeinen und der Frage nach einem adäquaten Feldzugang liegt das Augenmerk insbesondere auf den Herausforderungen und Unwägbarkeiten, die sich dem empirischen Sozialforscher stellen, wenn er Menschen in einer Interviewsituation zu ihren Trauererfahrungen befragt. Damit werden verschiedene Problematiken tangiert, die während des Forschungsprozesses immer wieder aufgetreten sind und die in der deutschsprachigen Methodenliteratur bislang noch wenig beleuchtet wurden.

\section{Die Rekonstruktion von Trauer(handlungen)}

Möchte man ein gesellschaftliches Phänomen empirisch ergründen, so stellt sich zu Beginn die Frage, welche Voraussetzungen dieses Unterfangen mit sich bringt und welches Forschungsdesign notwendig ist. Welcher (Teil-)Ausschnitt der sozialen Wirklichkeit soll unter welchen theoretischen Vorzeichen, mit welchem Erkenntnisinteresse und mit welcher Fragestellung zum Gegenstand der Untersuchung gemacht werden? Welche Datensorten sind für die Beantwortung der Forschungsfrage von Bedeutung - und welche Methoden erscheinen hilfreich, um an diese Daten zu gelangen?

Es bedarf der ausdrücklichen Betonung, dass der Einsatz sozialwissenschaftlicher Methoden alles andere als beliebig und weit mehr als eine Ge- 
schmacksfrage ist (vgl. Reichertz 2016: 32). Denn nicht jede Methode ist gleichermaßen dazu geeignet, zufriedenstellende Antworten auf eine spezifische Frage zu geben, nicht jede Methodenkombination ist sinnvoll, und generell ist keine Methode die ultima ratio für sämtliche Forschungsprobleme. Aus diesem Grund steht die endgültige Wahl der methodischen Verfahren häufig nicht schon am Anfang einer Forschungsarbeit unumstößlich fest; vielmehr ist sie das Ergebnis von Reflexionsprozessen, bei denen diverse Herangehensweisen hinsichtlich ihrer Effektivität, Passgenauigkeit, Reichweite und Grenzen gegeneinander abgewogen und erprobt werden (müssen).

Dass der Entschluss für oder gegen eine bestimmte Methode von den spezifischen Anforderungen des anvisierten Forschungsbereichs abhängt, erscheint insofern plausibel, als unterschiedliche Methoden das Thema in unterschiedlicher Weise durchdringen, dabei unterschiedliche Facetten adressieren und letztlich auch zu unterschiedlichen Daten führen. Um in dieser Hinsicht Klarheit zu gewinnen, ist es zunächst wichtig, seinen Untersuchungsgegenstand genau zu definieren, ihn also von all dem unterscheidbar zu machen, was nicht Teil davon ist. Übertragen auf das Forschungssujet dieser Arbeit muss also präzisiert werden, welches Verständnis von Trauer vorliegt (siehe den Beitrag von Thorsten Benkel in diesem Band) und, daran anschließend, auf welchem Weg Trauer sich operationalisieren, d.h. fassbar, beobachtbar und somit erforschbar machen lässt.

Tatsächlich kann nämlich nur ein Teil dessen, was Trauer ausmacht, mit sozialwissenschaftlichen Mitteln erfasst und analysiert werden. Stark vereinfacht lässt sich in diesem Zusammenhang unterscheiden zwischen a) einer Erlebniskomponente, also all dem, was >im Kopf $<$ von Trauernden stattfindet, und $b$ ) einer Handlungskomponente, also all dem, was sich in beobachtbaren Handlungen und deren Resultaten manifestiert. ${ }^{1}$ Bei einem explizit soziologischen Erkenntnisinteresse ist die Erlebniskomponente, die Innenperspektive des Subjekts, verständlicherweise mit erheblichen Problemen verbunden. Nicht das, was sich in den Gedanken eines Menschen aktuell abspielt oder zum Zeitpunkt des Verlusterlebnisses abgespielt hat, ist für den Forschenden registrierbar, sondern immer nur das, was auf un-

1 Diese Unterscheidung erfolgt in bewusster Abgrenzung zu der Auffassung Max Webers, für den auch Denken - als »inneres Tun« - eine Form von Handeln ist (Weber 1976: 1). 
terschiedliche Weise ausagiert und ausgesprochen wird und dadurch eine greifbare Gestalt erhält (dies ist die Handlungskomponente). ${ }^{2}$

Doch nicht alles, was Menschen im Anschluss an den Verlust einer nahestehenden Person tun, tun sie in der Absicht, dabei von Außenstehenden, noch dazu von fremden Personen, beobachtet zu werden. Folglich bedarf es noch einer weiteren Differenzierung zwischen a) Trauer, die ausschließlich im Privatbereich, d.h. unter Suspendierung fremder Blicke artikuliert wird, und $b$ ) Trauerhandlungen, die an öffentlichen Orten stattfinden. ${ }^{3}$ Die Spuren, die Letztere hinterlassen, können (oder: sollen?) mitunter auch von denjenigen gelesen werden, die am Trauergeschehen zunächst unbeteiligt sind - und spätestens hier kann die Sozialwissenschaft ins Spiel kommen. Gemeint sind sämtliche Formen der öffentlichen (verbalen wie nonverbalen) Trauerbekundung, z.B. im Internet (Benkel 2018c; Thimm/ Nehls 2017), in der Tageszeitung (Möller 2009), an Unfallorten (Aka 2007) oder auf dem Friedhof (Benkel 2012; Benkel/Meitzler 2013; dies. 2015; Meitzler 2016).

Die Analyse von Grabstätten, um das letzte der genannten Beispiele herauszugreifen, bildet demnach eine mögliche Herangehensweise bei der empirischen Erforschung von Trauer. Gräber und ihre sichtbaren, d.h. oberirdischen Bestandteile werden dabei als Artefakte betrachtet, die hinsichtlich der ihnen zugrunde liegenden Praktiken, Beziehungen, Erwartungen, Absichten, Normen, Ordnungen etc. genauer untersuchbar sind (Lueger/Froschauer 2018). Grundlegend hierfür ist die Annahme, dass Dinge eben nicht einfach nur Dinge sind (Blumer 2013), sondern sowohl bezüglich ihrer Herstellung wie auch ihrer Verwendung auf unterschiedliche Weise mit sozialen Handlungen verknüpft sind. Über Letztere bzw. über den dahinter verborgenen Sinn können sie spannungsreich Aufschluss geben - und als empirische Ressource damit Relevanz für die Beantwortung

2 Im anglophonen Sprachraum gibt es diesbezüglich die Differenzierung zwischen grief und mourning. Während grief für das psychologische, subjektive Trauererleben steht, bezieht sich mourning auf die kulturelle Rahmung von Trauer und damit verbundene Handlungskonventionen. Dass hierbei jedoch nicht von einem antagonistischen, sondern von einem wechselseitigen Verhältnis auszugehen ist (Hockey/Katz/Small 2001), wird in diesem Band in unterschiedlichen Zusammenhängen zu zeigen versucht.

3 Auch diese Unterscheidung unterliegt natürlich einer Vereinfachung, denn neben den beiden genannten Kategorien gibt es diverse Schattierungen und weitere Formen, etwa das Trauern unter anderen (persönlich bekannten oder unbekannten) Trauernden, das Trauern unter Bedingungen der Zurückhaltung persönlicher Dispositionen (z.B. im Berufskontext), Trauerhandlungen an semi-öffentlichen Orten usw. 
einer Forschungsfrage erlangen. So betrachtet gleicht das Grab nahezu einem (fremdsprachigen) Text, den man lesen, übersetzen und deuten muss, möchte man Näheres über seine gesellschaftlichen Implikationen erfahren. ${ }^{4}$

Ein wesentlicher Vorzug, den empirischen Zugang zu Trauer über die >letzten Ruhestätten auf einem Friedhof zu suchen, besteht vor allem darin, dass dieser mit vergleichsweise geringen Barrieren verbunden ist. Allein in Deutschland gibt es circa 32.000 Friedhöfe; als öffentliche Orte können sie innerhalb der regulären Öffnungszeiten prinzipiell von jedermann betreten werden. Überdies ist die soziologische Inaugenscheinnahme von Grabmaterial durch Nonreaktivität gekennzeichnet. Damit ist gemeint, dass der Forscher das, was er erforschen will, nicht durch seine bloße Anwesenheit oder durch die Art seines Auftretens beeinflusst (anders als z.B. bei der offenen Beobachtung oder während einer Interviewsituation; dazu später mehr). Von Vorteil ist außerdem, dass das Zustandekommen der Untersuchung weder vom Zeitbudget noch von der generellen Teilnahmebereitschaft des `Gegenübers ‘ abhängt. Hier braucht es also keinen Konsens zwischen Forscher und Beforschtem, vielmehr wurde das Grab unabhängig von den Erkenntnisinteressen des Wissenschaftlers errichtet; er hat dieses Datum (wiederum im Unterschied zu Beobachtungsprotokollen oder Interviewtranskripten) nicht selbst produziert, sondern es entspringt originär dem zu untersuchenden Feld. Am Grab lassen sich also menschliche Handlungen rekonstruieren, ohne dass die betreffenden Akteure unmittelbar und leibhaftig in den Forschungskontext involviert sind. Während sie ihren unbeabsichtigten Beitrag schon zu einem viel früheren Zeitpunkt geleistet haben, fungiert das Grabzeichen nun gewissermaßen als >stellvertretender Erzähler<- als auf Dauer gestellte Externalisierung von Sinn.

An dieser Stelle ergibt sich allerdings ein Problem, das deutlich macht, dass die Analyse von Grabartefakten einen sehr spezifischen Zugang zur Trauerthematik bildet, der nicht ohne Einschränkungen beschritten werden kann. Wenn die Ruhestätte als stellvertretender Erzähler charakterisiert wird, der Auskünfte gibt über zurückliegende Handlungen, dann drängt sich die Frage auf, welche Handlungen genau gemeint sind, und wer ihr Urheber ist. Trauerhandlungen sind dem Grabmaterial nicht lediglich eingeschrieben und lassen sich ihm deshalb auch nicht einfach als >ob-

4 Darum kann auch vom »Grabtext« gesprochen werden - als »Gesamtheit jener dem Grab beigefügten Gestaltungs- und Verzierungselemente, die in die Wahrnehmung des Betrachters geraten können und üblicherweise so platziert wurden, dass sie ein entsprechendes Maß an Aufmerksamkeit wenigstens hypothetisch erregen können«(Benkel 2012: 48). 
jektive Tatsachen ablesen; stattdessen müssen sie vom Rezipienten (hier: vom Soziologen) rekonstruiert und interpretiert werden. Damit aus den Artefakten wissenschaftliche, d.h. auswertbare Daten werden, mit deren Hilfe man eine Forschungsfrage beantworten kann, bedarf es einer gewissen Übersetzungs- und Transformationsarbeit vonseiten des Forschenden: Er muss vor Ort selektieren, also Relevantes vom weniger Relevanten trennen, brauchbare Daten fixieren (z.B. mit Fotokamera und Notizblock), das gesammelte Material aufbereiten (z.B. durch Kategorisierung und Typisierung) und es somit einer theoretisch sowie methodisch angeleiteten Analyse zugänglich machen.

Doch schon die Rohdaten sind nicht einfach >da<, sondern unterliegen einem vielschichtigen und schwer überschaubaren Prozess des Gewordenseins. Zwischen der soziologischen Untersuchung eines Grabmals und jenen Handlungen, die zu seinem Erscheinungsbild geführt haben, liegt ein bald größerer, bald geringerer Zeitraum. Anders als bei der unmittelbaren Beobachtung eines Interaktionsgeschehens wird in diesem Fall nicht der Augenblick eines Handlungsvollzuges erfasst, sondern dessen Resultat. Die rekonstruktive Herausforderung besteht also darin, vom Handlungsresultat zu dem Moment des Handlungsvollzugs zu gelangen, ohne während dieses Moments als Forscher dabei gewesen sein zu können. Was sich anhand eines bestimmten Grabensembles über den Prozess seiner Genese und Modifikation schlussfolgern lässt, ist allerdings recht vage - schon deshalb, weil üblicherweise nicht ein einziger, sondern verschiedene Akteure mit je eigenen Intentionen daran beteiligt gewesen sind. Neben den Hinterbliebenen sind beispielsweise das Friedhofspersonal, Friedhofsgärtnereien und Steinmetze zu nennen.

Dass Ruhestätten so aussehen, wie sie aussehen, ist folglich nicht allein mit der vergangenen oder gegenwärtigen Existenz von Trauer zu erklären; ebenso liegt eine Mixtur aus Pragmatismus, Pflichterfüllung, Berufsarbeit, wirtschaftlichem Handeln usw. vor. Um nur ein Beispiel zu nennen: Die Grabsteingravur von Worten des Abschieds, des Verlustschmerzes, der Hoffnung oder Versöhnung wird für gewöhnlich von trauernden Angehörigen in Auftrag gegeben, doch lässt sich die Umsetzung durch den Steinmetz weniger als Trauerhandlung interpretieren, denn als erlerntes, vergleichsweise nüchternes Handwerk, in dem zwar durchaus gesellschaftlich kursierende Vorstellungen von Trauer zum Ausdruck kommen, das aber in erster Linie einer ökonomischen Tauschlogik folgt: Dienstleistung wird erbracht gegen Bezahlung, nicht aufgrund individuell empfundener affektiver Betroffenheit.

Aber auch abgesehen von solchen Drittvariablen bleibt es ein schwieriges Projekt, anhand der Begutachtung von Gräbern Rückschlüsse auf die 
dahinter stehenden (Trauer-)Handlungen zu ziehen. ${ }^{5}$ Verantwortlich dafür ist ein Problem, das sich nicht nur dem mit Trauer befassten Wissenschaftler stellt, sondern die Soziologie ganz grundsätzlich beschäftigt. Selbst die umfassendsten methodischen Kenntnisse ändern nichts daran, dass der soziologische Beobachter die genauen Handlungsabsichten eines bestimmten Akteurs nicht durchschauen, sondern sie lediglich annäherungsweise erschließen kann. ${ }^{6}$ Diesbezüglich vorgenommene Sinnzuschreibungen lassen sich zwar darlegen, sie müssen aber nicht zwangsläufig denen des Handelnden entsprechen. ${ }^{7}$ Dass man Menschen snicht in den Kopf schauen kann, ist eine schwer zu widerlegende soziologische Binsenweisheit. In der Konsequenz stellen sozialwissenschaftliche Interpretationen nicht bloß eine Reproduktion dessen dar, was die untersuchten Akteure im Sinn hatten, sondern sind vielmehr als »Konstruktionen zweiten Grades « (Schütz 1971c: 7; vgl. Schütz 1971d: 68) zu betrachten, die sich von den vom Handelnden vorgenommenen Konstruktionen ersten Grades unterscheiden. ${ }^{8}$

5 Wie wäre vor diesem Hintergrund etwa das Vorhandensein von anonymen Beisetzungsflächen zu beurteilen, die auf den ersten Blick wenig Material bieten (Sachmerda-Schulz 2017)? In einem `fehlenden` Grab einen zuverlässigen Indikator für fehlende Trauer erkennen zu wollen, würde sicherlich zu kurz greifen. Dass allein die Erkundung von Friedhofslandschaften zur Beantwortung der Forschungsfrage nicht ausreicht, wird spätestens angesichts des Umstands evident, dass sich eben nicht jede Ruhestätte auf einem Friedhof befindet. Beisetzungen im Meer, in Flüssen oder auf privaten Gartengrundstücken kommen als mögliche Alternativen in Frage.

6 Weber (1976: 1) spricht in diesem Zusammenhang vom »subjektiven Sinn«, den man unter bestimmten Voraussetzungen durchaus »deutend verstehen « könne, der jedoch, gemäß der kritischen Erweiterung von Alfred Schütz, "selbst bei einem Optimum adäquater Deutung [...] niemals zur Deckung gebracht werden kann«. Ein subjektiv gemeinter Sinn ließe sich demgemäß immer nur mit dem eigenen, nicht aber mit dem fremden Handeln verbinden; für Letzteres beansprucht Schütz die Bezeichnung »objektiver Sinn«, der sich auf intersubjektiv geteilten Deutungsschemata gründet (Schütz 1974: 42).

7 Dem Soziologen geht es hier im Grunde nicht besser als dem Alltagsakteur - mit dem Unterschied, dass Letztgenannter das Problem des Fremdverstehens dadurch ’löst‘, dass er die Divergenz zwischen Fremd- und Selbstverstehen üblicherweise erst gar nicht problematisiert.

8 Nun könnte man das Problem des Fremdverstehens natürlich insoweit umgehen, als man ihm das Selbstverstehen vorzieht und seine eigenen Trauererlebnisse, sofern man über solche verfügt, zum Gegenstand des Forschungsinteresses macht (siehe exemplarisch die autoethnografischen Arbeiten von Brennan 2017 und Ellis 1995). Obschon die Subjektivität des Forschenden, wie später zu zeigen sein wird, ein ständiger Gefährte seiner wissenschaftlichen Tätigkeit ist und als »produktives Erkenntnisfenster« (Breuer 2003: unpag.) durchaus von Gewinn sein kann, wird die 
Wenn man, um weiterhin beim Friedhofssetting zu bleiben, ein Artefakt als Grabkerze identifiziert hat und konstatiert, dass diese von jemandem auf einer als Begräbnisfeld bezeichneten Fläche abgestellt wurde, hat man dann »tatsächlich verstanden, welchen Sinn dieser Handlungsablauf für den so Handelnden hat" (Schütz 1974: 36)? Die Fahndung nach einem dominanten Sinnmotiv erscheint wenig aussichtsreich, vergegenwärtigt man sich die unüberblickbare Vielfalt möglicher Varianten: etwa das Aufrechterhalten einer parasozialen Beziehung zum Verstorbenen, dem man mit dieser `Gabe` etwas Gutes tun will (Dürr 2018); der vielleicht nicht einmal bewusst greifbare Versuch, bei sich selbst eine heilsame Wirkung zu erzielen; die strategische Kennzeichnung einer ansonsten nicht genau lokalisierbaren Beisetzungsstelle;' die routinierte Umsetzung einer in regelmäßigen Intervallen wiederkehrenden Tradition - oder schlichtweg die Erfüllung normativer Erwartungen, um soziale Sanktionen zu vermeiden (vgl. Benkel 2017b: 279f.). Mit letztgenannter Lesart sei nahegelegt, dass trauernde Menschen nicht lediglich aus einem kulturunabhängigen sinneren Bedürfnis` heraus handeln, sondern immerzu vor dem Hintergrund einer spezifischen Trauersozialisation. Sie verfügen also über ein gesellschaftlich vermitteltes Wissen darüber, wie soziale Beziehungen symbolisch zu been-

Autoethnografie - die das Forscherselbst nicht nur mitberücksichtigt, sondern voll und ganz ins Zentrum der Untersuchung rückt - von einigen Komplikationen begleitet. Neben der Gefahr des Verlustes an kritischer Distanz und einem potenziellen Mangel an intersubjektiver Nachvollziehbarkeit von Forschungserkenntnissen steht u.a. das Problem der Externalisierbarkeit und Explizierbarkeit. Zwar mag der Autoethnograf mit den eigenen Motivlagen vertrauter sein als mit fremden, seine persönliche Gedankenwelt, und dazu gehört eben auch die Erlebnissphäre der Trauer, lässt sich indes weder vollends entschlüsseln - manche Handlungen erscheinen im Nachhinein bestenfalls plausibel, sie sind aber nicht immer auf bewusste Motive rückführbar -, noch kann sie bruchlos in die übersubjektive Wirklichkeit übertragen werden, ohne dass es dabei zu einer sSinnverschiebung, kommt. Letzteres ist wiederum ein grundsätzliches Problem empirischer Sozialforschung, denn nicht nur man selbst, sondern auch die beforschten Anderen bauen bei der Übersetzung von innerem Erleben in äußerliches Tun, etwa beim Verbalisieren einer prä-verbalen Empfindung, unbeabsichtigte Einflüsse und andere Verzerrungen ein. Ausführliche Auseinandersetzungen mit dem Für und Wider von Autoethnografien finden sich bei Ploder/Stadelbauer 2016.

9 Gemeint ist das auffallend häufig zu beobachtende Phänomen, dass Hinterbliebene Blumen, Tannenzweige, Kerzen und andere Gegenstände - wider dem ausdrücklichen Verbot - auf einem anonymen Bestattungsfeld platzieren und damit dem zunächst sspurlosen` Grab eine materielle Spur geben. Persönliche Aneignungsansprüche werden in diesem Zusammenhang offensichtlich höher bewertet als die Ordnungsinteressen der Friedhofsbetreiber; auch hier waltet eine Autonomie der Trauer. 
den sind. Auf dem Friedhof, und prinzipiell auch an anderen öffentlich zugänglichen Orten, gilt dies umso mehr, denn was hier geschieht, geschieht nicht selten in dem Bewusstsein, dass die erzielten Handlungsergebnisse auch von anderen beobachtet oder bezeugt werden können (und mitunter sogar: sollen!) - derweil man selber nur bedingt steuern kann, wer zu diesen anderen gehört und wer nicht. ${ }^{10}$

Unter derartigen Vorzeichen schleicht sich der Gedanke ein, dass so manches sorgsam gepflegte Grab weniger über faktische Trauerempfindungen verrät als über sozial erworbene Vorstellungen davon, wie spflichtbewusst « man Trauer an einer Ruhestätte zum Ausdruck bringt. ${ }^{11}$ Die Annahme, der betriebene Pflegeaufwand sei ein verlässlicher Trauerindikator ruft berechtigte Zweifel hervor - und wie sollte man wiederum solche Grabformen einstufen, die von vornherein wenig oder überhaupt keine sInstandhaltung erfordern? Unser Datenmaterial gibt jedenfalls aufschlussreiche Hinweise darüber, dass viele Menschen zwischen Grabpflege und Trauerbewältigung ausdrücklich unterscheiden und den Grabbesuch u.a. wegen des so empfundenen Pflichtcharakters problematisieren.

Generell stellt sich die Frage nach den eigentlichen Rezipienten einer bestimmten Grabanordnung. Auch die intimsten Botschaften an einen Verstorbenen unterliegen häufig der (potenziellen) Beobachtbarkeit durch Dritte. Die Ambivalenz aus Privatheit und Öffentlichkeit wird insbesondere dann evident, wenn bestimmte Texte in Stein graviert oder etwas ausführlicher auf einer Postkarte bzw. einem Brief niedergeschrieben und so drapiert werden, dass sie sich als Kommunikationsofferte an vorbeigehen-

10 Siehe hierzu den sogenannten Hawthorne-Effekt (Roethlisberger/Dickson 1964). Er steht für die sozialwissenschaftliche Einsicht, wonach Menschen, die davon ausgehen, dass sie beobachtet werden, dazu tendieren, sich anders zu verhalten als in einer Situation, in der sie sich unbeobachtet wähnen. Während sich der Hawthorne-Effekt originär auf die unmittelbare Beobachtung bezieht - im Zuge der ihm zugrunde liegenden Experimente in den 1920er und 1930er Jahren erhöhte sich die Leistung von Fabrikarbeitern, sobald sie ihre Tätigkeiten im Beisein von Zuschauern ausführten -, erfolgt die Beobachtung von Trauer im öffentlichen Raum häufig nicht unter der Bedingung gleichzeitiger Anwesenheit. Man denke z.B. an $A$, der einen niedergelegten Blumenstrauß an einer Grabstätte erblickt, derweil $B$ als Urheber jenes Arrangements den Schauplatz längst verlassen hat.

11 Eine Anekdote aus der Feldforschung vermag dies zu illustrieren: Einmal hielt uns eine ältere Dame offenbar für Mitarbeiter der Friedhofsverwaltung, weshalb sie uns mit empörter Stimme auf den Zustand des Nachbargrabs hinwies und um >offizielle< Intervention bat. Dort war ein Strauch gewachsen, dessen Blätter mittlerweile auf die Ruhestätte ihres Gatten fielen. 
de Friedhofsbesucher begreifen lassen. ${ }^{12}$ Entgegen ihrer Semantik ist der tatsächliche Adressat dieser Zeilen nicht der Tote, sondern der lebendige ominöse Andere, der diesen Ort vielleicht morgen, vielleicht irgendwann später betritt.

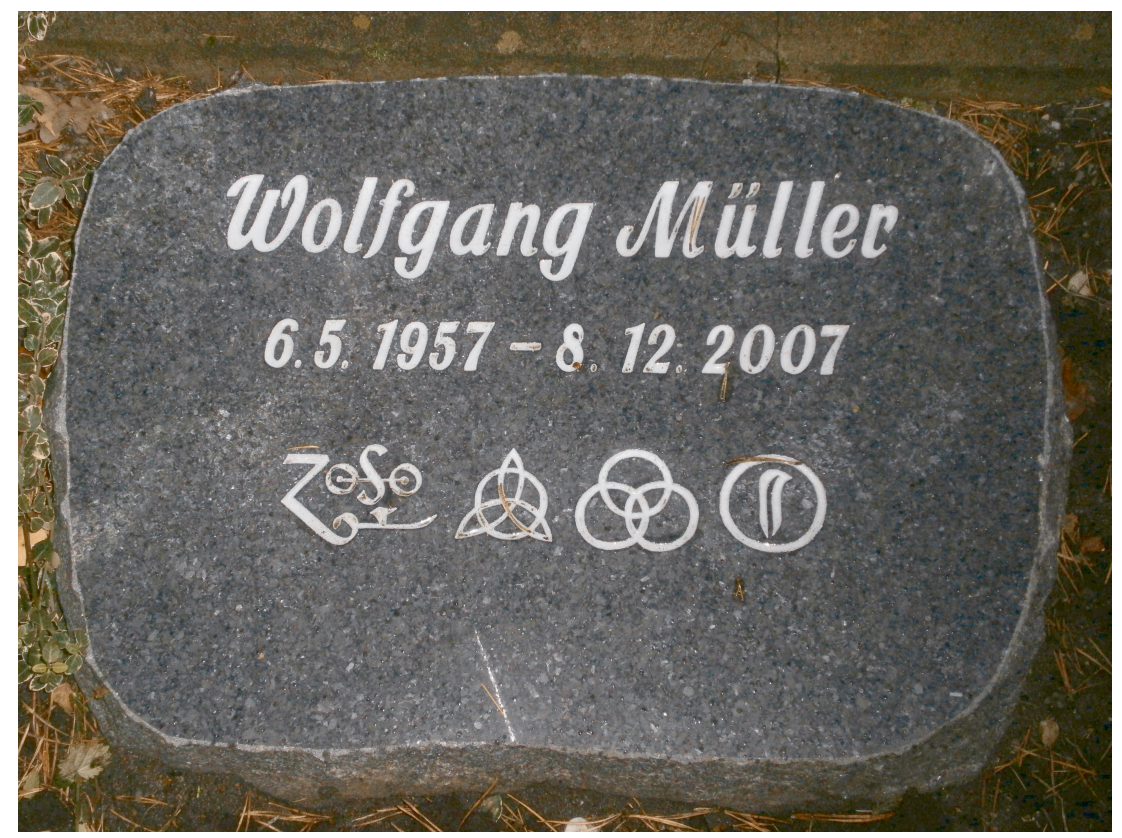

Doch nicht alle Handlungen, die an einem öffentlichen Begräbnisort vollzogen werden, sollen dauerhafte und für jedermann gut sichtbare Spuren hinterlassen. Manche der gerade erwähnten Schriftstücke befinden sich in einem verschlossenen Umschlag oder werden in einem (mal provisorisch gebastelten, mal fachmännisch produzierten) Briefkasten an der Ruhestätte eingeworfen. Das ändert nichts an der symbolischen Adressierbarkeit des Verstorbenen, indes werden fremde Einsichtnahmen somit gezielt sus-

12 An einer Grabstätte erblickten wir einen gut sichtbaren und gegen Witterungseinflüsse geschützten Brief, auf dem jemand eine emotionale, geradezu pathetische Nachricht für seine verstorbene "Geliebte und beste Freundin« hinterlassen hat. Mehrmalige Besuche dieses Friedhofs ließen uns erkennen, dass der Brief in regelmäßigen Abständen durch ein neues Exemplar mit jeweils anderem Text ausgetauscht wird. In mehrerlei Hinsicht wird das Grab hier als Kommunikationsort ernst genommen. 
pendiert. Auf diese Weise wird am Grab etwas gezeigt, ohne zu viel zu zeigen. Das gilt ebenso für die in letzter Zeit registrierbare Tendenz zur Verrätselung des Grabtextes. Trotzdem oder gerade weil es im Bewusstsein der Beobachtbarkeit geschieht, wählen Hinterbliebene eine Grabgestaltung, die zwar alle sehen, aber eben nur ein paar wenige Eingeweihte verstehen können. Der Beobachtbarkeit gänzlich entzogen sind wiederum all jene Dinge, die nicht etwa auf der Graboberfläche platziert werden, sondern die gemeinsam mit Sarg/Urne während der Beisetzung (oder erst einige Zeit danach) unter der Erde verschwinden.

Die Liste der mutmaßlichen Handlungsmotive ließe sich noch lange weiterführen. Auch wenn dabei das direkte oder indirekte Beobachtet-Werden durch andere nicht immer die entscheidende Rolle spielt, bleibt an dieser Stelle festzuhalten, dass die Annahme eines rauthentischen subjektiven Trauerkerns, der sich von seinem kulturellen Überbau isolieren lässt, eine populäre alltagsweltliche Vorstellung darstellt - die allerdings ausblendet, dass die Keimzelle von Trauer nicht im individuellen Bewusstsein zu suchen ist, sondern in der Gesellschaft, die dieses Bewusstsein geprägt hat. Für Soziologen ist das unproblematisch, weil es ihnen, wie betont, ohnehin nicht um die Binnenperspektive von Einzelakteuren geht, sondern um überindividuelle Muster, Praktiken und Deutungsrahmen.

\section{Trauern beobachten}

Trauerhandlungen lassen sich freilich nicht bloß aus der Distanz über die Betrachtung von Artefakt, Materialität und Raumarrangement verstehend rekonstruieren. Sie können durchaus unmittelbar und in Echtzeit< beobachtet werden. Möchte man wissen, wie der Verlust einer Sozialbeziehung gesellschaftlich verhandelt wird - was liegt dann näher, als Menschen beim Trauern süber die Schulter zu schauen<? Die »Beobachtung natürlicher Interaktionen " (Przyborski/Wohlrab-Sahr 2014: 7) ist ein in der empirischen Sozialforschung häufig angewandtes, bisweilen sogar alternativloses Mittel, um Einsichten in einen bestimmten Ausschnitt sozialer Wirklichkeit zu gewinnen. ${ }^{13}$ Handelt es sich bei diesem Ausschnitt um »Sinnwelten des Trauerns" (Schützeichel 2017), so trifft man allerdings auf eine forschungs-

13 Die Bezeichnung solcher Interaktionen als »natürlich« ist keineswegs wörtlich zu nehmen und insofern problematisch, als sie den Verdacht erweckt, es gäbe Interaktionen, die allein von der Natur gegeben und vor-sozial, d.h. frei von soziokulturellen Implikationen sind. Stattdessen ist »natürlich» hier im Sinne einer Abgrenzung zu Interaktionen in sogenannten Laborsituationen zu verstehen, wo 
praktische Hürde. Diese äußert sich nicht etwa in einem Mangel an potenziellen Gelegenheiten; insbesondere auf großstädtischen Friedhöfen finden fast täglich mehrere Beisetzungen statt, ferner bestehen durchaus Chancen, irgendwo auf dem Gräberfeld Besuchern zu begegnen. Nicht um die empirische Häufigkeit beobachtbarer Trauerhandlungen geht es also, sondern um die in solchen Kontexten zumeist entstehende Notwendigkeit, seine Präsenz zu legitimieren - zumindest dann, wenn man das Geschehen nicht aus der Ferne, sondern aus nächster Nähe verfolgen möchte.

Obschon an einem öffentlichen Ort, gilt beispielsweise die Partizipation an einer Trauerfeier (der Verlust liegt für gewöhnlich erst wenige Tage zurück) oder der Besuch einer Grabstätte in der Regel als private Angelegenheit, die nur wenige Eingeweihte kennt und nur in diesem intimen Kreis als legitimer Handlungsbereich verstanden werden soll. Wie viel Engagement und Auskunftsfreude darf man von seinem Gegenüber erwarten, unterrichtet man es in solchen Situationen von seinen Forschungsinteressen, bittet man es, zu seiner gegenwärtigen Befindlichkeit und zu seinen Handlungsmotiven Rede und Antwort zu stehen - optimalerweise während zugleich Diktiergerät und/oder Videokamera eingeschaltet sind? Es dürfte jedenfalls nicht allzu sehr verwundern, wenn diese und ähnliche Absichten (dazu zählt schon das bloße `Dabeisein`, ohne ein Gespräch zu beginnen) als illegitimes Eindringen in die eigene Intimsphäre empfunden werden und entsprechende Anschlusskommunikationen (oder vielmehr: Ausschlusskommunikationen) nach sich ziehen.

Der geschilderten Problematik lässt sich in mehrerlei Hinsicht entgegentreten. So könnte man sich beispielsweise damit begnügen, das Geschehen nicht shautnah', sondern mit etwas Sicherheitsabstand zu begutachten. >Unauffällig ‘ auf einer Bank zu sitzen, während ein paar Gräberreihen weiter jemand an einer Ruhestätte tätig ist, bedarf wohl keiner weiteren Legitimation; die Kopräsenz anderer ist in diesem Setting alles andere als untypisch und das absichtsvolle Unterlassen direkter Interaktion mit dem ortsspezifischen Normkanon durchaus kompatibel. ${ }^{14}$ Dass die vermeintlich zufällige Präsenz des Beobachters und dessen vermeintlich ungerichte-

Probanden sich in einem Setting fernab ihrer gewohnten alltäglichen Lebenswelt wiederfinden, darum auf andere Wissensbestände zurückgreifen müssen und sich gemeinhin anders verhalten.

14 Weniger leicht zu beantworten ist hingegen die Frage, in welcher genauen Distanz sich die beiden Akteure - der, der an diesem Ort etwas Forschungsrelevantes tut, und der, der es zu erfassen versucht - mindestens befinden müssen, damit der Observationsvorgang als gerade noch bzw. als nicht mehr legitimierungsbedürftig zu verbuchen wäre. 
te Aufmerksamkeit in Wahrheit methodisch kontrollierten Bedingungen, der Einhaltung wissenschaftlicher Standards und einer gewissen Systematik unterliegen (Festlegung eines Beobachtungsfokus und -zeitraums, Anfertigung von Feldnotizen und dergleichen), ist son außen se nicht ersichtlich. Und wenn es also keiner Legitimation der eigenen Anwesenheit bedürfte, bräuchte die Zielpersonen dann überhaupt über das feine Detail in Kenntnis gesetzt zu werden, dass sie in diesem Augenblick unwissentlich Teilnehmer einer Studie ist? ${ }^{15}$

Die Transparenznotwendigkeit der eigenen Forschungsabsichten kann selbst dann infrage gestellt werden, wenn man sich eben doch in unmittelbare Nähe zu seinen >Untersuchungssubjekten $<$ begibt und etwaige daraus resultierende Legitimierungserfordernisse in Kauf nimmt. Nehmen wir das Beispiel einer Trauerfeier in der Friedhofskapelle: Je nach Größe und Zusammensetzung des Teilnehmerfeldes könnte man etwa die Rolle eines Trauergastes einnehmen und - für den wohl unwahrscheinlichen Fall, dass jemand nachfragt - ein bestimmtes Beziehungsverhältnis vorgeben, das man zum Verstorbenen hatte. Die einzige Person, die diese improvisierte Nähe sofort hätte zum Einsturz bringen können, ist ihrer physischen >Gegenwärtigkeit‘ zum Trotz aus nachvollziehbaren Gründen nicht mehr in der Lage dazu.

Vermutlich mag diese Lösung den einen oder anderen Leser nicht so recht überzeugen, ihn vielleicht sogar irritieren ${ }^{16}$ und so manchen Einwand provozieren. Angesprochen ist damit ein grundlegender Diskurs darüber, wie weit Wissenschaft beim Datensammeln gehen darf, welche Mittel dabei als (il)legitim gelten ${ }^{17}$ und inwiefern den Zielpersonen prinzipiell auch ein »Recht auf Nicht-Erforscht- Werden« (Kaschuba 1999: 207) einzuräumen ist. Tatsächlich ist die verdeckte Beobachtung in der scientific community nicht unumstritten. Kritiker halten das Verfahren, vorsichtig for-

15 Für den ungefährdeten Auftritt eines sogenannten verdeckten Beobachters bedarf es ggf. einer je nach Untersuchungsfeld mal mehr und mal weniger ausgefeilten Cover-Story; manchmal ist sie aber auch gar nicht erforderlich - etwa dann, wenn man aufgrund der Beschaffenheit des Feldes eine legitime Rolle zugeschrieben bekommt, ohne aktiv mehr zu leisten, als vor Ort präsent zu sein (siehe hierzu etwa die ethnografischen Arbeiten zur Sozialstruktur des Frankfurter Bahnhofsviertels bei Benkel 2010 und Meitzler 2010).

16 Was wäre wiederum, um den Gedanken noch weiter zuzuspitzen, wenn eine legitimierende Cover-Story deshalb obsolet wäre, weil man von dem Todesfall tatsächlich lebensweltlich betroffen ist und als Angehöriger im Trauerfeierkontext privates Schicksal mit beruflichen Interessen verbindet?

17 Auf der Meta-Ebene ließe sich die Frage stellen, ob diese (Il-)Legitimitätsbehauptungen ihrerseits legitim oder illegitim sind. 
muliert, für forschungsethisch fragwürdig, weil Menschen die Probandenrolle schlichtweg zugemutet werde, anstatt sie im Vorfeld über die wissenschaftlichen Intentionen aufzuklären und sie um Einverständnis zu bitten. »Unter einem Vorwand Eingang ins Feld zu nehmen, ohne sich als Forscher auszuweisen und aus einer so erlangten Mitgliedsrolle heraus quasi 'geheim< Beobachtungen anzustellen, ruft daher nicht selten Empörung hervor." (Dellwing/Prus 2012: 126) Fürsprecher der Methode betonen hingegen, dass ihr Mehrwert ja gerade in der Chance liegt, authentische Einblicke in ein Feld zu gewinnen, welches sich andernfalls gegenüber neugierigen Beobachtern entweder vollständig verschließt oder wenigstens eine erhebliche Verzerrung der Beobachtungsergebnisse bewirkt. Wie snatürlich ist die zu beobachtende snatürliche Interaktion< noch, wenn die Beobachteten von ihrem Beobachtet-Werden wissen? Wie ist in dieser Hinsicht mit Feldern umzugehen, für die die Exklusion sfremder Akteure ein charakteristisches Merkmal ist (was zumindest partiell auch auf Trauer zutrifft)? Und kann/darf/muss eine wissenschaftliche Disziplin, deren Anspruch es ist, soziale Wirklichkeit zu ergründen, zu verstehen und zu erklären, es sich erlauben, vor solchen Hürden haltzumachen?

Die Frage nach der Notwendigkeit und Legitimität der Verdeckung lässt sich schwerlich mit Absolutismen und Generalklauseln beantworten; vielmehr tut eine differenzierte Betrachtung Not. Zurecht machen Lofland und Lofland (1984: 21) darauf aufmerksam, dass verdeckte Forschung hinsichtlich ihrer Ausgangsbedingungen (Untersuchungsgegenstand, Position des Forschenden im Feld, Existenz alternativer Zugangswege usw.) in verschiedene Formen zu unterscheiden ist, deren Einsatz bzw. Verzicht, so wiederum Dellwing und Prus (2012: 126), »eine praktische, keine prinzipielle Frage« darstellt.

So unterschiedlich die Haltungen ausfallen mögen, so unabgeschlossen bleibt der Diskurs. Wie die Entwicklung der empirischen, insbesondere der qualitativen Sozialforschung in den zurückliegenden Dekaden zeigt, waren die Grenzen des ethisch Vertretbaren ohnehin nie festzementiert, sondern immer nur das vorläufige Resultat von Aushandlungen (Friedrichs 1973). Vor diesem Hintergrund besteht wenig Zweifel daran, dass sie sich auch künftig in die eine oder in die andere Richtung verschieben werden schon deshalb, weil nicht nur Gesellschaft permanent im Wandel ist, sondern mit ihr auch die Auffassungen darüber, wie Gesellschaftsbeobachtung idealerweise zu betreiben ist. Ohne allzu tief in die hier nur an der Oberfläche gestreifte Debatte einsteigen zu wollen, sei angemerkt, dass im vorliegenden Forschungszusammenhang eine Unerlässlichkeit verdeckter Beobachtung (aufgrund anderer, aussichtsreicherer empirischer Zugänge) nicht bestand. 


\section{Internetgestützte Datenerhebung}

Ergänzend zu dem Datenmaterial, welches im Zuge früherer Projekte gewonnen wurde, und um nicht in die Verlegenheit $\mathrm{zu}$ geraten, potenzielle Probanden an Ort und Stelle (etwa auf dem Friedhof) mit dem Forschungsanliegen ad hoc konfrontieren zu müssen (siehe aber Schmied 2002), haben wir den zentralen Zugang darin gesucht, die Studie in einem öffentlichen Aufruf vorzustellen und um die (anonyme) Teilnahme an einer mündlichen oder schriftlichen Befragung zu bitten. Auf diese Weise ist es uns gelungen, eine umfassende Online-Umfrage sowie zahlreiche leitfadengestützte, narrative Interviews durchzuführen.

Zunächst einige Worte zur internetbasierten Befragung. Sie richtete sich an Menschen, die in ihrem Leben bereits (mindestens) einmal die Erfahrung des Verlustes eines Menschen im engen persönlichen Umfeld gemacht haben. Neben der Abfrage soziodemografischer Daten (Geburtsjahr, Familienstand, Konfession, höchster Bildungsabschluss, momentan ausgeübter Beruf, Geburtsort usw.) bildete die Umfrage eine Mixtur aus offenen und geschlossenen Frageformulierungen. Während die Teilnehmenden bei den offenen Fragen ihre Antworten in ein freies Feld eingeben konnten, galt es bei den geschlossenen Fragen zwischen verschiedenen Antwortmöglichkeiten zu wählen und Zutreffendes anzuklicken. Konkret wurden einige Aussagen vorgelegt, zu denen sich die Probanden positionieren sollten, indem sie anhand einer sogenannten Likert-Skala auswählen, wie sehr sie der Behauptung jeweils zustimmen (fünfstufig: >trifft überhaupt nicht $\mathrm{zu}</>$ trifft eher nicht $\mathrm{zu} / />$ unentschieden//strifft eher $\mathrm{zu}</$ strifft voll zu<). Um etwaige Antwortverzerrungen zu minimieren, wurden die Teilnehmer in den einleitenden Fragebogeninstruktionen darum gebeten, möglichst spontan und gemäß ihrer aktuellen persönlichen Einstellung zu antworten. Sollte die Person eine bestimmte Frage nicht beantworten können oder wollen, konnte sie diese problemlos überspringen; dazu riefen die Instruktionen explizit auf. Inhaltlich befasste sich der Fragebogen mit persönlichen Erfahrungen im Umgang mit Trauer, mit der Bedeutung von Traditionen, Konventionen, Symbolen, Orten und Ritualen sowie dem Stellenwert des toten Körpers für Trauer und Erinnerung. Die Umfrage war von Oktober 2017 bis Dezember 2018 freigeschaltet; die daraus gewonnen Rohdaten wurden anschließend aufbereitet und statistisch ausgewertet.

Bei der Online-Befragung handelt es sich um ein vergleichsweise neues Mittel zur Datengewinnung, von dem in den letzten Jahren zunehmend Gebrauch gemacht wird. An dieser Entwicklung wird einmal mehr deutlich, wie sehr die Möglichkeiten moderner Internetkommunikation neben 
sämtlichen Bereichen der alltäglichen Lebensführung auch die Forschungspraxis verändern. Insbesondere der pragmatische Mehrwert gegenüber analogen Befragungsinstrumenten macht nachvollziehbar, weshalb mittlerweile die meisten Erhebungen online durchgeführt werden (vgl. Wagner/Hering 2014: 661). Entsprechende Vorzüge waren auch für unsere Studie nutzbar: Ohne zusätzlichen finanziellen Aufwand konnte in vergleichsweise kurzer Zeit eine hohe Teilnehmerzahl (insgesamt über 900 Personen) erreicht und ein entsprechend großer Datenkorpus generiert werden. Aufgrund der mehrheitlich geschlossen formulierten Fragen und dank spezifischer Software (SPSS) ließ sich die Datenmenge zügig auswerten. ${ }^{18}$

Statt im Vorfeld jeden einzelnen (potenziellen) Teilnehmenden direkt und persönlich kontaktieren zu müssen, wurde der Aufruf samt UmfrageLink über öffentliche Internet-Portale (z.B. Social Media), über E-Mailverteiler oder in Print-Magazinen (z.B. Mitgliedszeitschriften von strauerbezogenen< Berufsverbänden) verbreitet. Die Rezipienten konnten daraufhin selbstständig entscheiden, ob, wann und wo sie den Fragebogen beantworten. Gerade die Ortsunabhängigkeit erwies sich als entscheidender Vorteil. Würde es bei der telefonischen, persönlichen oder postalischen Befragung eine logistische und nicht zuletzt eine finanzielle Herausforderung bedeuten (wenn sich die Kontaktperson zum Zeitpunkt der Teilnahme im Ausland befindet), lässt sich konstatieren, dass »online methods mitigate the distance of space (zit. nach Misoch 2015: 180). Ein Online-Fragebogen kann - unter der Voraussetzung eines Internetzugangs - prinzipiell an jedem Ort der Welt (und noch dazu zeitgleich von mehreren verschiedenen Teilnehmern) aufgerufen und ausgefüllt werden. Die gesamte Umfrage ließ sich in etwa 15 Minuten bearbeiten. Ein freies Textfeld am Ende gab den Teilnehmenden die Gelegenheit, ein Feedback zu hinterlassen sowie Aspekte zu thematisieren, die ihnen in diesem Zusammenhang wichtig erscheinen und bislang unerwähnt geblieben sind.

Von methodischer Relevanz ist überdies der Faktor Anonymität. Den Probanden blieb einerseits die freie Entscheidung, welche Informationen sie über sich preisgeben möchten und welche nicht, andererseits ließen die abgefragten Daten keine näheren Rückschlüsse auf die Identität zu. Daten, die das Gebot der Anonymität unterlaufen würden (z.B. Name oder Adresse) wurden nicht erhoben - sie wären für das Erkenntnisinteresse unserer

18 Die vorgelegten Fragen sind in ihrer Wortwahl, Reihenfolge und Vollständigkeit von einem Probanden zum nächsten identisch, weshalb sich die jeweiligen Antworten relativ unkompliziert miteinander vergleichen lassen. 
Studie ohnehin nicht von Belang gewesen. ${ }^{19}$ Anonymität war andererseits auch für das Erhebungssetting als solches garantiert. Ist die (un-)mittelbare Präsenz des Wissenschaftlers in anderen Forschungszusammenhängen (z.B. Interview, nicht-videogestützte Beobachtung, Artefaktanalyse usw.) notwendige Voraussetzung, so erfolgt die Beantwortung des Online-Fragebogens nicht nur zu jeder beliebigen Zeit und an jedem beliebigen Ort, sondern überdies ohne die Gegenwart des Forschenden, also unter Ausschluss einer weiteren Störvariable. Für die Qualität der Daten ist das ein wichtiger Aspekt, weil hierdurch der soziale Druck, dem sich der Befragte ansonsten ausgesetzt fühlen könnte, minimiert wird. Die Annahme, dass niemand nicht einmal die verantwortlichen Wissenschaftler - die zur Verfügung gestellten Daten auf die eigene Person wird zurückverfolgen können, führt, so das forschungsstrategische Kalkül, tendenziell zu ehrlicheren Antworten. ${ }^{20}$

Von einer lupenreinen Non-Reaktivität, wie etwa bei der verdeckten Beobachtung oder der Untersuchung eines Grabartefakts, kann in diesem Fall trotzdem nicht gesprochen werden. Zwar werden die Umfrageteilnehmer durch den Vorgang der wissenschaftlichen Beobachtung nicht direkt beeinflusst - eben weil im Moment der Bearbeitung kein Wissenschaftler anwesend ist, die Probanden anonym bleiben und ihre Auskünfte erst zu einem späteren Zeitpunkt von den Forschenden rezipiert werden -, wohl aber auf indirektem Wege. Ein Rest an Reaktivität bleibt nämlich insofern, als sich die Beforschten gewissermaßen in einer künstlichen Situation befinden. Künstlich ist die Situation deshalb, weil Menschen nicht etwa beim Vollzug ihrer Alltagspraxis (unwissentlich) beobachtet werden, sondern sich ihrer gegenwärtigen Rolle als Teilnehmende einer Studie bewusst sind. Ohne die Verwertungslogik genau zu durchschauen, haben sie doch zumindest eine vage Vorstellung davon, dass sie mit ihren eingegebe-

19 Wer hingegen daran interessiert war, an einem weiterführenden Telefoninterview teilzunehmen, erhielt am Ende des Fragebogens die Gelegenheit, seine E-Mailadresse bzw. Telefonnummer zur späteren Kontaktaufnahme zu hinterlegen. Selbstverständlich waren diese Angaben freiwillig und die überlieferten Daten wurden über den Gebrauch zum Interviewzweck hinaus nicht gespeichert.

20 Die Bedingungen, unter denen der jeweilige Forschungsteilnehmer den Fragebogen bearbeitet, lassen sich natürlich nicht vollends kontrollieren. Ist er in einer ungestörten und entspannten Situation? Ist er alleine oder sitzen weitere Personen neben ihm vor dem Bildschirm, die das Antwortverhalten beeinflussen könnten? Ist der Proband in Eile und kann die einzelnen Fragen deshalb nur süberfliegen ? Nimmt er sich Zeit für ausführliche Antworten? Oder nimmt er sich szu viek Zeit, indem er bei jeder Frage solange hin und her überlegt, bis er die >beste` Antwort gefunden hat? 
nen Antworten wissenschaftliche Daten liefern, mit denen sirgendwas gemacht wird.

Auch wenn die Forscher nicht in unmittelbaren Kontakt zu den Befragten treten, werden Letztere über das Medium der Online-Umfrage adressiert und reagieren ihrerseits darauf. Ihre Antworten dürfen dabei keineswegs als exaktes, ungefiltertes Duplikat ihrer persönlichen Einstellungen (miss-)verstanden werden. Vielmehr gilt es zu bedenken, dass die Art und Weise, in der die Fragen formuliert sind, und die Reihenfolge, in der sie gestellt werden, einen nicht zu unterschätzenden Einfluss auf das Antwortverhalten der Teilnehmenden haben können. Hinzu kommt, dass die Fragen bei einigen Probanden womöglich Reflexionsprozesse überhaupt erst freisetzen, sodass nicht von einer direkten Einstellungsabbildung die Rede sein kann, sondern von einer situationsgebunden oder eben von einer übermäßig `kalkulierten Antwort ausgegangen werden muss.

Um diesbezügliche Verzerrungen zu vermeiden, ist bei der Konstruktion eines Fragebogens, gleich ob digital oder analog, die Wortwahl und die Anordnung der Fragen genau zu bedenken. Eine Frage kann nicht nur eine bestimmte Antwort provozieren, wenn sie entsprechend formuliert ist (gemeint sind Suggestivfragen), sie kann darüber hinaus aufgrund ihrer konkreten Position im Fragebogen auch die Beantwortung der darauffolgenden Fragen beeinflussen. Üblicherweise werden vor dem endgültigen Einsatz eines Fragebogens sogenannte Pre-Tests durchgeführt: Bevor die eigentliche Untersuchung beginnt, wird der Fragebogen in überschaubarer Anzahl einigen Testpersonen vorgelegt (in unserem Fall waren es Studierende und Projektmitarbeiterinnen), die ihn ausfüllen und hinsichtlich einiger zentraler Gütekriterien bewerten (z.B. Verständlichkeit der Instruktionen, >Beantwortbarkeit` der Fragen, Genauigkeit der Formulierungen, etwaige Redundanzen etc.). Aus den Rückmeldungen können die Forschenden Schlussfolgerungen über die aktuelle Fragebogenqualität ziehen, ggf. Mängel identifizieren und eliminieren (vgl. Diaz-Bone 2015: 322). Je nachdem, wie zufriedenstellend der Pre-Test ausfällt, kann dieser nach Überarbeitung des Fragebogens wiederholt (vgl. Diekmann 2000: 415f.), oder es kann mit der eigentlichen Untersuchung begonnen werden.

Aus den Vorteilen einer Datenerhebung über schriftliche Online-Umfragen ergeben sich zugleich Nachteile. Weil das Vorhandensein eines Internetanschlusses notwendige Bedingung für die Teilnahme ist, wird eine gewisse - obschon stetig kleiner werdende - Population von vorn herein ausgeschlossen. Betroffen sind insbesondere die über 70-jährigen, von denen mutmaßlich jeder über Trauererfahrungen, aber gegenwärtig nur jeder Dritte über einen Zugang zum World Wide Web verfügt (vgl. Wagner/ Hering 2014: 664). Eine weitere, wohl noch gravierendere Einschränkung 
besteht darin, dass, der hohen Fallzahl zum Trotz (oder gerade durch sie bedingt), der Aussagegehalt eines einzelnen Fragebogens recht überschaubar ausfällt, weil es sich in der Regel um sehr knappe Antworten handelt, die häufig nur aus einer Ankreuzung oder einigen wenigen Wörtern bestehen und somit kaum tiefergehende Einsichten in mögliche Gründe für bestimmte Haltungen und Handlungen zulassen.

Solche Fragebögen kommen für gewöhnlich in quantitativ angelegten Forschungsdesigns zum Einsatz, die mit größeren Datensätzen operieren, anhand derer Erkenntnisse über allgemeine Gesellschaftstrends gewonnen werden sollen. Da sich unsere Forschung durchaus auch für solche Trends (hier am Beispiel von Trauer) interessiert, stellte sich der Fragebogen als ein hilfreiches Erkenntnisinstrument heraus - wenn auch nicht als einziges. Das Sammeln und statistische Aufbereiten nummerischer Daten sollte nämlich nur den orientierungsgebenden Rahmen geben für die weiterführende Forschungsarbeit, die aufgrund ihres Erkenntnisinteresses ausdrücklich qualitative Ansprüche verfolgt. Im Fokus von qualitativer Sozialforschung stehen somit nicht gesellschaftliche Makrotrends; vielmehr sucht sie anhand von (nicht- bzw. teilstandardisierten) Einzelfalluntersuchungen nach detaillierten Informationen über jene Mechanismen und Sinnkonstruktionen, die sich hinter dem offensichtlichen Handeln der untersuchten Akteure verbergen. Mit einfachen Worten: Von Interesse ist nicht so sehr, dass jemand etwas tut/getan hat und wie viele Menschen etwas tun/ getan haben, sondern wie und warum jemand etwas tut/getan hat. ${ }^{21}$ Aus diesem Grund besitzt qualitative Forschung »das Potenzial, sehr tiefe Einblicke in subjektive Welten zu ermöglichen" (Misoch 2015: 223).

Um diesen Ambitionen gerecht werden zu können, war es unabdingbar, den Untersuchungssubjekten mehr kommunikativen Raum zu geben. Konkret sollten Personen gewonnen werden, die bereit sind, in einem Interview über ihren Umgang mit Trauer zu sprechen. Mit welchen Fallstricken, Herausforderungen und Erkenntnispotenzialen nicht nur die Akquise solcher Gesprächspartner, sondern auch die Durchführung von Interviews zu dieser Thematik verbunden waren, darum soll es im Folgenden gehen.

21 Obschon sich quantitative und qualitative Methoden in einigen Punkten erheblich unterscheiden, schließen sie in der Forschungspraxis nicht grundsätzlich einander aus. Im Sinne eines sogenannten Mixed Methods Designs können sie sogar innerhalb ein und derselben Studie miteinander kombiniert werden, sodass sich idealerweise die Schwächen der einen Methoden durch die Stärken der jeweils anderen kompensieren lassen. Dies gilt auch für die vorliegende Forschungsarbeit. 


\section{Besonderheiten des Feldzugangs}

Dass der Umgang mit dem Verlust eines nahestehenden Menschen bislang nur selten in den Blick empirischer Sozialforschung gerückt wurde und das hierzu vorhandene Datenmaterial entsprechend spärlich ausfällt, erscheint nicht zuletzt angesichts der skizzierten methodischen Hürden verständlich. Am Beispiel Trauer lässt sich geradezu paradigmatisch aufzeigen, dass die Qualität der wissenschaftlichen Beobachtbarkeit eines Sozialphänomens nicht zwingend mit der Häufigkeit seines faktischen Auftretens korrespondiert. Denn wäre es so, dann hätten Soziologen, die sich für Trauer interessieren, relativ leichtes Spiel - schließlich handelt es sich bei einem Todesfall im sozialen Nahraum um ein biografisches Ereignis, dessen Eintritt mit zunehmendem Lebensalter wahrscheinlicher wird und das meist nicht singulär bleibt.

Nach potenziellen Interviewpartnern, die wenigstens einmal in ihrem Leben entsprechende Erfahrungen gemacht haben, bräuchte man wohl nicht allzu lange suchen, eine Zufallsstichprobe in der Fußgängerzone würde genügen. Auf erste Sicht unterscheidet sich der von uns gewählte Forschungsgegenstand daher von dem solcher Studien, die sich ausdrücklich und ausschließlich für Menschen mit hochspezifischen bzw. selten auftretenden Merkmalen interessieren (z.B. Personen mit ungewöhnlichen sexuellen Präferenzen, Angehörige einer sexotischen Analphabeten in Deutschland, sogenannte SSuperreicher etc.) und die schon deshalb Schwierigkeiten haben, adäquate Probanden zu finden. In der empirischen Sozialforschung spricht man hierbei von speziellen Populationen (Schütte/Schmies 2014), deren unangenehme (oder reizvolle?) Eigenschaft darin besteht, dass sie schwer zugänglich und dass über ihre >Mitglieder (die sich oftmals gar nicht als solche verstehen) wenige gesicherte Erkenntnisse vorhanden sind.

Dass sich demgegenüber Menschen mit Trauerfahrungen nicht als spezielle Population begreifen lassen, macht den Feldzugang keineswegs leichter. Denn über Trauererfahrungen zu verfügen, ist die eine Sache - darüber mit einem Fremden offen zu sprechen, die andere. Die Erfolgsaussicht bei der Akquirierung von Interviewpartnern hängt somit nicht nur von der empirischen Häufigkeit und der biografischen Erwartbarkeit, sondern augenscheinlich von einigen weiteren Faktoren ab. Ausschlaggebend dürfte vor allem sein, welcher kulturellen Codierung der Forschungsgegenstand unterliegt. Gemeinhin ist der Tod einer geliebten Person ein besonders markantes Lebensereignis, ein Biografieeinschnitt (wie übrigens auch ein Biografiegenerator; Winkel 2008), der als prägend für die eigene Identität erlebt wird. Anders als andere ^lebensweltnahe< Themen (z.B. Modepräfe- 
renzen, Hobbys, Reiseziele, Berufserfahrungen usw.) gilt die persönliche Behandlung des Verlustes eines bedeutsamen Anderen als (hochgradig) intime Angelegenheit, deren Thematisierung sich als spontaner Einstieg in eine Small-Talk-Unterhaltung mit dem unbekannten Sitznachbarn im verspäteten ICE wenig eignet, sondern üblicherweise nur dem engeren sozialen Umfeld (Familie, Freunde, Partnerschaft) vorbehalten ist. Mit Menschen, die diesem nicht angehören, über Trauererlebnisse zu sprechen, ist im sozialen Alltag eine eher untypische Situation, sieht man einmal von (oft professionalisierten) Konstellationen wie Seelsorge, Psychotherapie oder Trauerbegleitung ab.

Mancher Zeitdiagnostiker vermag hierin ein Symptom für die Tabuisierung des Todes zu erkennen, die auf einen soziokulturellen Wandel zurückgeht und sich in mehreren Handlungsfeldern bemerkbar macht (dazu exemplarisch: Elias 1990). Im Kern besagt diese These, dass in der modernen Gesellschaft im Zuge von Pazifizierungs-, Technisierungs-, Professionalisierungs-, Institutionalisierungs- und Privatisierungsprozessen nicht nur weniger öffentlich gestorben wird, sondern dass auch das Reden über Tod und Trauer wesentlich zögerlicher, unsicherer, ja verschämter von statten geht als noch in früheren Tagen. Die Liste empirischer Belege, die hierfür gerne angeführt werden, ist lang und reicht von der Euphemisierung todesbezogener Inhalte in der Bestatterreklame (vgl. Berger/Lieban 1960: 227ff.) bis hin zu den gegenwärtig immer häufiger zu lesenden Hinweisen in Todesanzeigen, wonach »von Beileidsbekundungen am Grab abgesehen « werden soll - sofern die Beisetzung nicht sowieso schon »im engsten Kreis« und »in aller Stille« stattfindet oder stattgefunden hat. ${ }^{22}$

Auch wenn sich dem gewiss einiges entgegensetzen ließe und der Sachverhalt ohnehin komplexer sein dürfte, als sich hier darstellen lässt, besteht Grund zur Annahme, dass neugierige Soziologen auf der Suche nach auskunftswilligen Interviewpartnern in Sachen Trauer auf vielfache Zurückweisung stoßen werden. Motive sind beispielsweise das Unbehagen, sich mit einer Person (deren genaueren Absichten man nicht kennt, der man aber Verwertungsinteressen unterstellen darf) über solche intimen Dinge zu unterhalten; die Scham für bestimmte Empfindungen oder Handlungen in Verbindung mit dem Verlust sowie die Befürchtung, während des Interviews die Kontrolle über seine Emotionen zu verlieren; oder schlicht-

22 Der englische Anthropologe Geoffrey Gorer spricht in diesem Zusammenhang von der »Pornography of Death (Gorer 1955) und weist dem Lebensende als Gesprächsthema somit einen ähnlich marginalen Stellenwert zu wie der überdeutlichen Darstellung der Sexualität im viktorianischen Zeitalter. 
weg das generelle Widerstreben, in einem Gespräch, dessen Verlauf man schwer antizipieren kann, zu diesem Krisenerlebnis kognitiv zurückzukehren und dabei mit schmerzhaften Erinnerungen konfrontiert zu werden.

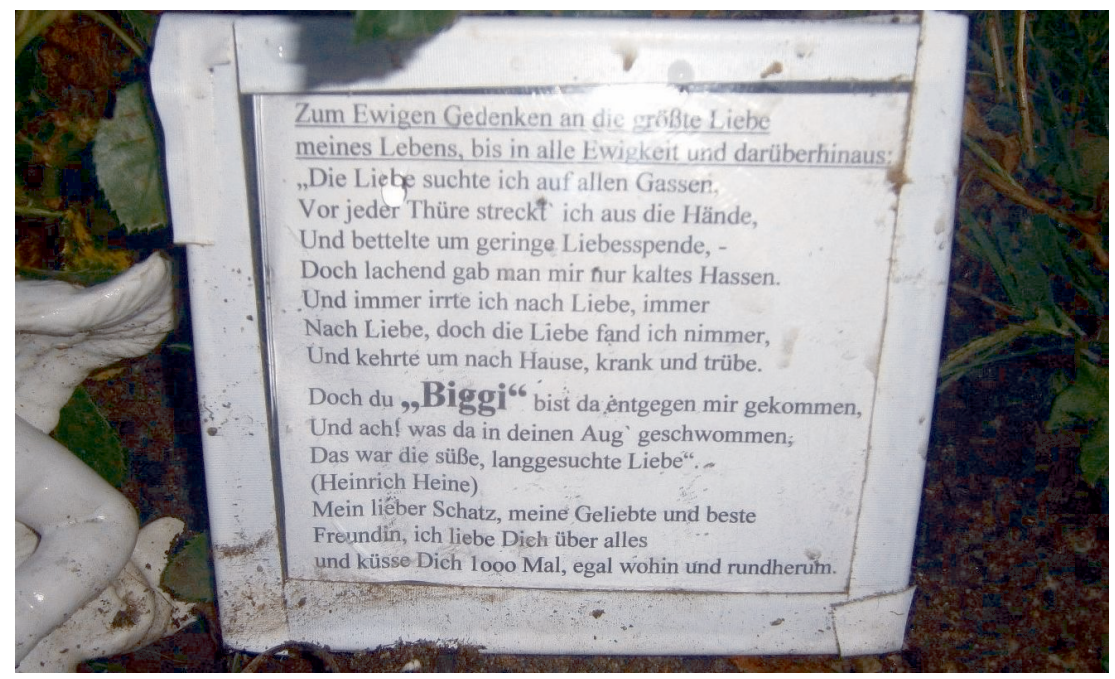

Als wäre dies nicht genug, ergibt sich bei näherer Betrachtung unserer Fallauswahl und des inhaltlichen Fokus' dieses Bandes noch ein weiteres Problem. Schließlich interessieren wir uns nicht nur allgemein für Menschen mit Trauererfahrung, sondern insbesondere für diejenigen, die sich aus unterschiedlichen Gründen über die bestehenden Bestattungsgesetze hinweggesetzt, also etwas getan haben, wofür sie nicht nur sozial, sondern mitunter auch juristisch sanktioniert werden könnten. Konkret ist hier an die Herausgabe der Kremationsasche zu denken und an den autonomen Umgang damit, etwa durch Urnenaufbewahrung in der eigenen Wohnung, Teilung der Asche, Weiterverarbeitung zu einem Erinnerungsartefakt, Verstreuen an einem bestimmten Ort usw. Wie und wo findet man Menschen, die bereit sind, von ihren privaten Trauererfahrungen und obendrein von ihren nach deutschem Recht illegalen Handlungspraxen zu berichten? Ist von Vertretern dieser Teilpopulation - die aufgrund ihrer spezifischen Eigenschaften nun in der Tat eine spezielle Population darstellt - nicht schon allein aufgrund der rechtlichen Sanktionsbedrohung ein erhöhtes Interesse zu erwarten, dass ihre `Geschichte im Verborgenen bleibt?

Doch inwieweit haben sich diese und andere Annahmen, die im Vorfeld der Interviewplanung aufgetreten sind, letztlich überhaupt bestätigt? Erfreulicherweise erwies sich die Befürchtung, nicht genügend Interviewpart- 
ner zu finden, bereits zu einem recht frühen Forschungszeitpunkt als unzutreffend. Hierin nun gleich eine handfeste Gegenevidenz zur Tabuisierungsthese zu sehen, wäre vielleicht etwas voreilig. Es ließe sich darüber nachdenken, ob die spezifischen Rahmenbedingungen des wissenschaftlichen Interviews bei den Zielpersonen nicht nur Reserviertheit hervorrufen, sondern im Gegenteil auch dazu führen können, dass sie im Bewusstsein der Anonymität gegenüber einem fremden Forscher, der sie nicht näher kennt und von dem sie (im Unterschied zum eigenen sozialen Umfeld) eine gewisse Sachlichkeit und Werturteilsfreiheit erwarten, eher bereit sind, sich in dieser persönlichen Angelegenheit zu äußern. Dessen unbeschadet ist die während der zweiten Hälfte des 20. Jahrhunderts noch populäre Annahme von der Tabuisierung des Todes zumindest relativierungsbedürftig geworden. Innerhalb der thanatosoziologischen Forschung wird inzwischen vielmehr von einer »Enttabuisierung " (Knoblauch 2009: 262), Wiederbelebung (»Revival«; Walter 1994), "Geschwätzigkeit« (Nassehi 2003: 301) und »neuen Sichtbarkeit« (Macho/Marek 2007) des Todes gesprochen.

Empirische Belege sind in vielerlei Hinsicht erbracht worden: Als Medienphänomen hat der Tod (und insbesondere der tote Körper) in den letzten Jahren an Bedeutung gewonnen (Schneider 2010; Meitzler 2017a); die in den 1960ern einsetzende und seither stark anwachsende Hospizbewegung kann als Idee gelesen werden, dem Lebensende buchstäblich mehr Raum zu geben (Dreßke 2005; Mielke 2007; Goebel 2012); im Schatten demografischer Transformationen werden vermehrt Diskurse über Sterbehilfe (Kamann 2009), Hirntod (Schlich/Wiesemann 2001) und Organspende (Groß/Kaiser/Tag 2016) geführt; die Gesetzgebung und die damit zusammenhängenden politischen Debatten verändern sich; Migrationsprozesse bringen neue Konzepte des Trauerns mit sich (Assmann/Maciejewski/Michaels 2005); Gedenkformen unterliegen einem Wandel (Fowler 2007); Grabgestaltungen werden zunehmend zum Ausgangspunkt individueller Aneignungen (Benkel/Meitzler 2014b; dies. 2016b); es bilden sich Expertenkulturen (Brüggen 2005); und vieles mehr. So verschiedenartig die genannten Felder sind, so notwendig erscheint eine differenziertere Betrachtung dessen, was eigentlich gemeint ist, wenn heute von >dem Tod / gesprochen wird. Wer ist zuständig: Medizin? Religion? Psychologie? Bzw. worum geht es: Sterben? Totsein? Tote Körper? Trauer? So oder so: In Zeiten der gesellschaftlichen Pluralität lässt sich die Frage nach der Tabuisierung oder Enttabuisierung nicht pauschal beantworten - und schon gar nicht abschließend. 


\section{Akquise von Interviewpartnern}

Ebenso wie die Teilnehmenden des Online-Fragebogens sollten auch unsere Interviewpartner im Zuge der Akquise nicht mit unseren Forschungsabsichten süberfallen werden, etwa durch das überraschende Abpassen am Friedhofstor oder das Ansprechen während eines Grabbesuchs. Stattdessen zogen wir es auch in diesem Fall vor, potenziell Interessierte schriftlich über die Studie und deren Hintergründe zu informieren und ihnen die Möglichkeit zu geben, anschließend über das je bevorzugte Kommunikationsmittel Kontakt mit uns aufzunehmen. Im Detail differierten die $\mathrm{Zu}$ gangswege zu den späteren Interviewpartnern voneinander, was insbesondere der Heterogenität der getroffenen Gesamtfallauswahl geschuldet ist. Je nach ihrem Hintergrund und dem primären Erkenntnisinteresse, das wir an sie richteten, lassen sich unsere Kontaktpersonen grob nach drei Kategorien unterscheiden.

- Personen, die sich die Kremationsasche aushändigen ließen und autonom damit verfahren sind

In Anbetracht der Schwierigkeit, forschungsrelevante Akteure dieser Kategorie zu ermitteln, entschieden wir uns für eine Kontaktaufnahme, die gewissermaßen auf indirektem Wege erfolgen musste. Konkret wandten wir uns an all jene Bestatter, mit denen wir bereits bezüglich anderer Angelegenheiten ${ }^{23}$ im Austausch standen, und fragten, ob sie uns Kontakte vermitteln können. Bei Zustimmung ließen wir dem Bestatter ein von uns verfasstes Anschreiben mitsamt vorfrankiertem Briefumschlag zur Weiterleitung an die Zielperson zukommen. Das Schreiben beinhaltete eine kurze Skizzierung unseres Forschungsvorhabens und eine Darstellung der Möglichkeiten, das Projekt zu unterstützen.

Hinsichtlich der weiteren Kommunikation sollten unsere Adressaten möglichst großen Spielraum erhalten. So stand es ihnen völlig frei, ob und in welcher Form ihre Rückmeldung und die spätere Befragung (persönlich, telefonisch, schriftlich) erfolgen sollten. Wurde der schriftliche Weg präferiert (was lediglich in zwei Fällen vorkam), versendeten wir einen Fra-

23 Das betrifft u.a. den Kontakt über unsere vorausgegangenen Forschungs- und Publikationstätigkeiten, Interviews, Vorträge in Bestattungsinstituten und Auftritte bei Podiumsdiskussionen. 
gebogen, ${ }^{24}$ während bei der mündlichen Befragung vorab Termin und ggf. Treffpunkt vereinbart wurden. Auch über die genauen Inhalte sowie über die Dauer des Gesprächs sollten die Teilnehmenden selbst entscheiden dürfen. Solche Zugeständnisse mögen der Forschungsmethodik auf den ersten Blick eine gewisse Beliebigkeit verleihen; sie gewinnen indes rasch an Plausibilität, wenn man sich die angesprochene heikle Ausgangslage (Intimität, Illegalität etc.) vor Augen führt. Zur Erhöhung der Teilnahmebereitschaft erschienen uns solche vertrauensbildenden Maßnabmen darum schon bei der ersten Kontaktaufnahme wichtig. Dazu gehörte auch, den Leser unseres Schreibens davon zu überzeugen, dass seine Mitwirkung für das Gelingen der Studie von hohem Wert sein würde und er einen wichtigen Beitrag dafür leisten kann, dass ein bisher noch unterbelichteter Diskurs an öffentlicher Aufmerksamkeit gewinnt. Weder sollte er befürchten, dass er sich für seinen Umgang mit der Kremationsasche an irgendeiner Stelle wird rechtfertigen müssen, noch, dass er aufgrund seiner Aussagen später in Misskredit geraten und/oder rechtlich belangt werden könnte.

Überdies wurden die Zielpersonen darauf hingewiesen, dass ihre Daten ausschließlich zu Forschungszwecken und selbstverständlich unter der Gewährung von Anonymität und äußerster Diskretion verwendet werden. Aussagen, die im Rahmen der Befragungen getätigt werden, sollten in die spätere Ergebnispublikation zwar mit einfließen, man würde sie dann aber nicht mehr auf die konkrete Identität ihres Urhebers zurückführen können. Die Umsetzung dieser Absicht sollte auch insofern unproblematisch sein, als ohnehin nicht Einzelakteure und ihre subjektiven Lebensumstände im Zentrum des Interesses standen, sondern die Positionen und Haltungen, die sie vertreten. Weil die Adressaten des Schreibens die Möglichkeit hatten, sich selbstständig zu melden, konnten sie auch den Forschern gegenüber mehr oder minder anonym auftreten - eine Nennung ihrer $\mathrm{Na}$ men und Adressen war nicht erforderlich. ${ }^{25}$

24 Auch wenn mit diesem Erhebungsmodus einige Nachteile verbunden sind (u.a. die fehlende Möglichkeit, spontane Nachfragen zu stellen), respektierten wir den Wunsch und ließen den Teilnehmern ein Dokument mit zehn Kernfragen zukommen, welches sie uns daraufhin ausgefüllt zurücksandten.

25 Wie sich in späteren Gesprächssituationen herausstellte, wurde die von uns ausgesprochene Gewährung völliger Anonymität von manchen Interviewpartnern mit dem Hinweis pariert, dass man kein Problem damit habe, namentlich in Erscheinung zu treten. Einige der Befragten sahen im Gegenteil die Chance, eine längst fällige Debatte anzustoßen, die - so glaubten sie - durch den Verzicht auf Anonymität an Authentizität gewänne. 
Dankenswerterweise traf unser Anliegen bei fast allen der von uns kontaktierten Bestatter auf positive Resonanz. Unter den genannten Bedingungen leiteten sie unsere Anschreiben an Kunden weiter, von denen sie annahmen, dass sie für unsere Studie in Frage kommen bzw. ein entsprechendes Maß an Mitteilungsbereitschaft aufweisen könnten.

- Menschen mit Trauererfahrungen im Allgemeinen

Im Laufe der Forschung hat sich unser Fokus dahingehend erweitert, dass nun nicht mehr nur die Überschreitung gegenwärtiger Bestattungsgesetze, sondern Trauerhandlungen im Allgemeinen von Interesse sein sollten unabhängig von der gewählten Bestattungsvariante. Das bedeutet natürlich nicht, dass das Thema Autonomie (als selbstbestimmtes Suchen und Finden individueller Umgangsformen, Abkehr von Traditionen, Konflikte mit Institutionen oder anderen Angehörigen, Unzufriedenheit mit dem derzeitigen Sepulkralangebot und dergleichen) nicht auch bei dieser expandierten Fallauswahl eine wichtige Rolle spielte.

Verglichen mit der erstgenannten Kategorie erschien die methodische Ausgangslage wegen der höheren Inklusivität und geringeren Spezifizität der Zielpopulation hier etwas einfacher. Gleichwohl blieb die bereits diskutierte Herausforderung bestehen, Personen zu finden, die nicht nur über Trauererfahrungen verfügen, sondern auch bereit sind, darüber zu reden. Statt Anschreiben zu verfassen und sie von Bestattern weiterleiten zu lassen, entschieden wir uns in diesem Fall für die Anfertigung eines Aufrufs, in dem wir den groben Hintergrund unseres Projektes erläuterten und Interessierte - ebenfalls unter der Gewährung von Anonymität und Diskretion - um Teilnahme baten. Den Aufruf verbreiteten wir über jene digitalen und analogen Kanäle, die wir auch im Kontext der oben erwähnten Online-Befragung bemüht hatten.

Neben der Rückmeldung auf unseren Aufruf ergaben sich weitere Wege der Kontaktaufnahme. Etwa ein Fünftel der Teilnehmenden der OnlineUmfrage zeigte sich an einem weiterführenden Interview interessiert und hinterließ Kontaktdaten. Überdies vermittelte uns mancher Gesprächspartner Personen aus dem eigenen Familien-, Kollegen- oder Freundeskreis, die ebenfalls dazu bereit waren, sich zu ihren Trauererfahrungen befragen zu lassen.

- Berufspraktiker im Bereich der Trauerkultur

Ferner haben wir Interviews mit Personen geführt, deren berufliche Expertise für die Beantwortung unserer Forschungsfragen ebenfalls von Relevanz ist (mit einigen von ihnen standen wir bereits seit längerem in Kon- 
takt). Bestatter, Steinmetze, Pfarrer, Hospizmitarbeiter, Palliativmediziner, Trauerbegleiter und andere Berufsakteure sind aufgrund ihrer professionellen Rolle besonders nah an jenen Menschen, für deren Erlebnisse, Absichten und Handlungen wir uns interessieren. Praktiker können Soziologen auf besondere Weise Einblicke und Zugänge in das anvisierte Forschungsfeld vermitteln; bald mehr, bald weniger bewusst verraten sie ihnen auch etwas über ihre eigene Berufsauffassung und ihre Normalitätserwartungen in Bezug auf Sterben, Tod und Trauer. Besonders lohnenswert erscheinen dabei Überlegungen zum Verhältnis von Berufspraxis auf der einen und den Haltungen gegenüber der Endlichkeitsthematik auf der anderen Seite. Wird etwa die Berufswahl durch spezifische Einstellungen wahrscheinlicher bzw. inwieweit verändern sich Letztere in Abhängigkeit zu alltäglichen und weniger alltäglichen Berufserfahrungen? Das hier in Erscheinung tretende Spezialwissen unterscheidet sich ohne Frage vom soziologischen Spezialwissen - ein Umstand, der jederzeit mitreflektiert werden muss. Andererseits erweist sich gerade der Austausch von Wissenschaft und Praxis für beide Seiten als ausgesprochen gewinnbringend, so zumindest der Eindruck nach unseren bisherigen Forschungsunternehmungen.

Die getroffene Unterscheidung nach drei Kategorien von Befragten ist keineswegs trennscharf, zwischen den einzelnen Gruppen kommt es durchaus zu Überschneidungen: Interviewpartner, die sich Kremationsasche aushändigen ließen, verfügen für gewöhnlich auch über Erfahrungen mit konventionellen Bestattungsmethoden; die eine oder andere Person, die ursprünglich $\mathrm{zu}$ ihren allgemeinen Trauererfahrungen befragt werden wollte und sollte, erzählte mitten im Interview plötzlich, dass sie die Urne eines Verwandten im Wohnzimmerschrank stehen oder die Asche an einem bestimmten Ort verstreut hat; und viele der Berufsexperten wurden insofern in einer >Doppelrolle< adressiert, als sie nicht lediglich über einen professionellen, sondern auch über einen privaten Zugang zu Trauer haben, der meist unaufgefordert mit angesprochen wurde. Beide Rollen lassen sich schwerlich isoliert voneinander betrachten, vielmehr kann durchaus eine Wechselseitigkeit unterstellt werden, deren Analyse aufschlussreiche Erkenntnisse verspricht.

Nachdem nun die unterschiedlichen Zugangswege zur Gewinnung von Interviewpartnern dargelegt wurden, befasst sich der nächste Abschnitt mit der konkreten Interviewdurchführung. Im Fokus der Reflexion stehen jene Gespräche, in den es explizit um die Trauererfahrungen der jeweiligen Untersuchungsperson ging. 


\section{Interviewdurchführung}

Interviews, die den irreversiblen Verlust einer emotional besetzten Sozialbeziehung zum Inhalt haben, sind mit einigen Voraussetzungen verbunden. Wer sie führt, dem verlangen sie ein hohes Maß an Empathie ab, und wer an ihnen teilnimmt, der wird mit einem meist fundamentalen Einschnitt in der eigenen Lebenswelt konfrontiert. Nach einer zufriedenstellenden Antwort auf die Frage, wie man sich als Interviewer in solch einer speziellen Situation optimalerweise verhält, dürfte man in den gängigen Lehrbüchern vergeblich suchen, weil es diesbezüglich keine Patentrezepte gibt. So unterschiedlich Menschen mit Trauer umgehen, so unterschiedlich können die Narrationen ausfallen, in denen sie von diesem Umgang erzählen, und so fallsensibel muss sich der Forschende auf sie einstellen.

Die empirische Sozialforschung kennt zahlreiche Varianten von Interviews, die sich hinsichtlich bestimmter Aspekte differenzieren lassen (dazu ausführlich Lamnek 2005: 330ff.). Einige Beispielfaktoren: die Anzahl der befragten Personen (Einzel- vs. Gruppeninterview), die Form (mündlich vs. schriftlich), das Medium der Kommunikation (persönlich, telefonisch, internetbasiert usw.), der sogenannte Autoritätsanspruch des Interviewenden (hart, weich oder neutral), die Art und Weise der Frageformulierung (offene vs. geschlossene Fragen).

Ein anderes zentrales Unterscheidungskriterium ist der Grad der Standardisierung. Diese Begrifflichkeit ist bereits weiter oben im Zusammenhang mit der Online-Umfrage als standardisiertes Erhebungsinstrument zur Sprache gekommen. Aber nicht nur schriftliche, sondern auch mündliche Befragungen können standardisiert sein. Bei einem standardisierten Interview verwendet der Interviewende einen ausgearbeiteten und zuvor getesteten Fragebogen, den er in Bezug auf Reihenfolge, Vollständigkeit und Wortlaut von einem Interview zum nächsten streng befolgt. Die einzelnen Fragen sind meist so gestellt, dass sie sich vom Interviewten kurz und prägnant beantworten lassen. Diese Bedingungen sorgen in der Regel dafür, dass der Interviewende den Gesprächsverlauf leicht antizipieren kann, er mit keinen besonderen Überraschungsmomenten zu rechnen hat und ein sehr überschaubares $\mathrm{Ma}$ an Improvisationskunst geboten ist. Der Umstand, dass den Interviewten relativ wenig Raum zur Entfaltung einer Antwort gegeben wird, mag zu der (gerade von Vertretern des qualitativen Paradigmas nur allzu gerne vorgebrachten) zynischen Schlussfolgerung verleiten, anhand von standardisierten Interviews erfahre man mehr über das Wissen der Fragebogenkonstrukteure als über das der Befragten (vgl. Reichertz 2016: 200). Demgegenüber liegt, wie ebenfalls bereits konstatiert, der pragmatische Mehrwert der Standardisierung in der vergleichsweise 
aufwandsarmen Realisierung einer hohen Fallzahl sowie in der besseren Vergleichbarkeit einzelner Interviews.

Das Pendant zum standardisierten stellt das nicht-standardisierte bzw. offene Interview dar. Es ist dadurch gekennzeichnet, dass außer einem vorgegebenen Generalthema für das Gespräch keine weiteren Vorgaben bestehen. Wo ein ausgefeilter Fragebogen fehlt und der Interviewpartner zu längeren Erzählepisoden eingeladen ist, können die Befragungen nicht nur hinsichtlich ihrer Dauer, sondern auch ihres konkreten Verlaufs beträchtlich variieren und durchaus überraschende Wendungen bzw. Perspektivverschiebungen bereithalten.

Der prinzipiell offene Verlauf erfordert es umso mehr, das Gespräch in Gang zu setzen und in Gang zu halten, in passenden Momenten vertiefend nachzufragen oder sich im Sinne eines erzählunterstützenden Schweigens (vgl. Küsters 2014: 578) strategisch zurückzuhalten. Wie gut dies gelingt, hängt nicht allein vom Improvisationsgeschick, von den fachlichen Kompetenzen und Persönlichkeitsmerkmalen (subjektive Einstellungen, Präferenzen, Abneigungen usw.) des Interviewers ab, sondern auch davon, inwieweit sein Gegenüber bereit und in der Lage ist, auf entsprechende Impulse zu reagieren. Nicht zu unterschätzen ist ferner das, was sich zwischen den beiden Interagierenden bewusst und unbewusst abspielt - wechselseitige Sympathien und Antipathien können den Interviewverlauf und das Interviewresultat entscheidend beeinflussen.

Anders als bei standardisierten Befragungen oder bei Interviews in außerwissenschaftlichen (etwa: journalistischen) Kontexten kommt das landläufig bekannte Ablaufmuster, wonach der Interviewende ausschließlich derjenige ist, der die Fragen stellt, und der Interviewte ausschließlich derjenige ist, der die Antworten gibt, hier nur bedingt zum Tragen. Je nach Erkenntnisinteresse der Studie und dem >Background des Gesprächspartners kann der Interviewende »die Rolle des distanzierten >Befragers « insoweit verlassen, als er durchaus auch Stellung zu bestimmten Aussagen bezieht, sich auf Gegenfragen einlässt, »flexibel auf den >Befragten und dabei seine eigenen Reaktionen genau reflektiert (Bortz/Döring 2006: 308f.). Auf diese Weise kommt das Interview einem >natürlichen Alltagsgespräch jenseits der wissenschaftlichen Versuchskulisse wesentlich näher, als dies standardisierte Befragungen vermögen.

Zwischen den beiden Polen >standardisiert und >nicht-standardisiert< befindet sich das teil-standardisierte Interview, dessen formale und inhaltliche Ausrichtung weder völlig verbindlich festgelegt noch gänzlich offen ist. Ein Interviewleidfaden steckt den groben Rahmen ab, indem er dem Forschenden eine übersichtliche Auswahl an Fragen bietet, auf die er während des Gesprächs zurückgreifen kann - mehr aber auch nicht. Statt sich 
der »Leitfadenbürokratie« (Hopf 1978: 101) zu unterwerfen, alle vorbereiteten Themenfelder nacheinander abzuhaken und sich dabei sklavisch an Reihenfolge und Wortlaut der Fragen zu halten, ist der Leitfaden eher als Orientierungshilfe zu sehen, die insbesondere dann bedeutsam werden kann, wenn das Gespräch ins Stocken gerät oder zu sehr vom eigentlichen Untersuchungsgegenstand abschweift.

Wichtiger als die Orientierung am Leitfaden ist jedoch die Orientierung an den Äußerungen des Interviewpartners. ${ }^{26}$ Fragen werden folglich nicht dann gestellt, wenn der Fragebogen dies vorsieht, sondern dann, wenn sie dem Interviewenden als sinnvoll erscheinen. Spontane Einfälle, die sich aus der individuellen Gesprächsdynamik heraus ergeben und auf Zusammenhänge abzielen, die vom ursprünglichen Leitfaden zwar abweichen, indes gewinnbringende Erkenntnisse versprechen, sind nicht nur erlaubt, sondern sogar ausdrücklich erwünscht. Zudem erhält der Befragte üblicherweise die Möglichkeit, seinerseits Fragen aufzuwerfen und Aspekte zu ergänzen, die ihm wichtig erscheinen und nach seiner Einschätzung im bisherigen Gespräch zu kurz gekommen sind. Der interaktive Austausch, der sich zwischen Interviewer und Interviewtem entfaltet, ist nicht lediglich als notwendiges Übel zu betrachten, um an verwertbare Informationen zu gelangen, sondern gilt selbst schon als »ein wesentlicher Teil des Forschungsprozesses« (Rosenthal 2014: 141).

Im vorliegenden Forschungskontext fiel die Entscheidung deshalb auf das teilstandardisierte Interview, weil es einerseits flexibel auf die konkrete Gesprächssituation und -konstellation eingestellt werden kann, ohne dass dabei andererseits das essenzielle Erkenntnisinteresse aus den Augen verloren wird. Abgesehen von einigen Leitfragen, die den Kern unseres Forschungsvorhabens (implizit) erfassen, haben wir bewusst auf weitere Standardisierungen verzichtet. Ansonsten wäre es schwergefallen, den je besonderen Lebensumständen unserer Untersuchungspersonen gerecht zu werden, von denen wir im Vorfeld nicht wissen konnten, wer zu welchem Aspekt wie viel sagen kann oder will. Damit verbunden ist eine prinzipielle Offenheit gegenüber den Inhalten, die ins Zentrum des Gesprächs rücken können. Gleichzeitig konnte auf diese Weise jeder Gesprächspartner selbst entscheiden, an welchen seiner Trauererfahrungen er den Interviewenden teilhaben lassen möchte und was eher unausgesprochen bleiben soll. (In-

26 Welche Relevanz dem Leitfaden insgesamt zukommt, hängt letztlich davon ab, wie wichtig es dem Forschenden ist, spätere Interviewprotokolle bzw. -transkripte miteinander vergleichen zu können. Insofern kann eine stärkere Befolgung des Leitfadens gewährleisten, dass die "gleichen Bezugspunkte berührt werden" (Merton/Kendall 1979: 184). 
des verrät auch und gerade das Nicht-explizit-Machen bestimmter Inhalte im Zuge rhetorischer Vermeidungsstrategien Grundlegendes über den Fall!)

Im Unterschied zur standardisierten Online-Umfrage bestand die ausdrückliche Absicht unserer Interviews darin, den Teilnehmenden genügend Gelegenheit zu bieten, zurückliegende biografische Erlebnisse und Entscheidungsprozesse in angemessenem Umfang zu rekonstruieren, vergangene Handlungsverkettungen retrospektiv zu interpretieren und dem Zuhörer nachvollziehbar zu machen, wie sich das Eine aus dem Anderen ergeben hat. Es ging also darum, »die in die Gegenwart transportierte Erfahrungsaufschichtung durch die Dynamik des Erzählvorgangs« wieder zu verflüssigen (Glinka 2008: 9). Von einem einschränkenden Frage-AntwortMuster abzusehen, erschien nicht zuletzt angesichts dieser hochkomplexen, hochspezifischen und noch dazu hochsensiblen Thematik mehr als angemessen. Die gewählte Gesprächsvariante könnte man deshalb auch als Spielart des narrativen Interviews begreifen, "welches den Informanten zu einer umfassenden und detaillierten Stegreiferzählung persönlicher Ereignisverwicklungen [...] veranlasst « (Schütze 1987: 49).

Die einer geringen Standardisierung geschuldeten Freiheitsgrade erweitern nicht nur die Möglichkeiten des Interviewten, sie erlauben überdies dem Interviewenden eine emphatische Partizipation an der ihm vorgetragenen Erzählung und bereiten den Boden für eine vertrauensvolle Beziehung. Kennzeichnend hierfür ist »eine betont einfühlsame, entgegenkommende und emotional beteiligte Gesprächsführung [...]. Man hofft, dem Befragten auf diese Art seine Hemmungen zu nehmen und ihn zu reichhaltigeren und aufrichtigen Antworten anzuregen" (Bortz/Döring 2006: 239). Vertrauensgenerierende Maßnahmen, in der empirischen Sozialforschung auch als das Herstellen von Rapport bezeichnet, enden demnach keineswegs in dem Moment, in dem sich die Zielperson für ein Interview bereit erklärt, sondern sie sind auch im weiteren Verlauf von elementarer Bedeutung. Eine möglichst alltagsnahe Gesprächsatmosphäre, in der sich die Befragten wohl fühlen und offen über ihre Erlebnisse und Einstellungen sprechen können, weil sie wissen, dass ihre Aussagen auf Interesse stoßen und diskret behandelt werden, erhöht die Qualität der Interviewdaten.

Der Stellenwert eines geglückten Gesprächseinstieges ist dabei nicht zu unterschätzen, kristallisiert sich doch bereits zu diesem frühen Zeitpunkt häufig heraus, welche Erwartungen beide Kommunikationspartner voneinander hegen und wie sie ihr Verhältnis zueinander interpretieren. Ein geeigneter Erzählstimulus kann dabei helfen, den möglicherweise noch unsicheren und angespannten Teilnehmer - für gewöhnlich gehört das Interviewt-Werden nicht zu seiner alltäglichen Routine - zu ‘zwanglosen Aus- 
führungen einzuladen, mit denen er einerseits einen wertvollen wissenschaftlichen Beitrag liefern und andererseits snichts falsch machen kann. Allzu spezifische, herausfordernde, provokante Fragen erweisen sich demgegenüber als eher ungeeignet, denn hierdurch läuft man Gefahr, den anderen gleich zu Beginn in Erklärungsnöte zu bringen, ihn in die Defensive zu drängen oder ihn gar daran zweifeln zu lassen, überhaupt die richtige Untersuchungsperson für diese Studie zu sein. Mit der eher allgemein gehaltenen Frage nach bisherigen Erfahrungen im Umgang mit Trauer wurde der Einstieg stattdessen so gewählt, dass der Interviewte anhand persönlicher Relevanzsetzungen eine längere Erzählsequenz entfalten und damit zugleich einen Horizont für den weiteren Gesprächsverlauf aufspannen konnte.

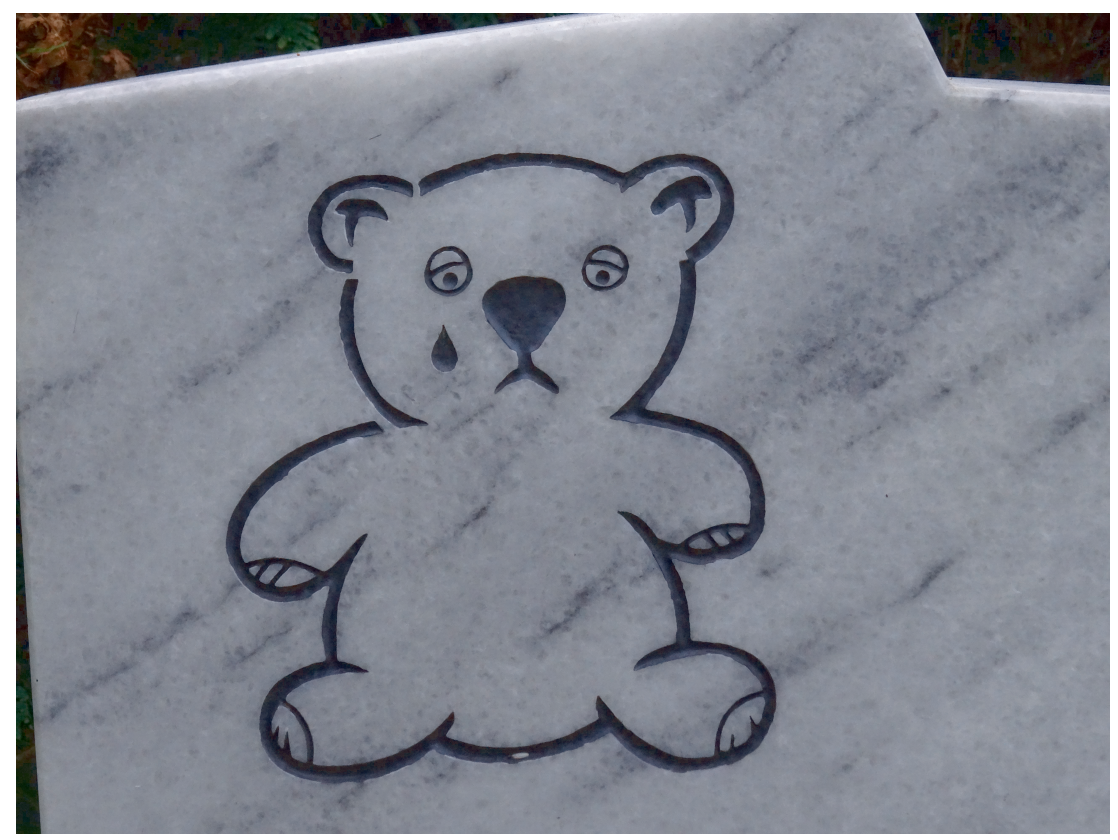

Gelingt es dem Interviewenden mit einer geeigneten Einstiegsfrage Narrationen bei seinem Gesprächspartner auszulösen, gilt es zunächst, »sich auf seine Rolle als interessierter Zuhörer ( (Lamnek 2005: 359) zu beschränken und möglichst wenig zu intervenieren. Dem Erzähler wird einerseits die Entscheidungsfreiheit über die Strukturierung und den Detailierungsgrad seiner Geschichte zugestanden (sowie die Definitionshoheit darüber, was in diesem Zusammenhang mehr und was weniger wichtig ist), andererseits 
wird ihm die Kompetenz und Bereitschaft abverlangt, mit diesen Zugeständnissen auch adäquat umzugehen. Was der eine als willkommene Gelegenheit sieht, ausführlich zu erzählen, was ihn bewegt, kann von jemand anderem als Zumutung empfunden werden, der er sich am liebsten entzieht. Einmal mehr wird hieran die für die qualitative Forschung elementare Erkenntnis deutlich, dass Interviewpartner eben keine beliebig austauschbaren Datenträger sind, an denen man >die Wahrheit nur abzulesen braucht (vgl. Bortz/Döring 2006: 248). Ungleichheiten bestehen folglich nicht bloß beim Zeitbudget, sondern u.a. auch im Hinblick auf die (selbst empfundene) persönliche Involviertheit in die Thematik, das alltagsweltliche und/oder fachliche Interesse an der Studie, das subjektive ,Wissenschaftsbild<, die Erwartungen an die Rolle des Probanden (und die des Forschenden), die narrative Kompetenz, die Interaktions- und Kooperationsbereitschaft, die Fähigkeit, sich an die für den Wissenschaftler relevante Begebenheiten zu erinnern, den kulturellen Hintergrund, ${ }^{27}$ das Ausmaß der Extrovertiertheit/Introvertiertheit, die Ambitionen, den Gesprächsverlauf zu gestalten und dabei persönliche Interessen zur Geltung kommen zu lassen, und dergleichen mehr. Demgemäß liegt die Herausforderung für den Interviewenden darin, von Beginn an ein Gespür für die Eigenschaften seines Gesprächspartners zu entwickeln und den eigenen Interviewstil daran auszurichten. ${ }^{28}$

Narrative Interviewsequenzen waren für unser Forschungsdesign eine wichtige Datengrundlage, gleichwohl bedeuten längere Erzählepisoden weder automatisch bessere Daten, noch war eine ausgesprochen hohe narrative Kompetenz zwingende Bedingung für die Teilnahme an unserer Studie. Nicht jedes unserer Gespräche war ein narratives Interview im strengen Sinne, vielmehr kann hier zwischen verschiedenen Graden der Narrativität unterschieden werden. Letztlich gilt das, was auch auf alle anderen Interviewformate zutrifft: Es handelt sich um Idealtypen, deren Abgrenzung mehr analytischer denn forschungspraktischer Natur ist. Meist lässt sich ein geführtes Gespräch als Konglomerat aus verschiedenen Elementen (narrativ, episodisch, biografisch, problemzentriert usw.) betrachten und somit weder eindeutig der einen noch der anderen Kategorie zuordnen.

27 Schließlich ist es nicht in jeder Kultur sozial legitim, einer fremden Person ausgiebig über private Angelegenheiten zu berichten (vgl. Przyborski/Wohlrab-Sahr 2014: 9).

28 Bei aller Betonung interpersoneller Unterschiede sind situative Faktoren nicht minder gewichtig. Wer sich mit der zugewiesenen Erzählerrolle anfangs schwer tut, kann sie im weiteren Gesprächsverlauf, nach der ominösen >Auftauphase‘, durchaus noch zu schätzen lernen oder sich zumindest mit ihr arrangieren. 
Unter Abwesenden - Charakteristika des telefonischen Interviews

Im Zeitraum von Januar 2015 bis Dezember 2018 konnten wir insgesamt 126 qualitative Interviews mit einer durchschnittlichen Dauer von circa 85 Minuten realisieren (das kürzeste Gespräch dauerte 29, das längste $182 \mathrm{Mi}$ nuten). ${ }^{29} 11$ der Gespräche fanden persönlich, d.h. face-to-face statt (in Cafés, im Universitätsbüro oder am Arbeitsort des Interviewten), eines via Internet (Skype), und alle anderen Befragungen - die deutliche Mehrheit wurden telefonisch geführt. ${ }^{30}$ Gegenüber dem klassischen Vis-à-Vis als »Prototyp aller gesellschaftlichen Interaktion « (Berger/Luckmann 2004: 31) bringt das Kommunikationsmedium Telefon einige für die Gesprächssituation nicht unerhebliche und vor allem in methodologischer Hinsicht bedenkenswerte Spezifika mit sich. Während die Fachliteratur reichliche Auseinandersetzungen mit dem qualitativen Leitfadeninterview im Allgemeinen aufweist (siehe z.B. Gläser/Laudel 2010; Flick 2006), sind die besonderen Ausgangsbedingungen von Telefoninterviews bislang wenig beleuchtet worden (Schulz/Ruddat 2012).

Das Telefon schafft gleichermaßen Nähe wie Distanz. Nähe schafft es, indem sich Menschen über größere Entfernungen hinweg ohne höheren zeitlichen, logistischen und finanziellen Aufwand synchron miteinander austauschen, und Sozialwissenschaftler auf ressourcenschonende Weise auch größere Stichproben erreichen können. Distanz entsteht wiederum insofern, als dieser Austausch "unter Abwesenden" (Kieserling 1999) und damit unter Ausblendung nonverbaler Kommunikationsformen geschieht, die für das Interview unter Anwesenden ansonsten charakteristisch sind. Sämtliche visuelle Daten in Form von Mimik und Gestik, Blickkontakten und -vermeidungen, Kleidung usw. - die Sprache des Körpers also, die bekanntlich nicht immer der willentlichen Steuerung gehorcht und gerade deshalb so interessant ist - können auf telefonischen Wegen nicht erfasst werden. ${ }^{31}$

29 Auch wenn ein längeres Interview die Gelegenheit bietet, mehr Daten zu generieren, lässt sich deren Qualität natürlich nicht pauschal an der Gesprächsdauer ablesen. Im Einklang mit dem qualitativen Paradigma sind die Fälle stattdessen in ihrer Singularität zu betrachten - und ein Gespräch von 30 Minuten (oder weniger) kann somit aufschlussreicher ausfallen als so manches zweistündige.

30 Mit der Interviewführung waren neben den drei Autoren dieses Bandes noch zwei Projektmitarbeiterinnen befasst.

$31 \mathrm{Ob}$ diese visuellen Daten dort, wo sie tatsächlich erfassbar sind (etwa im Kontext von face-to-face-Interviews), bei der späteren Analyse auch Berücksichtigung finden, steht freilich auf einem anderen Blatt (Opdenakker 2006). 
Eine derartige, wie man gewissermaßen sagen könnte, "Schweigsamkeit des Sozialen « (Hirschauer 2001) kann zu Missverständnissen und Unsicherheiten darüber führen, wie das Vorgetragene am anderen Ende der Leitung ankommt. ${ }^{32}$ Für den gerade im Trauerkontext so wichtigen Vertrauensaufbau fehlen dem Interviewenden essenzielle kommunikative Mittel: Ein Lächeln, eine Blickerwiderung oder ein verständnisvolles Nicken verlieren ihre Wirkung, wenn das Gegenüber, welches hier eben kein leibhaftig präsentes Gegenüber ist, davon keine Notiz nehmen kann. Das Gleiche gilt für den Einsatz nonverbaler Zeichen, um dem Gesprächspartner zu signalisieren, nun selbst das Wort ergreifen zu wollen, oder um ihn zur Fortsetzung einer begonnenen Narration zu animieren. Auch aus Sicht des Befragten sind die dem Kommunikationsmedium geschuldeten Ausdrucksund Resonanzrestriktionen mit gewissen Unwägbarkeiten verbunden, die sich insbesondere während längerer Erzählepisoden äußern können: Stößt meine Geschichte beim anderen auf nachhaltiges Interesse - oder überfordere ich ihn mit zu vielen Details? Beantworte ich gerade seine Frage oder wollte er eigentlich etwas ganz anderes erfahren? ${ }^{33}$ Weil der Interviewende um das Es-nicht-so-genau-wissen-Können seines Gesprächspartners weiß oder diesbezüglich zumindest eine Erwartung hat, verfolgt er für gewöhnlich das Interesse an einer Kompensation seines abwesenden Resonanzkörpers. Hierfür bleibt ihm die Wirkmacht seiner Stimme - ein spezifischer

32 Damit sind nicht nur konkrete Wortbeiträge gemeint, sondern auch Gesprächspausen, die zwar häufig als unangenehm empfunden werden, deren AushaltenKönnen jedoch gerade zu den Kernkompetenzen eines methodisch geschulten Interviewers gehört. Das Telefonsetting sorgt nun insofern für eine Erhöhung von Komplexität, als das Schweigen des anderen unter erschwerten Bedingungen dechiffriert werden muss (sofern dies überhaupt gelingt). Vielleicht ist es ein Zeichen höchster Konzentration und der Interviewte braucht schlichtweg einen Moment, um die aus seiner Sicht richtigen Worte zur Beantwortung meiner Frage zu finden? Vielleicht ist er aber auch genau damit überfordert und möchte mich mit seinem Schweigen darum bitten, die Frage anders zu formulieren? Vielleicht stellt meine Frage aber auch keine sachliche, sondern eine emotionale Überforderung dar und mein Gesprächspartner kennt zwar die Antwort, möchte sie jedoch nicht preisgeben? Vielleicht ist er aber auch gerade abgelenkt, weil es an der Tür geklingelt, eines der Kinder gerufen oder der Hund etwas angestellt hat? Oder ist am Ende der Telefon-Akku leer?

33 Das soll hingegen nicht bedeuten, dass bei Telefoninterviews lediglich der jeweils gesprochene Text vernommen werden kann. Relevant ist nicht nur, was gesagt wird, sondern auch und vor allem, wie es gesagt wird. Über das Medium Stimme verraten die Interagierenden mehr oder minder unbeabsichtigt Essenzielles über ihre aktuelle Befindlichkeit (fröhlich, traurig, überrascht, genervt, gerührt, konzentriert, entspannt, nervös usw.) und über spezifische habituelle Eigenschaften. 
Sprachduktus, eine bestimmte Intonation von Wörtern, oder eben ein in regelmäßigen Abständen vorgebrachtes » $\mathrm{Mmm}-\mathrm{Hmm} \ll .34$

Auf der anderen Seite geht mit der Distanz auch eine wechselseitige (optische) Anonymität und Unverbindlichkeit einher, die nicht ausschließlich problematisch sein und $\mathrm{zu}$ einer niedrigeren Datenqualität führen muss, sondern sich positiv auf die Teilnahmebereitschaft und die Offenheit der Untersuchungsperson auswirken kann (insbesondere bei heiklen Themen wie Trauer und Gesetzesübertretungen). ${ }^{35}$ Das "Telefon als selbstbestimmtes Medium « (Schulz/Ruddat 2012: unpag.) ermöglicht es ihr, dass sie niemandem etwas >ins Gesicht sagen zwischen ihr und dem Interviewenden fungiert als eine Art Schutzraum, der es ihr offen lässt, an welchem Ort sie sich während des Interviews aufhält - sie kann einerseits eine vertraute und intime Umgebung wählen (etwa die reigenen vier Wände`), ohne andererseits einer fremden Person in dieses "Territorium des Selbst " (Goffman 2009: 54ff.) physischen Zutritt gewähren zu müssen. (Selbige Annehmlichkeiten werden dem Interviewenden zuteil.) Für den Fall, dass der Befragte die Unterhaltung abbrechen möchte - ein Wunsch, mit dem angesichts des Gesprächsgegenstandes zwar prinzipiell zu rechnen ist, der während unserer Studie jedoch zu keinem Zeitpunkt geäußert oder realisiert wurde -, sind die Hürden bei

34 Hinzu kommt, dass bei Telefoninterviews keine zusätzlichen Stimuli, wie etwa die Vorlage von visuellem Material, eingebracht werden können (zum fotogestützten Interview siehe Dimbath 2013). In den Gesprächen, die wir face-to-face führen konnten, haben wir den Befragten an passender Stelle einige selbst angefertigte Fotografien von zeitgenössischen Grabstätten vorgelegt und sie jeweils um ein Statement gebeten. Zwar wäre das Zeigen von Bildern prinzipiell auch im Rahmen der Telefoninterviews möglich gewesen - beispielsweise durch Vorabversand der Fotodateien per E-Mail -, jedoch haben wir aus forschungslogistischen Gründen von dieser Option abgesehen.

35 Entsprechende Zusammenhänge wurden in der Vergangenheit von mehreren Autoren nachgewiesen (siehe z.B. Reuband/Blasius 1996; Lamnek/Schäfer 1998; Weissman/Steer/Lipton 1986). In einer qualitativen Studie zu kinderlosen Doppel-Karriere-Beziehungen führten Schulz und Ruddat (2012) Interviews sowohl face-to-face als auch telefonisch; dabei stellten sie fest, dass die Befragten bei den Telefongesprächen stärker dazu tendierten, auch intime Kontexte (Sexualität, Trauerfälle usw.) zu thematisieren. "Möglicherweise fühlen sich die Befragten durch die räumliche und optische Distanz freier und antworten demnach unbeschwerter und ehrlicher." Einschränkend weisen die Autoren indes darauf hin, »dass Erfahrungen aus quantitativen Erhebungen eine gegenläufige Tendenz zeigen. [...] Vielleicht beruht diese verstärkte Verweigerungshaltung darauf, dass die Befragten ihre Antworten nicht wie bei einem qualitativen Interview erläutern, erklären oder begründen können.« (Ebd.: unpag.) 
einem Telefonat wesentlich niedriger, als unter den Bedingungen räumlicher Kopräsenz. Es genügt ein Tastendruck.

Dem Interviewenden bietet die fernmündliche Kommunikation insofern Entlastung, als er keine Kontrolle über den adäquaten Einsatz von Gestik und Mimik wahren, sondern sich lediglich auf die auditiven Aspekte (die eigenen wie die des anderen) konzentrieren muss. Sogenannte Interviewereffekte, verstanden als Antwortverzerrungen des Befragten, die auf die Anwesenheit und die Wirkung des Forschenden zurückzuführen sind, lassen sich hierdurch reduzieren. Soziodemografische Indikatoren wie Alter, Geschlecht und Bildungsgrad mögen zwar nach wie vor im Spiel sein und die Gesprächsdynamik beeinflussen, indes steht die Person des Interviewers zugunsten seiner Wortbeiträge insgesamt weniger im Vordergrund, als dies bei einer persönlichen Begegnung der Fall wäre. Das wiederum kann die Hemmung senken, auch solche Aspekte anzusprechen, die intime Lebensbereiche des Interviewpartners tangieren.

\section{Soziodemografische Merkmale der Interviewten}

Im Hinblick auf die soziodemografischen Merkmale jener Personen, die uns ein Interview gegeben haben, sind einige, hier nur in Form exemplarischer Auszüge vorgetragene Aspekte zu berücksichtigen. Zunächst fällt auf, dass (wie auch bereits bei der Online-Umfrage) die überwiegende Zahl der Teilnehmenden (etwa 80\%) weiblich ist. Dafür könnte man auf den ersten Blick recht profane Gründe demografischer Art vermuten: Aufgrund der geschlechtsspezifischen Mortalität gibt es hierzulande rund viermal so viele Witwen wie Witwer (vgl. Stegmann/Bieber 2012: 47). Die Statistik spricht eine deutliche Sprache, doch halten wir diese Ungleichverteilung schon deshalb nicht für den ausschlaggebenden Punkt, weil die von uns untersuchten Fälle neben der trauernden Witwe noch diverse weitere Konstellationen kennen (z.B. der Verlust von Eltern, Kindern, Geschwistern, Freunden oder Arbeitskollegen). Eine plausiblere Erklärung für die Geschlechterdifferenz - welche im Übrigen keine Eigenheit unserer Stu$\mathrm{die}^{36}$ und deren Forschungsgegenstand darstellt, sondern sich in ähnlicher Weise auch bei vielen anderen Untersuchungen findet - bieten etwa sozialisationszentrierte Ansätze. Es hat den Anschein, dass in der westlichen Gesellschaft der expressive Umgang mit Emotionen, nicht zuletzt mit der Trauer

36 Siehe auch den nahezu identischen Anteil weiblicher Teilnehmerinnen an der Studie von Wissert (2013) über die Wirkungen von Trauerbegleitung. 
um einen verstorbenen Menschen, stärker ein Bestandteil der weiblichen als der männlichen Sozialisation ist (vgl. Götz 2013: 266f.; Kahlert 2014: 151; Klein 2011: 240; Höpflinger 2017). Demzufolge erhöhen sich der Wunsch und die Bereitschaft, über seine Verlusterlebnisse zu sprechen, wenn man gelernt hat, dass dies nicht nur legitim ist, sondern mithin auch zur (hier: weiblichen) Rollenerwartung gehört. Zudem wird Frauen im Allgemeinen ein höheres $\mathrm{Ma}$ an Empathie und Aufgeschlossenheit zugeschrieben - was sich positiv auf die Beteiligung an qualitativen Studien auswirkt.

Das Durchschnittsalter unserer Interviewpartner im Erhebungszeitraum beträgt knapp 52 Jahre. ${ }^{37}$ Dieser Wert verwundert nicht, wenn man sich vergegenwärtigt, dass ein höheres Lebensalter nicht nur mit einer größeren Lebenserfahrung, sondern auch mit zunehmenden `Todeserfahrungen hergeht. Insbesondere diejenigen Befragten, die sich die Kremationsasche ihres Verstorbenen aushändigen ließen, sind in einem Alter, in dem man vermehrt zum Kreise der Bestattungspflichtigen gehört und dadurch überhaupt erst in die Lage gerät, entsprechende Entscheidungen zu treffen bzw. umzusetzen. Die Interviewten jener Kategorie verfügten entweder über die Asche ihres Ehepartners oder über die eines Elternteils. Unter den restlichen Gesprächspartnern sind freilich auch Personen, die zum Interviewzeitpunkt jünger als 25 Jahre waren. Im Vergleich zu den älteren Probanden wiesen sie jedoch zum einen weniger Trauererfahrungen auf und zum anderen ist niemand von ihnen bereits für die Auswahl einer Beisetzungsart und/oder die Gestaltung einer Ruhestätte hauptverantwortlich gewesen. Dass das Durchschnittsalter der Teilnehmenden des Online-Fragebogens mit circa 44 Jahren etwas niedriger ausfällt, dürfte insbesondere dem Umstand geschuldet sein, dass Vertreter der jüngeren Alterskohorte eine höhere Internetaffinität besitzen und der Fragebogen - der ebenso unter den Studierenden kursierte - verstärkt auch diese Population erreicht hat.

Bei den Teilnehmenden zeigte sich ferner eine Tendenz zu höheren Bildungsabschlüssen. Auch hierbei handelt es sich um einen für qualitative Studien nicht ungewöhnlichen Befund. Unter Berücksichtigung der Gefahren von Pauschalisierungen und monokausalen Erklärungen kann hinter einem höheren Bildungsniveau ein allgemein größeres Interesse an gesellschaftsrelevanten, die eigene Lebenswelt transzendierenden Themen sowie ein stärker ausgebildetes Vermögen vermutet werden, persönliche Gefühle, Erlebnisse, Haltungen und Handlungen zum Reflexionsgegenstand zu machen und diese mithin auch kritisch zu hinterfragen. Gerade qualita-

37 Die jüngste Person war zum Interviewzeitpunkt 20, die älteste 87 Jahre alt. 
tive Forschungsdesigns, bei denen einem nicht lediglich das Ankreuzen von vorgegebenen Antwortoptionen abverlangt wird, sondern die Bereitschaft, zurückliegende Ereignisse bald mehr, bald weniger spontan in längere, rhetorisch konsistente Erzählungen zu transformieren ${ }^{38}$ (was einschließt, mit unerwarteten Fragen konfrontiert zu werden), mögen insbesondere bei Menschen aus bildungsferneren Schichten Unbehagen, Abneigung und Angst »vor etwaigen negativen Konsequenzen « auslösen. »Unterschichtangehörige sehen in einer Befragung häufig eine Art Test und befürchten, den kognitiven Anforderungen einer Befragung nicht gewachsen zu sein, weshalb sie oft aufgrund von Minderwertigkeitsgefühlen verweigern« (Schütte/Schmies 2014: 800).

Stichprobenselektivität, wie hier insbesondere am Beispiel von Geschlecht und Bildungsniveau angeführt, ist trotz einer für qualitative Erhebungen vergleichsweise hohen Fallzahl schwer vermeidbar. Das mindert nicht per se den Wert der Daten, ist aber bei deren Auswertung mit zu reflektieren. Es stellt sich die Frage, inwieweit sich die Ergebnisse unserer Studie auch auf jene Bevölkerungsgruppen übertragen lassen, die aufgrund eines spezifischen Merkmals (hier: persönliche Erfahrungen im Umgang mit Trauer) forschungsrelevant wären, aus unterschiedlichen Gründen allerdings nicht erreicht wurden. Nicht nur soziodemografische Faktoren können über die Wahrscheinlichkeit einer Teilnahme entscheiden, sondern auch inhaltliche Einstellungen gegenüber der Forschungsthematik. Wer mit einer bestimmten Ausgangssituation (hier: mit dem gesellschaftlichen Verhältnis zu Tod und Trauer bzw. mit den Bestattungsgesetzen in den deutschen Bundesländern) unzufrieden ist und für deren Veränderung eintritt, dem darf man ein gesteigertes Interesse unterstellen, auf öffentlichem Parkett - und dazu zählen eben auch wissenschaftliche Studien - >gehört $<$ zu werden. Entsprechende Absichtsäußerungen finden sich, mal mehr und mal weniger explizit, auch in unserem Interviewmaterial. Wie groß fällt demgegenüber das Interesse derjenigen aus, die mit all dem einverstanden sind und sich deshalb nicht weiter damit beschäftigen - oder die sich umgekehrt gar nicht damit beschäftigen und deshalb auch keinen Innovationsbedarf sehen?

38 Das (Nicht-) Vorhandensein eines der Interviewsituation angemessenen sprachlichen Artikulationsvermögens könnte eine wesentliche Facette bei der Entscheidung für oder gegen die Teilnahme sein. Dass sich unter unseren Gesprächspartnern fast ausschließlich Muttersprachler befanden, halten wir jedenfalls nicht für einen Zufall. 


\section{Abschließende Reflexionen der Gesprächsdynamik}

Innerhalb der qualitativen Sozialforschung gehören Interviews gegenwärtig zu den am häufigsten verwendeten Datenerhebungsmethoden. Offenbar hat es sich herumgesprochen, dass man mit Menschen reden muss, wenn man etwas über ihre Lebenswelt erfahren will. Nichtsdestotrotz legen Interviewdaten keineswegs letzte Wahrheiten offen, denn ihr Entstehen ist immerzu in soziale Konstruktionsprozesse eingebunden, die sowohl vonseiten des Interviewten wie auch vonseiten des Interviewenden vollzogen werden. Dies wird allerdings gerne übersehen und die Erzählungen von bestimmten Erfahrungen werden fälschlicherweise mit den Erfahrungen als solche verwechselt (vgl. Honer 1993: 246). Interviewdaten sind keine unbestechliche Kopie der vergangenen Wirklichkeit, sondern grundsätzlich rekonstruktiv überformt. Sie schieben sich »wie eine Wischblende über das, was sie zu repräsentieren vorgeben; das Ergebnis ist ein stark verschwommenes Bild, auf dem die Konturen des Objekts und die Wirkung des Filters nicht mehr auseinanderzuhalten sind « (Bergmann 1985: 307). ${ }^{39}$ Eine erzählte Erfahrung ist stets eine vom Erzähler gedeutete Erfahrung (vgl. Reichertz 2016: 187; Bude 1984), strategisch angepasst an und einbettet in eine bestimmte Kommunikationssituation (eben beispielsweise ein Interview). Und was der Rezipient unter dieser Erzählung versteht, ist seinerseits eine Deutung - sozusagen: eine Deutung einer Deutung einer Erfahrung.

39 Gerade dem biografischen Standpunkt kommt dabei eine kaum zu überschätzende Relevanz zu. Die erlittenen Verluste, die Thema der Interviews waren, haben sich zu ganz unterschiedlichen Zeitpunkten im Leben der Befragten ereignet der jüngste Todesfall lag nur wenige Wochen zurück, der älteste mehrere Jahrzehnte. (Interessant ist in diesem Zusammenhang, dass sowohl ein zu kurzfristig geschehener als auch ein zu lang in der Vergangenheit liegender Trauerfall von Probanden der Online-Umfrage als Begründung gegen die Teilnahme an einem weiterführenden Interview genannt wurden. Gibt es einen optimalen Termin?) Interviewdaten sind somit immer nur Momentaufnahmen, die zu einer anderen Zeit sehr wahrscheinlich anders ausfallen würden. Das soziale Verhältnis zum Verstorbenen, die emotionale Bewertung seiner `Nicht-Präsenz $<$, die Bedeutung kraftgebender Trauer- und Erinnerungsrituale, die Zufriedenheit mit der Wahl einer Bestattungsart, der Stellenwert eines Beisetzungsortes und vieles Weitere sind keine festen, sondern dynamische Größen. Langzeituntersuchungen, in denen die Befragten zu einem späteren Zeitpunkt noch einmal interviewt werden, versprechen vor diesem Hintergrund spannende Erkenntnisse. 
Der nachfolgende finale Abschnitt befasst sich mit einigen weiteren reflexionswürdigen Gesichtspunkten, die auch und vor allem bei Interviews mit Trauernden relevant sind.

\section{- Soziale Erwünschtheit}

Wie bereits an früherer Stelle konstatiert, sind Menschen in Interaktionssituationen tendenziell darauf bedacht, im Sinne einer kalkulierten öffentlichen Selbstpräsentation das Bild, das andere von ihnen haben (sollen), möglichst positiv zu beeinflussen. Allen Bemühungen um eine angenehme, vertraute und diskrete Gesprächsatmosphäre zum Trotz - und unbeschadet der Möglichkeit, dass sich der Befragte an einem Ort aufhält, zu dem er nur wenigen Menschen Zutritt gewährt - finden Interviews auf der Vorderbühne statt (Goffman 2006: 100ff.). Der Erzähler trägt seine Geschichte nicht für sich selbst vor, sondern für ein auf den ersten Blick überschaubares Publikum (den Interviewer), das auf den zweiten Blick vielleicht gar nicht mehr so überschaubar ist (potenzielle Leser der späteren Forschungspublikation). ${ }^{40}$ Dazu bedient er sich, möchte man die Goffman'sche Terminologie noch weiter strapazieren, zahlreicher dramaturgischer Mittel: Überzeichnung, Ausblendung, Straffung, Selektion und dergleichen. Erzählt wird vor allem das, was sich mit dem eigenen Selbstbild und den Erwartungen von sozialer Erwünschtheit vereinbaren lässt - umso mehr, je höher die normative Aufladung und das moralische Empörungspotenzial des thematisierten Gegenstandes ausfallen (die Trauer um einen verstorbenen Menschen dürfte recht weit vorne liegen). Das Wissen um jene potenzielle Verzerrungsquelle gehört zur Standardausrüstung eines empirisch arbeitenden Sozialforschers. Was seine Untersuchungsperson sagt, ist nicht automatisch das, was sie meint.

Dies ist jedoch weniger als Plädoyer zu verstehen, seinen Interviewpartnern grundsätzlich zu misstrauen und die Authentizität einer jeden Erzählung anzuzweifeln. Was im Hinblick auf Trauer tatsächlich eine private Meinung darstellt, und was im Dienste der sozialen Anerkennung und der Vermeidung negativer Sanktionierung schlichtweg snur gesagt wird, ist

40 Dieser Umstand mag auch durch das Wissen des Interviewten befeuert werden, dass seine Aussagen meist nicht lediglich protokolliert bzw. ex post aus dem Forschergedächtnis heraus rekonstruiert werden, sondern dass jedes seiner Wörter von einem Gerät aufgezeichnet wird und sich somit der späteren `Herrschaft « des Sprechers entzieht. Gleichwohl berichten Wissenschaftskollegen häufig - unsere Erfahrungen decken sich damit -, dass »das Aufzeichnungsgerät und der Fakt des Mitschneidens im Laufe des Interviews meist in Vergessenheit geraten " (Gläser/ Laudel 2010: 158). 
von außen ohnehin nicht zuverlässig zu ermitteln, sondern weiß - wenn überhaupt - nur der Trauernde selbst. Und weil Interviews immerzu in sozialen Kontexten stattfinden und somit innerhalb einer Gesellschaft, die von spezifischen Normalitätserwartungen getragen wird, lässt sich in solchen Forschungen ein an sozialer Erwünschtheit ausgerichtetes Antwortverhalten niemals gänzlich eliminieren. Dennoch ist diese Drittvariable ernst zu nehmen und ihr möglicher Einfluss auf die Interviewdaten zu berücksichtigen. Dieser lässt sich durch bestimmte Fragetechniken zumindest in einem gewissen Ausmaß kontrollieren und minimieren. ${ }^{41}$

\section{- Tränen}

Wer Interviews mit Menschen führt, die von ihrer Trauer erzählen, hat damit zu rechnen, dass diese Gespräche mitunter sehr emotional ausfallen und dass es zu Momenten kommen kann, in denen sowohl der Interviewte als auch der Interviewer in Verlegenheit geraten. Schließlich geht es, wie in diesem Text mehrfach betont, bei qualitativen Interviews nicht lediglich um das sachgerechte Sammeln und Auswerten von Informationen, sondern um den Aufbau von und die Arbeit an einer sozialen Beziehung. Die vorgetragenen Geschichten sind keine beliebigen Erlebnisberichte, sondern häufig werden hochdramatische Schicksalsschläge mitgeteilt, die nicht nur ihren Erzähler betroffen machen. ${ }^{42}$ Gelegentlich kam es vor, dass der Gesprächspartner ins Stocken geriet, um Fassung rang oder gar für einen Augenblick in Tränen ausbrach. Diese Momente auszuhalten, dem

41 Als zuträglich können sich ferner die bereits angesprochene Distanz und Anonymität im Rahmen einer telefonbasierten Unterhaltung erweisen.

42 Die Frage nach den Emotionen des Wissenschaftlers vor, während und nach einem Interview wurde im sozialwissenschaftlichen Methodendiskurs bislang relativ selten thematisiert (siehe aber Flam/Kleres 2015). Nicht zuletzt in Bezug auf die Trauerthematik ergeben sich spannende Anschlussüberlegungen, deren weitere Vertiefung lohnenswert erscheint: Wo verläuft etwa der Grat zwischen einer eher symbolischen und einer affektuellen Anteilnahme? Wie wichtig ist es, in solchen Momenten die Kontrolle zu behalten und Abstand zum Untersuchungsgegenstand zu wahren? Gibt es so etwas wie eine unbemerkte, aber folgenreiche wissenschaftliche Emotionssozialisation? Gewöhnt man sich schlichtweg an das >Leiden der anderen? Und was ist, wenn nicht nur der Interviewte, sondern auch der Interviewende Tränen vergießt? Welche Auswirkungen hätte dies für die weitere Gesprächsdynamik? Sind Soziologentränen illegitime Tränen, weil sie die Vorstellung von wissenschaftlicher Professionalität konterkarieren und eine Distanz aufheben, die unbedingt notwendig ist? Oder sind sie im Gegenteil sogar als essenzielle Erkenntnisquelle ernst zu nehmen: Wenn (die eigenen) Tränen nicht lügen, dann lügen auch nicht die daraus ableitbaren Daten (Gould 2015)? 
inneren Drang zu widerstehen, seinen Gesprächspartner mit einem schlagartigen Themenwechsel abzulenken, ihm stattdessen die Zeit zu geben, die er benötigt, ihm empathisch das Gefühl zu vermitteln, dass dieser zeitweilige Kontrollverlust absolut legitim ist, und ein situationsabhängiges Feingefühl dafür, wie detailliert man überhaupt nachfragen soll, um an forschungsrelevante Informationen zu gelangen - ob man also einem bestimmten Thema trotz beiderseitiger Anstrengungserscheinungen weiter nachgehen oder zur Wahrung einer möglichst angenehmen Gesprächsatmosphäre besser mehr Vorsicht walten lassen sollte - all das gehört zu den wesentlichen Anforderungen des Interviewers im Trauerkontext.

Gerade solchen Forschenden, die mit ihrem Handwerk noch nicht so sehr vertraut sind und für die die Befragung einer fremden Person mit derart intimen Inhalten vermutlich ein Novum bedeutet, mögen Situationen wie diese höchst befremdlich erscheinen und eine enorme psychologische/ soziale Herausforderung darstellen. Wie sehr man ihr gewachsen ist und wie sehr man an ihr wächst, hat natürlich nicht nur mit den persönlichen Eigenschaften des Interviewenden und seinen Vorerfahrungen zu tun, sondern auch mit dem Gesprächspartner und der Beziehung zu ihm. Wie sich diese gestaltet und ob es überhaupt zu den beschriebenen heiklen Momenten kommt, lässt sich im Vorfeld schwer antizipieren. Im Kontinuum von defensiver Nüchternheit und expressiver Emotionalität, so eine Erkenntnis aus unserer Forschung, bieten die einzelnen Interviews eine bemerkenswerte Variation. Während manche Personen einen relativ abgeklärten Umgang an den Tag legten oder zumindest einen entsprechenden Eindruck erweckten, ließen andere erkennen, dass sie den Verlust (zum Teil auch nach vielen Jahren/Jahrzehnten) nicht überwunden hatten, und meldeten mitunter Zweifel an, dass dies überhaupt jemals möglich sei. ${ }^{43}$ Zudem verstanden sich nicht alle Befragten zum Zeitpunkt des Gesprächs als Trauernde, sondern vielmehr als Menschen mit Trauer- bzw. Verlusterfahrung - ein feiner Unterschied, der durchaus von Gewicht sein kann.

43 Allein aus dem Verhalten des Gesprächspartners lassen sich freilich nur vage Mutmaßungen über dessen faktische affektuelle Betroffenheit und den Status quo seiner Trauer anstellen. Wer während eines Interviews Tränen vergießt, trauert nicht automatisch mehr als jemand, der dies nicht tut - ein solcher Kausalschluss wäre schon deshalb unterkomplex, weil er die Wirkmacht sozialer Normen der Privatisierung und Regulation von Emotionen ausblendet. Ohnehin liegt unsere Aufgabe nicht darin, zu bewerten, wie erfolgreich eine Untersuchungsperson ihren Verlust bewältigt hat; gleichwohl ist diese schwer zugängliche Variable bei der Entscheidung für oder gegen eine Interviewteilnahme (und letztendlich auch für die Gesprächsdynamik) sicher nicht ohne Belang. 
- Definition der Interviewsituation

In welche Richtung ein Interview verläuft, hängt nicht zuletzt davon ab, wie die jeweils Beteiligten den Gesprächsrahmen deuten. Meist geschieht dies implizit, d.h. das, was die Interagierenden in ihrer Interaktion sehen, bringen sie zwar in ebendiese ein, es kommt jedoch nicht ausdrücklich zur Sprache, sondern ist mehr oder minder szwischen den Zeilen $<$ zu lesen. Aufschlüsse versprechen beispielsweise Antworten auf die Frage, was einen zur Teilnahme an unserer Studie bewogen hat. Neben dem Wunsch, etwas verändern $\mathrm{zu}$ wollen, wurde auffallend häufig darauf aufmerksam gemacht, dass man - gemäß dem subjektiven Empfinden - nur selten die Gelegenheit erhält, mit einem anderen Menschen über die eigene Trauer zu sprechen, ohne dabei Konsequenzen zu befürchten (Ignoranz, Distanzierung, Unverständnis, Zurückweisung, Verurteilung, aber auch ein `Zuviek an Mitleid und Bemutterung). Ansprechpartner finden sich klassischerweise im Familien- oder Freundeskreis, in der Person des Lebensgefährten manchmal aber auch im professionalisierten Bereich (Trauergruppe, Seelsorge, Psychotherapie).

Auch ein Soziologe, der zu Trauer forscht, tut dies von einer professionellen Warte aus. Doch obwohl sich gewisse Parallelen zu psychotherapeutischen und (telefon-)seelsorgerischen 'Trauerthematisierungszusammenhängen ${ }^{44}$ nicht leugnen lassen (offene, narrative Ausrichtung, gemeinsamer Beziehungsaufbau, Auskünfte des Befragten über intime Dinge, unterstützendes Zuhören durch den Interviewer usf.), folgt das qualitative Interview ausdrücklich anderen Prinzipien. Diese stehen nicht etwa im Dienst der Trauerbewältigung, der psychosozialen Intervention bzw. der Hilfe (zur Selbsthilfe) in einer akuten Notlage, sondern der methodisch kontrollierten Generierung von wissenschaftlichen Daten. Ob ein qualitatives Interview gut oder weniger gut gelungen ist, bemisst sich folglich nicht an der anschließenden Gefühlslage des Befragten - wenngleich unter forschungsethischen Gesichtspunkten negative Effekte wohl kaum beabsichtigt sein dürften und sich das Gespräch optimalerweise für beide Akteure als gewinnbringend (zumindest nicht als verlustbringend) erweist. Von der

44 Dass Psychotherapie, Seelsorge und Trauerbegleitung hier in einem Atemzug erwähnt werden, ist allein der notwendigen Reduktion von Komplexität geschuldet und erfolgt unter Anerkennung grundlegender Unterschiede, die jene Konzepte schon hinsichtlich Tätigkeitsqualifikation, Voraussetzungen, Klientel, Ziele, Durchführung und ihrer Variantenvielfalt aufweisen. Ihr verbindendes Element besteht in der Bemühung um Intervention eines spezifischen Problemzustandes das macht sie als Kontrastfolie zu qualitativen Interviews attraktiv. 
Figur des Therapeuten unterscheidet sich die des Interviewers bereits in seinem Autoritätsanspruch: »Therapists become authority figures, responsible for life changes and improvement; they seek to enable affective experiencing, cognitive mastery, and behavioral regulation. Qualitative research interviewers are more equal partners in an intersubjective storytelling experience.« (Rossetto 2014: 483)

Obwohl der Interviewer sich seiner Wissenschaftlerrolle mit den an sie gerichteten Erwartungen bewusst ist und wohl kaum ernsthafte therapeutische Ambitionen hegen dürfte, stellen sich in der Forschungspraxis doch einige Unsicherheiten ein, die insbesondere das Verhältnis von Distanz und Nähe betreffen. Wie distanziert steht man den Kommunikationsinhalten und Deutungsangeboten des anderen gegenüber, um nicht zu therapeutisch/seelsorgerisch zu wirken - und wie viel Nähe ist andererseits notwendig, um nicht zu emotions- und teilnahmslos, oder gar desinteressiert zu wirken? Soll man die teils unter Tränen berichteten Erlebnisse lediglich registrieren, um den Gesprächspartner in seiner weiteren Erzählung möglichst wenig zu beeinflussen? Oder erreicht man eine in den einschlägigen Lehrbüchern oft empfohlene snatürliche` Gesprächsatmosphäre gerade dadurch, dass man sich in dieser Angelegenheit so verhält, wie man sich in außerwissenschaftlichen Kontexten verhalten würde? Pauschale Lösungen gibt es nicht; solche und andere Fragen müssen die Forschenden aus der jeweiligen Situation heraus (und im Einklang mit ihrer konkreten Forschungsfrage) für sich beantworten. Jedenfalls wird hier deutlich, dass die Wissenschaftlerrolle, konfrontiert man sie mit dem spezifischen Bezugsrahmen der Trauer, eben doch nicht so klar ist, wie man vielleicht meinen möchte.

Auch wenn das Studium der Soziologie weder zum Psychotherapeuten noch zum Seelsorger noch zum Trauerbegleiter qualifiziert, wissenschaftliche Interviews eigenen Absichten folgen und sich auch die Interviewpartner für gewöhnlich nicht in der Rolle des hilfebedürftigen Klienten sehen, ${ }^{45}$ kann es im Zuge des Gesprächs durchaus zu (nicht-intendierten)

45 Das Gegenteil lässt sich natürlich nie ganz ausschließen - denn sonst wären die Erwartungen, die Wissenschaftler und ihre Gesprächspartner an ein qualitatives Interview richten, immerzu deckungsgleich und man könnte die genauen Absichten des jeweils anderen völlig durchschauen. Manchmal bringen Forschungsteilnehmer ihr persönliches Verständnis von der Wissenschaftlerrolle explizit zum Ausdruck. In einem telefonischen Vorgespräch zur Abstimmung eines Interviewtermins betonte ein Proband, wie wichtig es ihm sei, endlich mit jemandem über seine Erlebnisse sprechen zu können - bisher habe er nämlich keinen Therapieplatz bei einem Psychiater bekommen! 
quasi-therapeutischen Effekten kommen. Dazu zählen ausgelöste Reflexionsprozesse, die nicht nur den Interviewverlauf, sondern auch den weiteren Umgang mit der Trauer prägen, das Emporkommen längst vergessener Erinnerungen, neu erschlossene Horizonte und (Selbst-)Erkenntnisse bis hin zu Neuinterpretationen des Verlustes, der Trauer und der Beziehung zum Verstorbenen - oder schlichtweg das befreiende Gefühl, in einem geschützten Kommunikationsraum, in dem man mit seiner Trauer ernst genommen wird, sich etwas son der Seele reden zu können (vgl. Loch/ Rosenthal 2002: 223), ohne dabei bestimmte Auffassungen, Gefühle, Entscheidungen usw. verteidigen zu müssen. ${ }^{46}$ Die Gleichsetzung von Interviews mit der bloßen Übertragung von Informationen, bei der nur der Befragte etwas gibt und nur der Interviewende etwas nimmt, greift auch und gerade vor diesem Hintergrund zu kurz. Es liegt vielmehr ein wechselseitiges Geben und Nehmen vor; die freiwillige Partizipation an einer wissenschaftlichen Studie, für die man kein Geld bekommt, aber Zeit investieren muss, ist jedenfalls nicht allein auf altruistische oder prinzipiell wissenschaftsfreundliche Beweggründe zurückzuführen (Reichertz 2012; Meitzler 2017b).

Der angedeuteten Berührungspunkte zum Trotz ist beim Vergleich von qualitativen Interviews mit psychotherapeutischen bzw. seelsorgerischen Gesprächen prinzipiell Vorsicht geboten. Es hängt vom konkreten Untersuchungsgegenstand ab, wie sehr einem Interview therapeutische Potenziale zuzutrauen sind. Und auch wenn es tatsächlich um den Verlust eines Sozialpartners geht, wäre es doch etwas voreilig, würde man dem Forschungsteilnehmenden ein pauschales Interventionsinteresse unterstellen. Nicht für jeden Hinterbliebenen gilt ein Todesfall als akutes Krisenerlebnis mit längerfristigen psychosozialen Folgen und das Darüber-interviewt-Werden als heilsame Erfahrung. Inwiefern all dies tatsächlich der Fall ist, ist nicht zuletzt eine Frage der (nachträglichen) Deutung des Befragten (vgl. Birch/Miller 2000: 194). So betrachtet mögen manche Interviews ihrem Charakter nach stherapeutischer sein als andere. Ferner kann Forschung

46 Passend dazu resümierte eine Interviewpartnerin am Ende des Gesprächs: »Ich muss jetzt sagen, jetzt so im Nachhinein denk' ich mir, das Gespräch mit Ihnen, das war jetzt toll. Weil man da doch mal auch jemandem, der wirklich interessiert ist, weil die meisten Leute sind auch nicht wirklich interessiert, wenn man ihnen sowas erzählt. Die hören dann zwar zu und sagen: jaja. Aber bei Ihnen war das jetzt so, dass Sie sich wirklich dafür interessiert haben, für Gefühle, für Emotionen und den ganzen technischen Ablauf auch. Ja das hat mir jetzt doch, muss ich sagen, das fand' ich jetzt prima!« (Interview M106, 62:31) 
nicht nur Einfluss auf die subjektive Sichtweise des Beforschten nehmen, sondern auch auf die des Forschenden.

\section{- Subjektivität des Forschenden}

Weiter oben wurde bereits festgehalten, dass qualitative Interviews den Wissenschaftler vor die Herausforderung stellen, nicht lediglich Fragen zu formulieren und sich »hinter der Rolle des neutralen, bloß analysierenden Beobachters « zu verstecken (Hopf 1978: 107), sondern sich darüber hinaus rals Person e einzubringen und an der sozialen Beziehung zu seinem Gesprächspartner aktiv mitzuarbeiten. Dass Interviewer nicht lediglich informationsverarbeitende Maschinen sind, sondern »lebende Messinstrumente«, die ein eigensinniges "Reaktions- und Einstellungsvermögen « besitzen (Bortz/Döring 2006: 246) und nolens volens immer wieder ihre eigenen subjektiven Qualitäten in die Interviewsituation hineintragen, dürfte innerhalb der qualitativen Sozialforschung kaum mehr bezweifelt werden. ${ }^{47}$ Und welches Untersuchungsfeld provoziert die Frage nach der Forschersubjektivität deutlicher als der Umgang mit dem Lebensende?

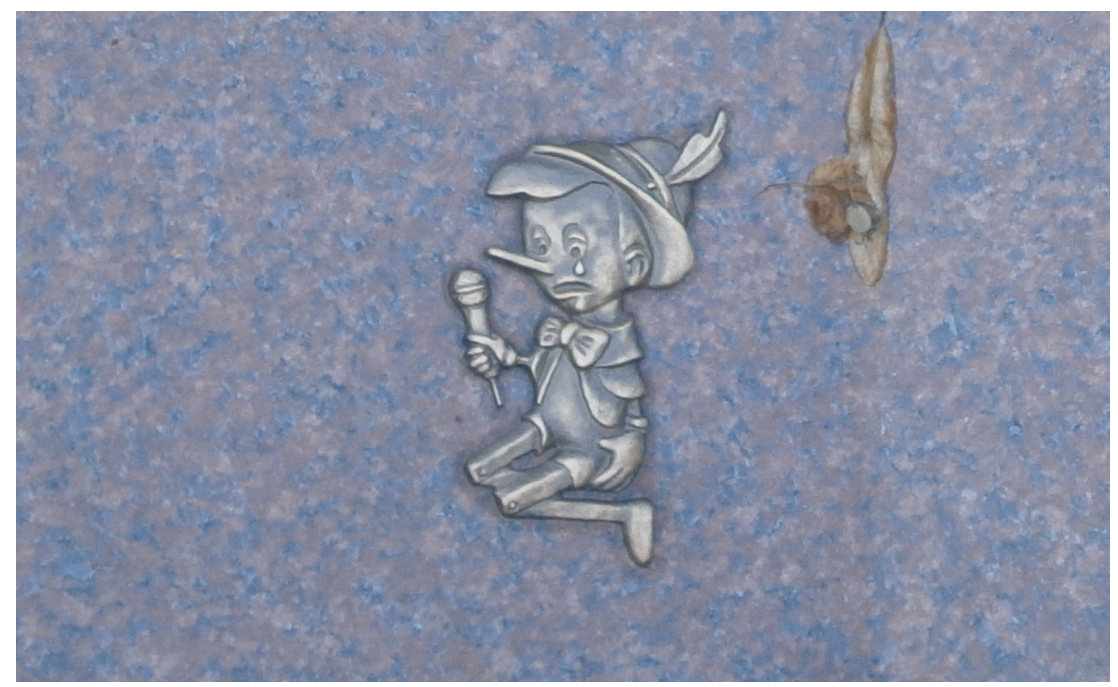

47 Doch nicht nur während der Datenerhebung, sondern auch in den anderen Phasen des Forschungsprozesses (Suchen und Finden von Thema und Fragestellung, Datenauswertung, Theoriebildung, Ergebnisdarstellung) spielt die Forschersubjektivität eine Rolle (Reichertz 2015). 
Als »Grenzsituation per excellence« (Berger/Luckmann 2004: 108) überschreitet der Tod aufgrund seiner Nicht-Erfahrbarkeit die eigene Lebenswelt; gleichzeitig ist das Sterblichkeitswissen elementarer Bestandteil ebendieser und schiebt sich je nach konkreter Ausgangslage bald mehr, bald weniger aufdringlich ins Bewusstsein. Anders als bei solchen Forschungsgegenständen, die aufgrund hochspezifischer Eigenheiten wahrscheinlich keine Berührungspunkte zum alltagsweltlichen, d.h. außerwissenschaftlichen Leben des Forschenden aufweisen, ist es schier unmöglich, keine wie auch immer geartete Haltung zum Lebensende zu haben. Es ist weder als erwartbares biografisches Faktum noch als Wissensbestand eliminierbar. Das wiederum erleichtert eine »Vertauschbarkeit der Standpunkte. Wäre ich dort, wo er [der andere; MM] jetzt ist, würde ich die Dinge in gleicher Perspektive, Distanz, Reichweite erfahren wie er; und wäre er hier, wo ich jetzt bin, würde er die Dinge in gleicher Perspektive erfahren wie ich « (Schütz) Luckmann 2003: 99). Was eine bestimmte Angelegenheit für jemanden bedeutet, ist vor allem dann nachvollziehbar, wenn man selbst schon einmal in einer vergleichbaren Situation gewesen ist (das ist die Kernprämisse der sogenannten lebensweltanalytischen Ethnografie; Honer 1993; Hitzler/Eisewicht 2016). ${ }^{48}$ Kein Forscher mag glaubhaft versichern können, sich nicht schon einmal in irgendeiner Weise gedanklich mit der Endlichkeit auseinandergesetzt zu haben; in den meisten Fällen wird man sogar davon ausgehen können, dass diese Auseinandersetzung nicht nur theoretisch-abstrakter Natur gewesen ist, sondern sich auch schon mindestens einmal als konkrete Trauererfahrung geäußert hat. Und auch ohne sie besteht zumindest eine Vorstellung davon, »dass man jeden Moment selbst die Seite wechseln und vom Forscher zum Betroffenen, zum Trauernden werden kann« (Aka 2007: 37).

Trotz aller artifizieller Befremdungsbemühungen geht der Wissenschaftler nicht als unbeschriebenes Blatt in die Interviewsituation, sondern er führt ein »Gepäckwissen« (Benkel 2013: 86) mit sich. Zwar mag dieses Ge-

48 Sein lebensweltliches Trauerwissen kann dem Interviewenden ohne Zweifel dabei helfen, sich in die Situation seiner Untersuchungsperson hineinzuversetzen und somit bestimmte Gefühle, Gedanken und Handlungen nachzuvollziehen - dies gelingt jedoch immer nur bis zu einem gewissen Punkt. Die von beiden Interagierenden geteilte Erfahrung des Verlustes eines bedeutsamen Anderen bietet eine Ressource für annäherndes, nicht aber für totales Verstehen (selbst wenn es sich bei diesem bedeutsamen Anderen um dieselbe Person handeln würde). Denn andernfalls wäre Trauer nichts weiter als eine automatisierte Reaktion auf einen bestimmten Reiz, die sich von einem Fall zum nächsten in gleicher Weise wiederholt. Das würde (nicht zuletzt in der zeitgenössischen, pluralen Gesellschaft) der Komplexität des Gegenstandes alles andere als gerecht werden. 
päck mal leichter und mal schwerer ausfallen, ablegen lässt es sich allerdings nicht, sondern es begleitet einen während des gesamten Forschungsprozesses und meldet sich auch und gerade während der konkreten Interviewsituation zu Wort. Ist somit all das, was der Gesprächspartner mitteilt, nur vor dem Hintergrund der eigenen Einstellung zum Tod im Allgemeinen und der subjektiven Trauererfahrungen im Besonderen zu verstehen? Es lässt sich zumindest nicht leugnen, dass die doch recht unterschiedlichen Erzählungen zugleich unterschiedliche affektuelle Reaktionen beim Interviewenden auslösen können. Manchem davon wird er mit größerer Distanz begegnen, weil er es als >unumgängliche Lebensrealität ‘ verbuchen kann. Anderes mag ihn ob seiner Tragik weitaus mehr berühren, ja vielleicht sogar schockieren und ein Gefühl höchster Beklommenheit auslösen, etwa weil das fremde Schicksal auffallend an das eigene Schicksal erinnert oder weil es grundlegende Ängste tangiert (z.B. davor, dem eigenen Kind könnte etwas zustoßen; man könnte die Nachricht vom plötzlichen Unfalltod eines Nahestehenden erhalten; oder es besteht die Sorge, im jungen Alter an einer schweren Erkrankung sterben zu müssen - bzw. im hohen Alter erst nach einer langen Leidenszeit sterben zu dürfen).

Nicht nur im Zusammenhang mit der Trauerthematik gilt: Der Versuch, seine eigene Betroffenheit und Perspektivgebundenheit im Dienste der Wissenschaft vollends auszuradieren, ist zum Scheitern verurteilt, und es stellt sich ohnehin die Frage, was damit gewonnen wäre. "Lässt man die Forscher/innensubjektivität etwas mehr zu, dann sind Interviews keine Datenerhebungen mehr, sondern Gespräche mit einem Gegenüber, und Auswerten ist kein Kodieren mehr, sondern das Deuten von Handlungen. Und das tut unter dem Strich auch der Forschung gut (Reichertz 2015: unpag.). Subjektive Reaktionen des Forschers sind deshalb nicht schlichtweg »als Quelle einer bedauerlichen Störung [abzutun], sondern als wichtige, ja sogar unverzichtbare Quelle relevanter, ergänzender verhaltenswissenschaftlicher Daten« anzuerkennen (Devereux 1984: 52).

Ferner stellt sich die Frage, inwieweit der Interviewende sein Gepäckwissen nicht nur hintergründig smitschwingen lassen, sondern auch explizit machen soll. Das Mitteilen eigener Ansichten, vielleicht sogar die Preisgabe persönlicher Trauererfahrungen könnten insbesondere jenen Gesprächen, die nicht so recht in Gang kommen wollen oder zu sehr festgefahren erscheinen, neue Impulse verleihen und insofern zu einer vertrauensvollen Atmosphäre beitragen, als der Forscher damit signalisiert, auch setwas zu investieren<. Andererseits geht damit die Gefahr einher, die Äußerungen des Interviewten durch die Präsentation einer möglicherweise normativ wirkenden Vergleichsfolie unnötig zu manipulieren. Das gilt erst recht dann, wenn der Gesprächspartner eher eigenwillige Ansichten vertritt, die 
konträr zu denen des Wissenschaftlers stehen. Unsere Teilnehmenden sprachen bisweilen davon, dass diese oder jene ihrer Verhaltensweisen ${ }^{49}$ »krank« sei oder zumindest »nicht ganz normal«; anderen Erzählungen wurde ein kurzer Prolog vorausgeschickt, der sinngemäß lautet: »Ich weiß, das hört sich für Sie jetzt verrückt an... « Solche Deutungsangebote bringen den Interviewer in die ungünstige Position, nicht nicht normativ auf sie reagieren zu können. Soll man die Selbststigmatisierung des anderen relativieren, etwa indem man ihm gegenüber beteuert, schon häufiger von solchen Dingen gehört, sie womöglich sogar selbst schon einmal getan zu haben? Oder ist in diesem Zusammenhang weniger tatsächlich mehr? Doch selbst (oder gerade) wenn man das Gesagte schweigend ignoriert bzw. schlichtweg zu einem anderen Thema übergeht, könnte dieses kommunikative Manöver entsprechende Deutungen auf der anderen Seite nach sich ziehen.

Das qualitative Interview stellt sich vor diesem Hintergrund als Balanceakt heraus, der darin besteht, sich einerseits weit genug selbst einzubringen, um die Frage-Antwort-Statik zu überwinden und die Künstlichkeit des Gesprächsarrangements zu vermindern, ohne dabei andererseits dem Gegenüber Erwartungen von Normalität und sozialer Erwünschtheit zu suggerieren, die wiederum als Drittvariablen auf die Qualität der Daten einwirken. Inwieweit sich dieser Anspruch in der konkreten Interviewsituation faktisch umsetzen lässt, ist eine andere Frage. Die gezielte Thematisierung eigener Einstellungen und Erfahrungen vonseiten des Interviewenden könnte bei der Untersuchungsperson wiederum den Eindruck erwecken, ihr werde nicht die erhoffte Aufmerksamkeit zuteil und es gehe gar nicht so sehr um ihre Person, sondern um die des Forschenden. Nicht zuletzt aus diesen Gründen haben wir es während der Interviews so weit wie möglich vermieden, unser lebensweltliches Trauerwissen offen zu legen. Auch sollten die Interviewpartner optimalerweise nicht schon im Vorfeld durch unsere bisherigen wissenschaftlichen Erkenntnisse beeinflusst werden - derweil sich diese Variable natürlich nur bedingt kontrollieren lässt. ${ }^{50}$

49 Auffallend häufig genannt wurde in diesem Kontext das Reden mit Verstorbenen.

50 Die überwiegende Mehrheit der Befragten hatte sich vor ihrer Teilnahme nicht näher mit unseren thanatologischen Arbeiten auseinandergesetzt und war somit noch relativ unvoreingenommen. Andere kannten uns bereits aus früheren $\mathrm{Zu}$ sammenhängen (insbesondere die oben erwähnten Berufspraktiker) oder recherchierten im Vorfeld des Gesprächs im Internet. Wieder andere baten uns nach dem Interview um die Zusendung von Fachliteratur aus unserer Feder. 


\section{Umgang mit dem Interviewmaterial und Ausblick}

Sämtliche unserer Interviews wurden - nach ausdrücklicher Zustimmung der Teilnehmenden - mit einem Diktiergerät aufgezeichnet. ${ }^{51}$ Der handlungsentlastende Nutzen dieser »registrierende[n] Konservierung " (Bergmann 1985: 305) bestand darin, dass nicht schon während des Gesprächs ausführliche Protokollierungen vorgenommen werden mussten. Insbesondere bei wenig standardisierten, narrativen Interviews ist dies eine wichtige Ressource, weil hierdurch die Konzentration auf die vom Interviewpartner getätigten Aussagen und das Überlegen von geeigneten Fragen deutlich erleichtert wird.

Im Anschluss wurden die Interviews anhand der Audioaufzeichnungen protokolliert. Die entstandenen Protokolle hielten nicht nur die thematisierten Inhalte fest, sondern auch die subjektiven Eindrücke des Interviewenden bezüglich seines Gesprächspartners und der Gesprächsdynamik im Allgemeinen. Vereinzelt wurden >dichte Interviewpassagen transkribiert gemeint sind solche Sequenzen, in denen die Schwerpunkte unseres Forschungsinteresses besonders aufschlussreich problematisiert wurden. In einem weiteren Schritt haben wir diese Passagen aus den Protokollen extrahiert und nach verschiedenen Kategorien sortiert (siehe nachfolgendes Kapitel). 52

Im Zentrum dieses Beitrags standen methodologische Reflexionen einer empirischen Untersuchung der Emotion Trauer. Dass dieses Unterfangen aufgrund der spezifischen Ausgangslage diverse Schwierigkeiten bereithält, wurde anhand eigener Felderfahrungen zu zeigen versucht. Zwar gehört die Emotionsforschung nicht gerade zum Kerngeschäft der Soziologie. Eine Disziplin, die sich die Analyse von menschlichem Handeln auf die Fahnen geschrieben hat, kommt indes nicht umhin, auch Emotionen zu berücksichtigen, die Handlungen schließlich sowohl anleiten, als auch aus ihnen hervorgehen. ${ }^{53}$ Trauer kann somit als Beispiel für weitere Arbeiten dienen, die mit je eigenen Prämissen ähnliche oder ganz andere affektuelle

51 Abgesehen von einer Ausnahme, bei der sich der Interaktionspartner gegen die Aufzeichnung des Interviews aussprach.

52 Eine nähere, auch statistische Implikationen und Korrelationen berücksichtigende Darstellung der Datenauswertung ist in Vorbereitung.

53 Trauer als Gegenstand der Emotionssoziologie wird thematisiert bei Petersen/ Jacobsen 2019 und Jakoby 2012. Zu Emotionen und Sozialtheorie im Allgemeinen siehe Schützeichel 2006 und Barbalet 2000. Grundsätzliches zur Emotionssoziologie thematisieren Bericat 2016, Harris 2015, Stets/Turner 2007/2014 sowie Turner/Stets 2005. 
Zustände in den Vordergrund rücken. Gerade für eine empirisch (qualitativ) operierende Soziologie, die ihr Potenzial auf diesem Gebiet noch nicht annähernd ausgeschöpft hat, bieten sich hier spannungsreiche Möglichkeiten, ihre Leistungsfähigkeit auch an vermeintlich rabgeschlossenen< Forschungsfeldern aufzuzeigen. 


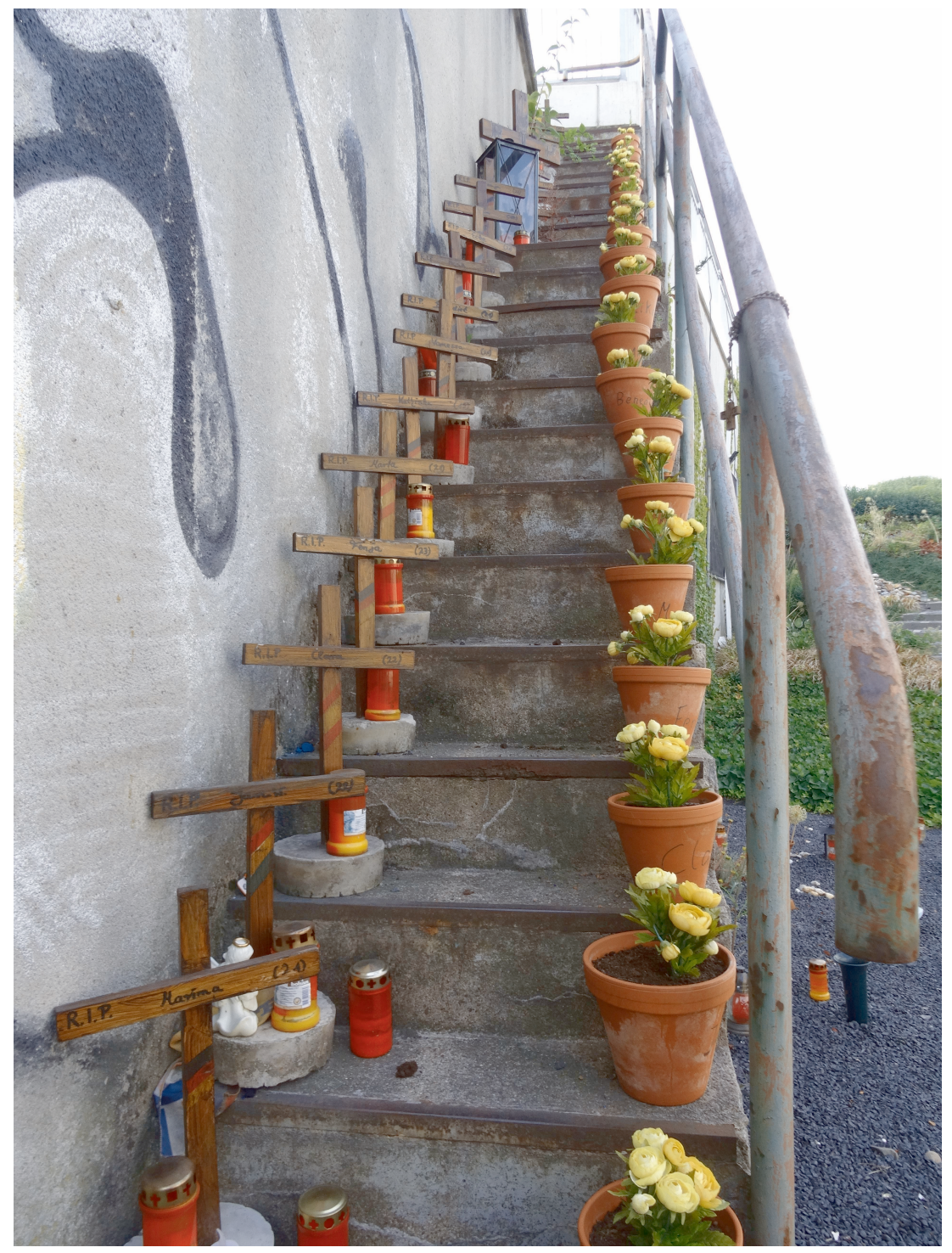




\title{
Zur Rekonstruktion von Trauererfahrungen. Einstellungsäußerungen im Interviewkontext
}

\author{
Thorsten Benkel \& Matthias Meitzler
}

Aus der Menge der Interviews, die wir zwischen 2015 und 2018 geführt haben, lassen sich einige aussagekräftige Passagen extrahieren, die den Wandel nicht nur der Gesellschaft, sondern - damit untrennbar und dialektisch verbunden - vor allem von Mentalitäten aufzeigen. Unsere Gesprächspartner fungieren in diesem Sinne als >Lautsprecher sozial kursierender Haltungen, die sich insbesondere in den letzten circa 20 Jahren Bahn gebrochen haben. Angesichts unserer Interview- und auch Umfragesowie ethnografischen Daten kristallisiert sich in der soziologischen Analyse heraus, dass eine immer stärkere Ausdifferenzierung das öffentliche Image von Trauer und Trauern kennzeichnet. Mit anderen Worten: Es gibt nicht die< Trauernden, sondern kultur-, subjekt- und durchaus auch situationsspezifische Trauerfigurationen. Wir verstehen diesen Transformationsvorgang als Effekt der Individualisierung, die hier in Verbindung mit gesellschaftlichen Ordnungsansprüchen tritt.

Es erscheint gerade vor dem Hintergrund der aktuellen Revision diverser Landesbestattungsgesetze in Deutschland (bzw. des Versuchs der Gesetzesreform) adäquat, diejenigen Stimmen, die sich aus einer Betroffenenperspektive heraus melden, anzuhören. Damit soll nicht zum Ausdruck gebracht werden, dass die abgedruckten Wortmeldungen die >Objektivität< bzw. WWahrheit< des Diskurses abbilden. Vielmehr geht es uns um ein Kaleidoskop kursierender Einstellungen und Einschätzungen am Beispiel eines im Umbruch befindlichen gesellschaftlichen Phänomens.

Im Folgenden sind Zitate aus Gesprächen mit Menschen, die über Trauererfahrung verfügen, nach bestimmten kategorialen Dimensionen sortiert worden, um anhand spezifischer Themen und Sachfragen Einblicke zu geben in lebensweltliche Perspektiven zu Sterben, Tod und vor allem Trauer. Die Kategorien lassen sich als das Ergebnis einer typologisch orientierten Inhaltsanalyse des Interviewmaterials verstehen; genau genommen sind sie das Resultat der mit häufigster Frequenz genannten Bereiche. Ein Datenkorpus dieses Umfangs kommt schon aus forschungsökonomischen Gründen nicht ohne adäquate Kodierungsmaßnahme aus. Die Kategorisierung, die wir nachfolgend verwenden, ist selbstverständlich un- 
ter Vorbehalt zu genießen: Wie jede Einteilung in separate Kontextdimensionen steht auch sie zwangsläufig im Zeichen einer Komplexitätsreduktion am Material. Die kategoriale Zuordnung hebt selektive Interviewexzerpte notwendigerweise aus ihrem Zusammenhang und sortiert sie neu. Sie könnten auch anders angeordnet sein - und würden sich dann vermutlich anders >lesen lassen<.

Überdies ist zu bedenken, dass sich die jeweiligen Fallkonstellationen in diversen Punkten unterscheiden, etwa hinsichtlich der Frage, in welcher biografischen Situation sich der berichtete Verlust ereignet hat, wie lange dies inzwischen zurückliegt, ob sich der Interviewte gegenwärtig als Trauernder begreift, und um welche Personen (Kinder, Geschwister, Eltern, Großeltern, Freunde, Arbeitskollegen usw.) konkret getrauert wird. Weil es uns insbesondere darum geht, was die einzelnen Fälle ihrer heterogenen Ausgangslagen zum Trotz gemein haben, sind feinere Differenzierungen an dieser Stelle für unsere Zwecke weniger ausschlaggebend. Nachfolgend soll es, auch mit Blick auf die Praxisverwertbarkeit unserer Daten, nicht um eine streng hermeneutische Auslegung der mitgeführten Sinngehalte gehen. Wer sich über das abgebildete Datenmaterial hinaus für die soziologischen Implikationen interessiert, sei auf unsere weiteren Publikationen verwiesen.

Im Dienste der besseren Lesbarkeit wurde der Wortlaut der Interviews während der Verschriftlichung behutsam sprachlich angeglichen. Die Geschlechterzugehörigkeit wurde neutralisiert, da sie sich im Kontext der gewählten Kategorien nicht als Einflussfaktor herausgestellt hat (was indes nicht bedeutet, dass sie nicht für andere Forschungsfacetten der zugrundeliegenden empirischen Arbeit von Bedeutung ist!). Wenn vom »Gesprächspartner « die Rede ist, dann steht dies für alle Geschlechter. Hervorhebungen sind durch Unterbrechung der Kursivierung gekennzeichnet. Im Zuge der Anonymisierung wurden darüber hinaus sämtliche Personen- und Ortsnamen verfremdet.

Die abgedruckten Auskünfte entstammen einem empirischen Korpus aus 153 Stunden Interviewaufzeichnungen. Das Material bildet einen zentralen Bestandteil unserer Forschungsdaten, die daneben aus über 900 ausgefüllten Fragebögen, aus Beobachtungen während der Feldforschung, aus Ad-hoc-Gesprächen und aus weiteren Angaben bestehen. Eine intensivere Auseinandersetzung mit den Aufzeichnungen ist für spätere Publikationen vorgesehen. 
(1) "Dass man das vielleicht auch öffentlich macht..." - Gründe für die Teilnahme an der Studie

Empirische Untersuchungen in den Sozialwissenschaften sind selten mit hohen Rücklaufquoten gesegnet. Dies gilt insbesondere für Studien, die wie unsere Arbeit zur Autonomie der Trauer - gleich zwei heikle Facetten aufweisen. Zum einen sind Nachforschungen zur Trauer immerzu mit einem Eindringen in die persönliche Intimsphäre verbunden. Zum zweiten wird dabei (unter anderem) eine illegale Praxis thematisiert, die, wenigstens theoretisch, in Deutschland unter Strafe steht.

In die hier dargestellten Äußerungen sind überdies Zitate von Personen mit Trauererfahrung eingeflossen, die zwar nicht im juristischen Graubereich der Ascheaneignung zu verorten sind, die aber dennoch für die Debatte von Interesse sind. Die grundsätzliche Frage nach der Motivation, an unserer Studie teilzunehmen, ist auch für sich genommen schon aufschlussreich, offenbart sie doch Erwartungen und Hoffnungen, die von Menschen in der Rolle der Hinterbliebenen gehegt werden und die sie folglich mit der wissenschaftlichen Auseinandersetzung verbinden.

$01 \mid$ | Ja, ich find' das praktisch, finde das sebr schön, dass Sie das machen, denn es sind ja doch so viele Unsicherheiten bei den Menschen. Ich hatte sehr viele Bekannte, die wollen überhaupt nichts wissen vom Sterben, obwobl sie auch in meinem Alter sind. Die stecken den Kopf in den Sand. Ich finde, man sollte vielleicht die Menschen mehr aufklären. (P6, 5:51)

$02 \mid » J a$, weil ich das total interessant finde, dass es da überhaupt Überlegungen oder überhaupt mal 'ne Studie gibt, wie man's auch anders machen kann. (B5, $7: 16)$

03 | "Ich find's wichtig auch, dass es möglichst publik wird, weil viele Leute wissen das nicht, die wissen's nach wie vor nicht, die denken, sie müssen [...]. Also, wir ha'm ja in Deutschland noch 'ne Art oder wir ha'm einen Friedhofszwang, der aber problemlos zu umgehen ist.«(B8, 14:40)

$04 \mid$ "Die deutsche Mentalität ist sehr konservativ, die ist so altbacken. Und wenn sich keiner bemüht oder die Wünsche äußert [...] und wenn sich hier keiner rüttelt und schüttelt, [...] dann wird sich hier nichts ändern können. Die Masse macht das. Und wenn ich dazu ein bisschen beitragen kann, [...] es sind ja Erfahrungswerte, die ich weitergeben kann.«(B3, 10:08) 
$05 \mid$ "Weil ich's einfach wichtig finde, dass einfach, dass, ähm ja, vielleicht Sie was bewirken können, dass dieses Bestattungsrecht sich tatsächlich ein bisschen liberalisiert. Also, dieser Friedhofszwang, der mir selber, glaub ich, auch irgendwie ein Gräuel ist. Ich sag' zu meinen Kindern immer: Ihr könnt mich so, wie ich bin, einfach im Wald ablegen [lacht]. Stört mich überhaupt nicht.«(P1, 8:40)

o6 | "Äh, ich denke mal, dass es ibr Wunsch gewesen wäre, wenn ich jetzt mit ibr darüber gesprochen hätte, dass da 'ne Studie erstellt wird, ich glaube, sie wär' damit einverstanden gewesen, dass wir uns melden [...]. Dass man das vielleicht auch öffentlich macht [...], denn viele Menschen können sich das ja gar nicht vorstellen.«(B7, 6:05)

$07 \mid$ |Mir tut es auch gut, dass ich da an einer Studie mitwirken darf, weil, jetzt kommen mir nochmal die Tränen, weil das... [weint] vielleicht ein bisschen Sinn macht. [...] Wenn das irgendjemandem hilft, Ihre Studie, mit der eigenen Trauer umgehen zu können, dann macht das einen Sinn.«(M60, 119:26)

08 | »Ich hab' wirklich überlegt, als ich diesen Brief bekommen hab', hab ich gedacht: Ja, machste das, machste das nicht? Sag'ich: Ja, nee, das muss man machen. Das muss ich machen. Äh, aus dem einfachen Grunde, weil die Menschen schweigen immer solange und überhaupt und dann kannst du's so nicht verändern. Und ich bin dafür, dass sich das ändert. «(P3, 57:57)

(2) »...von da an war ich sowas von erleichtert." - Entscheidungsfindung

Diese Fragekategorie richtet sich an Personen, die den oben beschriebenen Weg der privaten Aschebeschaffung gegangen sind (oder diese Option zumindest gutheißen). Damit geht, bald mehr, bald weniger intensiv, die Erfahrung der skizzierten rechtlichen, moralischen und mitunter auch psychologischen Grenzüberschreitung einher. Inwiefern tatsächlich vorhandene Barrieren in Frage gestellt wurden, hängt vom Blickpunkt des Beobachters ab; Dimensionen wie >falsch und >richtig< sind hier, wie so häufig, schwerlich objektivierbar.

Uns interessiert, welche Reflexionsprozesse der Intention, so zu handeln, vorausgegangen sind (und sie begleitet haben). Relevante Fragen sind dabei: Gibt es klar benennbare Auslöser für den Entschluss? Handelt es sich um sehr ähnliche oder um divergente Motivlagen? Wer genau hat (wann) die Entscheidung getroffen? Welche Wissensquellen waren dabei von Relevanz? Wurden auch alternative Lösungswege in Erwägung gezogen? Und gibt es schließlich sogar Konstellationen, bei denen die Autono- 
mie der Handelnden so gestaltet wurde, dass sie gegen den (erklärten) Willen (oder das, was dafür gehalten wurde) der verstorbenen Personen verstieß?

09 | $\gg J$ a das war eigentlich ziemlich gleich klar. Also, mein Mann hatte mit diesem Thema insofern... ähm, also seine Mutter ist ganz normal klassisch beerdigt worden und da tat er sich schon ziemlich schwer mit und er hat auch immer gesagt [...], dass er mit dem... christlichen Glauben überhaupt nicht verbandelt war. Also insofern war die Idee schon klar, dass es nicht eine klassische Beerdigung werden würde. Und da er sehr verbunden mit dem Sauerland war, weil wir da auch sehr viel Rad gefahren sind, kam mir ziemlich schnell die Idee und da waren wir ziemlich schnell mit der Entscheidung auch durch.«(B5, 5:58)

$10 \mid » U n d$ so in der ersten Situation war das innerhalb von Sekunden klar, dass das eine richtige Entscheidung war und dann erst eigentlich Monate später dachte ich so, ja, wenn die Mama das so gewusst hätte von vornherein, wäre sie vielleicht nicht mit einverstanden gewesen. Aber jetzt wiederum hab ich ein ganz tiefes Gefühl, das ist das Richtige.«(B2, 7:00)

$11 \mid$ "Also, ich habe ja [...] wenn Sie so wollen [...] über die Verstorbene hinweg entschieden... äh, mit ibrem Wunsch. Also, ich... weiß aber genau, wenn es meine Mutter gekannt hätte, dass sie... damit einverstanden gewesen wäre. Also, für mich ist es eine super Lösung. «(P5, 23:14)

12 | Also, ihr Wunsch war, dass ich dann die Asche nehme und in diesen Wasserfall gleiten lasse und sie somit über das Wasser die Erde und die Wiese und das Tal, also alle Elemente... bestreicht und dann noch vielleicht bis ins Meer kommt. Das war ihre Vorstellung [...] und ich hatte auch das Gefühl, sie braucht kein Grab. Also, das war mir immer klar, ich... bewahr' sie im Herzen. [...] Ich hab' also gewusst, ich hab' kein Problem damit. Im Gegenteil, ich hab das Freunden erzählt, die so bisschen schamanisch unterwegs sind, und die haben gesagt: Wow, dann nehmen wir noch Weibrauch mit und Trommeln und... ha'm das auch meiner Mutter erzäblt und die hat gesagt, ja [...] vor Sonnenaufgang, damit uns nicht irgendwelche Wanderer überraschen und so [lacht]. Also, es war für sie ein Thema, mit dem sie wunderbar umgehen konnte und auch darüber sprechen.« $(\mathrm{B} 8,6: 11)$

13 | Interviewpartner berichtet von der Situation, in der er von der Möglichkeit einer privaten Ascheverwahrung erfuhr: »Und dann war ich so verzweifelt und unterhielt mich mit jemandem und die erzählte mir das hier, diese Version. Und wissen Sie, von da an war ich sowas von erleichtert. Es war, als 
wenn mir jemand die Schuld des Ganzen genommen hatte. Ich wusste nun, was ich wollte. Und da bin ich natürlich unheimlich dankbar [...]. Das war wie ein Glückstreffer, sag' ich jetzt mal. [...] In dem Moment, wo ich diese Möglichkeit bekommen habe, war das für mich die selbstverständlichste Sache.«(P3, 5:37)

$14 \mid$ "Ja, ich hab' nachts 'nen Anruf bekommen und musste am nächsten Morgen dann gucken, was ich mach' [...]. Das ging dann ganz schnell und dann bin ich natürlich, ähm... durchs Internet und hab' geguckt, was ist. Ich war schon überrascht, weil es gab viele Möglichkeiten... Fand ich auch alles... lustig, nur in dem Zusammenhang jetzt nicht wirklich passend... ähm ja, und dann dieses nach Hause bringen, zurück. Und da dacht $t^{\star}$ ch: Boah, das isses! Er wollte ja nach Hause zurück, also kommt er zurück.«(P10, 7:08)

15 | "Und ich finde das Ganze ja noch schöner, wenn man die Urne mit nach Hause nehmen könnte, dann hätt'ich mein Schatz hier zu Hause. Wir waren 59 Jahre verheiratet und hatten eine sehr gute Ehe, sehr glückliche Ehe. Und wenn ich den jetzt hier bei mir zu Hause hätte, wäre mir das noch lieber. Weil für mich ist es auch beschwerlich. Ich wohne in X-Stadt, das ist ein Vorort von Y-Stadt, ungefähr fünf Kilometer entfernt. [...] Wenn ich meinen Mann im Kolumbarium besuchen will, muss ich mit dem Taxi fahr'n, was mich immer so 28 Euro kostet. Ist natürlich auch nicht unerheblich. [...] Ich hab' mal im Internet geguckt, und da hab'ich eben gelesen, dass man die Urne nicht mit nach Hause nehmen darf, dass das nicht gestattet wird. Sonst hab'ich das Thema nicht weiterverfolgt. Ich wollte nur wissen, ob ich das machen kann, dass ich meinen Mann mit nach Hause nehme und... da hieß es: nein. Und jetzt vor zwei, drei Tagen hab ich zufällig gehört, dass man die Urnen auch mit nach Hause nehmen kann, wenn man das über die Schweiz macht. Das wusst'ich aber nicht. Wenn ich das gewusst hätte, hätt' ich das gemacht.«(P6, 6:22)

16 | "Ich hab's bereut, dass wir uns den Ort vorher nicht besser ausgesucht haben. [...] Aber es war schon das Richtige, dass er in den Bergen verstreut wurde, weil weder im Haus von meiner Tante noch von meiner Oma hätte die Urne stehen sollen. Ich fand halt, er wollte halt, er wollte halt irgendwie in die Berge [...]. Ich glaube, er hat schon gesagt, dass er verbrannt werden möchte und das Verstreuen war dann irgendwie klar. [...] Ich hätt' gern 'ne Beerdigung gehabt, ich hätt' gern, ähm, halt ein Grab. Aber er hat halt irgendwie in Deutschland nichts zu suchen. Also, es ist richtig, dass er in den Bergen ist.«(I6, 21:18)

$17 \mid$ |Wir haben uns dann natürlich mit beschäftigt, weil wir kinderlos sind. Und, äh, wir niemanden ha'm, der die Gräber gepflegt hätte [...]. Mein Mann wollte sich dann daraufhin anonym bestatten lassen. Da hab'ich gesagt: Das 
kommt ja überhaupt nicht in Frage! Du hast 'ne Lebensleistung vollbracht und sollst nicht irgendwie wie so'n Hund vergraben werden, das möcht" ich nicht." (P6, 3:00)

18 | „... also, sie hatte sehr viel Fantasie und Vorstellungskraft, was, äh, irgendwelche Würmer mit ibrem Körper machen und in welchem langsamen Verwesungszustand... und im Grunde genommen war der Wunsch, kremiert zu werden, wesentlich mehr daraus resultierend, dass sie dann nicht von irgendwelchen Würmern aufgefressen würde. Und sie fand das Fener sowieso, [...] das hat was Reinigendes und die Asche ist... was Schönes und das kann man der Natur auch zumuten.«(B8, 8:36)

19 | "Es ist 'ne ganz große Liebe, wissen Sie, die man eigentlich haben muss, glaub' ich, um diesen Weg zu gehen. ( $(\mathrm{P} 3,23: 08)$

$20 \mid$ |Man ist eh schon in einer ganz, also derjenige, der übrig bleibt, in so einer ganz... furchtbaren Situation und ist eigentlich nur daran interessiert, wirklich den letzten Wunsch desjenigen zu erfüllen, und wie auch immer der dann aussehen mag, ne? $(\mathrm{B} 5,8: 56)$

(3) "Ich will jetzt Mutters Asche!" - Kommunikation(skonflikte) im sozialen Nabraum

In Zeiten der Individualisierung tritt die Autonomie des einzelnen Akteurs immer stärker in den Vordergrund. Die damit verbundenen Selbstverwirklichungsinteressen können durchaus auf andere Personen bezogen sein denn Individualisierung findet nicht immer nur vereinzelt statt, sondern auch in der sozialen Beziehung zu nahestehenden Anderen. Soziologen sprechen diesbezüglich von Co-Individualisierung.

Dennoch sind Konfliktlinien im Kontext bestattungspraktischer Anforderungen nicht immer vermeidbar - im Gegenteil. Da individuelle Entscheidungen sich mit kollektiven Vorgaben bzw. Prinzipien reiben, besteht ein erhöhter Aushandlungszwang. Erst recht gilt dies bei kontroversen Entscheidungen wie dem beschriebenen Umgangsmodus mit Ascheresten.

Vor diesem Hintergrund ist relevant, wie persönliche, zu Lebzeiten getroffene Entscheidungen Verstorbener und/oder Angehöriger im sozialen Umfeld kommuniziert werden und welche Probleme oder Spannungen sich daraus tatsächlich ergeben haben. 
21 | Nach dem Tod der eigenen Mutter berichtete der Gesprächspartner dem Bruder vom mütterlichen Wunsch, ihre Asche in einen Wasserfall zu verstreuen: "Mein Bruder, dem ich das mitteilte, dass Mutter diesen Wunsch hat, sagte dann zu mir: nein! Das will er nicht. Er will, er braucht jetzt ein Grab. Und da war... ich zuerst natürlich stinksauer. Weil er sich auch nicht um Mutters Pflege gekümmert hat und... ähm... und eigentlich mit ibr wenig Beziehung hatte. [...] Wir hatten alles schon... geregelt mit Freunden, in Herrgottsfrühe aufstehen, vor Sonnenaufgang da hochwandern und... dann Mutters Asche ins Wasser. Rief er an und hat gesagt: Ich will jetzt Mutters Asche! Und da dacht ${ }^{\circ}$ ich, irgendwie schicksalshaft, weil wenn der Wasserfall nicht zugefroren wäre, wär sie ja schon längst da, wo sie hinwollte und... nachdem sie aber solange bei mir war, hab'ich sie, weil ich war sehr irritiert und letztendlich hab' ich dann... wenn man so will auf 'ner energetischen Ebene sie einfach gefragt... wie wichtig ihr das ist. Und ich hatte dann das Gefühl, dass es ihr vollkommen... also dass sie in 'ner anderen Welt ist, wo es ihr egal ist, ob ibr... Bestattungswunsch noch in Erfüllung geht. Und da hab' ich gedacht: Komm, wenn er jetzt ein Grab braucht, um vielleicht letztendlich mit seiner Mutter in Kontakt zu kommen, ja um Gotteswillen, dann soll er 'se halt haben.«(B8, 20:24)

22 | Wir hatten auch also welche, die das nicht fassen konnten, die das also auch nicht glauben wollten. Und da hatt' ich gesagt: Ja, ich muss doch keinem Menschen 'ne Erklärung abgeben. Ich mein', ich kam mir da letzten Endes so vor, als wenn man mich da irgendwo bedrängen wollte. Und, äh, ich habe dann irgendwann danach $[. .$.$] hab ich dann die, die mir lieb waren und die also auch$ für mich also auch gesorgt haben und für meine Schwester, die hab' ich dann eingeladen. [...] Und da hab ich dann gesagt, so und so ist es, und dann hab ich ihnen das so ein bisschen näher erklärt, aber ich bin jetzt nicht ins einzelne Detail gegangen. Es hat mich auch keiner gefragt, und wer mich nicht fragt, der kriegt auch keine Antworten. [...] Also, ich meine, zum Schluss hab' ich dann ne Notlösung gebraucht und hab erzählt, dass sie in X-Stadt [im angrenzenden Ausland] beigesetzt ist worden. [...] Was soll man machen, wenn man gebeten wird, man möchte das also nicht unbedingt so breittragen? « (P3, 18:01)

$23 \mid$ | Also, ich kenne eine Reihe von Leuten in meinem Bekanntenkreis [...], die sagen: Für mich ist das ganz klar. Ähm, ich will klassisch... beerdigt werden. Also, ich will einen Sarg haben und ich will klassisch beerdigt werden, damit meine Familie, äh, einen Ort zum Trauern haben kann. Für mich kommt nur der Friedhof in Frage. Es gibt aber welche, die sich mit meiner Idee gar nicht anfreunden können, weder mit dem Verbrennen noch also mit der Einäscherung noch mit dem Kolumbarium noch mit anonymen Beisetzen.«(P5, 25:44) 
24 Der Interviewpartner hat den aus Afrika stammenden Vater in Deutschland kremieren lassen und die Asche - gemäß dessen Wunsch - im Mittelmeer verstreut. Antwort auf die Frage, ob und wie dies gegenüber den in Afrika lebenden Verwandten kommuniziert wurde: »Die haben nicht konkret gefragt und ich hab nicht konkret, ich hab's auch von mir aus einfach nicht konkret erzäblt. Ich vermute, dass sie denken, dass er irgendwo in Deutschland beerdigt wurde. [...] Ich war sehr dankbar, dass es keine konkrete Frage gab... ähm, ansonsten hätte ich... irgendwie versucht, den... wir haben hier am Krematorium, wo er kremiert wurde, gibt's direkt daneben so 'nen Friedwald. Wenn sie en Ort gebraucht hätten, hab' ich mir halt überlegt, dass ich ibnen einfach diesen Ort nenne... " (M8, 28:45)

(4) »Das kann mir kein fremder Mensch verbieten." - Selbstbestimmter Umgang mit Trauer

Wie oben bereits dargestellt, ist Autonomie im Kontext der Individualisierung zu einem zentralen Thema der Lebensführung geworden. Die kulturhistorischen Ursprünge eines selbstbestimmten Lebensentwurfes lassen sich insbesondere in philosophischer Hinsicht natürlich noch wesentlich ausführlicher rekonstruieren, als an dieser Stelle möglich ist.

Selbstbestimmung ist in vielen unserer Interviews ein bedeutendes Motiv. Im Zusammenhang mit Trauer und Bestattungshandeln gibt es zahlreiche Anknüpfungspunkte, an die Betroffene mit Mitwirkungs- bzw. Selbstverwirklichungsanliegen herantreten. Das empirische Material macht deutlich, dass die Antwort auf die Frage, wer gegenüber wem Autonomie beansprucht, sehr unterschiedlich ausfallen kann. Oft geht es um Kritik an institutionellen Vorgaben - aber nicht immer.

$25 \mid$ |Jeder kann das tun, wenn er das für richtig bält, ja? Und das ist eigentlich das Wichtigste. Dass die Menschen frei in ihren Entscheidungen sind, wann sie was tun möchten und können."(M98, 31:37)

$26 \mid$ |Die Menschen sollten nach ibrer Façon selig werden. Das fänd" ich eigentlich schön. [...] Ich find', wenn es so ein kleines Fähnlein von Menschen gibt, die es gern anders hätten, ja mein Gott, dann lasst sie doch.« (B8, 19:35)

27 | Wenn einer sich die Urne daheim hinstellen will, soll er's machen, ne? Er kann es auch im Garten machen. Was soll's, ne?« (M1, 32:11) 
28 Die Szenerie spielt kurz vor der Urnenbeisetzung in einem Bestattungswald: "Wir saßen da mit der Urne. Und dann sagte mein Größter: Ey Mama, eigentlich können wir das doch jetzt aufmachen und können Asche rausnehmen, und dann hammer's doch! Dann können wir das doch für den Papa machen. Und dann sind wir an die Urne und ha'm den oberen Deckel aufgemacht, dann war ja aber noch so'n zweiter Deckel, der irgendwie wie so 'ne Lackdose irgendwie da war. Und dann hab' ich nur gesagt: Ey David, lasses, es ist mir jetzt grad zu viel. Also, weißte, wir hatten im Prinzip, hättste irgendwie was, 'nen Schraubenzieher dabeigehabt und'n kleines Döschen, dann hätten wir's wahrscheinlich gemacht. Es war auch irgendwie nix Gruseliges oder Schlimmes dabei, aber es war dann mir einfach... hab' gesagt: Lass stecken. Was willste jetzt machen? Willste dir jetzt irgendwie 'ne Handvoll Asche in die Sakkotasche stecken? Aber das war so dieser Moment, wo wir gedacht ha'm: Okay, da hätten wir noch die Möglichkeit gehabt, ihm diesen Wunsch zu erfüllen. Davon haben wir aber abgesehen. (M4, 96:16)

29 | Und ich finde, dass auch dieses, dieses Ganze [...], dass man so bevormundet wird oder dass einem jemand also nur das erlaubt, was zu erlauben ist, obne darüber nachzudenken, wie es Menschen in der Hinsicht geht. Das geht nicht! [...] Ich finde es nicht in Ordnung, dass das so 'ne Geheimnistuerei sein muss. Ich finde, damit muss man offen umgehen dürfen. Und ich finde, da muss auch jeder also selbst entscheiden dürfen. Das kann mir kein fremder Mensch verbieten.«(P3, 9:30)

30 | Gesprächspartner äußert sich über das Verbot, Gegenstände auf anonymen Beisetzungswiesen abzulegen: »Und dieses Nichtdürfen. Also gut, ich kann das verstehen, wenn da gemäht werden soll, dass da nichts stehen soll. Und wenn das Schild da nicht stehen würde, würden es vielleicht noch viel mehr machen, weil Verbote, die ausgesprochen werden, an die muss man sich ja halten. Wir halten ja schließlich auch bei Rot an der Ampel [...]. Wenn ich da was hinlege, dann isses definitiv wie bei Rot über die Ampel fahren. Nur, da schädige ich niemand, weil wenn ich bei Rot über die Ampel fahre, dann kann was passieren. Hier kann nix passieren, da muss der Friedhofsgärtner sich nur einmal bücken und das hochheben [...]. Das ist natürlich nicht rechtens, klar. Nur ich finde, mein Mann hat es verdient.«(M35, 88:29)

31 | "Diese feste Friedhofspflicht find' ich nicht gut, [...] weil, ähm, jeder Mensch ist anders und jeder Mensch trauert anders und hat ein anderes Trauerbedürfnis. Und da find' ich das wichtig, dass es da halt vom Staat keine Vorgaben gibt, wie und auf welche Art, sach'ich mal, ich meine Traner bewältige. Und in dem Moment aber, wo ich eine Friedhofspflicht einführe, geb ich schon die 
Trauerbewältigung quasi vor. Ne, es gibt schüchterne Menschen, die möchten nicht auf dem Friedhof gesehen werden, so ungefähr, oder nicht angeguckt werden. Kann ich verstehen, die dann sagen: Nee, ich möchte ibn zu Hause haben oder ich möchte ihn bei mir haben.«(M94, 56:21)

$32 \mid »$ Also, ich denke mir, jeder hat eigentlich die Idee oder darf diese Ideen treffen, die er für richtig bält. Und deswegen kann man da eigentlich nur Toleranz üben und Großherzigkeit und kann sich eigentlich in die Gefüble anderer Menschen nicht hineinversetzen. Jeder leidet anders, jeder erlebt es anders und jeder möchte es anders. «(P3, 33:50)

33 | Also, ich glaube, es hängt auch wirklich mit dem Begreifen zusammen. Weil, ähm, das war so ein Schock, dieses Kind, auf das ich mich so gefreut hatte, war-puff und weg war es. Es ist einfach nicht da, also das ist wirklich, als wenn man in voller Fahrt vor 'ne Wand läuft. Ja, und das, worauf man hingelebt hat, man hat ja Sachen angeschafft und so weiter, ist alles nicht mehr möglich. Es ist einfach weg. [...] Und für mich war das dann 'ne Möglichkeit, [...] wirklich jeden Tag 'nen Weg zu haben, 'ne Aufgabe, es ging wirklich ganz banal um 'ne Aufgabe. Die Aufgabe, ich geh' da hin, ich fass' einmal an die Erde oder gieße, $j a$ ? Also, ich hab'... ich weiß noch, ich hab mich mit meinem Schwiegervater gestritten, weil der gewagt hat, zu gießen. Also, im Nachbinein kann ich eigentlich auch fast nur noch darüber lachen, aber damals war es bitterer Ernst. Das war meine Aufgabe, die ich noch machen konnte. Das war das Einzige, was ich noch für mein Kind tun konnte, nach meinem Gefühl... die Blumen auf dem Grab zu gießen. [...] Da 'ne Möglichkeit zu haben, ähm, noch... wirksam zu sein." (M60, 40:03)

34 | Und ich glaube, für ihn war es auch ganz wichtig, dass er irgendwie was Besonderes bis zum Ende sein wollte. Er wollte irgendwas ganz Besonderes, was eigentlich so nicht geht und eigentlich so auch nicht gemacht wird. «(M8, 44:40)

35 | Also, das Leben, was ich jetzt führe, könnt' ich mit meinem Mann ja gar nicht führen. Das wäre ausgeschlossen. [...] Ich würde gerne, dass er noch da ist. Ich möchte mein Leben auch so führen, wie ich es jetzt führe. Das Leben ist ja immer ein Kompromiss, das meine ich nicht im negativen Sinne. Wir können ja nicht alles haben. Und ich kann nicht sagen, ich hab" meinen Mann... und mach das, was ich will. Das geht ja nicht, und... wenn ich jetzt... die... [seufzt] nee, das kann ich nicht... ich wollt' grad sagen, wenn ich jetzt die Wabl hätte zwischen meinem Mann hier sitzend und... ich alleine, das geht ja gar nicht, das kann... weil es illusorisch ist. Und ich bin soo frei und soo... ich, ich kann machen was ich möchte. Ich fahr ganz viel Fahrrad, ich war jetzt in Schwe- 
den auf'ner Fahrradtour, ich fahre am Sonnabend ins Burgund, mach 'ne Fahrradtour, ich... im August, Ende August bin ich in Italien - das würde alles nicht gehen... Und ich weiß, der sitzt jetzt da oben, das ist natürlich ganz blöd, was ich sag', und er sagt: Du machst das alles richtig!« (M35, 35:22)

(5) "Das war schon 'ne komische Sache." - Reflexion der rechtlichen Situation

Über die durchaus widersprüchlich anmutende Gesetzgebung im Bestattungswesen in den unterschiedlichen Bundesländern wurde oben bereits berichtet. Die dadurch bestehenden Konfusionen führen zu Unsicherheiten, insbesondere beim Vergleich mit dem innereuropäischen Ausland sofern er denn bemüht wird.

Es ist leicht nachzuvollziehen, wie die Rechtslage im Zusammenhang mit der beschriebenen Praxis der Ascheaneignung eine erheblich höhere Komplexität mit sich bringt. Dies belastet Betroffene auch in sozialpsychologischer Hinsicht; zu dem Wunsch, das >Richtige< tun zu wollen, treten Angst und Schuldgefühle sowie ein (womöglich nur so empfundener) Rechtfertigungszwang. Selbst unter denjenigen, die ihre diesbezügliche Entscheidung selbstbewusst vertreten, scheint sich im Gespräch darüber hin und wieder ein Moment der Unsicherheit bzw. der Unklarheit über mögliche Konsequenzen einzuschleichen.

36 | »... denn im Grunde genommen hab ich mich ja... ungesetzlich verhalten. Ich sag' mal, insofern mich ungesetzlich verhalten, dass ich tatsächlich, ähm, 'ne Urne in Deutschland eingefübrt habe, ohne einen, ja, Bestattungsplatz nachweisen zu können. Das war schon auch ein bisschen unangenehm für mich, obwobl für mich im Vordergrund stand, den Wunsch meines Mannes zu erfüllen. (B5, $7: 24)$

37 | »Ich hab' immer Angst, dass wir uns strafbar gemacht haben [...]. Ich bin da sehr vorsichtig.«(B3, 9:10)

$38 \mid$ |Es war für mich schon 'ne Sache, die sehr, ähm... also mich schon zum damaligen Zeitpunkt belastet hat [...]. Ganz extrem, als ich diese Urne... mit dem Auto eingeführt hab'. Das war schon 'ne komische Sache. Und ich hatte die ja noch ein paar Tage hier, bevor dass dann tatsächlich in die Tat umgesetzt wurde, das war schon ziemlich unangenehm. Und zu überlegen, wem erzählt man die Geschichte oder wem erzählt man sie nicht. Weil ich ja weiß, dass ich [...] wirklich nicht ganz sauber gehandelt habe. [...] Das würd' ich jetzt nicht jedem erzählen.«(B5, 12:10) 
39 | »Ja, man muss schon gucken, wem man's erzählt.«(P1, 4:43)

$40 \mid$ | Also, der Bestatter hat uns Tipps gegeben, was wir tun sollen... um die Urne unkenntlich zu machen [...]. In der Urne liegt ein Schamottstein mit den Daten, den ha'm wir rausgenommen, den Tipp hat uns der Bestatter gegeben. Dann kann man wirklich nicht mehr nachvollziehen, welche Asche überhaupt in der Urne ist, es könnte auch der Hund sein.«(P1, 11:00)

41 Auf die Frage, ob der Umstand der Gesetzesübertretung dem Interviewpartner Sorgen bereitet: »Nee... also mir nicht, weil ich gern Untiefen auslote [lacht]. [...] Aber darum ging's nicht, weil meine Mutter wollte das und ich wusste, ich find 'nen Weg. Weil ich schade niemandem, ich mach' nichts, was der Gesellschaft schadet.«(B8, 27:20)

42 | "Ich habe nichts Illegales gemacht, also deswegen... Die Möglichkeit gab's und ich hab' zugegriffen. «(P10, 22:41)

(6) „Er ist einfach da.« - Bedeutung des Verwahrungsortes

Da ein toter Körper sich nicht vom einen auf den anderen Moment auflöst, sondern als materielle Restsubstanz einer pietätvollen, aber auch professionellen und zugleich der Person entsprechenden verwaltung unterliegt, ist die Frage nach dem Verwahrungsort der Kremationsasche häufig mehr als nur sepulkrale Routine. Zwar gibt es juristisch festgeschriebene Ablaufschemata, die Ausgestaltung - und damit: die konkrete >Ritualisierung - dieser Prozeduren obliegt jedoch zumindest partiell den Hinterbliebenen.

Gerade hier werden Ambivalenzen deutlich; vom täglichen Grabbesuch bis hin zur expliziten Bekundung, dass dieser Ort nicht (mehr) gebraucht werde, sind empirisch alle möglichen Umgangsformen mit dem Verbringungsort des Körperrestes gegeben. Es wurden u.a. auch solche Orte angesprochen, die aus Sicht der Befragten ausdrücklich nicht als Grabstätte in Frage gekommen wären.

Verwahrungsorte können durchaus temporär und atypisch sein: Die Aufb(ew)ahrung zu Hause oder an anderen 'Zwischenstationen ‘ bringt besondere Herausforderungen mit sich, sie kann aber für den Vollzug der Trauer von großer Bedeutung sein. Zu klären ist mindestens die Frage nach dem Status der Zugänglichkeit. Findet die zeitlich befristete >Lagerung im privaten oder im öffentlichen Raum statt - oder auf semiöffentlichen Übergangsplätzen? 
43 | "Die Urne steht ja noch bei mir zu Hause, und ich sag" das nicht jedem, weil ich weiß, dass sich manche da gruseln. «(B2, 16:00)

$44 \mid$ "Das ist nicht so' $n$ Grab, wie man das hier traditionell auf' $m$ Friedhof hat an so 'nem Urnenstand oder so. Das ist was Weiches, es ist ein Ort, der macht nicht traurig. Das ist ein Ort, da kann man Kraft tanken. Das ist ein Ort, da hat man das Gefühl, dem Verstorbenen ganz nah zu sein.«(B3, 18:55)

$45 \mid$ "Da hatt' ich auch, ähm, 'nen richtigen kleinen Altar mit 'ner Kerze, die Tag und Nacht brannte, und dachte, das ist ein guter Ort für sie. Also, ich hab sie nicht einfach ins Regal gestellt [...]. Also, irgendwie hab' ich dann auch immer mal wieder mit ibr geredet $[\mathrm{lacht}] . \ll(\mathrm{B} 8,21: 07)$

$46 \mid$ |Ich kann mir jetzt 'ne Urne hinstellen, ich kann mir alles jetzt hinstellen, das nimmt mir keiner weg! [...] Es gibt keinen anderen Trauerort für mich." (P3, 22:46)

$47 \mid$ |Ich habe einen Ascheanhänger, 'nen sehr provokanten, wo man die Asche auch direkt sehen kann, ja? Und meine Mutti ist auf jeder Reise dabei, wo ich auch hingehe, ist meine Mutti. Sobald ich im Auto sitze und rausgehe, ist meine Mutti immer bei mir, ja? Und bei meiner Tochter, die fäbrt 'nen Vierzigtonner, Tanklastzug, ist die Oma auch immer dabei.« (M98, 9:30)

$48 \mid$ "Ich hab" hier jetzt keinen Altar und ich zünd" auch keine Kerzchen an oder mach hier meine was weiß ich für Sachen [lacht]. Er ist einfach da und er wollte da sein und wenn ich mich irgendwann mal für mich selbst anders entscheid', dann werd' ich 'ne andere Lösung finden.«(P10, 20:33)

$49 \mid$ |Ich würd' die auch nicht auf den Flügel stellen, wenn Sie mich das jetzt fragen. Ich würd' die auch nicht in meinem Garten haben wollen. Also, das sind für mich keine Orte des Trauerns. Kolumbarium ist für mich ein Ort des Trauerns, der Friedhof ist für mich ein Ort des Trauerns. « (P5, 27:45)

50 | Antwort auf die Frage, weshalb die Kremationsasche des verstorbenen Ehepartners nicht zu Hause verwahrt werden sollte: »Vielleicht weil er... er ja in dem Leben, in dem ich hier jetzt lebe, das ist jetzt meins. Da gehört er ja nicht mehr dazu. [...] Also, wenn er hier den Garten seh'n würde, würde er Vieles nicht gut heißen. [...] Wenn ich mir vorstelle, dass mein Mann hier jetzt im Bücherregal steht - geht gar nicht! [...] Jetzt ist er nicht mehr da, und dann soll er hier auch nicht sein. « (M35, 91:28) 
51 | Also, ich weiß, im Endeffekt ist es ja doch nur Asche, aber es ist auch irgendwas in meinem Kopf. Diese Asche an sich ist mir nicht wichtig. Aber es ist, glaube ich halt, symbolisch, dass ich sie da verstreut hab', und das ist in meinem Kopf. Mein Dad hat da die Ruhe. Da ist ein Ort, wo's still ist sozusagen. Wenn die Asche halt irgendwo anders gelandet wäre, wär's halt einfach in meinem Kopf, glaub ich. Weil ich immer das Gefübl hätte, dass er seine Ruhe nicht gefunden hätte. Obwohl ich weiß, es ist nur Asche.« (I6, 26:50)

$52 \mid$ |Meine Mutti ist schon an verschiedenen Orten, ja? Ich bin groß geworden als Kind im FKK. Und, äh, auf diesem FKK-Gelände in X-Stadt, da bin ich hingefahren und hab gefragt, ob ich da was verstreuen darf, weil meine Mutti da wunderschöne Zeiten verlebt hat, wir hatten da wunderschöne Wochenenden und Urlaubszeiten, Ferienzeiten gehabt. Die fanden die Idee ganz toll.« (M98, 101:01)

$53 \mid » A m$ Anfang war es schön... letztendlich, ähm, irgendwie... 'nen Platz zu haben, wo man hingehen konnte. [...] Er war halt hier, aber [...] ob das jetzt irgendwo auf'm Berg gewesen wär' oder nicht, war für mich nicht wirklich relevant.«(P10, 23:40)

(7) »Eigentlich kann ich das überall.« - Braucht Trauer einen festen Ort?

Auch die Frage, ob Trauer einen festen Ort benötigt, lässt sich nicht von der Pluralisierung der Bestattungskultur lösen. Unser Interviewmaterial legt nahe, dass es ebenso sehr den Wunsch nach (oder die >Fähigkeit zu) ortloser Trauer gibt - im Sinne einer rein kognitiven Auseinandersetzung mit dem Verlust - wie den Wunsch nach einer konkret lokalisierbaren und möglichst permanent körpernahen Beschäftigung. Für einige Menschen ist der Tod nicht nur ein ent-räumlichtes, sondern auch ein ent-körperlichtes Phänomen. Für andere sind beide Variablen untrennbar bedeutungsvoll.

Es lässt sich genauer differenzieren zwischen Sterbe-, Beisetzungs- und Trauerort. Auch der Einfluss des virtuellen Raumes auf die Bestattungskultur kann heutzutage kaum mehr überschätzt werden. Die Verzahnung von Online und Offline macht deutlich, dass der soziale Wandel fundamentale Deutungsverschiebungen erlaubt: Während der Körper in der Gesellschaft lange wenig thematisiert war, dafür aber in der Bestattungskultur eine zentrale Position einnahm, gibt es heute Anzeichen dafür, dass sich diese Verhältnisse umkehren.

Konsequenz und zugleich Motor gesellschaftlicher Wandlungsprozesse ist der Umstand, dass bei der Wahl der Bestattungsmodalitäten die Person 
des Verstorbenen den quasi-objektiven Ankerpunkt darstellt, um den sich die Rituale und Maßnahmen drehen. Faktoren wie Mobilität, alternative Bestattungsvarianten und dergleichen mehr können im Einzelfall von erheblicher Relevanz sein.

54 | »Trauer trägt man in sich, dazu brauch` ich keinen Ort.«(P5, 17:45)

$55 \mid$ | Also, ich glaube schon, dass es wichtig ist, so 'nen Ort zu haben, der mit der Person in Bezug steht. Aber das muss nicht mit dem... mit der Leiche oder mit der Asche sein, also für mich ist das ein Ort, wo ich mit meiner Mutter früher oft war, im Wald. Das ist eher der Ort, da haben wir auch ein bisschen Asche dahin gebracht und illegal verstreut.«(B2, 20:07)

56 | Also, eigentlich ist das bei mir zu Hause. [...] Ich denke an meinen Mann mehr zu Hause. Ich hab ihn überall stehen, die Bilder... an meinem Bett, hier an meinem Sessel, wo ich sitze und da hinten eben im Wobnzimmer, wo ich auch hingucken kann. Da hab ich das größere Bild stehen. Und dadurch ist er immer bei mir.«(P6, 14:58)

57 | »... er hat mir immer gesagt, auf seinem Sterbebett, ähm, er würde immer auf mich aufpassen und vom Sternenhimmel runtergucken, so vom Prinzip wie der kleine Prinz. Und diesen Gedanken, den hab ich auch immer, also dieses Gefühl, ähm, wenn's denn Not am Mann ist, dass er immer dabei ist. Den bätt' ich an jedem Ort, egal wo ich lebe.«(B5, 22:33)

58 | "Ne Schulfreundin von meiner Mutter, die hat schon mal gesagt: So schade! Wenn man ein Grab hätte, könnte man mal hingehen.« (B2, 23:00)

59 | "... weil es immer noch andere Menschen gibt, wie seine Eltern, die ibren Sohn gerne besuchen wollten auch nach dem Tod. Und ich glaube, für die ist es ganz wichtig, dass es einen Ort gibt, wo sie hin können. Und ich denke, also der Garten wäre am Anfang für mich kein guter Ort gewesen, weil ich Menschen, die noch gerne dahin gegangen sind oder auch heute noch hingehen, glaub $i c h$, nicht so nab haben wollte.«(B6, 6:10)

60 | "Wissen Sie, das ist mir noch nie so klar gewesen wie gerade eben. Mit meiner Großmutter, mit der ich ja gelebt habe, der fübl' ich mich an vielen Orten verbunden. Da muss ich nicht auf diesen Friedhof gehen, weil mit der hab ich ganz viel erlebt, wo Verbundenheit entstanden ist. Mit meinem toten Kind hab ich nicht gelebt. Und ich glaube, dass dadurch dieser Platz Grab viel wichtiger ist als bei Menschen, mit denen ich gelebt habe. «(M60, 45:47) 
$61 \mid$ |Mein Mann ist überall dort, wo ich bin. Ich brauche keinen speziellen Ort.«(M35, 110:08)

62 |Niele haben gesagt: Naja, ich glaub', ich hätt' das nicht gemacht, ich brauch" die Grabstelle, wo ich jede Woche hinlaufen kann. Dann sag' ich: Ja, das ist auch alles richtig, aber wir werden ja auch nicht jünger [...]. Ich hab' zu meinem Sohn gesagt: Wenn mir was passiert, mach' das genauso, hol' dir die Asche und setz' mich da und da bei. [...] Such' dir 'nen schönen Platz aus und dann machste das da.«(B3, 15:13)

$63 \mid$ "Eigentlich kann ich das überall. [...] Dadurch, dass ich ganz oder relativ lange schon meditiere, kann ich eigentlich, wenn du's so willst, auch in der Straßenbahn manchmal in mich gehen. Insofern ist es für mich, ähm, nahezu ortsunabbängig.«(M4, 93:45)

$64 \mid$ "Ich denke immer, die Seele, auf die es ankommt, die ist ja weg. Ich kann mir nicht vorstellen, dass ich da einen Ort brauche. Und das Andere verfällt ja. [...] Ich brauche keinen Ort, das kann ich überall machen. [...] Wenn ich an ibn denke, dann denke ich an ihn. Egal wo ich bin." (M1, 23:35)

$65 \mid » I c h$ hab" mich halt zum Beispiel gegen Seebestattung entschieden, [...] weil ich gesagt hab', da krieg' ich 'nen Zettel mit Koordinaten drauf und kann das Schiff auch auslaufen seh'n. Aber das ist für mich kein greifbarer Ort. Also, ich wollte schon was haben, wo ich mich anlehnen kann, was ich umarmen kann, wo ich meinen Kopf mal dranhalten kann, wo ich auch mal gegentreten kann und sag': Was bist du für'n Arsch? Warum? (M94, 41:36)

$66 \mid$ "Mir ist es nicht wichtig, dass ich an einen Ort gehen kann, um... um des Toten zu gedenken. Für mich ist der immer anwesend. Und deswegen ist das für mich auch nicht schwierig, zu sagen: Gut, wir verstreuen den da jetzt im dänischen Meer.«(P1, 11:58)

$67 \mid$ | Ich glaube, für mich braucht Trauer vor allen Dingen eine besondere Erinnerung und einen eigenen festen Ort für sich selbst, aber nicht unbedingt für... Ich kann mir gut vorstellen, dass das hilft, und irgendwie kann ich mir auch vorstellen, warum das hilft, ohne das in Worte zu fassen, weil man irgendwo hingehen kann, um zu trauern... Aber ich glaube, man braucht es nicht.«(M8, $67: 25)$

$68 \mid$ |Trauer braucht in erster Linie Menschen, ja? Und dann vielleicht auch den festen Ort.«(M60, 89:30) 
(8) »... manchmal geh" ich hin und leg' die Hand drauf." - Umgang mit Kremationsasche und Urne

Die Zahl der Feuerbestattungen, die häufig fälschlich mit einem Verbrennungsprozess gleichgesetzt werden (tatsächlich liegt eine Oxidation vor), nimmt in Deutschland kontinuierlich zu. Dies mag zum einen weltanschauliche Gründe haben (es bedarf keines intakten toten Körpers, weil an die leibliche Auferstehung nicht geglaubt wird), es gibt aber auch ökonomische und pragmatische Motive von Menschen, zu Lebzeiten oder stellvertretend für verstorbene Angehörige die Kremation zu favorisieren.

Im Lichte einiger bereits zitierter Interviewpassagen kann die Kremationsrate darüber hinaus als souveräner Umgang mit dem Körperüberrest verstanden werden, der gezielt an der Tradition (Sargbestattung) vorbeiläuft und deren offensichtliche >Friedhofsnotwendigkeit< umgeht. Eine Urne ist leichter zu handhaben; und dennoch ist sie da, wo sie in den eigenen vier Wänden aufbewahrt wird, vermutlich kein Einrichtungsgegenstand wie jeder andere. Oder doch?

Wo genau werden Asche und Urne platziert? Wie intim und wie öffentlich ist ihre Präsenz? Wem wird auf welche Weise Zugang zu ihnen gewährt? Werden sie gezielt oder unbewusst in den eigenen Alltag einbezogen? Findet eine kommunikative Adressierung statt - und wenn ja: auf welche Weise? Welche Rolle spielt die der verstorbenen Person nicht mehr gleichende Asche - von der Angehörige dennoch annehmen, dass sie diese Person repräsentiert, ihr entspricht, oder sogar diese Asche ist? Wird etwa durch das Vorhandensein der Asche auch der auf den ersten Blick abwesende Verstorbene präsent? Fällt der Abschied dadurch womöglich leichter? Oder stellt sich all dies vielleicht sogar als unangenehm und hinderlich für den eigenen Trauerprozess heraus? So unterschiedlich die geäußerten Erfahrungen zunächst ausfallen mögen, lassen sich aus der Fülle der Wortbeiträge durchaus fallübergreifende Motive erkennen.

$69 \mid$ | Also, ich glaube, dass ich besser Abschied nehmen konnte dadurch, dass er so nah bei mir ist. Ich glaub, dass das dem Trauerprozess geholfen hat [...]. Ich glaub, ich hab' einfach diese Nähe gebraucht, um Abschied nehmen zu können." (P1, 15:26)

$70 \mid$ |Aber dadurch, ähm, irgendwie... dadurch, dass sie, dass sie räumlich so nah ist, ja? Sie hilft mir dadurch auch, nicht so sehr zu vermissen. [...] Also, ich glaub... wenn ich dieses Gefühl hätte, die Reste von meiner Mutter irgendwie weit weg zu tragen und dann da zurück zu lassen, das wäre [...] sehr schwierig [...]. Und diese räumliche Nähe zur Urne, die ist irgendwie auch tröstlich. Also, 
meine Mutter ist auf zweierlei Arten noch da, so durch ibre Liebe und... ja durch ibre Asche halt. [...] Wobei eigentlich dieses Immaterielle viel stärker wirkt.«(B2, 26:05)

71 | "Ich bin auch manchmal nachts wach und dann sag 'ich: Naja, siehste, jetzt sind wir beide zu zweit hier. Mein Mann liegt und schläft, dann bin ich nicht allein.«(P3, 31:02)

72 | $S$ ein bester Freund kommt hin und wieder [...] und ja dann fragt er mich tatsächlich: Darf ich mal reingeh'n zu ihm? Sag' ich: Ja, na klar! Und dann legt er die Hand auf die Urne und dann spricht er ein paar Worte und dann ist wieder gut bei ibm.«(P1, 13:22)

73 | Auf die Frage nach der Häufigkeit des Kontakts zur Urne: »Mehr zu Bildern oder zu Fotos meiner Mutter oder ibren Sachen, [...] zur Urne vielleicht... Also, am Anfang natürlich oft, aber jetzt eigentlich so... einmal in der Woche? [...] Aber ich denk' oft dran [...]. Also, manchmal geb' ich hin und leg' die Hand drauf oder so [weint]. [...] Aber so in Gedanken eigentlich täglich." (B2, 25:30)

$74 \mid »$ Aber meine Mutti hat sich bis heute auch noch nicht beschwert. Die steht hier an 'ner weißen Marmor-Pyramide, ich sag' jeden Morgen: Guten Morgen Mutti, hast du gut geschlafen? Ich krieg' natürlich keine Antwort, ja? Aber ich weiß genau, was meine Mutti sagen würd': Kind, ich steh' hier irgendwie schön im Warmen, du begrüßt mich morgens, mittags, abends [...]. Viel besser kann's mir doch gar nicht gehen!« (M98, 9:50)

75 | "Wenn ich hier Silvester feiere, dann geh" ich automatisch zu meiner Mutti und sag': Prost Mutti! Du gehst auf deiner Seite in das neue Jahr, ich auf der anderen! [lacht] Ja? Das können Sie auf 'nem Friedhof gar nicht machen." (M98, 138:42)

$76 \mid$ | Wenn ich jetzt zum Beispiel von meinem anderen Bruder, der ja im Garten ist, ne? [...] Da geht man automatisch hin und sagt: Hallo Jürgen! Und dann macht man automatisch auch diese Stelle ein bisschen schön, obwobl keiner es erkennen würde. Da ist kein Kreuz, kein Stein, kein gar nichts. Aber ich weiß genau die Stelle. Und da macht man halt das, was an Blättern da drauf liegt, macht man weg und redet ein bisschen mit ihm, ne? Und wenn man da sitzt und irgendwie Kuchen isst oder irgendwas feiert - er ist immer dabei! Und das ist irgendwie ein schönes Gefübl.«(M98, 55:46) 
77 | "... so wie's jetzt ist, ist sie halt immer da und ist so'n Teil von dem Leben hier auch, obwohl sie natürlich nicht teilnimmt. Aber sie hat sozusagen ibren Platz in der Wohnung und ist irgendwie da, ja? (B2, 35:33)

78 | "Sie steht hier im Wohnzimmer und sie ist immer bei mir. Also, letzten Endes hab ich doch nicht loslassen können. «(P3, 6:42)

79 Die Urne des verstorbenen Ehepartners steht aktuell zu Hause; zu einem späteren Zeitpunkt soll die Asche im Meer verstreut werden: »Es $k a-$ men tatsächlich schon Gedanken auf, dass ich mir dachte: Oh, ich glaube, ich kann mich vielleicht nicht trennen davon. Aber.. nee, das ist jetzt so beschlossen und dann wird das so gemacht.«(P1, 12:50)

$80 \mid$ "Also, ich hätt " nicht ewig mit ihr zusammenleben wollen... mit dieser Urne. Ähm, also dieses Gefühl, sie dann doch irgendwo an einen Ort zu bringen, wo sie hinwollte, das war schon beruhigend. «( $\mathrm{B} 8,28: 35)$

81 | Irgendwann ist so ein Trauerprozess auch gut, dass er mal in eine Phase kommt, dass man wieder neu am Leben teilnimmt. Und da war für mich auch wichtig, dass die Urne tatsächlich, also dass die Asche weg ist.«(B5, 31:49)

(9) "... dann hatt" ich das Gefübl, das ist mein Mann." - Was ist die Asche?

Von der Form her ähnelt ein Aschehaufen vielem, nicht jedoch einem menschlichen Körper. Die Assoziation bzw. Gleichsetzung von Asche und verstorbener Person ist ein Resultat des Wissens, nicht des `Erfahrens«. Man kann diesen Zusammenhang verstehen, aber buchstäblich nicht begreifen. Letztlich handelt es sich, zumindest für Skeptiker, nicht einmal um Wissen, sondern vielmehr um Glauben, denn nachvollziehbare Beweise dafür, dass die betrauerte Person tatsächlich dem Ascherest in der Urnenkapsel sentspricht, liegen bekanntlich nicht vor.

Wie Angehörige mit der Asche umgehen, ist weder pauschal an den Wissens- noch an den Glaubensaspekt gekoppelt. Die Bewertungen stellen sich in unseren Interviews vielmehr als überaus ambivalent heraus. Trost steht neben Unbehagen, Indifferenz neben Fantasien der Fortexistenz. Zentral für Befragte ist die Kategorie der Präsenz: Sorgt die Asche für ein 'Dasein < verstorbener Akteure, repräsentiert sie dies nur, ist sie ein symbolischer Verweis auf das Fehlen - oder gar nur ein 'Souvenir<, das an vergangene Zeiten erinnert, und damit implizit an die fehlende gemeinsame $\mathrm{Zu}$ kunft? 
$82 \mid$ |Doch, ich denke schon, das sind die Reste des Menschen, ja!«(B7, 27:26)

83 $\mid$ "Weiß ich in letzter Konsequenz, ob er überhaupt da drin ist? Weiß ich doch auch nicht [lacht]. Im Prinzip isses 'ne Symbolik.«(P10, 22:53)

$84 \mid$ "Also, ich würde nicht sagen, meine Mutter ist in der Asche, aber es ist wie so $n$ Erbe. Also, da ist was, was mal ein großer Teil von meiner Mutter war und das... ist noch da, das darf noch mit leben sozusagen, so kann man's vielleicht sagen. [...] Und es ist was anderes als einfach nur ein Stückchen Stein oder Holzkoble oder so.«(B2, 28:45)

85 Die Frage, ob man sich hätte vorstellen können, die Totenasche zu Hause zu haben, wird mit folgender Begründung verneint: »Weil sie's ja nicht ist, also es ist tatsächlich, es sind so die letzten Reste. Und ich find', die gehören tatsächlich irgendwie, also für uns gehören die auf den Friedhof. [...] Also, zu Hause, da hat auch mein Mann gesagt: Das möcht' ich nicht.« (M5, 57:45)

$86 \mid$ |... und zwar hatte man mir mal so Zweifel herangetragen: Weiß man denn überhaupt, ob das so ist? Und da sag'ich: Weißte, darüber will ich gar nicht nachdenken. Das ist einfach so, ich glaube daran. Und der Glaube, der versetzt ja allgemein Berge. Und das genügt mir. Ich kann's nicht überprüfen, ich kann's nicht nachvollziehen, also ist es für mich wertvoll. Alleine die Tatsache, dass es so ist, ist für mich beruhigend und befriedigend. «(P3, 51:10)

$87 \mid$ »Also, dieses Gefühl, einen Mann von 1 Meter 84, total durchtrainiert, in dieser Urne zu sehen, das war ganz schlimm. [...] Mein Drang, diese Urne loszuwerden, war ziemlich groß.«(B5, 12:50)

$88 \mid$ |Ich hab' hier 'ne Zweizimmerwohnung, hab' die Urne dann ganz bewusst aber nicht in mein Schlafzimmer gestellt, weil ich das irgendwie wirklich komisch fand. Und die Tage, die dann war'n, nee, ich hab' ihr keinen besonderen Platz gegeben. Ich hab' sie aber irgendwie auch nicht ausgepackt, ich hab' einmal kurz reingeguckt und hab' sie aber dann wieder in ibren Karton gesteckt. [...] Und hab' den dann einfach in 'ne Ecke hinter'm Tisch gestellt, weil ich das irgendwie ganz komisch fand. Das war doof. Da war ich auch froh, als die wieder weg war, auch wenn das Quatsch ist, weil das eigentlich ja auch nur Asche ist." (M8, 35:36)

$89 \mid$ "Und ich war so schockiert... hab" gedacht: Ist der Marcell in dem kleinen Ding da drin?« (M1, 16:28) 
90 | Abholung der Urne beim Bestatter: »Und irgendwann war's dann soweit, wo ich gesagt hab: Okay... ja, dann gehste mal los. Wie soll ich ibn denn einpacken? Da guckt er mich ganz verdattert an und sagt: Wie einpacken? Du willst doch den Stefan jetzt nicht in 'ne Tüte packen, den nimmste jetzt in den Arm. Und da hab' ich gesagt: Guck mal, ich hab" hier seine Mütze mit. Aja, hat er gesagt, zieh sie ihm auf! Da hab ich diese Strickmütze ihm auf diese Urne [lacht], hab' ihn untern Arm genommen und bin ins Parkhaus marschiert. Also, im Nachbinein denk' ich mir, ja es ist schräg, aber das hätt' ibm so gefallen. Ja, und dann hab' ich ibn, also auf' $n$ Beifahrersitz hab' ich mich nicht getraut, dass er mir nicht umfällt, da musste er halt auf den Rücksitz. Das war jetzt nicht sein Platz [...]. Stefan, jetzt hast Pech, jetzt fährste auf'm Rücksitz mit nach Hause. Ja, und jetzt steht er heut noch hier.«(P10, 18:00)

$91 \mid$ "Zusammen haben wir die Urne entleert. Und ich hab die Hände der Kinder berübrt, dann hatt' ich das Gefübl, das ist mein Mann, ja, wie er leibt und lebt.«(B3, 37:32)

92 | Und dann standen wir da und hatten diese Urne in der Hand, die aufgemacht war. War schon ein bisschen komisch, dass die Asche so wenig ist [...]. Und dann haben erst meine Schwester und ich angefangen, die Asche zu verstreuen. Meine Tante hat mir dann einen Löffel gegeben, damit es einfacher geht, weil wir haben's eigentlich bloß auf'n Boden verschüttet so. Und es war nix mit irgendwie im Winde oder irgendwie, keine Abnung. Die Hälfte ist auf meinen Schuhen gelandet oder irgendwie in meinem Gesicht, wenn der Wind falsch gegangen ist. [...] Und das war absolut komisch und einfach unangenehm, diesen Löffel in der Hand zu haben.«(I6, 19:15)

$93 \mid$ |Mhm. Also, was die an Asche zusammenkratzen, wenn ich das mal ganz real sagen soll, weiß ich nicht. So, wenn ich die Leiche in einen Sarg lege, dann ist die für mich für einen gewissen Zeitraum, bis sie die Würmer aufgefressen haben, präsent. Das ist tiefer, für meine Begriffe. In meiner Denke ist es tiefer. Aber... äh... wer sich eine Urnenbestattung wünscht - bitteschön!« (P5, 21:57)

(10) »... als würd' er grad ein Mittagsschläfchen machen."Visualität der Leiche

Die westlich orientierte Bestattungskultur ist geprägt von der Ausblendung des toten Körpers. Dahinter steht ein zweiseitiges Phänomen: Die Ausblendung betrifft zum einen die Verlagerung des toten (mithin auch schon des sterbenden) Körpers aus familiären Lebensräumen. Zum anderen ist dar- 
unter die Unsichtbarmachung der Leiche im Zuge der Bestattung zu verstehen. Verantwortlich dafür ist nicht zuletzt die negative Reputation des toten Körpers, der seit Jahrtausenden als Hygienegefahr und damit als Ordnungsbedrohung apostrophiert wird.

Für die Trauerverarbeitung spielt der Leichnam dennoch häufig eine große Rolle. Ein leeres Grab wird von manchen als gewissermaßen sunvollständiger Trauerort verstanden; andere artikulieren ihren Verlustschmerz online und somit absichtsvoll unabhängig von der Leiche. Insbesondere der Übergang vom Leben in den Tod verleiht dem Körper eine atypische Position: Er kann aufgebahrt, d.h. gesehen und vielleicht sogar berührt werden, er kann aber auch stillschweigend verschwinden. Die folgenden Sequenzen bilden vordergründig solche Situationen $\mathrm{ab}$, in denen die Betroffenen eine letzte Begegnung mit dem toten Körper haben. Relevante Fragen sind hier: Welche Stimmungen löst dieser Anblick aus? Welche sozialen und psychologischen Bedeutungen sind damit verbunden? Ist der Leichnam noch der Verstorbene oder ist er nur mehr eine Hülle - ein Indikator für das, was dieser Mensch einmal war, nun aber nicht mehr ist?

94 Schilderung der Situation, in der die Leiche des verstorbenen Ehepartners für zwei Tage in der gemeinsamen Wohnung verblieb: »Also, das konnt' ich mir vorher nicht vorstellen, dass das so... funktioniert. Es war für mich hinterher aber... ähm, total schön und total stimmig, ich konnt immer mal wieder ins Zimmer reingehen. Hätt' ich vorher nie gedacht, dass ich das schaff', das war dann aber tatsächlich so... und, ähm, das hat irgendwie dazu gehört. Das war ja so das, quasi wie das Tüpfelchen auf dem I.«(P1, 25:25)

$95 \mid$ | Ich hab dann eben, obwohl ich... ich mein, das kennt man dann nur aus dem Tatort, aber ich hab' dann irgendwie gedacht: So, jetzt versuch' ich mal die Augen zuzumachen. Bin dann so drüber, wie man das aus 'nem Krimi kennt. Ich, wie gesagt, wusste ja nicht, öffnet der jetzt... gehen die jetzt wieder auf, die Augen? Also, das war so ein bisschen, wo ich so, ja schon auch Berührungsängste dann auf einmal hatte. Aber dann auf der anderen Seite, es ist ja dein Mann... wo ich dann dachte: Also, meine Güte, die [...] Hände, die haben dich gestreichelt und die haben dich berührt - und wieso soll ich jetzt Angst haben? Also das war irgendwie so dieser Moment, wo man dann einfach so ein bisschen zwischen... Neugier, Bange und [...] irgendwie dann aber doch noch Fürsorge schwankt. Da geht so ganz viel durch den Kopf.« (M4, 29:00)

$96 \mid$ "Mein Sobn hatte einen Autounfall gehabt, der hat sich das Genick gebrochen. Und der lag da, als würd' er gerade ein Mittagsschläfchen machen, der hat immer gesagt: Ich muss mal chillen. Und genauso... hat's ausgesehen. [...] Also, 
er hat aus den Obren geblutet und aus der Nase, aber ansonsten hat er überhaupt keine Schramme gehabt. Und das war für mich auch nochmal wichtig, man überlegt ja dann: Wie war das? Und hat dann auch so Fantasiebilder, die ja dann mitunter schlimmer sind als das, was wirklich ist.«(M34, 105:48)

97 | "Wenn man einen Toten anfasst, der wird immer kälter und die Haut wird immer starrer, das ist so. Und da hilft es auch ein Stück weit, also es hilft, um zu sagen: Okay sie ist halt nicht mehr da. Ja, das ist nur der Körper, der da ist." (M5, 86:57)

$98 \mid » A l s o$, um wirklich zu begreifen... Das war der erste tote Mensch in meinem Leben, den ich angefasst hab. Und es war gut, zu spüren zwei Stunden nach dem Tod, sie ist noch warm - sechs oder acht Stunden später, jetzt isse kalt, ja? Und dann zu merken, das ist plötzlich nur noch die Hülle meiner Großmutter, das ist nicht mehr meine Großmutter.« (M60, 19:40)

$99 \mid$ |Ja, irgendwie zieht's einen dort hin. Ich denk', das ist auch der Körper, der ist da hingegangen. Und, ähm, ich war auch mal davorgestanden und hab gedacht: Ich möchte ihn jetzt am liebsten mit den Händen wieder ausgraben." (M34, 73:32)

$100 \mid$ |Also, ich denk', wir in unserer abendländisch-christlichen Kultur brauchen den Körper. Wir brauchen ibn einfach, um unsere Trauer richtiggehend zu verorten.«(B8, 54:41)

\section{(11) »Andenken, das sind ibre Bilder." - Materialität am Lebensende}

Am Lebensende bleibt nicht nur die Erinnerung an eine geliebte Person übrig. Verstorbene hinterlassen Gebrauchsgegenstände und andere persönliche Besitztümer, die in der Folge ihre Bedeutung verändern. Sie lassen sich in Gedenkobjekte transformieren, wenn Hinterbliebene dies wollen oder sie können absichtlich verbannt werden, um durch ihren Anblick den Verlustschmerz nicht noch zu erhöhen.

Für die Funktion und Art dieser Erinnerungsgegenstände interessieren wir uns. Wo und wie werden sie aufbewahrt, wo und wie werden sie in Gebrauch genommen, wenn überhaupt? Und inwieweit wandeln sich die Bedeutungen von Gegenständen im Laufe der Zeit? Gegenständlichkeit kommt vor allem Fotografien zu, die schon zu Lebzeiten Erinnerungsfunktionen ausüben, post mortem aber eine andere Qualität gewinnen. Letztlich 
kann auch die Urne, so sie denn den Weg in den häuslichen Lebensbereich findet, als ein solches Gedenkobjekt angesehen werden.

$101 \mid » I c h$ hab' zu Hause meinen Mann hier steh'n im Bild und hab' auch zwei Lichter, die ich jeden Tag anzünde, und 'ne rote Rose, allerdings 'ne künstliche. Ich verabschiede mich jeden Abend von ibm und begrüße ibn auch jeden Morgen.« (P6, 13:35)

102 | Auf die Frage, ob man sich vorstellen könne, die Urne des Verstorbenen bei sich zu Hause aufzubewahren: "Ich hab die Bilder zu Hause von meinem Mann, die gucken mich immer an, da möcht' ich nicht das Andere sehen." (M1, 18:01)

$103 \mid$ | Andenken, das sind ibre Bilder, das sind ihre...ja, ihr Leben, das ist ein Andenken, die Zeit, die wir gemeinsam verbracht haben, in den letzten Jahren sehr intensiv, die Gespräche, die wir hatten [...]. Die kann einem ja auch keiner nehmen, das Andere ist alles eigentlich unwichtig.«(B7, 30:26)

104 Der Gesprächspartner hat für sich und jedes seiner Kinder eine Haarsträhne der verstorbenen Person in eine Glaskugel einarbeiten lassen und besitzt zudem ein Foto der Kremationsasche. Zur Bedeutung dieser körpernahen Materialität: »Gerade für die Kinder zäblt dieses Irdische. Euer Papa war hier. [...] Er war hier, er war menschlich. Auch wenn du jetzt schon 30 Jahre älter bist, aber dein Papa war da, er war auf Erden. Weil es verblasst, die Erinnerung, die Vorstellung, das Aussehen, das verblasst alles. (M94, 93:17)

105 | Beschreibung des heimischen गTraueraltarsı: »Da ist jetzt ein Bild von meiner Mutter und meinem Vater. Und da brennt so 'ne kleine, ja, im Grunde so ähnlich wie diese ewigen Lichter, so'n doppelwandiges Glasgefäß, wo innen 'ne Kerze brennt [...]. Und es sieht sehr schön aus und es ist eigentlich... es brennt immer. Und dann sind so noch so'n paar Utensilien, ein Ring von ibr und von meinem Vater auch noch was, weil der hat viele Bergtouren gemacht, hat Federn gesammelt von Raubvögeln. Also, es ist ein richtiger kleiner... Hausaltar. [...] Es ersetzt mir das Grab, weil irgendwie hab' ich so 'ne Art Ansprache oder Verbindung zu den beiden [...] direkt hier bei mir. [...] Dieser Hausaltar, der... der ist, glaub ich, wirklich an die Stelle von einem Grab getreten. Ich glaub', wenn ich den nicht hätte, dann hätte ich Probleme.«(B8, 32:28)

106 | »Und die Gegenstände, muss ich sagen, haben jetzt auch nicht mehr den Stellenwert. Also, das ist so wie der Friedhofsgang, wo man dem Körper nachgeht und allem, was mit dem Körper zu tun hat, Kleidungsstücke, Gebrauchsgegen- 
stände und und und. Aber das Allerentscheidendste trag' ich in mir. Im Grunde genommen könnt' ich jetzt auch sagen, ich bräucht' so weiter gar nichts mehr, weil ich weiß, in mir ist was gewachsen, das ist da und das kann mir auch keiner nehmen. Aber das war einfach ein langer Prozess, bis es dabin gekommen ist, und auf dem Weg dahin war das alles auch unheimlich wichtig. (M34, 86:16)

(12) "Der Baum absorbiert irgendwann Papa."Legale Bestattungsalternativen

Die Ausdifferenzierung der Trauerkultur korreliert mit einer Ausdifferenzierung des Bestattungsmarktes. Neue Angebote ergeben sich nicht nur für die Ausgestaltung von Ritualformen, sondern - im Rahmen enger juristischer Grenzziehungen - auch für alternative Bestattungsplätze. $\mathrm{Zu}$ den bekanntesten Beispielen gehören die privatwirtschaftlich strukturierten Angebote von Friedwald und Ruheforst. Sie versprechen naturnahe Gedenkplätze jenseits allzu restriktiver Formalien (wenngleich auch hier normative Spielregeln beachtet werden müssen). Die Kernidee, das Beisetzen der Asche unter Baumwurzeln, wird mittlerweile von diversen regulären Friedhöfen nachgeahmt.

Der historische Vorläufer für moderne Naturbestattungen dürfte indes die Seebestattung sein, die, zunächst aus pragmatischen Gründen entstanden, auf eine lange Kulturgeschichte zurückblickt. Für unsere Forschung sind die Motive und Erwartungen von Menschen relevant, die sich für diese Bestattungsvarianten (und damit gegen eine Beisetzung auf dem traditionellen Friedhof) entschieden haben.

107 | Erinnerung an die Beisetzung des Ehepartners im Bestattungswald: "Einsegnung in der Kapelle. Und dann sind wir alleine, ohne Pfarrer sind wir ans Grab. Und das war so schön! [...] Wir hatten ein Licht und hatten einen Korb mit Rosenblättern... und die Tochter hat 'nen Stein. Und da konnt' jeder... $a ̈ h$, wer ans Grab gegangen ist, der hat den Stein in die Hand genommen und der hat mit ihm gesprochen. Und der ging immer weiter, bis alle durch waren, und dann kam der Stein in die Urne. « (M1, 6:23)

108 | »Mein Mann war unter anderem ausgebildeter Forstwirt [...], hatte also auch mit dem Holz ganz viel zu tun gehabt, ähm, und ich denke, aus dem ökologischen Denken heraus ist das einfach... ja, das ist genau der Platz, den er brauchte. $(\mathrm{B} 6,11: 24)$ 
$109 \mid$ | Aber was für mich ganz entscheidend war: Um einen Friedwald oder um einen Ruheforst sind keine Zäune. Ich hab' gesagt: Er hat da offenen Acker neben sich, er hat da Flussläufe, natürliche, bei sich, [...] das ist die Natur. Also, er hat den Weg der Ruhe gewählt, den soll er auch bekommen. Und nicht auf' $m$ Friedhof, wo's eingezäunt ist, wo ich bestimmte Öffnungszeiten hab', damit ich den betreten kann, sondern einfach nur: Wenn ich zu ibm will, will ich da hin. Und nicht: Oh, es ist nach 22 Uhr, ich kann jetzt nicht mehr fahr'n. (M94, 36:51)

110 | "Weil man da eben die Bäume rauschen hört, weil man's da eben so rubig hat und man der Natur so nab ist. Das fände ich schöner, als sich irgendwelchen Konventionen beugen zu müssen." (M92, 70:55)

111 | "Und ich verbind' das eher mit Waldspaziergängen. Einfach Natur und Seele baumeln lassen. (M94, 37:34)

112 | "...dass da kein Grab gepflegt werden soll/muss, wie auch immer, dass alles so wachsen darf, wie es möchte.« (B6, 16:19)

113 | "Ich bin nicht in der Lage, ein Grab zu pflegen. Das kann ich nicht mehr, und die Kinder sind teilweise... weg und müssen arbeiten. Ich kann denen nicht zumuten, dass sie nach 'nem Grab schauen. Und das will ich auch gar nicht." (M1, 4:56)

$114 \mid$ |... also alleine, wenn man Kinder zum Beispiel hat, ne? Also, dass ich nicht sagen muss: Seid doch mal ruhig! Wir gehen da durch 'nen natürlich angelegten Wald, gehen wir da spazieren. [...] Ich kann da im Ruheforst halt genau an seinem Baum Picknick machen, wir können uns aber auch so an dem Baum anlehnen und Bilder malen und basteln, obne dass einer doof guckt. Das kann ich auf dem Friedhof nicht mit meinen Kindern machen. Wenn ich auf dem Friedhof 'nen Stein umarme, sieht's doof aus quasi, also wird geguckt. Wenn ich aber da im Wald den Baum einfach umarme, weil da einfach Leben durchfließt, also das war für mich ganz wichtig, ja Papa ist Asche, ja Papa liegt am Baum, aber der geht irgendwann über. Der Baum absorbiert irgendwann Papa und der fließt dann dadurch, er ist irgendwo noch irdisch.«(M94, 25:55)

$115 \mid$ | Ich kann damit wenig anfangen. Dass ich mir da zu Lebzeiten irgendein Baum aussuche... unter den ich... mich da verbuddeln lasse.« (P5, 29:07)

116 | Interviewpartner erzählt von der Seebestattung einer Freundin: »Ja gut, erst einmal fuhr man ja mit dem Kutter raus auf's offene Meer. Und [...] es war schönes Wetter, es war auf Sylt, muss ich dazu sagen, [...] die Sonne schien, 
wir war'n in einem ganz kleinen Kreis, also nur 'ne Freundin und ich haben sie begleitet... Und es war sehr würdevoll, würdevoll und... nicht so pathetisch. Also, ich, [lacht] hatte ein gutes Gefühl, muss ich sagen.«(B7, 10:05)

$117 \mid$ "Die Seebestattung an sich war auch ein... angenehmer Vorgang. Ich hab" das nicht als so schlimm empfunden, als wenn sie jetzt, äh, erdbestattet worden wäre.«(B7, 3:25)

118 | "Ich denke mal, ja symbolisch. Die Asche, also die Überreste, verbinden sich jetzt mit dem Meer und das ist das, was sie eigentlich gewollt hat. [...] Sie war auch schon früber häufiger auf dieser Insel. Und, äh, wenn sie Urlaub hatte, sie fubr entweder in die Berge zum Wandern oder Skilaufen oder sie fuhr zur See [...]. War auch 'ne gute Schwimmerin und ich denke, diese Verbundenheit zum Meer zählt.«(B7, 19:41)

\section{(13) »...wenn man trauert, will man keine Regeln." - Gründe für die Entscheidung gegen den Friedhof}

Der traditionelle Friedhof, wie er über Jahrzehnte hinweg im deutschsprachigen Raum strukturiert war, steht im Kreuzfeuer der Kritik, nicht nur im Lichte unserer Interviews. Die Unzufriedenheit mit eingefahrenen Routinen und mangelnder Flexibilität wird von vielen Seiten geäußert und von den beteiligten Institutionen mittlerweile durchaus reflektiert. Das Problembewusstsein ist auch durch Vergleichsprozesse mit europäischen Nachbarstaaten entstanden, die mehrheitlich über eine liberalere Bestattungsgesetzgebung verfügen.

Die nähere Recherche zeigt, dass auch hier die Haltungen ambivalent sind. Weder gibt es eine pauschale Friedhofsablehnung noch eine grundsätzliche Zustimmung. Es dominieren Reformwünsche, Aneignungsinteressen, Kritik an unzeitgemäßen Regularien, und es lässt sich eine Zunahme der >Friedhofsbefremdung feststellen. Damit ist gemeint, dass der Friedhof als Funktionsort generell zwar seine Berechtigung hat, er aber gleichwohl von der konkreten Person nicht >gebraucht < wird. Nicht immer geht es dabei um Gesetze, Ordnungen und Regularien: Problematisiert und kritisiert werden bisweilen auch die atmosphärischen Verhältnisse, der Druck auferlegter Verhaltenskonventionen, finanzielle Belastungen - oder die räumliche Distanz des Friedhofs zum eigenen Lebensmittelpunkt, die den Betrauerten nicht nur in geografischer, sondern auch in sozialer Hinsicht in schmerzhafte Ferne rücken lässt. 
119 | "Was soll sie denn dort, wenn wir alle hier sind? Es ist so wie man ja auch 'nen Familienangehörigen nicht einfach in 'nem Hotel 200 Kilometer weit weg unterbringt, auch wenn das 'n tolles Hotel ist, ja? Wenn ich sie jetzt einfach irgendwo auf den Friedhof lege, der weit weg ist, dann ist sie da so alleine [lacht]. «(B2, 37:00)

$120 \mid$ "Ich find'schon, wenn man einen geliebten Menschen verloren hat, das ist ein immenses Loch, und wenn man dann die Umgebung noch hat... so dunkel, so traurig, so still, so leise. Wenn man die Rube, diese Stille braucht, dann geht man ins Schlafzimmer, man zieht sich zurück. [...] Aber ein Friedhof, ich mein', wenn man weiß, der liegt da, dann will man doch auch, dass der es ein bisschen belle hat.«(B3, 33:14)

121 | "Also, ich hätte es nicht ertragen können, sag'ich immer wieder, da auf' $m$ Friedhof zu stehen, das ist mir so unpersönlich. Und mir kam es, ähm, wirklich vor, als würd'es vom Himmel kommen [gemeint ist die Möglichkeit der privaten Urnenverwahrung]. Das war sowas Schönes, ich kann mich jetzt hinstellen, kann meine Hand drauf halten, ich... ich kann mit ibr reden hier, ich muss nicht auf'n Friedhof gehen und irgendwelchen anderen Leuten mich aussetzen. Ich füble mich richtig also auch von ihr beschützt. «(P3, 23:14)

122 | Wir ha'm zwar kleine Friedhöfe, wo man auch nächtens drauf darf, ja... aber das tun die Leute doch gar nicht, ja? Die großen Friedhöfe sind ja alle geschlossen, ab Einbruch der Dunkelheit kommen Sie auf keinen Friedhof mehr. Und das sind einfach so Dinge, wo ich sage, ich hab' hier alle Freiheiten, wenn ich diese Totenasche hier habe und reden kann, wann immer mir danach zumute ist und wann ich das haben möchte. (M98, 138:53)

123 | »Da isser ja sowieso nicht - da ist die Asche!«(M35, 48:00)

$124 \mid$ "Wenn wir zum Friedhof gegangen sind, hab ich immer gesagt: Da ist nicht mein Vater. Da liegt ein Haufen totes Fleisch, das verfault, und da drüber ist ein Blumenbeet. [...] Und, äh, ich brauch' kein Grab, ich persönlich nicht, aber ich kenne viele, die brauchen es unbedingt. Ja, da gibt's ganz große Unterschiede. [...] Also, für mich ist der Mensch eben nicht da in dem Grab. [...] Für mich ist die Seele, das, was meinen Vater ausgemacht hat oder meine Mutter oder wen auch immer, das ist nicht da. "(M89, 18:22)

$125 \mid$ "Der Ort meiner Trauer, der ist nie im Friedhof. Ich hab‘ ja Angehörige auf dem Friedhof. Nein, wenn ich um meine Großeltern trauern wollte, dann gehe ich in ihr Haus, in die Stube, wo ich Zeit mit diesen Menschen verbracht habe, 
wo Gemeinsamkeiten herrschen, nicht an einen wildfremden Ort, wo eine kalte Steinplatte mich anschaut. [...] Trauer findet da statt, wo wir die meisten Berührungspunkte mit dieser Person hatten. Also, ich hab' das bei meinen Großeltern gesehen, da war wirklich die Stube bei meiner Großmutter oder die Küche, wo ich ihr zugeschaut habe, wie sie gekocht hat, die Gespräche, die sie geführt hat. Beim Großvater war das auf der Jagd, wenn ich jetzt wandern geb' und an gewissen Stellen steh', dann seh"ich ihn noch vor mir, wie er mit dem Spiegel Dinge angeschaut hat. Und das sind dann die Momente...«(M18, 69:39)

126 | »... unsere Friedhöfe sind so hässlich. Das sind keine schönen Orte. (B8, $30: 28)$

127 | »... und der Friedhof ist extrem eng, also man liegt da wirklich fast aufeinander und das wär', find' ich irgendwie... einengend.«(P1, 20:16)

128 | „Für mich persönlich... nee, Friedhof hilft mir nicht bei der Trauerbewältigung. « (B7, 26:00)

129 | "Wissen Sie, es ist ja heute auch 'ne Geldfrage. Wenn Sie jetzt zum Beispiel 'ne Erdbestattung haben. Sie müssen die Grabpflege bezahlen, Sie möchten 'nen Stein haben. Also, das ist alles mit großen Umständen verbunden, Sie müssen dauernd zum Friedhof laufen. Und wenn jetzt die Leute älter sind, ist das ja auch beschwerlich da immer hinzukommen. Und vor allen Dingen auch im Winter, wenn das dann schneit und so weiter... «(P6, 18:20)

$130 \mid$ "Ich hab' gerade so 'ne Zeitachse der Trauer im Kopf. Das hängt davon ab, wo auf dieser Zeitachse man sich gerade befindet. Hätte ich meinen Vater jetzt auf einem Friedhof beerdigt, wäre das in den ersten Wochen mit Sicherheit der Ort gewesen, an dem ich nicht getrauert hätte. Und zwar auch der Ort, an dem ich mit Absicht versucht hätte, nicht zu trauern. Was aber daran liegt, dass ich jemand bin, der solche Gefüblsäußerungen, in welcher Form auch immer sie sich dann äußern, sehr privat findet - und das ist einfach ein öffentlicher Ort. « (M8, 69:00)

131 | "Also, wir ha'm halt zwei Kinder [...] und ich hab' gesagt, und das möcht ich halt nicht, also die Dramatik, dass er gestorben ist, ist viel zu groß, als dass ich jetzt noch sag': Wir fabren jeden Sonntag oder zwei Mal im Monat fabren wir hin zur Grabstelle. Und dass ich dann, ich sag' mal, meine Kinder dann aber in dem Moment, wo wir den Friedhof betreten, maßregeln muss: Pssst, seid doch mal leise, wir sind hier auf dem Friedhof! Das wollt' ich nicht, weil die Sache an sich ist schon, auf gut Deutsch gesagt, beschissen genug. " (M94, 24:51) 
132 | »... du musst ja immer leise sein auf dem Friedhof. Aber da, wo wir meinen Mann hingebracht haben, da können wir singen, da können wir im Wasser plantschen und das Herz hüpft dann ein bisschen.«(B3, 30:18)

$133 \mid$ "Das ist für mich auch so eine gewisse Fürsorge, dass ich sage, äh, wenn ich ein normales Grab nehmen würde, [...] ich wär da ständig am Zupfen. Und da$z u$ hab' ich eigentlich gar keine Lust. [...] Es ist eine Verpflichtung da. Nun kann man natürlich sagen, das sollte einem der Tote wert sein, nur das hat für mich überhaupt nichts miteinander zu tun. Also, nur weil ich jetzt ein Grab hab', was ich pflegen muss, denk' ich ja nicht mehr an den, der gegangen ist." (M35, 78:01)

$134 \mid$ | Ich hab“ meine Mutter beerdigt und meinen Vater beerdigt [...]. Ich fand das nicht so sehr prickelnd, weil ich sage, das ist alles nur dem Schein, den anderen zu liebe. Ich kann meine Trauer also auch anders ausdrücken. [...] Das ist für mich alles so wenig Aufrichtigkeit. Ich mein', sicherlich leiden etliche darunter und ich sehe das auch, wenn manchmal Kinder verstorben sind, was die Leute alles da hinbringen. Ich wünscht' mir dann lieber, dass ich das hier bei mir zu Hause hätte, das würd' ich bei mir zu Hause schaffen, weil ich brauch das nicht für die Leute. Die Leute sind mir so unwichtig, die kennen mich doch gar nicht. Und nur der Blume wegen, die da liegt, oder der Blumen, die dabin gebracht werden, und ein Vermögen ausgegeben wird.«(P3, 19:03)

$135 \mid$ "Die klassischen Friedhöfe, [...] wo man irgendwie so die Grabpflege betreibt, so wie du samstags in kleinen Orten bis um zehn Uhr tunlichst die Straße gefegt hast, das find' ich grauenhaft und beengend und das hat nix... das hat was für mich mit Bedienen von Formalien, aber nichts mit Bedienen von eigenen Bedürfnissen zu tun.«(M4, 69:16)

136 | »Man hat auf dem Friedhof so zu funktionieren, wie die Gemeinde oder die Friedhofsverwaltung das einem übertütet. Und das finde ich schade und schwierig.«(M92, 67:50)

$137 \mid »$ Also, ein Friedhof hat immer was Beklemmendes... wo man sich zusammenreißen muss, wo's Regeln gibt und... nee, wenn man trauert, will man keine Regeln.«(M94, 27:12)

138 | "Dieses Gesetz ist so mechanisch, so unwahrscheinlich konservativ. Also... es fängt schon an, vor den Bebörden alles abzumelden [...]. Ich fänd's schöner, wenn's nicht so extrem... Ich hab' manchmal das Gefühl gehabt, man ist 'ne Nummer in Deutschland. Nummer 510 stirbt, Nummer 510 wird ausradiert, 
Nummer 510 kommt in ein Archiv, der ganze Werdegang - Anmeldung, Abmeldung. Das ist ja auch alles richtig, das muss ja auch irgendwo dokumentiert sein, aber die Art, wie's geht, ist nicht sehr... find' ich nicht sehr menschlich [...]. Diese Vorgaben, also das find' ich schon sehr... erdrückend.«(B3, 24:35)

139 | "Ich mag zum Beispiel die Praxis nicht, dass... es wird jemand ins Grab gelegt und 20 Jahre später wird er da rausgenommen und keiner weiß, wohin er dann kommt und wohin die Erde oder das, in was er sich dann verwandelt hat, binkommt, und keiner kann's mehr wirklich beantworten. Und irgendwie ist das dann auch so 'ne Art Grabschändung, find' ich.«(B2, 8:47)

(14) »... da hat mich eigentlich die Stille da erdrückt.« - Allgemeine Haltungen zum Friedhof

Die im vorliegenden Buch in vielen Schattierungen dargestellte Ambivalenz des Friedhofs kann einerseits als Ausweis einer gestiegenen Pluralität der Sepulkralkultur gewertet werden - und andererseits als Zeichen der Verunsicherung über die konkrete Funktion jener Stätte. Dieser Zwiespalt wurde in diversen Interviews recht unverhohlen angesprochen: Friedhöfe können ästhetische Räume sein, die als Parkersatz usw. verwendet werden, und sie können im gleichen Moment Orte sein, an denen die gefragte Person nicht beigesetzt sein möchte.

Facetten wie die vorgeschriebene Anordnung der Ruhestätte, die buchstäbliche >Grabesstille und die individuell zu bewerkstelligende Aufgabe, die eigene Trauerempfindung mit diesem materiellen Ort zu verknüpfen, können mittlerweile ebenso positiv wie negativ bewertet werden.

140 | "Ich würde sagen, das ist für mich ein Ort, wo meine Lieben bestattet werden können, und ich dann die Möglichkeit habe, da immer mal hinzugehen und mit ihnen zu sprechen oder sie zu besuchen.«(P6, 25:43)

$141 \mid$ |ch persönlich brauch" ihn nicht, obwohl ich sehr gern auf große alte Friedhöfe geh', weil es dort sehr ruhig und sehr schön ist. Ich mag die Atmosphäre dort.«(P10, 26:02)

$142 \mid » A l s o$, ich lebe ja in der Stadt, und da sind die Friedhöfe eigentlich schöne Orte. Erstens dadurch, dass sie grün und friedlich sind. Und... auch das Gedenken, das die Leute dahinbringen, tut dem Ort ja gut. Also, es ist eigentlich eher positiv belegt.«(B2, 43:49) 
$143 \mid$ |... ist natürlich ein Traum, wenn es ein Park ist. Und auch diese wellenartigen Nekropolen [...] da kann man einfach schön wandern...«(B8, 49:28)

$144 \mid$ |Es gibt Friedhöfe, die ich ganz doll bewunder ${ }^{6}[. .$.$] weil ich finde, das$ sind ganz ausgezeichnete Parkanlagen... wo ein bisschen unserer Kultur auch zu sehen ist, aber eben auch ganz spannend, ähm, vom Bewuchs her, von dem groBen alten Baumbestand... vermooste Grabsteine und was auch immer. Ansonsten seb' ich das eher als Parkanlage und weniger als Friedhof.« $(\mathrm{B} 6,21: 17)$

$145 \mid$ | Also, ganz grundsätzlich gehe ich super gerne auf Friedhöfe, weil das unheimlich tolle Parkanlagen sind... So das Gefübl, was Friedhof bei mir auslöst, ist immer so ein schwermütiges Gefühl. Und genau dieses Gefühl möcht' ich gar nicht haben, es soll auch... so nach dem Prozess, es ist ein neuer Abschnitt, der kommt, weil's eben nicht der körperliche, sondern der seelische Aspekt ist. Und das ist auch ein freudiger Aspekt, und den würd'ich eben anders begehen... Ich finde, Friedhof ist immer so schwermütig.« (B5, 28:12)

146 | »... da hat mich eigentlich die Stille da erdrückt. Es war alles da, aber es hat keine Bewegung da [...]. Die Gräber sind zwar schön, schöne bunte Blumen, aber... wen interessiert das denn, ob da ein Herr Meyer liegt, kenn' ich nicht, eine Frau Sommer, kenn'ich nicht... Man guckt sich's halt an und läuft vorbei, man nimmt das aber nicht wahr. [...] Als Kind hab' ich den Friedhof immer schön gefunden, weil's da halt so ruhig war, aber jetzt als erwachsener Mensch find' ich das eher... ja... ein bisschen... unheimlich, traurig.. . bedrohlich sogar." (B3, 29:24)

147 | "Dieses in Reib" und Glied bestattet werden, ähm, diese Art von Ordnung gefällt mir eigentlich nicht. Ich glaub ${ }^{\star}$ nicht, dass die irgendjemand gefällt. «(B8, 49:55)

148 | „Der Friedhof ist gar nicht so wichtig, dass man da hingeht. Und ich glaube einfach auch, die Menschen, die wirklich auf den Friedhof gehen, die haben zum Teil, haben sie 'ne Verpflichtung, weil sie wollen nicht, dass andere über einen reden. [...] Die Angst, dass andere darüber herziehen könnten, treibt manchen dazu, zum Friedhof zu geh'n und das Grab ordentlich zu machen, nicht weil man unbedingt dabin will jetzt.«(M98, 122:12)

$149 \mid$ | Also, ich muss Ihnen sagen, je älter der Mensch wird, desto häufiger geht er ja auf Friedhöfe, ne? Also, in jungen Jahren wäre ich nie auf die Idee gekommen, [...] auf'n Friedhof zu gehen. Aber so im Alter geht man auf Friedhöfe, weil man sich natürlich dem Tod nähert, das ist ganz klar... Da kriegt man auch 
glaub ich... ne andere Einstellung zu dem... Ich finde Friedhöfe mittlerweile... Wie soll ich sagen? Das das ist so eine, so eine Ruhe, die dann einkehrt... an mir selbst, wenn ich das sehe, [...] wie die Leute die Gräber pflegen und... wie sie ibrer Traurigkeit freien Lauf lassen und wie sie an den Gräbern stehen und beten. Das find' ich toll! Das hab' ich früher nicht wahrgenommen. «(P5, 19:34)

(15) "Sorry, aber ich bin in dem Moment tot." - Perspektiven auf die eigene Bestattung

Am Ende jedes unserer Interviews steht der Perspektivwechsel von der Trauererfahrung zur Sichtweise der Toten in sper. Wir befragten unsere Gesprächspartner nach ihren Aussichten zur eigenen Endlichkeit mitsamt Berücksichtigung solcher Aspekte wie Testament, Bestattungswünsche, Beisetzungsort, Betrauert-Werden, usf. Wie konkret sind entsprechende Vorstellungen und auf welche Weise wurden sie bereits wem gegenüber kommuniziert? Die hierzu geäußerten Einstellungen können Unterschiedliches zum Inhalt haben; insgesamt deutet sich jedoch ein verstärkter Wunsch nach einem individuell gefärbten Abschied an, der dem persönlichen Lebensstil gerecht wird und sich häufig von traditionellen, eher kollektivistisch geprägten Konzepten emanzipiert.

Auffällig ist allerdings, dass sehr häufig eine Art Verantwortungsdelegation an die Adresse der Hinterbliebenen abgegeben wird. Da sie es sind, von denen Trauer erwartet werden kann, rücken die Angehörigen folgerichtig seit geraumer Zeit in den Vordergrund der Bestattungsrituale. In Zeiten, in denen das Bild vom Tod als Übergang in eine jenseitige Fortexistenz an Popularität verloren hat und eine Beerdigung mehr den Lebenden dient als den Toten, gewinnt die Auffassung an Gewicht, wonach in erster Linie nicht das entscheidet, was einem selbst als künftig Sterbender zusagen würde, sondern schlichtweg das, was den Hinterbliebenen gut zu tun verspricht.

$150 \mid$ |Was Individuelles, es muss natürlich zu mir passen [...]. Es muss natürlich was über mich aussagen und ich möchte, dass man zu mir an mein Grab kommt und sagt: Ja, das ist die Laura! Dass man genau sieht, ja, genauso war sie und genauso haben wir sie positiv in Erinnerung. Dass sie gar nicht erst dazu kommen, über Jahre das in sich reinzufressen und viel zu sehr zu trauern, dass es sie einfach kaputt macht [...]. Die gehen mit 'nem anderen Gefühl von diesem Friedhof, als wenn es einfach so ein eckiges Grab wär." (M2, 140:20) 
$151 \mid$ "Es muss einen Festcharakter haben, das soll keine Trauerfeier sein. [...] Natürlich nicht in schwarz, das haben wir bei unserem Sohn schon nicht gemacht.«(M84, 64:37)

152 |Vielleicht bin ich da auch egoistisch, dass ich denk': Wer braucht schon ein Grab? Also, die Kinder sind weit weg und, äh, ich glaub auch nicht, dass die, also... Komischerweise hab ich nicht das Gefühl, dass ich jemandem ein Grab schulde.« $(\mathrm{B} 8,66: 00)$

153 | "Für mich persönlich ist Natur einfach wichtig. [...] Wer das dann zum Schluss entscheidet, wo ich dann lande, ist mir letztendlich gleich. Aber auf 'nem Friedhof will ich auch nicht landen, ganz ehrlich gesagt.« (P10, 27:58)

$154 \mid$ |Wobei ich mir, wenn der Friedhof schön ist, auch vorstellen könnte, ein ganz normales Erdgrab zu haben.«(P1, 29:08)

$155 \mid$ | Ich würde zusammen überlegen. Ich würde meinen Wunsch äußern, aber ich würde niemanden in Schwierigkeiten bringen, ich würde niemanden unter Druck setzen. Wenn die Kinder das nicht könnten, [...] würde ich nicht drauf bestehen.«(B3, 36:13)

156 | "Sorry, aber ich bin in dem Moment tot. Und alles, was aber den Hinterbliebenen hilft zur Trauer, ist dann für mich in Ordnung. Weil mich betrifft's dann, ich sag' mal, nicht mehr so stark [...]. So wenn, ich sag' mal jetzt übertrieben, wenn meine Tochter sagt, sie möchte 'ne pinke Urne für mich, weil sie pink toll findet und die Farbe sie glücklich macht, dann soll sie's machen. Pink ist nicht meine Farbe, [...] aber wenn's ibr hilft, dann ist es okay. «(M94, 83:22)

157 | "Also ich find's immer furchtbar, wenn so Leute sagen: Ich will, dass an meiner Beerdigung nur gelacht wird und fröblich. Hey, hallo? Geht's noch? [lacht] Die sprechen mir meine eigene Trauer ab! Geht gar nicht, ja? [...] Ich kann mir doch nicht vorschreiben lassen vom Verstorbenen, was ich zu machen hab:«(M60, 118:01)

(16) »... diesen persönlichen Druck wegnehmen."-Generelle Wünsche

Im Rahmen der Befragungen kamen, wie es bei narrativen Interviews nicht unüblich ist, auch ganz grundsätzliche Reformwünsche, persönliche Anliegen und andere subjektiv gefärbte Interessen zur Sprache. Die Zielrichtung dieser Äußerungen ist heterogen: Es geht in Richtung der Institutio- 
nen, Berufsverbände und abstrakten Akteure (wie >die Menschen`) ebenso sehr um Kritik wie um Appelle.

Bei aller Vielfalt dieser Beiträge sticht auch hier der Faktor Individualität ins Auge. Der Wille zur Autonomie ist ein entscheidender Antrieb von Verbesserungs- und Ergänzungsanforderungen, die gegenüber den mit Sterben, Tod und Trauer befassten Einrichtungen artikuliert werden.

158 | »... dass die Bestatter auf jeden Fall das den Angehörigen auch, ich sag ${ }^{\star}$ das jetzt mal ganz banal, besser verkaufen. Ohne diese gewisse Angst im Rücken, dass man eben von dem Glauben was Falsches macht oder eben...ja, vom Gesetz her was Falsches [...]. Diesen Druck, diesen persönlichen Druck wegnehmen, weil also letztendlich davor hab ich die meiste Angst gehabt. Weil ich's nicht verstanden hab , in Holland darf ich, in der Schweiz darf ich - und in Deutschland nicht, nur weil's so ein Nazigesetz mal früher gegeben hat, dass die Bestimmungen halt so sind. Kann ich nicht verstehen.«(B3, 41:51)

159 | »Ich weiß, was ich will. Aber da es ein anderer für mich tun muss, weiß ich ja nicht, wie der damit umgehen kann. Ob die Belastung dann nicht so stark ist, dass sie ihn erdrückt. Und das darf man dabei nicht vergessen. Das muss eine ganz [...] freie Entscheidung für den anderen sein. Also, das kann man nicht erzwingen und es darf auch kein Druck ausgeübt werden, dass man nicht darüber reden darf, dass es in der Verschwiegenheit passiert.«(P3, 45:32)

160 | »Mein Wunsch wäre, dass der Tod wieder in der Gesellschaft Platz hat.« (M60, 105:30)

$161 \mid » M a n$ sollte dieses Thema nicht tabuisieren, also man sollte viel häufiger in der Öffentlichkeit darüber sprechen und sich mit dem Ende auch auseinander setzen. [...] Man verdrängt es zu sehr, und ich denke, das muss eigentlich Bestandteil, noch mehr Bestandteil sein.«(B7, 39:25)

$162 \mid$ "Man müsste sich vielleicht auch mal in den anderen Ländern umschauen, wie man daraufhin dann, äh, etwas ändern kann, mit unserer Situation, mit diesen Zwängen erreicht man nichts. Wenn man in den Niederlanden schaut, welche wunderschönen Friedhöfe es da gibt, da macht's ja richtig Spaß drauf zu gehen. Unsere seh'n nach altherkömmlichem Muster altbacken aus. Da hat sich im Laufe der vielen Jahre eigentlich nichts geändert. [...] Wenn ich meine Ideen bätte, wie ich Friedhof gestalten würde, würde ich das ein bisschen auflockern und würd' sagen: Leute, ibr könnt rubig auch hier mal 'nen größeren Stein hinmachen und da 'ne Wasserurne hinmachen. Und dann hätte mein Friedhof auch garantiert einen wunderschönen Pavillon, wo die Menschen, äh, sich mal hinset- 
zen könnten und Eis essen könnten und Kaffee trinken könnten, ja? Und auch vielleicht eben einen Spielplatz für Kinder, damit ich nämlich Kinder auch früh genug auf den Friedhof mitnehmen kann, und nicht: Hach, hier müsst ibr immer ganz still sein. -Nein, man muss gar nicht immer ganz still sein!«(M98, 65:55)

$163 \mid$ "Insofern würd' ich mir natürlich wünschen, dass es da einfach mehrere Möglichkeiten gibt, ohne dass man sich als derjenige, der dann im Grunde genommen die Umsetzung macht, rechtlich in so 'ner Grauzone befindet.«(B5, $7: 46)$

$164 \mid$ |Man muss Veränderungen schaffen, man muss einfach den Horizont erweitern. Und für mich heißt das generell ja nicht, ich will den Friedhof abschaffen, sondern ich möchte eigentlich nur erreichen, dass die Menschen sagen: Wenn andere es anders brauchen, dann sollten sie ohne Wenn und Aber andere Wege gehen dürfen. Und die Politiker entscheiden über das, was Menschen nachher erleiden müssen. [...] In die Familie so einzugreifen, wie es die Politik tut, ist für meine Begriffe eine Bevormundung, ja? Und diese Bevormundung möchte ich eigentlich abgeschafft haben. (M98, 95:44)

$\mathbf{1 6 5} \mid$ »Friedhöfe müssen für die Trauernden sein und nicht für die Verwaltung." (M60, 65:40) 


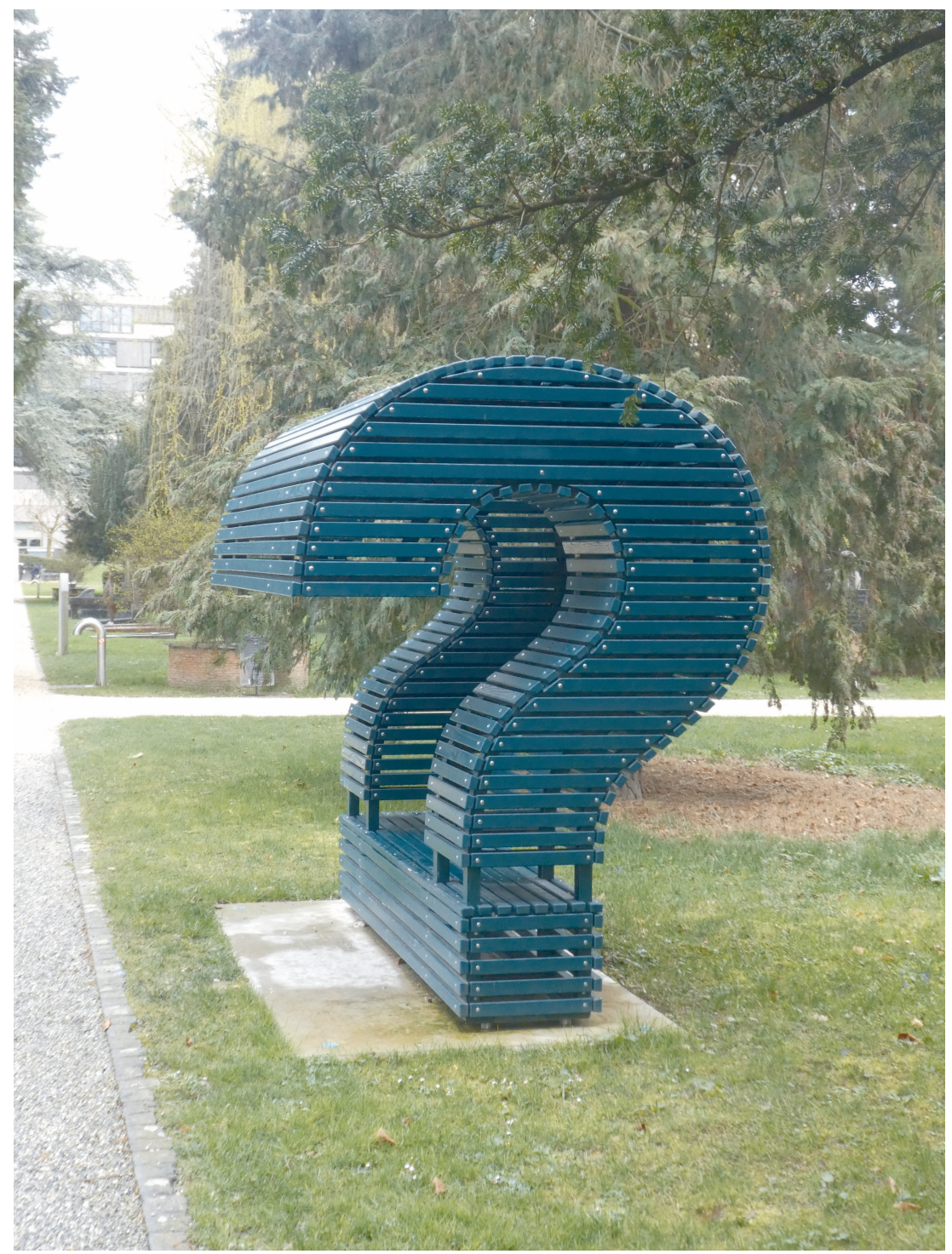


Normen im Umgang mit Trauernden. Ethische Überlegungen

Dirk Preuß

\section{Vorbemerkung zur Unterschiedlichkeit von Normen}

Normen bieten, so die Übersetzung der lateinischen norma ins Deutsche, eine Richtschnur, einen Maßstab, eine Regel oder eine Vorschrift für die Gestaltung von Objekten oder für unser Handeln (vgl. Hau et al. 1991: 666). Sie finden sich als Anforderung an Verfahren, Dienstleistungen oder Produkte im Wirtschaftssektor (oft als DIN-Normen festgelegt) ebenso wie als grammatikalische Regeln in der Sprache oder als Standard im medizinisch-naturwissenschaftlichen Bereich. Als »handlungsbezogene präskriptive Setzungen, die sich mit einem Verbindlichkeitsanspruch geltend machen, der es ermöglicht, menschl[iches] Verhalten nach seiner Wünschbarkeit od[er] Zulässigkeit zu bewerten « (Korff 2006: 907), werden aber vor allem auch sittlich-moralische und rechtliche Vorgaben als Normen bezeichnet. Wie die Definition andeutet, können sie sowohl einer als verbindlich angesehenen Forderung Ausdruck verleihen, als auch im Sinne einer wohlwollenden Empfehlung verstanden werden - die Aussagen >Du sollst nicht töten! und >Du solltest Dich sozial engagieren! haben eine durchaus unterschiedliche normative Kraft und unterschiedliche Stoßrichtungen.

Betrachtet man insbesondere Recht und Moral bzw. deren jeweiligen Normen, sind diese keineswegs immer deckungsgleich, auch wenn sie sich gegenseitig beeinflussen (können). Zwar stimmen moralische und gesetzliche Forderungen in vielen Fällen inhaltlich weitgehend überein und sind die sittlichen Überzeugungen einer Gesellschaft in Gesetzestexte gegossen worden. Andere Menschen zu bestehlen oder Körperverletzung sind beispielsweise sowohl in rechtlicher als auch in moralischer Hinsicht verboten. ${ }^{1}$ Oft gehen sittliche Forderungen aber über das rechtlich Einzuklagende hinaus. Ortsunkundige absichtlich auf einen falschen Weg zu schicken, ist kaum justiziabel, gleichwohl sittlich fragwürdig. Manche gesetzlichen Festlegungen sind auch moralisch neutral. Ob ein Staat Links- oder Rechtsverkehr festschreibt, ist keine moralische Frage; sich an die getroffene Re-

1 Solche Verbote müssen freilich nicht in allen Situationen gelten, - wiederum normierte - Ausnahmen sind, etwa im Falle der Notwehr, möglich. 
gelung zu halten, dann freilich schon. Zu zahlreichen ethischen Herausforderungen existieren wiederum noch keine rechtlichen Regelungen, während sich im moralischen Diskurs bereits Positionen gebildet haben. Dies ist sehr oft beim Entstehen neuer Technologien der Fall. Man denke aktuell etwa an die Diskussion um die Programmierung selbstfahrender Autos für jene Dilemmasituationen, in denen sich ein Unfall nicht vermeiden lässt und entschieden werden muss, mit welchem von zwei Verkehrsteilnehmern die Kollision erfolgen soll. Und schließlich können sich moralische Vorstellungen und rechtliche Vorgaben widersprechen. So vertreten beispielsweise größere Teile der Bevölkerung hinsichtlich aktiver Sterbehilfe oder des ärztlich assistierten Suizids vom Gesetz abweichende Auffassungen (vgl. Knoepffler 2010: 18f.). Dabei sind weder juristische noch moralische - wie auch technische oder grammatikalische - Normen fix, sondern sie verändern sich aufgrund neuer Umstände, Entwicklungen und Einsichten, werden umgeschrieben, neu formuliert, eingeführt, abgeschafft oder anders gewichtet und bewertet. Beeinflussen sich Recht und Moral also gegenseitig, ist es doch entscheidend, die Ebenen nicht zu verwechseln. ${ }^{2}$

Im Folgenden werden in ethischer Perspektive nun dezidiert moralische Normen reflektiert und in einem ersten Schritt nach der Möglichkeit gefragt, wie solche im Bestattungskontext überhaupt allgemein gültig begründet bzw. plausibilisiert werden können. Anschließend sind die Erkenntnisse auf einen Aspekt hin zu applizieren, der zentraler Gegenstand jener Interviews war, die in diesem Buch dokumentiert sind: die Fragestellung, wie mit der Kremationsasche verfahren werden sollte - oder genauer: ob und inwieweit die sogenannte Friedhofspflicht (>Friedhofszwang`) für sie zu gelten hat. $\mathrm{Ob}$ und wie die ethischen Einsichten in Rechtsnormen übersetzt werden können und sollten, ist nicht mehr Gegenstand dieser angewandt-ethischen Betrachtung.

\section{Allgemeine Überlegungen zur ethischen Orientierung in Bestattungsfragen}

Was als eine sschicklicher Bestattung gilt, wird nicht nur individuell innerhalb eines mehr oder weniger großen Toleranzbereiches beantwortet und

2 Dies gilt im Übrigen auch für die verfahrenstechnischen Normen. Im Bestattungskontext etwa wird mit der DIN EN 15017 zunächst nur die standardisierte Umsetzung einer Dienstleistung ausgewiesen, aber damit nicht automatisch oder zuvorderst die moralische Qualität der Handlungen garantiert. 
unterschiedlich empfunden, sondern variiert auch historisch und je nach Kultur. ${ }^{3}$ Dies sei anhand dreier Beispiele kurz verdeutlicht.

Betrachtet man die Bestattungsbräuche und den Umgang mit dem Leichnam im Gebiet des heutigen Deutschlands in den vergangenen 2.000 Jahren, haben sich hier über die Jahrhunderte hinweg zahlreiche Verschiebungen ergeben. Es finden sich private Grabstätten ebenso wie kollektive Bestattungsplätze, Feuer- und Erdbestattung wurden sowohl in der ausgehenden Antike als auch ab dem 18. Jahrhundert nebeneinander praktiziert, während einer langen Phase hingegen wurde nur ein Erdbegräbnis akzeptiert. Das Familiengrab mit reichem Schmuck und das egalitäre Reihengrab konnten beide als Ideal vor Augen stehen bzw. entschieden abgelehnt werden. Die Bestattung in der Nähe von Kirche und Altar erschien im Verlauf der Jahrhunderte stellenweise ebenso erstrebenswert wie zu anderen Zeiten der Ruheplatz auf dem Friedhof vor der Stadt. Wie, ob und wann bestimmte Beisetzungen und Grabformen im Einzelnen kultiviert wurden, konnte kleinräumig stark divergieren. Was als normale Bestattung galt, lässt sich für längere Zeiträume und größere Gebiete so nur schwerlich detaillierter definieren (siehe Sörries 2009; Scholz 2006: 323f.).

Während in jüngerer Zeit die Beisetzung im Sarg in den deutschen Bundesländern über viele Jahrzehnte hinweg zu einem `anständigen` Begräbnis gehörte und gesetzlich vorgeschrieben war bzw. heute zum Teil noch ist, ${ }^{4}$ ist sie in anderen Kulturen und Religionen nicht gefordert, sondern eher die Ausnahme bzw. wird sie problematisiert. Traditionellerweise wird der tote Körper etwa im Islam im Tuch erdbestattet. ${ }^{5}$ Im Hinduismus wird der Leichnam ebenfalls meist in ein Totentuch gehüllt, dann aber verbrannt (siehe Fachverlag des deutschen Bestattungsgewerbes 2008: 171ff.; Scholz 2000: 164f.).

Hier deutet sich drittens schon an, dass der Körperbestattung selbst je nach Zeit und Kultur einmal der Vorzug gegenüber der Kremierung gegeben wurde bzw. wird, oder umgekehrt. Man denke nur an das frühere bzw. gegenwärtig noch gültige bzw. nachwirkende Verbot der Feuerbestattung

3 Für eine ausführlichere Rekonstruktion und Reflexion der im Folgenden vorgestellten allgemeinen Überlegungen siehe Preuß 2015. Dort findet sich auch eine umfangreiche Bibliografie zum Thema.

4 So etwa das bayerische Bestattungsgesetz vom 24.9.1970 in der zuletzt durch $\$ 1$ des Gesetzes geänderten Fassung vom 2.8.2016.

5 Entsprechend erlaubt die überwiegende Zahl der Bundesländer mittlerweile die sarglose Bestattung aus religiösen oder weltanschaulichen Gründen (siehe etwa das Gesetz über das Leichen-, Bestattungs- und Friedhofswesen von Schleswig-Holstein, $\mathbb{} 26$ Abs. 4). 
in der katholischen oder orthodoxen Kirche, im Judentum oder im Islam (can. 1176 \3 CIC/1983; can. 876 \3 CCEO; Preuß 2014; Sörries 2012: 136f.). Für zahlreiche buddhistische Gesellschaften sowie für Hindus stellt hingegen (von Ausnahmen abgesehen) die Feuerbestattung die Norm dar. Davon weichen nochmals die klassischen Vorstellungen der tibetanischen Buddhisten oder der Zoroastrier ab, die die sogenannte Himmelsbestattung durch Geier als Richtschnur ihrer Beerdigungspraxis kennen (Fachverlag des deutschen Bestattungsgewerbes 2008: 176f.; Scholz 2000: 164f.; Clark 1998: 114ff.). ${ }^{6}$

Angesichts dieser hier lediglich kursorisch angedeuteten Normenvielfalt, die nicht nur in den Vorschriften der Religionsgemeinschaften, sondern ggf. auch in den Gesetzestexten von Staaten und Bundesländern ihren je spezifischen Niederschlag gefunden hat, stellt sich die Frage nach Orientierung. Sie stellt sich zum einen für den Einzelnen, der für sich selbst und/oder für seine verstorbenen Angehörigen unter den möglichen Alternativen wählen kann bzw. muss und hierbei zu bestimmen hat, was eine >gute oder >richtige Wahl wäre (und was vor allem auch die Kriterien für >gut und >richtig sind). Zum anderen stellt sie sich für Gesellschaft bzw. Gesetzgeber, die zu bestimmen haben, welche Formen der Beisetzung und des Umgangs mit dem toten Körper sie ggf. fördern und/oder unterbinden wollen. Denn der Hinweis, sich an die überlieferten Vorgaben oder das >Ortsübliche halten zu müssen, verfängt kaum. Erstens wandeln sich die Bestattungskulturen, wie angedeutet, ständig und erscheinen zudem von Rahmenbedingungen und praktischen Gegebenheiten abhängig. So dürften einer These gemäß historische Wechsel von der Feuer- zur Körperbestattung oft mit dem regionalen Mangel an Brennmaterial in Zusammenhang gestanden haben (vgl. Sörries 2009: 36). Zweitens existieren in einer Gesellschaft meist mehrere Konfessionen, Religionen und damit auch Bestattungskulturen nebeneinander. Der Islam gehört ebenso zu Deutschland wie das Judentum, das protestantische oder calvinistische Christentum, der Katholizismus usf. Und drittens fühlen sich zahlreiche Menschen ohnehin nicht mehr einer konkreten Weltanschauung zugehörig, nach deren Empfehlungen und Vorgaben sie sich richten müssten bzw. könnten. So stellen die Konfessionslosen mittlerweile die zahlenmäßig größte Gruppe innerhalb der deutschen Bevölkerung (FoWiD 2017).

6 Aktuell variiert die Häufigkeit von Körper- und Feuerbestattung je nach Region. Im Mittel waren 2017 rund 70\% der Bestattungen in Deutschland Feuer- und 30\% Erdbestattungen (laut Mitteilung der Gütegemeinschaft Feuerbestattungsanlagen e.V. mit Stand vom Juli 2018), wobei der Anteil der Urnenbeisetzungen in vielen Teilen Ostdeutschlands deutlich größer ist (Aeternitas o.J.; Happe 2012). 
Sind folglich nicht alle Vorgaben im Bereich der Bestattungspraxis höchst relativierbar? Für diese Problemstellung fast schon klassisch zu nennen ist eine Begebenheit, die der antike Historiograph Herodot (verstorben um 425 v. Chr.) in seinem Geschichtswerk schildert:

"Als König Dareios einige Griechen seines Reiches fragte, was sie haben wollten, wenn sie ihre toten Väter essen sollten, sagten sie, dazu würden sie sich für kein Geld verstehen. Darauf ließ er Inder kommen, Kallatier, wie sie heißen, welche ihre toten Eltern essen, und fragte sie in Gegenwart jener Griechen mit Hilfe eines Dolmetschers, was sie haben wollten, wenn sie ihre toten Väter mit Feuer verbrennen sollten; die aber schrieen vor Entsetzen und baten ihn, um Gottes willen nur solche Worte nicht in den Mund zu nehmen. «7

Wie wollte man entscheiden, ob das Verbrennen oder das Verspeisen der Toten die richtige Handlung darstellt? Oder wie wollte man, den Gedanken weiter verfolgt, von einem neutralen Standpunkt aus entscheiden, ob das Verbrennen oder das Vergraben von toten Körpern richtig ist? Wie wollte man entscheiden, ob die Totenasche im Erdboden beizusetzen, in einen Fluss einzubringen oder dem Meer zu überantworten ist - und welche dieser Formen eine swürdige< Bestattung darstellen? Wie wollte man entscheiden, ob die Ahnen ihren Platz in den Häusern ihrer Familien finden sollten, ein gemeinsamer Beisetzungsort für die Verstorbenen eines ganzen Dorfes gewählt oder die Mitglieder einer Religionsgemeinschaft an einem ggf. weit entfernten heiligen Ort bestattet werden sollten?

Tatsächlich deutet sich in der Anekdote Herodots aber zugleich eine Richtschnur für ein Handeln an, welche jenseits der kultur- bzw. religionsgebundenen Vorgaben von Verbrennen, Vergraben und Verspeisen liegt. Denn offensichtlich würde es den Kallatiern ebenso wie den Griechen schaden, würde man sie hindern, ihre Toten ihren Vorstellungen und Bedürfnissen gemäß zu bestatten. Es würde ihren Trauerprozess mutmaßlich negativ beeinflussen und ihren Schmerz vergrößern. Die zentrale Forderung in Bestattungsfragen wird entsprechend lauten, Menschen in ihrer Trauer sowie in der Konfrontation mit Tod und Sterblichkeit nicht über den erlittenen Verlust hinaus zusätzlich zu schaden, ihnen also nicht noch größeren Schmerz zuzufügen - zumindest nicht ohne sehr guten Grund (siehe unten). Dieses Prinzip, anderen Menschen nicht zu schaden, ist nun wiederum eine Norm, die, so meine These, allgemein geteilt wird.

7 Herodot 2001: 250 (= III, 38). Vgl. hierzu auch Knoepffler 2010: 25ff.; Quante 2006: $151 \mathrm{ff}$. 
Dies sei im Folgenden zumindest andeutungsweise entfaltet und differenziert, zunächst mit einigen Anmerkungen zum Trauerprozess. Hierbei liegt das Augenmerk nicht auf den nach außen hin gezeigten Trauerhandlungen (engl. mourning), die nicht unbedingt mit dem inneren Erleben korrespondieren müssen. Vielmehr soll dieses innere Erleben selbst (engl. grief) betrachtet werden. $\mathrm{Zu}$ betonen ist zunächst, dass Trauer individuell höchst unterschiedlich verlaufen kann, auch wenn mit unterschiedlichen Modellen versucht wurde, sich dem Phänomen zumindest heuristisch anzunähern (siehe etwa Kast 1982; Worden 2011). Wenn Trauer in diesem Sinne in Reaktionen, Ausmaß und Stärke breit variiert, lassen sich doch einige regelhafte Beobachtungen festhalten, die moralische Relevanz besitzen. Die meisten Menschen, die einen Verlust erlitten haben, befinden sich in einem Zustand hoher emotionaler Belastung, der sie besonders vulnerabel macht. Sie müssen den erlittenen Verlust realisieren, verkraften bzw. verarbeiten und lernen, mit den Folgen umzugehen. Nicht nur Traurigkeit und Schmerz über den Tod eines Menschen, sondern auch Schuldgefühle, Empfindungen wie Wut, Erleichterung oder Dankbarkeit können sich einstellen und zu einem emotionalen Ungleichgewicht führen. Die Hinterbliebenen müssen die lebenspraktischen Folgen des Verlustes meistern, Selbst- und Weltdeutung können fragwürdig werden; die eigene Identität, der eigene Lebensentwurf wird ggf. in Frage gestellt. Sehr oft geht Trauer mit psychischen und somatischen Reaktionen und Symptomen einher, die als unangenehm erlebt werden. Im affektiven und kognitiven Bereich können Schock, Schlaflosigkeit, Gefühle von Angst und Einsamkeit, Konzentrationsschwierigkeiten, Halluzinationen, Schuldgefühle und vieles mehr auftreten. Im Bereich der körperlichen Auswirkungen sind u.a. Herz- und Kreislaufbeschwerden, Krämpfe und Verspannungen, Beklemmungsgefühle, Kurzatmigkeit und eine verringerte Immunfunktion zu nennen. Trauernde ziehen sich oftmals zurück; die Gefahr von Substanzenmissbrauch steigt (vgl. Worden 2011: 25ff.).

Ist eine snormale Trauerreaktion auch nicht als Krankheit einzustufen, ${ }^{8}$ lassen sich so doch zahlreiche Phänomene beobachten, die - ähnlich wie bei Kranken - die Rücksichtnahme Dritter verlangen. Orientiert man sich in diesem Sinne an der Vulnerabilität Kranker und den hierfür bewährten medizinethischen Prinzipien, ist der Rekurs auf das Nichtschadensprinzip auch im Falle der Trauer einsichtig: Das Leid, die schmerzreiche und unangenehme Situation der Trauernden sollte nicht ohne guten Grund noch

8 Zur Diskussion um langanhaltende Trauer als psychische Erkrankung siehe Wagner 2016. 
vergrößert werden, die nachhaltige Verarbeitung des Verlustes sollte nicht behindert werden. Zwar sind Traurigkeit, seelischer Schmerz, die emotionale Belastung etc. zu durchlaufen, damit der Tod eines geliebten Menschen verarbeitet werden kann. Diese dürfen bzw. müssen jedoch nicht über das unumgängliche und in der jeweiligen Situation verkraftbare Maß hinaus vergrößert werden. Das Verbot zu schaden bezieht sich hierbei nicht allein darauf, Traurigkeit und Leid nicht kurzfristig zu vergrößern. Vielmehr umfasst es auch den Anspruch, den Trauerprozess langfristig im Auge zu haben, d.h. der Entstehung sogenannter komplizierter Trauer keinen Vorschub zu leisten. So kann es sich beispielsweise erschwerend auf den Trauerprozess auswirken, wenn die Trauer sozial nicht anerkannt wird oder die Art des Todes stigmatisiert wird. Können oder dürfen Menschen ihre Trauer nicht zeigen, weil etwa der heimliche Geliebte verstorben ist, oder verwehrt man ihnen die Möglichkeit, ihrer Traurigkeit, ihrer Wut etc. Ausdruck zu verleihen, kann sich dies mittel- bis langfristig nachteilig auf die Verarbeitung des Verlustes auswirken, bis hin zu Depressionen und Suizid.

Anderen Menschen keinen Schaden zufügen zu dürfen, ist nun als moralische Forderung nicht unbestreitbar, doch ist sie weitgehend unbestritten. In allen bedeutsamen Ethikkonzeptionen (wie auch der Alltagsmoral) wird dem Nichtschadensprinzip große Bedeutung zugemessen. Insbesondere für den medizinethischen Kontext haben Beauchamp und Childress (2009) die Anschlussfähigkeit dieses sogenannten Prinzips mittlerer Ebene und Reichweite für unterschiedlichste fundamentalethische Entwürfe und Begründungsverfahren nachgezeichnet.

Dieses Prinzip kann durch andere Prinzipien bzw. entgegenstehende Werte und gute Gründe nun aber durchaus eingeschränkt werden. Im Falle der Bestattungskultur wird zum Beispiel das Recht auf sofortige Abschiednahme am Leichnam und die Erhaltung der körperlichen Integrität eingeschränkt, wenn eine rechtsmedizinische Sektion geboten erscheint, die der Strafverfolgung dient und somit auf abstrakte Weise Rechtssicherheit zu stabilisieren hilft (vgl. Preuß 2011: 289). Unter anderem aus Gründen der Hygiene und Gesundheit werden manche Bestattungs- oder Konservierungswünsche ebenfalls nicht erfüllt, etwa der Wunsch, von wilden Tieren gefressen zu werden (Cantor 2010: 201). Daher wäre auch Herodots Kallatier heute mit gutem Grund, nämlich unter anderem aufgrund der Gefahr der Übertragung von Krankheiten, das Verspeisen ihrer Toten untersagt.

Dem Anliegen, einem Trauernden im Augenblick nicht zu schaden, mag aber auch das Anliegen entgegenstehen, ihn langfristig zu stabilisieren. So kann bei Diagnose einer komplizierten Trauer die Konfrontation 
mit dem Verlust unter professioneller Anleitung sinnvoll sein, wenn dadurch der Trauerprozess langfristig befördert wird, obwohl dies kurzfristig die Traurigkeit vergrößern mag und die Konfrontation mit dem Verlustereignis unangenehm bis schmerzhaft ist.

In dieser letztgenannten Situation wird deutlich, dass das Nichtschadensprinzip mit dem Fürsorgeprinzip eng verknüpft ist. ${ }^{9}$ Denn trauernde Menschen können in ihrem Schmerz und in ihrem Kummer auch danach verlangen, dass man ihnen wohltut; die Trauer zu ignorieren, sich nicht um die Trauernden zu sorgen, ihnen z.B. nicht mit Empathie zu begegnen, würde ihnen vermutlich schaden. Dabei wird man prima facie davon ausgehen dürfen, dass die Möglichkeiten und Verpflichtung zu fürsorglichem, d.h. trostreichem Verhalten umso größer sind, je besser bekannt und vertraut die trauernde Person einem ist. Man kann in diesem Fall besser einschätzen, ob und welcher Unterstützung sie bedarf, man befindet sich vielleicht sogar in einer Art Garantenstellung. Am Beispiel Herodots veranschaulicht könnte dies bedeuten: Fremde dürften die Griechen nicht hindern, ihre Toten zu verbrennen, man würde aber auch nicht vehement einfordern, dass jene diesen bei den Bestattungsfeierlichkeiten behilflich sein müssen, obwohl dies gewiss anzuerkennen wäre. Nachbarn der Trauernden hingegen könnten schon eher in der Pflicht gesehen werden, den Hinterbliebenen nicht nur nicht zu schaden, sondern sie bei anstehenden Aufgaben zu unterstützen, falls die Familie diese temporär nicht aus eigner Kraft ausführen kann.

Bisher wurde vor allem von den Trauernden gesprochen und die Rücksichtnahme auf deren Situation beschrieben. Hierbei dürfte der Grad des Schmerzes und der Trauer den Grad der notwendigen Rücksichtnahme bestimmen. Kurz nach dem Trauerfall bzw. bei Menschen, die dem Verstorbenen sehr verbunden waren, wird der Schmerz und die Gefahr, ihnen in ihrer Trauer zu schaden und ihnen weiteres Leid zuzufügen, mutmaßlich größer sein, als Jahre nach dem Verlust und/oder bei Personen, die den Verstorbenen nur flüchtig kannten. Wie mit einem Leichnam oder dem Andenken umgegangen wird, kann aber auch Dritte tangieren, die den Verstorbenen nie kennengelernt haben. Dies kann mit einigen Aspekten in Zusammenhang stehen, welche hier lediglich kurz angedeutet seien. So können sich, erstens, Menschen als Menschen in dem toten Körper wiedererkennen und sich selbst verletzt fühlen, wenn mit dem Leichnam oder Andenken an den Verstorbenen in einer Art und Weise umgegangen wird,

9 Es wird diskutiert, ob die beiden überhaupt zu unterscheiden sind. Sie sind jedenfalls nicht immer scharf zu trennen (vgl. Beauchamp/Childress 2009: 149ff.). 
die ihnen nicht behagt und die ihnen als unangemessen erscheint. Man denke im Extremfall an das oben erwähnte Verspeisen des Leichnams. Hier wird, ließe sich sagen, die Gattungswürde tangiert (vgl. Knoepffler 2004: 26). Der Tod eines Unbekannten kann zweitens auch die Erinnerung an eigene Verlusterfahrungen wachrufen. Wird Hinterbliebenen unsanft der Tod eines Dritten vor Augen geführt, kann dies ihre Trauer um einen ihnen lieben Menschen wieder aufbrechen lassen bzw. noch vertiefen. Und drittens kann der Tod eines Menschen einen stets auch mit der je eigenen Sterblichkeit konfrontieren. Furcht vor dem eigenen Sterben und Angst vor dem eigenen Tod können so induziert oder verstärkt werden. Vielleicht ist man aufgrund einer Erkrankung u.ä. überdies momentan psychisch nicht in der Lage oder an sich nicht willens, sich mit dem eigenen Tod auseinanderzusetzen, sodass auch hier Respekt vor der jeweiligen Lebenssituation geboten erscheint. ${ }^{10}$

Gewiss ist es angesichts der doch relativ diffusen Menge einer >breiteren Öffentlichkeit bzw. >Dritter sehr viel schwieriger zu bestimmen, was welche Menschen im Umgang mit den sterblichen Überresten oder mit dem Andenken an einen Verstorbenen konkret stört oder abstößt. Auch dürfte gelten, dass bis dato unbeteiligte Dritte zwar irritiert und vielleicht auch schmerzlich berührt werden können, wenn der Umgang mit einem Toten nicht ihren Vorstellungen entspricht. Allerdings dürften die Hinterbliebenen in der Regel deutlich intensiver davon betroffen sein, sodass deren Bedürfnisse und Einstellungen bei einer Abwägung aus ethischer Sicht stärker zu gewichten sind. Irritiert der angestrebte Umgang mit dem Leichnam nun aber doch viele Menschen offensichtlich sehr stark, kann durchaus darüber nachgedacht werden, diesen zu modifizieren oder zu untersagen. In Deutschland menschliche Leichen von Tieren fressen zu lassen, könnte hierfür ein Beispiel liefern. Ist dies in anderen Kulturen durchaus gewohnter Bestattungsbrauch, stieße jener doch in Mitteleuropa mutmaßlich - und ggf. noch? - auf starke Vorbehalte sehr vieler Menschen, sodass er, unabhängig von zusätzlichen hygienischen Einwänden (s.o.), zu untersagen wäre.

Die bisher aufgeführten Überlegungen entstammen dem Anliegen, den Lebenden, sei es den Hinterbliebenen in ihrer Trauer oder sei es einer gröBeren Öffentlichkeit in ihrer Konfrontation mit Sterblichkeit und Tod, möglichst nicht zu schaden, ersteren vielleicht sogar in ihrer schmerzli-

10 Diese Gründe sprechen etwa auch dagegen, Plastinate an öffentlichen Plätzen zu zeigen (vgl. Preuß 2008: 26), da sich Trauernde, Schwerkranke etc. hier kaum der Konfrontation mit Sterblichkeit und Tod entziehen können. 
chen Situation hilfreich zu sein. Ein weiterer zentraler Aspekt des Ethos im hier betrachteten Raum ist die Respektierung des letzten Willens des Verstorbenen hinsichtlich seiner Bestattung. Während es zu Lebzeiten ein zentrales Prinzip darstellt, die Selbstbestimmung des Menschen gerade mit Blick auf seinen Körper zu achten und z.B. - unter dem Stichwort der sogenannten Patientenautonomie - selbst medizinisch indizierte Eingriffe nicht gegen den Willen eines einsichts-, urteils- und einwilligungsfähigen Patienten vorzunehmen, ist eine Berücksichtigung der Bestattungswünsche des Verstorbenen nicht ganz so einfach zu begründen. Denn womöglich existiert ein Subjekt, dem die einst formulierten Wünsche zuzuordnen wären, gar nicht mehr. Wer behauptet, dass >mit dem Tod alles aus` sei, kann schwerlich mit Blick auf den Verstorbenen argumentieren, dass dessen einst formulierten Wünsche seinetwegen zu beachten seien - denn wer jetzt nicht mehr existiert, dem kann jetzt auch nicht geschadet werden. Auch ein Schaden, der von unserem Verhalten heute in die Vergangenheit zurückwirkt, als die Person noch lebte, lässt sich nicht ohne Weiteres postulieren, ohne den Zeitstrahl umzukehren. Folglich sollte die Forderung, den letzten Willen des Verstorbenen zu achten, besser als Verpflichtung gegenüber den noch Lebenden hergeleitet werden, will man sie allgemein plausibilisieren und nicht an starke metaphysische Annahmen knüpfen.

Wie dies aussehen könnte, sei kurz angedeutet: Faktisch entwickeln zahlreiche Menschen Wünsche hinsichtlich ihres dereinst toten Körpers bzw. ihrer Bestattung. Zumindest diese Personen würde es bereits zu Lebzeiten offensichtlich beeinträchtigen, könnten sie nicht mit der Umsetzung ihres letzten Willens rechnen, etwa weil dieser in einer Gesellschaft grundsätzlich nicht oder nur geringgeachtet wird. Insbesondere könnte eine solche Beunruhigung zu Lebzeiten ausgelöst werden, wenn Menschen glauben, dass ihr postmortales Schicksal mit dem Schicksal ihres Grabes, Körpers oder dem posthumen Geachtetwerden zusammenhängt. Klassisch sind hierfür jene Vorstellungen, wonach die Seelen der Verstorbenen keine Ruhe finden, wenn ihre Körper nicht bestattet oder ihre Grabstätten geschändet werden. Natürlich ließe sich an dieser Stelle kritisch nachfragen, woher man nicht nur wisse, dass der Verstorbene als Seele o.ä. überhaupt noch existiert, sondern ferner, aufgrund welcher Belege man denn sogar konkretisieren könne, was in diesen Fällen der jenseitigen Existenz schadet oder nutzt. Umgekehrt kann es aber durchaus tröstlich für die Hinterbliebenen und/oder die zukünftig Toten sein, wenn die Bestattungswünsche, etwa gemäß den jeweiligen religiösen Vorgaben, grundsätzlich erfüllt werden, auch wenn diese von Dritten nicht geteilt werden. Womöglich aber verweist das Ansinnen, über den Tod hinaus das Schicksal des eigenen Körpers bestimmen zu wollen, neben religiösen Überzeugungen auf einen 
weiteren grundlegenden Aspekt des Menschseins. Denn immerhin entwickeln auch viele Menschen, die keine konkreten Jenseitsvorstellungen haben, den Wunsch, ihre Bestattung zu regeln. So kommt als ein weiteres Argument die Fähigkeit des Menschen, sich selbst entwerfen zu können, ins Spiel (Gröschner 1995). Der Renaissance-Philosoph Pico della Mirandola hat diese als konstitutiv dafür angesehen, von der Würde des Menschen sprechen zu können.

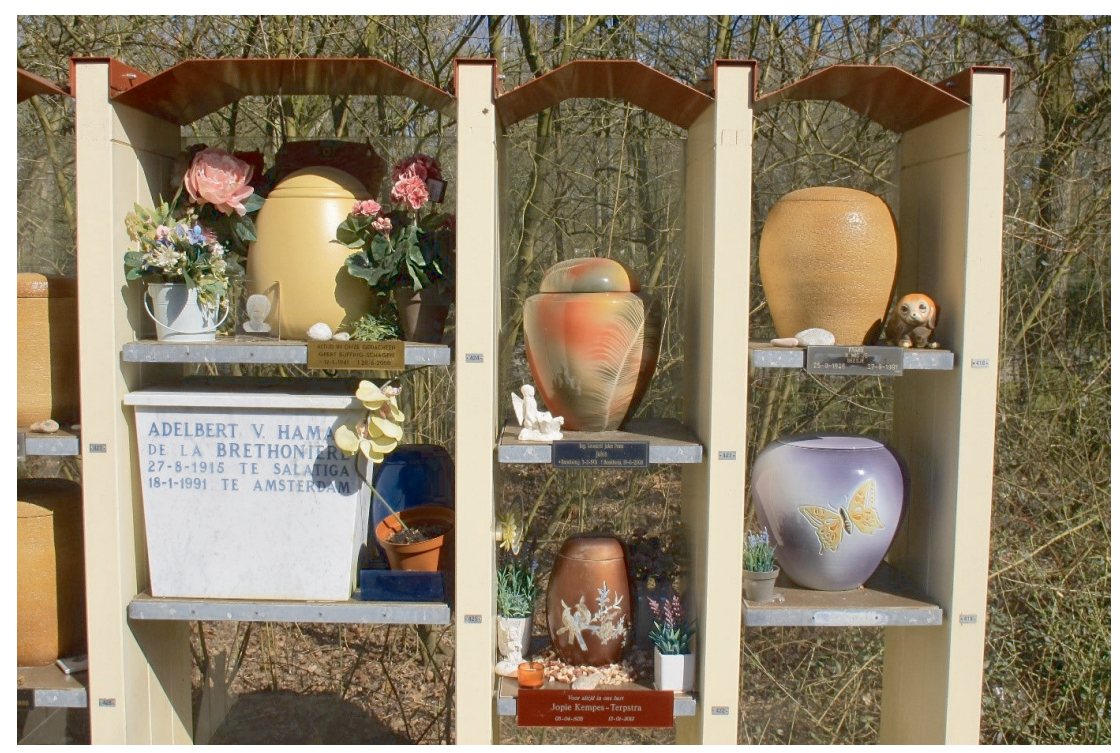

Bezogen auf die eigene Bestattung eröffnet deren Vorausplanung die Möglichkeit, sich prospektiv und zugleich rückblickend noch einmal zum eigenen Leben zu verhalten. Indem man festlegt, was wesentliche Aspekte des eigenen Lebens gewesen sein werden bzw. welche Lebenseinstellung oder welche Überzeugungen man für sich als zentral erachtet hat, gibt man noch einmal Auskunft darüber, wie man sich selbst gesehen hat oder verstanden wissen möchte. Die letztwillige Verfügung der Beisetzungsmodalitäten ist so auch Ausdruck der Fähigkeit, sich angesichts des Todes und der eigenen Sterblichkeit als Lebender zu entwerfen. Wer seinen Körper der anatomischen Ausbildung von Studierenden der Medizin überantwortet, wer in einer Urne mit dem Logo des FC Bayern München beigesetzt werden möchte, wer im Wald seine letzte Ruhestätte zu finden beabsichtigt, wer anonym bestattet werden will oder wer auf derartige Festlegungen bewusst verzichtet, kann sich damit etwa noch einmal als Altruist, als Fuß- 
ballfan (allerdings mit schlechtem Geschmack), als Naturfreund, als Atheist oder als Realist bestimmen. Wenn auch die Fähigkeit des Selbstentwurfs, auf die es Pico ankommt, nicht genommen werden kann, so wird diese Fähigkeit doch nur dann sinnvoll wahrzunehmen sein, wenn mit der Umsetzung des letzten Willens auch postmortal gerechnet werden darf. Damit wäre es aber wiederum ein Schaden für die Lebenden, könnten sie nicht auf die Berücksichtigung ihrer Bestattungswünsche angesichts einer im wahrsten Sinne des Wortes existenziellen Situation vertrauen.

\section{Konkret: die Urne zuhause, die Asche im eigenen Garten}

Wie lassen sich diese Überlegungen nun auf die Optionen hin applizieren, die in den hier abgedruckten Interviews im Mittelpunkt standen? Wie sollte man sich in ethischer Perspektive hinsichtlich der Mitnahme der Urne nach Hause positionieren?

Folgt man den bisherigen Überlegungen, gilt auch hier prima facie: Die Totenfürsorgeberechtigten sind (1) nicht daran zu hindern, die Totenasche den eigenen Vorstellungen gemäß beizusetzen bzw. aufzubewahren, falls dies (2) auch dem (mutmaßlichen) Willen des Verstorbenen entspricht, falls dies (3) mit den anderen, nicht zur Totenfürsorge berechtigten Trauernden abgesprochen ist und von diesen nicht abgelehnt wird, falls es (4) in der Bevölkerung mutmaßlich keine tiefgehenden Vorbehalte gegen die vorgenommene Beisetzungs- bzw. Aufbewahrungsart gibt und falls (5) keine anderen gewichtigen Gründe gegen die gewünschte Beisetzungsform sprechen.

Ad 1: Wie am Beispiel Herodots aufgezeigt, existieren san sich r richtige oder falsche Bestattungspraktiken nicht. Zentral ist vielmehr die Frage, welche sepulkralkulturelle Praxis den Hinterbliebenen bei der Bewältigung ihres Verlustes hilfreich ist bzw. erscheint. Denn zum einen würde es sie schmerzlich berühren, sich nicht auf ihre Weise von den Toten verabschieden zu können. Zum anderen sind es aufgrund der individuellen und kulturellen Prägung des Trauerprozesses mutmaßlich die Betroffenen selbst, die am besten einschätzen können, welches Vorgehen sie für ihre Trauer als adäquat beschreiben bzw. wie sie ihre Trauer leben wollen. Gewiss ist dies keine Garantie, dass der Trauerprozess gelingt und sich die gewählte Bestattungsform für die Trauerarbeit langfristig als tragfähig erweist, insbesondere dann, wenn die Trauernden bisher noch keine entsprechenden Erfahrungen gesammelt haben. Dies gilt jedoch letztlich für viele prospektive Entscheidungen. Haben sich umgekehrt bestimmte Bestattungspraktiken bereits bei früheren Beisetzungen als tröstlich und hilfreich 
erwiesen, ist dies ein gewichtiger Grund, diese bei einem erneuten Trauerfall in Erwägung zu ziehen - oder eben zu verwerfen, sollten sie sich nicht als Trost spendend erwiesen haben. Haben die Hinterbliebenen etwa bei vorangehenden Bestattungen die Erfahrungen gemacht, dass sie nach dem Verlust eines geliebten Menschen keinen konkreten Trauerort benötigten und/oder der Friedhof keinen für sie hilfreichen Ort darstellt (bzw. darzustellen verspricht), liegt es nahe, den Friedhof zu meiden und/oder sogar auf ein Grab gänzlich zu verzichten. Die Interviews zeigten, dass dies zumindest für einige Hinterbliebene zutrifft (siehe hierzu die Zitate 54 bis 57 im Kapitel Zur Rekonstruktion von Trauerfahrungen).

Ad 2: Die Wünsche des Verstorbenen zu beachten und seinen (mutmaßlichen) Willen zu respektieren, gehört zu den zentralen Forderungen unserer Bestattungskultur. Könnte man nicht grundsätzlich mit der Beachtung des letzten Willens - soweit vorhanden - rechnen, würde dies vermutlich viele Menschen beunruhigen und negativ tangieren. Die Beisetzung oder Aufbewahrung der Asche außerhalb des Friedhofs sollte also dem Willen des Verstorbenen entsprechen. Im Idealfall ist dieser schriftlich von ihm fixiert worden. Dies verhindert etwa Uneinigkeit bei der Interpretation bzw. Erinnerung an einst getroffene Aussagen innerhalb der Familie. Ein klar formulierter Wunsch ist aber oftmals auch hilfreich, insbesondere wenn er nicht den Bedürfnissen der Hinterbliebenen widerspricht. Für sie kann es tröstlich sein zu wissen, dass der Tote so bestattet wird, wie er es sich selbst gewünscht hatte. In diesem Sinne sind ebenso ein mündlich bekräftigter Wunsch, außerhalb des Friedhofs beigesetzt zu werden, oder eine Aussage, dass Form und Ort der Bestattung vollkommen gleichgültig seien, ein gewichtiges Indiz, dass die Abkehr vom Friedhof legitim ist. Im Umkehrschluss heißt dies aber auch, dass die Asche eines Verstorbenen nicht gegen dessen (mutmaßlichen) Willen außerhalb des Friedhofs beigesetzt werden sollte. In einigen unserer Interviews zeigte sich, wie wichtig es für die Hinterbliebenen war, den Wunsch des Verstorbenen erfüllen zu können. So sei etwa die Entscheidung, die Asche des Verstorbenen in der dänischen Ostsee auszustreuen "von vornherein klar" (Interview P1, 3:49) gewesen, um seinen "ganz konkrete[n] Wunsch « (ebd.: 1:17) auch tatsächlich umzusetzen.

Ad 3: In die Entscheidung sollte der engere und weitere Kreis der Trauernden abgestuft einbezogen werden. Im Idealfall hat der Verstorbene bereits zu Lebzeiten mit seinen Angehörigen geklärt, welche Art der Bestattung er sich wünschen und welche Form der Beisetzung seinem Umfeld mutmaßlich im Trauerfall helfen würde. Eine Interviewpartnerin schilderte beispielsweise, wie die vier Töchter zusammen mit ihrer Mutter den Modus der Beisetzung für den Fall deren Versterbens besprachen. 
So sollte sich idealerweise eine Konsenslösung finden lassen, die allen Betroffenen zugutekommt und von ihnen mitgetragen werden kann. Dabei sollte dann nicht nur die Kernfamilie berücksichtigt, sondern auch bedacht werden, ob es weitere Menschen gibt, die beispielsweise ein Grab als Trauerort brauchen, oder wie der Zugang zu einem Aufbewahrungsort der Asche im Haus oder auf dem eigenen Grundstück für Trauernde bei Bedarf möglich werden bzw. geregelt sein könnte. Einzubeziehen sind bei der Wahl des Beisetzungsortes - ob nun vor dem Todesfall oder erst anschließend - also idealiter alle Menschen, die wahrscheinlich intensiver um den Verstorbenen trauern werden.

Ad 4: Die Urne auf dem Kaminsims, wie sie aus Hollywood-Produktionen medial bekannt ist, ist beinahe schon sprichwörtlich geworden. Gewiss ist sie in Deutschland lebenspraktisch nicht so vertraut, wie es uns Kinokomödien für den anglo-amerikanischen Raum suggerieren. Doch wird die Aufbewahrung der Urne im Haus oder die Beisetzung im Garten von unbeteiligten Dritten mutmaßlich nicht als so skandalös wahrgenommen, dass dadurch eine größere Beunruhigung entstehen und tiefe Abscheu hervorgerufen würde. Zwar gaben 2001 bei einer Umfrage (Aeternitas 2001) noch 43\% der Befragten an, sie hätten ein ungutes Gefühl, wenn der Nachbar die Urne im Garten oder Wohnzimmer aufbewahren würde. Die diesem Buch zugrundeliegenden Interviews zeigen jedoch, dass die Urne - so sie sich denn im heimischen Umfeld befindet - selten in Bereichen platziert wird, die auch Gästen zugänglich sind, bzw. dass die Urne so aufgestellt wird, dass sie nicht ohne weiteres als solche zu identifizieren ist. Urnen, so ließ sich aus den Interviews erfahren, sind beispielsweise so arrangiert, dass sie Uneingeweihte als Wohnaccessoire, aber nicht als Ruhestätte Verstorbener wahrnehmen, oder sie stehen in einem Zimmer, in das zwar eingeweihte Freunde, aber nicht jeder Besuch Zugang hat. Gräber im Garten sind bisweilen nicht als solche erkennbar (siehe Zitat 76 in Zur Rekonstruktion von Trauererfabrungen), in einem anderen Fall wurde das Grab »als Gedenkstätte deklariert« (P7 [schriftlicher Fragebogen], S. 2, Pkt. 25).

Man nimmt hier anscheinend auf mögliche negative Reaktionen der Besucher und Nachbarn Rücksicht; zusätzlich mag auch die unsichere Rechtslage vor einem allzu offensichtlichen Aufstellen der Urne abhalten. Geschildert wurden in den Interviews jedoch durchaus auch positive Reaktionen der Besucher. Entsprechend gaben schon bei der besagten Umfrage von 2001 57\% der Befragten an, dass die Urne in Nachbars Garten oder Haus ausdrücklich kein ungutes Gefühl bei ihnen hervorrufe.

Auch das Ausstreuen der Kremationsasche an Lieblingsorten in der Landschaft dürfte wohl kaum Unbehagen bei Dritten auslösen, ist diese Praxis doch aus Staaten wie den Niederlanden, Frankreich oder der 
Schweiz bekannt. Und auch die Ausstreuung am Meer oder auf hoher See unterscheidet sich im Ergebnis doch wohl kaum von der legalen Seebestattung, bei der die Asche dem Meer in einer wasserlöslichen Urne übergeben wird.

Ad 5: Könnte es aber gute Gründe geben, die Beisetzung oder Aufbewahrung der Asche außerhalb des Friedhofs zu verweigern, obgleich sowohl (manche) Hinterbliebene als auch der Verstorbene dies gewünscht haben? Dies sei im folgenden Kapitel eigens bedacht.

\section{Potenzielle Einwände}

Die vorangegangenen Überlegungen stellen insofern idealtypische Fallkonstruktionen dar, als sie ein konsensuales Vorgehen voraussetzen, bei dem alle Beteiligten oder zumindest die mutmaßlich intensiver Trauernden und deren Bedürfnisse berücksichtigt und einbezogen werden. Doch die Beziehung zwischen Familienmitgliedern und Verwandten ist nicht immer spannungsfrei. So könnte die Bestattung oder Aufbewahrung der Urne an einem nichtöffentlichen Ort auch die Möglichkeit eröffnen, die ungeliebte Verwandtschaft zu benachteiligen, ihr in der Phase der Trauer zu schaden und die Beisetzung zum Machtspiel und Gegenstand des Familienzwistes werden zu lassen. Bei zerstrittenen Familien wäre die Versuchung vermutlich groß, verhassten Verwandten den Zugang zum Beisetzungsort zu verweigern oder den Ort der Aschenausstreuung nicht bekannt zu gegeben. Gleiches könnte zum Beispiel gelten, wenn der oder die Verstorbene eine außereheliche Beziehung pflegte: Auch hier wäre dem/der außerehelichen Partner(in) wohl meist der Weg ans Grab verwehrt. Sollte folglich, um dies zu vermeiden, die Beisetzung stets an einem öffentlichen Ort vorgeschrieben sein?

Einerseits ergibt sich aus dem bisher Gesagten, dass die Totenfürsorgeberechtigten auch anderen Trauernden gegenüber moralisch verpflichtet sind, diesen nicht willentlich zu schaden und etwa den Zugang zur Asche nicht u.a. mit dem Ziel zu privatisieren, ihnen seelischen Schmerz zuzufügen. Wählen sie die Aufbewahrung der Urne zuhause, um anderen zu schaden, machen sie sich schuldig. Andererseits wird man bedenken müssen, dass auch so schon die Möglichkeiten zahlreich sind, um Menschen, die nicht die Totenfürsorgeberechtigten sind und die einen Trauerort bräuchten, einen solchen vorzuenthalten. Das Verschweigen des Bestattungstermins und/oder des Beisetzungsortes ist hier ebenso zu nennen wie die Wahl einer Beisetzung ohne namentliche Kennzeichnung des Ruheortes usf. Im Interview schildert beispielsweise eine Gesprächspartnerin, wie 


\section{Dirk Preuß}

sehr sie unter der von ihr nicht mitbestimmten Beisetzungsart leidet. Nachdem ihr Lebensgefährte verstarb, veranlasste dessen bestattungsverantwortliche Schwester eine anonyme Urnenbeisetzung. Die Interviewpartnerin zeigt sich mit dieser Entscheidung jedoch alles andere als glücklich und sagt, sie schaffe es einfach nicht, diesen Ort aufzusuchen: »Weil mich das so annervt, dass man da vor einem Feld steht, wo 500 bis 1.000 Leute beerdigt sind $[\ldots]$ und ich nicht weiß, wo er genau liegt « (Interview M47, 8:30).

Die Mitnahme der Urne nach Hause ist insofern nicht von gänzlich neuer Qualität. Nimmt man das vorgebrachte Argument gegen die Aushändigung der Asche ernst, müssten auch manche anderen legalen Beisetzungsarten verboten werden. Vor allem aber sollte man sich fragen, ob man allen Hinterbliebenen die Mitnahme der Asche verbieten will, nur weil es in manchen Familien Streit um die Asche geben mag. Zwar stützen sich die von uns geführten Interviews nur auf die Aussagen jeweils einer Person, doch scheinen in einigen Fällen angemessene Arrangements getroffen worden sein. Eine Interviewpartnerin berichtet sogar, dass sie die Urne mit der Asche ihrer Mutter ihrem Bruder aushändigte, weil dieser das Bedürfnis nach einem Grab äußerte, obgleich die Ausstreuung der Asche in einem Wasserfall schon vorbereitet war (und auch dem Wunsch der Mutter entsprach) und obgleich sich die Beziehung zum Bruder eher schwierig gestaltete (siehe hierzu Zitat 21 in Zur Rekonstruktion von Trauererfahrungen).

In die ethische Fragestellung strahlt in diesem Kontext auch die juristische Frage aus, ob die Kremationsasche mit der Möglichkeit, sie unbegrenzt zuhause in Gewahrsam zu haben, de facto nicht eigentumsfähig werde (vgl. Sörries 2009: 241), der Status - zumindest nach herrschender rechtswissenschaftlicher Meinung - einer res extra commercium also nicht mehr hinreichend sichtbar werde. Von dort ausgehend ließe sich befürchten, dass die Aschen, insbesondere von berühmten Personen, ${ }^{11}$ verkauft oder versteigert bzw. zum Spielball von Spekulationen werden könnten. ${ }^{12}$ Nun ist aber hinsichtlich des ersten Einwandes zumindest in philosophischer Perspektive keineswegs ausgemacht, dass die Asche eines Verstorbenen diesbezüglich dem Leichnam gleichzustellen ist, wie es die Rechtsaus-

11 Man denke etwa an die Versteigerung der vermeintlichen Asche von Truman Capote (siehe Rhan 2016).

12 Hinsichtlich des Streites zwischen Familienmitgliedern und der sich daraus eventuell ergebenden Frage, wer die Asche sein Eigen nennt bzw. diese auch vererben und deren weiteres Schicksal bestimmen kann, gilt in ethischer Perspektive das im vorausgegangenen Absatz Gesagte. 
legung teilweise suggeriert (vgl. Spranger/Hönings 2014: 305), und dass sie folglich auch in Status und Schutzumfang diesem zwangsläufig anzugleichen ist. Vielmehr könnte sie auch den Knochen nach erfolgter Verwesung parallel gesetzt werden. Denn wie die Knochen zumindest in basischem Boden Endprodukte einer Bestattung sind, nämlich der Erdbestattung, ist die Asche das Endprodukt der Feuerbestattung. Nach dieser Logik spricht für die ontologische Angleichung von Asche und Knochen ferner, dass die Asche nur mit Zusatzinformationen, etwa dem Namen auf der Urne oder dem Schamottstein, auf einen konkreten Menschen zurückverweist. Nur dank dieser Zusatzinformationen kann sie überhaupt als menschlich wahrgenommen werden. ${ }^{13}$ Daher empfehlen Bestatter auch, den Schamottstein aus der Aschekapsel zu entfernen, wenn diese im privaten Bereich verbleiben soll, um so die Zuordnung der Asche als menschlich durch Ordnungsamt oder Zoll zu verunmöglichen (siehe hierzu Zitat 40 in Zur Rekonstruktion von Trauererfahrungen). Eine Angleichung von Leichnam und Asche hinsichtlich ihres moralischen und/oder rechtlichen Status ist also nicht per se einsichtig und könnte der weiteren Diskussion lohnen.

Dies besagt allerdings umgekehrt noch nicht, dass die Asche nicht schutzwürdig - und eventuell genauso schutzwürdig wie der Leichnam sein könnte. Denn solange die Asche einem Menschen bzw. sogar einem konkreten einst lebenden Menschen zugeordnet werden kann, kann es für andere Personen bzw. Trauernde und Hinterbliebene durchaus relevant sein, wie mit ihr verfahren wird. Sie könnten irritiert bzw. tief verletzt oder in ihrer Trauer stark beeinträchtigt werden, wenn die Asche eines Menschen wie eine Ware oder gar als Ware gehandelt wird. Demnach ist ein Verbot, mit menschlichen Aschen aus rezenten Kontexten zu handeln, ${ }^{14}$ durchaus angebracht. Dieses wird aber nicht grundsätzlich dadurch in Frage gestellt, dass Aschen zuhause aufbewahrt werden können.

13 Bei Knochen ist dies etwas anders, denn wie der Schädel auch von Laien als human identifiziert werden kann, können Fachleute auch jeden anderen Knochen durch bloße Inaugenscheinnahme als menschlich bestimmen.

14 Über welchen Zeitraum ab der Einäscherung sollte dieses Verbot gelten - 50 Jahre, 80 Jahre oder 100 Jahre? Etwas überspitzt ließe sich formulieren: So lange Menschen bereit sind, etwas für die Kremationsasche zu zahlen. Denn - von wissenschaftlichen Interessen vielleicht abgesehen - werden Menschen für Aschen doch vor allem dann etwas zahlen, wenn ihnen selbst oder anderen die Überreste etwas bedeuten, etwa weil sie von einer berühmten Persönlichkeit stammen. Damit tangiert der Umgang mit der Asche aber offensichtlich Menschen, sodass sich die Käuflichkeit verbietet. Verbindet aber niemand mehr etwas mit der Asche, weil mit dem Toten niemand mehr etwas verbindet - warum sollte sie dann jemand kaufen? 
Zudem zeigen die geführten Interviews, dass es alltagspraktisch tatsächlich die personalen Kategorien wie Nähe und Selbstbestimmung sind, in denen die Hinterbliebenen hinsichtlich ihrer Verstorbenen und deren Überreste denken, und nicht die von Eigentum und Besitz. Eine unserer Befragten betonte, wie wichtig es ihr sei, die Asche ihrer Zwillingsschwester bei sich zu haben. Die Zwillingsschwester sei ihr das Liebste gewesen, wollte man ihr die Asche wegnehmen, da wäre sie »absolut Kämpferin, [...] da würd' ich zur Katze werden « (Interview P3, 28:18), so die Gesprächspartnerin.

Dies mag sich ändern, wenn der Totenfürsorgeberechtigte selbst verstorben ist oder das Interesse an der Asche mit der Zeit schwinden sollte. Wichtig wäre es dann, die unkomplizierte Beisetzung der Asche zu ermöglichen, um zu vermeiden, dass sie schlichtweg entsorgt wird (siehe unten).

Ein Argument gegen das Aushändigen der Urne an die Hinterbliebenen könnte lauten, dass diese später bereuen werden, was sie mit der Asche gemacht haben. Insbesondere das Ausstreuen der Asche lässt sich schließlich nicht mehr korrigieren. Sie kann nicht mehr in ein Grab auf dem Friedhof oder in ein Kolumbarium verbracht werden, wenn sie beispielsweise dem Meer übergeben wurde. Sie kann aber auch nicht mitgenommen werden, wenn das Wohngrundstück, auf dem sie ausgestreut wurde, verkauft werden muss. Wie unsere Interviews zeigen, gilt aber zum einen, dass die getroffenen Entscheidungen in der Regel gut überlegt sind und so mutmaßlich weniger die Gefahr einer unbedachten und vorschnellen Wahl bergen. Zum anderen gibt es, wie bereits geschildert, im Leben viele Entscheidungen, die nachträglich kaum oder nur sehr schwer zu korrigieren sind. Dies gehört gewissermaßen zum >Lebensrisiko< und gilt übrigens auch bei zahlreichen anderen Entscheidungen im Bestattungskontext. Die Wahl der Kremierung lässt sich ebenso wenig rückgängig machen wie - in der Regel - die Wahl eines Reihengrabes anstelle eines Wahlgrabes oder einer anonymen Bestattung anstelle einer namentlich gekennzeichneten Grabstelle. In all diesen Fällen zeigt sich, dass eine gute Beratung, vor allem durch die Bestatter, zentral und wesentlich ist, damit die Beisetzungsform zu den Wünschen und Bedürfnissen der Verstorbenen und Hinterbliebenen passt und Risiken, wie ein Grundstücksverkauf, miterwogen sind. ${ }^{15}$ So schrieb beispielsweise eine Teilnehmerin unserer Befragung hinsichtlich des Grabes ihres Mannes im eigenen Garten: »Mein Sohn hat das Eigentum über-

15 Derartige Probleme treten bekanntermaßen nicht nur beim Verkauf eines Grundstücks auf, sondern auch bei Umbau und Neubau von Fußballstadien, in denen die Aschen von Fans ausgestreut wurden (vgl. Herzog 2005: 202f.). 
nommen. Es gibt noch einen 2-jährigen Enkel, sodass ich hoffe, dass der Wunsch meines Mannes, nicht zu verkaufen, sondern zu erhalten, in Erfüllung geht.« (P7 [schriftlicher Fragebogen], S. 3, Pkt. 33b)

Als Argument speziell gegen die Aufbewahrung der Asche zuhause schließt hier an, dass die Totenruhe nicht gewahrt sein könnte, wenn die Asche nicht auf dem Friedhof - oder an einem anderen spezifischen Ort beigesetzt wird (Schulz Meinen 2009). Der Tote in Form seiner Asche würde dann nicht sin Frieden ruhen können, sondern zöge mit jedem Wohnungswechsel seiner Witwe um, ginge vielleicht sogar mit auf Urlaubsreise oder zum Einkaufen. Totenruhe wird laut dieser Bedenken und Argumentation vor allem als Grabesruhe verstanden - und ist nicht, wie in $\$ 168$ StGB, als Schutz vor unbefugter Wegnahme des Leichnams, Grabschändung und beschimpfendem Unfug definiert. Die Forderung nach einer solchen Grabesruhe erschließt sich als ethischer Minimalstandard, der unabhängig von den Bedürfnissen der Hinterbliebenen bzw. den Wünschen des Verstorbenen durchzusetzen wäre, allerdings nicht (vgl. Preuß 2015: 244ff.). Denn immerhin sind zahlreiche Kulturen bekannt, die das Mitführen der körperlichen Überreste ihrer Verstorbenen, Sekundär- und Tertiärbestattungen bzw. die sStörung der `Grabesruhe kennen. Zudem beschränkt sich auch in Deutschland die Grabesruhe der Friedhöfe auf eine übersichtliche Frist von einigen Jahren und variiert zudem von Stadt zu Stadt. Es ist also nicht ohne weiteres ersichtlich, warum es eine erzwungene Grabesruhe geben sollte, falls diese, etwa bei Migranten, dem kulturellen Hintergrund oder den individuellen Bedürfnissen der Hinterbliebenen widerspricht und auch der Verstorbene keinen Wert auf sie legte.

Wo den Hinterbliebenen aufgrund ihrer kulturellen, religiösen und/ oder individuellen Überzeugungen die Grabesruhe hingegen wichtig ist, gilt es, sie zu garantieren. Man denke z.B. an jüdische oder muslimische Begräbnisstätten. Wie die Befragungen zeigen, wenden sich Menschen interessanterweise aber u.a. deshalb von den Friedhöfen ab, weil die Ewigkeitsgarantie dort gerade nicht besteht. Der durchschnittliche Friedhof wird also momentan weder denen gerecht, die ihre Toten bei sich wissen wollen und diese beim Umzug in eine andere Stadt mitnehmen wollen; noch wird er denen gerecht, die sich eine wirklich auf Dauer bestehende Grabstätte wünschen - wie manche unserer Interviewpartner (siehe z.B. die Zitate 119 und 139 in Zur Rekonstruktion von Trauererfahrungen).

Ein weiteres Argument gegen die Aushändigung der Urne an die Totenfürsorgeberechtigten besagt, dass deren Trauerprozess prolongiert und eine Ablösung vom Verstorbenen verhindert wird, wenn die Urne zuhause aufbewahrt oder im eigenen Garten beigesetzt wird. Träfe dies zu, könnte es tatsächlich im langfristigen Interesse der Trauernden liegen, die Aufbewah- 
rung der Asche im häuslichen Kontext zu limitieren. Allerdings müsste die Prämisse des Arguments erst plausibel gemacht werden. Erstens müsste empirisch belegt werden, dass eine Verzögerung der Trauer tatsächlich regelmäßig vorkommt. Denn denkbar ist ja im Gegenteil auch, dass der Trauerprozess positiv im Sinne einer nachhaltigen Verlustbewältigung unterstützt wird. So könnte beispielsweise die individuell austarierbare Abstimmung von Nähe und Distanz zu den materiellen Überresten des Verstorbenen den Trauerprozess befördern. Das Muster von Sekundär- und Tertiärbestattungen, die man aus vielen Kulturen kennt und die dort als hilfreich erlebt werden, könnte so repliziert werden: Die Einäscherung wäre in diesem Sinne die Primärbestattung, die Aufbewahrung der Urne im Haus für eine längere Zeit entspräche dem sekundären Bestattungsort, dem als dritte Phase die Ausstreuung der Asche in der Natur folgt. Dass die Traueraufgabe der Ablösung erschwert (bzw. erleichtert) wird, wäre erst in einer größer angelegten Studie zu zeigen - und dies würde wiederum voraussetzen, die Mitnahme der Urne nach Hause zumindest vorübergehend zu erlauben.

Zweitens wäre hinsichtlich der Schlagkraft des Arguments auch die Kausalität zu prüfen. Verlängert und verkompliziert die Mitnahme der Urne nach Hause den Trauerprozess - oder nehmen ggf. nicht vielmehr jene Hinterbliebenen die Urne zu sich nach Hause, die ohnehin (und unabhängig vom Aufbewahrungsort) eine besonders schwere Verlustbewältigung vor sich haben?

Drittens könnte es in diesem Zusammenhang eine bewusste Entscheidung sein, sich gar nicht vom Verstorbenen lösen zu wollen, auch wenn dies dem snormalen< Lauf des Lebens widersprechen mag (wer auch immer dies nach welchen Kriterien festlegt). Denn natürlich gehört es zum Recht auf Selbstbestimmung, auch Lebensentscheidungen zu treffen, die vvon außen betrachtet< nicht vernünftig erscheinen. Im medizinischen Kontext etwa können Behandlungen vom Betroffenen selbstverständlich abgelehnt werden, auch wenn sie medizinisch indiziert sind. Durchaus nachvollziehbar mag es daher sein, wenn eine Frau die Urne mit der Asche ihrer eineiigen Zwillingsschwester zu sich nimmt und ausführt, dass es für sie gar nicht in Frage komme, sich von der Asche ihrer Schwester zu trennen. Vielmehr solle ihre eigene Asche selbst einmal neben der ihrer Schwester stehen (siehe hierzu auch Zitat 78 in Zur Rekonstruktion von Trauererfabrungen).

Vielleicht soll die Totenasche aber auch ausgestreut und nicht im häuslichen Kontext aufbewahrt werden. Als Einwand gegen die Aushändigung der Urne an die Hinterbliebenen könnte in diesem Fall vorgebracht werden, dass durch die mit Schadstoffen kontaminierten Verbrennungsrück- 
stände die Umwelt belastet würde. Folglich sei die Ausbringung der Asche auf bestimmte Areale außerhalb von Grundwasserschutzgebieten zu beschränken; dies sei wiederum nur über die Friedhofspflicht zu garantieren.

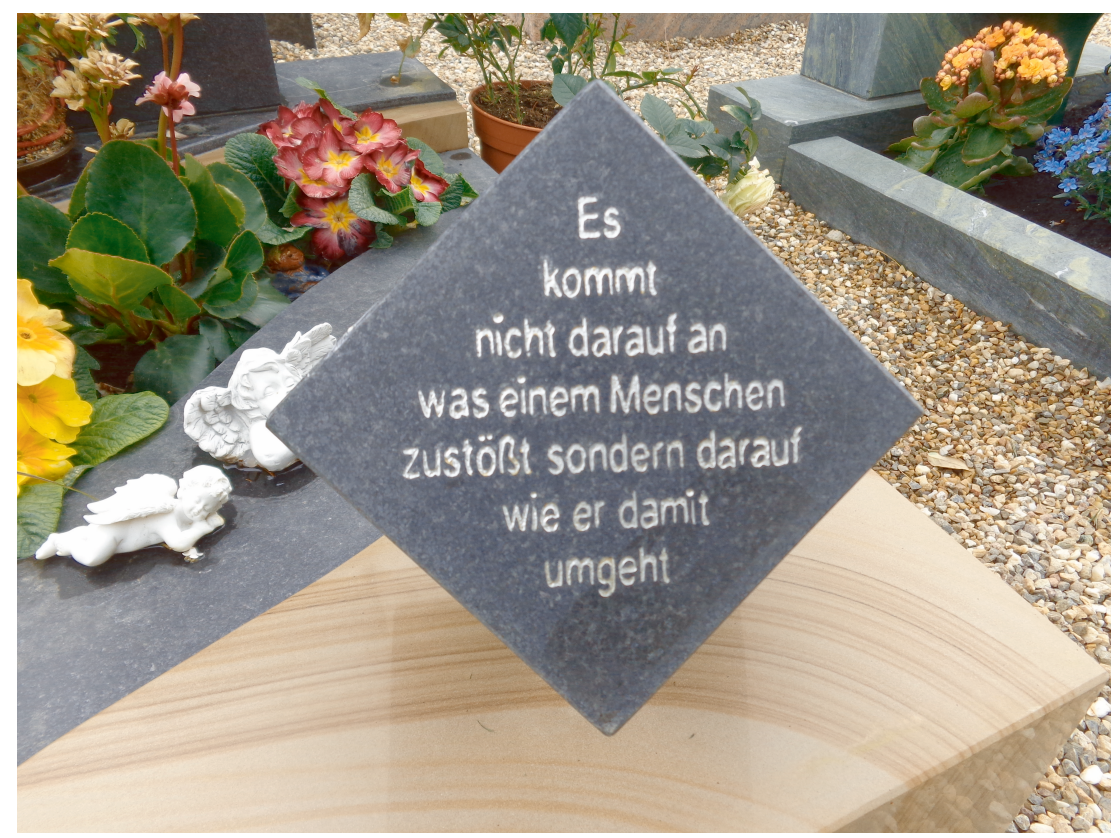

In welchem Umfang die Totenaschen tatsächlich eine Belastung für Boden und Grundwasser darstellen, ist aktuell noch nicht klar. Sollte sich herausstellen, dass die Asche eine nennenswerte Umweltbelastung darstellt, müsste von dort ausgehend ggf. bestimmt werden, welche Umweltbelastung man für tolerierbar hält, um damit Menschen in ihrer Trauer zu helfen. Denn aus dem Fakt einer Umweltbelastung folgt nicht automatisch, dass die Ascheausstreuung verboten werden müsste. Immerhin verbieten weder der Gesetzgeber noch der gesellschaftliche Commonsense den Flug nach Mallorca oder die Spritztour mit dem PS-starken Auto in die Alpen, obgleich beides die Umwelt erheblich belastet und 'nur der Erholung dient (die übrigens in diesen Fällen durchaus umweltverträglicher zu erreichen wäre). Die Belastung der Asche wäre also unter Umständen ins Verhältnis zu setzen zu anderen anthropogenen Belastungen. Dieses Argument spräche im Übrigen auch für die Beibehaltung der Seebestattungen oder der Beisetzung in Wäldern, solange sich die Belastung und Gefahren für Umwelt und menschliche Gesundheit in engen Grenzen halten und sie 
angesichts des Benefits für die Hinterbliebenen verantwortet werden können. Vielleicht spräche dann sogar manches für die nicht ortsgebundene Ausstreuung und oder Beisetzung der Asche, weil Schadstoffe nicht in bestimmten Arealen, einer bestimmten Bucht, einem bestimmten Waldstück, akkumulieren.

Schließlich wird noch befürchtet, dass die Aushändigung der Urne an die Totenfürsorgeberechtigten zum >Ausbluten $<$ der Friedhöfe und zum Niedergang der Gewerke (wie Steinmetze oder Friedhofsgärtner) führen könnte. Vielleicht haben wir es, betriebswirtschaftlich gesprochen, bei der Mitnahme der Urne nach Hause tatsächlich nicht nur mit einem zusätzlichen Angebot zu tun, sondern mit einer echten Verwerfung für die Branche? Realistisch wird man daraufhin erstens feststellen können, dass sich ein neuer Trend mittel- und langfristig kaum durch Verbote aufhalten lässt. In ethischer Perspektive wird man aber vor allem festhalten können, dass auch kein Grund besteht, ihn aufzuhalten, solange er nicht moralisch verwerflich ist. Wie gezeigt, ergeben sich in Richtung einer sittlichen Verwerflichkeit aber keine Hinweise. Zweitens sind Trauernde und Verstorbenen nicht dazu da, einen Industriezweig zu erhalten oder den Friedhof vor Verkleinerungen zu bewahren. Vielmehr gilt doch umgekehrt, dass es Auftrag der Dienstleister und der Friedhöfe ist, die Trauernden zu unterstützen bzw. in deren Sinne Daseinsvorsorge zu betreiben.

Es gehört zu den wirtschaftlichen Zusammenhängen sowohl im öffentlichen wie auch im privaten Sektor, dass Kapazitäten angepasst werden müssen. Trauernde, die sich gegen einen klassischen Bestattungsplatz entscheiden, dürfen nicht die im wahrsten Sinne des Wortes Leidtragenden und Lückenbüßer für Fehlausrichtungen von Branchen und Verwaltungen werden, die zudem relativ viel Zeit haben bzw. hatten, sich auf den Wandel einzustellen.

\section{Fazit und Ausblick}

Es ist richtig, dass man den Totenfürsorgeberechtigten die Mitnahme der Asche nach Hause und/oder deren Ausstreuung an einem Ort außerhalb des Friedhofs nicht immer - oder vielleicht sogar nur selten? - empfehlen wird. Daraus folgt allerdings nicht, dass dies zu verbieten ist, zumal eine nicht geringe Zahl von Menschen offensichtlich davon profitiert, wenn der Umgang mit der Totenasche liberalisiert wird. Wie die geführten Interviews zeigen, kann der freiere Umgang mit der Asche dem Bedürfnis zu trauern und/oder der Biografie des Verstorbenen bisweilen besser gerecht 
werden, als die Bestattung auf den rechtlich vorgesehenen Beisetzungsflächen.

Von dieser These ausgehend erscheint es wichtig, dass eine gute Beratung, etwa durch die Bestatter und/oder Krematorien, durch Verbraucherportale und -zeitschriften etc. stattfindet - wie dies für alle Bestattungsfragen gilt, aber längst nicht immer umgesetzt wird. Dies schützt zwar gewiss nicht vor Fehlentscheidungen, die sich durch falsche Antizipation, Fehleinschätzungen etc. nie ausschließen lassen, doch reduziert es jene Gefahren, die sich durch umfassende Information vermeiden lassen.

Diese These liefert aber auch ein Argument dafür, auf Friedhöfen kostenfreie Gräber anzubieten, die im Sinne der Daseinsvorsorge z.B. steuerfinanziert sind. Denn zum einen könnte durch sie garantiert werden, dass die Mitnahme der Urne nach Hause oder die Ausstreuung der Kremationsasche in der Landschaft nicht aus Kostengründen, sondern aus Überzeugung gewählt wird. Zum anderen wäre so die Möglichkeit gegeben, die Urne abzugeben und beisetzen zu lassen, wenn sie nicht mehr zu Hause erwünscht ist, weil z.B. der hinterbliebene Angehörige, in dessen Gewahrsam sie sich befand, selbst verstorben ist.

Die Aufhebung der Friedhofspflicht, denkt man sie auf diese Weise zu Ende, könnte aber so wiederum dem Friedhof selbst zugutekommen, könnte sie doch Anlass sein, das umzusetzen, was seit geraumer Zeit gefordert und diskutiert wird (vgl. Sörries 2016: 99): die unentgeltliche Vergabe von einfachen Grabstätten auf unseren Friedhöfen. 


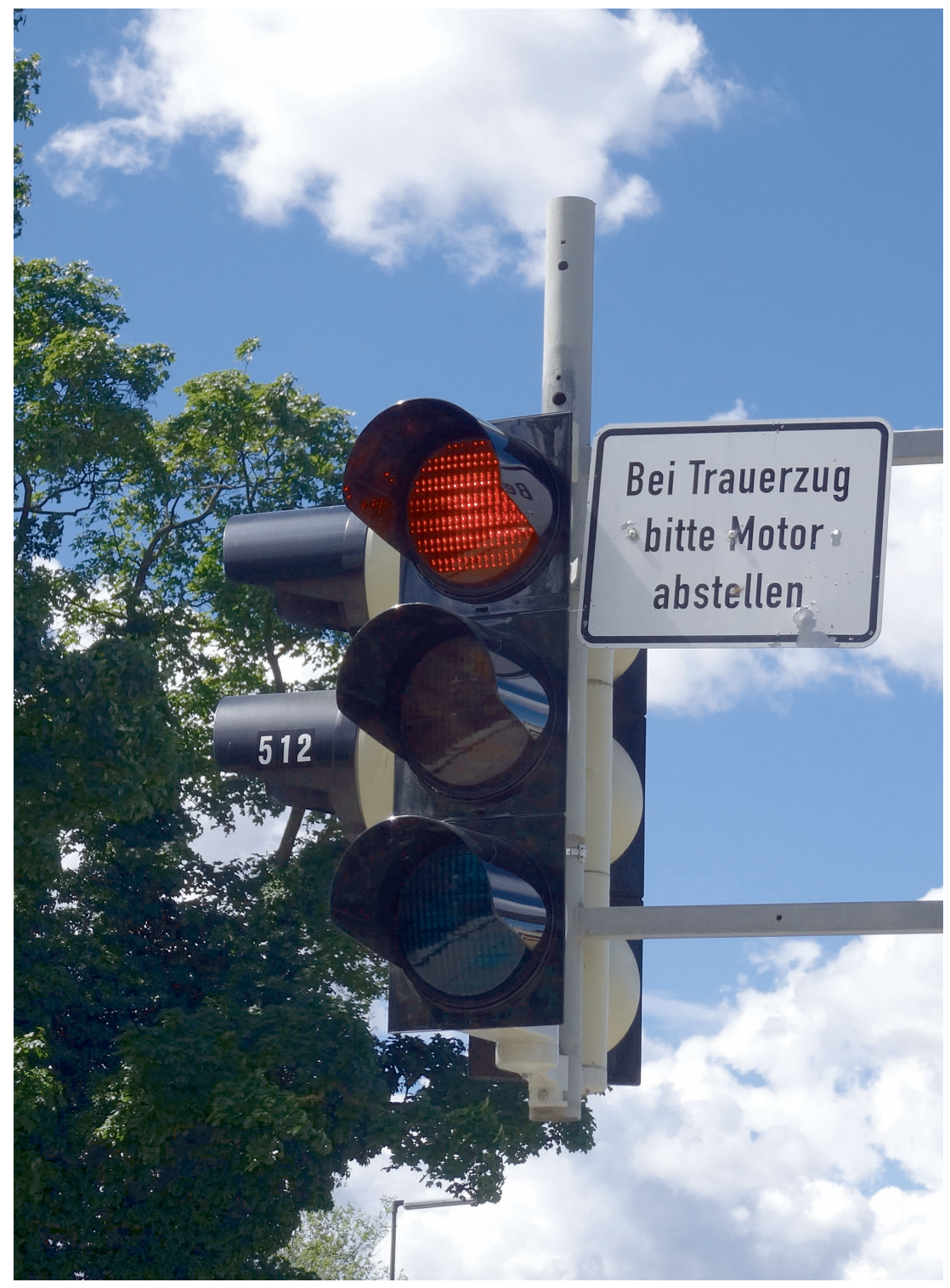




\section{Nachwort- \\ Wie die Theorie zur Praxis kommt. Acht Vorschläge}

Thorsten Benkel, Matthias Meitzler \& Dirk Preuß

Dies ist kein Buch gegen den Friedhof. Es ist auch kein Buch, in dem das (vermeintliche) Sterben des Friedhofs dokumentiert werden soll (im Unterschied zu Sörries 2016). Denn der Friedhof stirbt nicht. Der Friedhof hat gute Überlebenschancen, deren Realisierung allerdings abhängig ist von der Weitsicht, Innovationsbereitschaft und der Sensibilität der Verantwortlichen gegenüber gesellschaftlichen Veränderungen.

Die Forschungen, die dem vorliegenden Band zugrunde liegen, mögen in diesem Sinne interpretiert werden. Wir möchten sie ausdrücklich als Datengrundlage für den empirischen Beleg eines Transformationsprozesses verstanden wissen. Die Logik des sozialen Wandels gründet einerseits in der Permanenz der Veränderung; oder, um es mit einem Grabsteinzitat aus Nordhessen zu beschreiben: "Nichts ist, wie es bleibt." Andererseits sind Umbrüche des gesellschaftlichen Normen- und Wertegerüstes die subtilen und doch effektiven Konsequenzen individuellen Handelns. In der Soziologie gibt es für den komplexen Zusammenhang, der diesen fortwährenden Mechanismus antreibt, eine anschauliche Darstellung - die Coleman'sche Badewanne.

Es handelt sich um ein vereinfachtes Modell, um vielschichtige Prozesse abzubilden (vgl. Coleman 1995: 6ff.). Im Kontext der Trauer erscheint es schon deshalb brauchbar, weil sich darin die gesellschaftliche mit der individualpsychologischen Ebene zusammendenken lässt: Das Modell erklärt, wieso vermeintlich ganz eigenwillige Einstellungen in Wahrheit ssozial geerdet sind und in der Folge selbst wieder kollektive Wirkungen entfalten. 


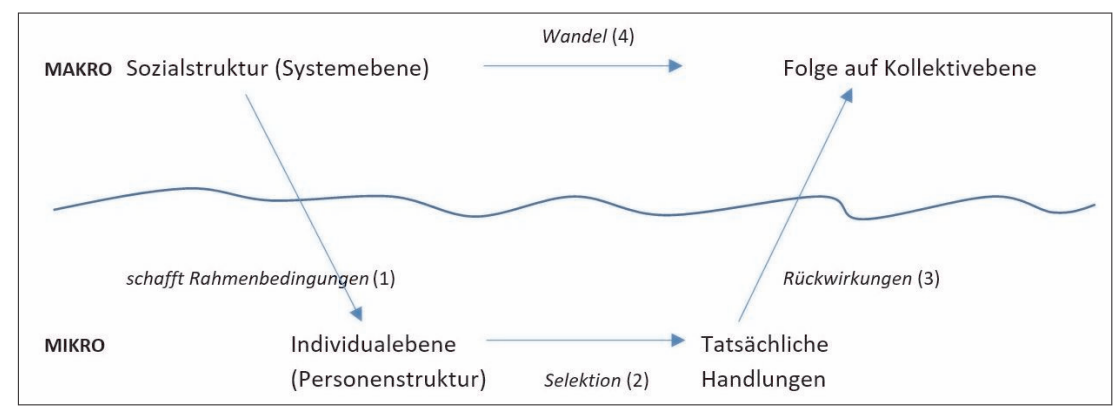

Erklärungsmodell nach James S. Coleman (eigene Bearbeitung) zum Zusammenhang der gesellschaftlichen Ebene (Makro) und der Interaktionsebene (Mikro). Die von den sozialen Verhältnissen eröffneten Entscheidungspotenziale ermöglichen eine Selektion unter allen Handlungsoptionen. Dies kann zur Anhäufung bestimmter Einstellungen führen, durch die langfristig Gesellschaft verändert wird.

Diverse gesamtgesellschaftliche Entwicklungen, die mithin seit Jahrzehnten virulent sind, sind ebenfalls und zum Teil sehr deutlich von der Verbindung zwischen der gesamtgesellschaftlichen Makro- und der von Einzelindividuen geprägten Mikroebene beeinflusst. Gerade im Bereich zwischenmenschlicher Austausch- und Aushandlungsprozesse, dort also, wo sich laut Georg Simmel Prozeduren der Vergemeinschaftung abspielen (Simmel 1999), sind es vermeintlich persönliche Haltungen, die nach außen dringen und das Individuelle über die private Existenz hinaustragen. Das Beispiel Trauer zeigt dies besonders deutlich: Kaum jemand versteht sein oder ihr eigenes Empfinden als das Produkt einer gesellschaftlichen sEinrichtung`. Und nur einige wenige dürften ernsthaft der Ansicht sein, dass ihre somit ganz persönliche Disposition zwingend die Grundlage für die Einstellung anderer sein müsse. Tatsächlich sind all die vermeintlich originären und subjektiv empfundenen Affekte nicht losgelöst von den zahllosen sozialen Verbindungen zu denken, die jedermann alltäglich knüpft, bestätigt, löst und wiederherstellt. Trends, die das Gesagte bestätigen können, sind etwa die Säkularisierung, Pragmatisierung, Ökonomisierung, Pluralisierung und Individualisierung (dazu ausführlich Benkel/Meitzler 2013: 273ff.).

Die Auseinandersetzung mit Trauerprozessen ist, diese Erkenntnis zwingt uns das Interviewmaterial auf, unabdingbar auch eine Auseinandersetzung mit den juristischen, ethischen, ökonomischen, medizinischen und sepulkralen Elementen und Ritualen, die je kulturspezifisch das Ende des Lebens einrahmen. Auch sie sind einem Wandlungsprozess unterworfen, der sich schwerlich ignorieren lässt, und der sich bei langfristiger 
Ignoranz von selbst aufdrängen dürfte. Insbesondere die Bestattungskultur und die Akteure in den damit verbundenen professionellen Handlungsfeldern stehen in der Kritik, sind einem Innovationsdruck ausgesetzt, müssen geradezu sseismografisch ermitteln, welche künftigen Entwicklungen sich abzuzeichnen scheinen, und sie müssen bei all dem im Stande sein, den akuten Einzelfall adäquat zu thematisieren und ihn gemäß der Prinzipien sozialer Erwünschtheit zu behandeln. Wir möchten an dieser Stelle einige Schlussfolgerungen ziehen, die im Lichte unserer Befunde für die Praxisdimensionen des Lebensendes von Bedeutung sein könnten.

\section{Schlussfolgerungen für die Praxis}

\section{1 | Grundsätzliche Orientierung an gesellschaftlichen Transformations- prozessen}

Wie oben gesagt, darf Gesellschaft - der Raum, in dem Trauer- und Bestattungskultur sich entfalten - nicht als unveränderliche `Naturgegebenheit< verstanden werden. Alles ist im Wandel, und selbst dieser Satz ist eine wandlungsfähige Aussage. Individuelle Fallgeschichten können nicht frei von ihrer gesellschaftlichen Verwurzelung gedacht werden und sind deshalb in Wahrheit nie voneinander isoliert. Vielmehr ist es so, dass die individuelle Ausprägung sich nicht selten als Effekt jener Rahmenbedingungen herausstellt, die mit ihr scheinbar unverbunden sind, tatsächlich aber die Grundlage ihres Zustandekommens bilden.

Auf die Praxis professionellen Handelns bezogen bedeutet dies: Wer im Kontext von Sterben, Tod und Trauer beruflich aktiv ist, kommt um die Wahrnehmung und aktive Recherche gesellschaftlicher Wandlungsprozesse nicht herum. Die medialen Berichterstattungen geben durchaus Einblicke in entsprechende Vorgänge, wenn sie auch bisweilen eher das Kurzlebige und Oberflächliche fokussieren. In der alltäglichen Berufspraxis ergeben sich ohne Frage wertvolle Erkenntnisse hinsichtlich der Veränderung von Strukturen. Professionell Handelnde mit Weitblick und einem entsprechenden Reflexionsbewusstsein wissen dies für die Neuausrichtung oder Überarbeitung ihrer Handlungspraktiken bzw. ihres Angebotes zu nutzen. Allerdings ist nicht immer leicht zu trennen zwischen anekdotischen Begebenheiten und den Kennzeichen tatsächlicher, d.h. überindividueller Vorgänge. Da es sich bei Veränderungen im gesellschaftlichen $\mathrm{Zu}$ sammenleben überwiegend um langfristige Abläufe handelt, braucht es Beobachtungen mit entsprechend ausgerüsteten Instrumenten. Es braucht also die wissenschaftliche Expertise. 


\section{Hinterfragung normativer Regelungen}

Die mit dem Bestattungsrecht verbundenen Verwaltungsprozesse und Bestimmungen haben sich vielfach als unflexibel herausgestellt. Regelwerke besitzen gemeinhin eine kollektive Orientierung und akzentuieren einen kollektiv verbindlichen Charakter von Trauer - sie wird hierdurch versachlicht, als sei Trauer eine berechenbare Größe, als könnte das Skandalon des Todes damit eingefangen und könnten Tod und Tote damit befriedet werden (vgl. Jankélévitch 2003: 90f.). Dies wiederum führt dazu, dass die individuelle Betroffenheit eines einzelnen Trauerfalls und der Eigenwert individueller Trauer potenziell unterlaufen werden. Einige der oben dargestellten Interviewzitate thematisieren genau dies: Verbote werden als Einschränkung der persönlichen autonomen Verlustverarbeitung erlebt. Der Friedhof wird in erster Linie als ein Ort der Verbote wahrgenommen und nicht als ein Ort, an dem sich Trauer frei und uneingeschränkt entfalten kann. Welchen Zweck erfüllt es überhaupt, wenn man Friedhofsbesuchern gleich am Eingang offenlegt, was hier alles nicht sein darf - wäre es nicht besser, auf die Vielfalt der erlaubten Handlungsspielräume hinzuweisen und es zu ermöglichen, die eigene Trauer zu leben?

Problematisch erscheinen vor allem Konflikte mit Behörden und Ämtern, die ein vergleichsweise standardisiertes und enges Konzept von Trauer durchsetzen wollen. Für einige unserer Gesprächspartner ist es so, als müsse man jene Individualität, die man im Leben aktiv gestaltet hat, am Friedhofstor abgeben. Vor diesem Hintergrund ist eine höhere Flexibilität von Bürokratie gefragt. Damit sie nicht erstarrt, braucht sie Aktionsfreiräume. Im europäischen Vergleich gibt es viele Länder, die sich diesbezüglich wesentlich liberaler zeigen - und in denen die Friedhofskultur offensichtlich dennoch nicht zusammenbricht. Im Gegenteil: Mit mehr festgeschriebener Liberalität ändert sich auch das Bewusstsein der Menschen. Sie fühlen sich in ihrer Entscheidungsfindung freier und werden sich in der Folge auch mit traditionellen Konzepten wieder besser versöhnen können, weil sie sie aus dem Blickwinkel der autonomen Handlungsbefugnis betrachten - und nicht aus der Perspektive des Gezwungenseins.

\section{Notwendigkeit fallbezogener Reflexion}

Man kann nicht pauschalisieren. Jede Trauer- und Bestattungskonstellation ist einzigartig, und die Menschen wollen diese Einzigartigkeit zunehmend berücksichtigt wissen. Konfliktbeispiele sind Insidern der Szene bekannt: Betreiber eines kirchlichen Friedhofs sind unzufrieden mit dem Logo der Lieblingsmannschaft eines fußballbegeisterten Jungen. Ein anderer Friedhofsverwalter stört sich an der Bepflanzung der Grabstätte und fürchtet 
um die Außenwirkung, die entstünde, wenn eine einmalige Ausnahmegenehmigung gestattet würde. Ein spezifisches Grabdesign wird aus verschiedenen, manchmal fadenscheinigen Gründen zurückgewiesen. Die Gestaltung der Bestattungsfeier muss institutionell abgesegnet werden und führt zu Problemen. Der Eingriff in die Gestaltungsanliegen von Hinterbliebenen erfolgt auf den ersten Blick bei diesen und vielen weiteren Beispielen im Sinne von Schutzbestimmungen. Es geht somit nicht um den Einzelfall, sondern vor allem um die Signalwirkung nach außen, um Nachahmungseffekte also, um den drohenden Autoritätsverlust von Institutionen, um die Unterbrechung von Traditionslinien, um überlieferte ästhetische Vorstellungen, um den Verlust von Gemeinschaftssinn und um andere Dammbrüche. Dies alles impliziert, dass es im Trauerkontext vor allem um Kollektivangelegenheiten und nicht um subjektive Interessen und Bedürfnisse geht. Betrachtet man beispielsweise die juristischen Ausprägungen solcher Konflikte (Spranger/Pasic/Kriebel 2014; Ritter/Keldenich 2010), wird dieser Eindruck noch bestärkt. Jedoch ist andererseits kaum jemand im thanatologischen Feld bereit, die Subjektivität des Trauerns und die Notwendigkeit individueller Inanspruchnahmen zu leugnen oder gar zu verdammen. Ist denn die Sepulkralkultur nun eine Sache des Kollektivbewusstseins oder eine Angelegenheit persönlicher Bezugnahme?

Einige Hinweise gibt der Blick von außen: Die mediale Berichterstattung legt bisweilen nahe, dass das Friedhofswesen pauschalisierend und festzementiert ist; ganz so, als wäre der Friedhof nicht für die Trauernden da, sondern die Trauernden sals Kunden< für den Friedhof. Selbst dort, wo Kommunen und die Gewerke aktiv gegen diesen Eindruck angehen, haben sie unter der negativen Reputation zu leiden, die das so konstruierte Image mit sich bringt. Wenn sich aus Einzelfällen schlechte Presse ergibt, betrifft dies im ungünstigsten Fall alle in diesem Branchensegment Tätigen. Der Grund ist die implizite Pauschalisierung - die schon deshalb falsch ist, weil der Tod, wie gesagt und wie bekannt, stets ein Einzelfallphänomen und eben nicht etwas Kollektives ist. So zumindest stellt sich das Lebensende für Betroffene (Sterbende und ihre Angehörige) dar. Ein pauschaler Vorschriftenkanon und die Orientierung an pauschalen Regeln laufen der individuellen Betroffenheit zuwider. Nicht die Ähnlichkeit der Sterbefälle schafft eine (statistisch rauswertbare`) Todeskategorie, sondern die generalisierten Leitlinien erzeugen ein Korsett, das bisweilen eine stabilisierende Wirkung hat, aber längst nicht in jedem Einzelfall passt.

Diese Kollektivierung entsprechender Vorgänge ist historisch nichts Neues, im Gegenteil. Solche Elemente waren in vorindividualisierter Zeit für die Bestattungskultur durchaus sinnvoll und konstitutiv. Ausnahmen bildeten Eliten, deren Lebenspersönlichkeit auch post mortem greifbar 
sein sollte. Heute ist das anders. In der gegenwärtigen »Multioptionsbestattungskultur (Benkel/Meitzler 2013: 250) gehört die freie Wahl nicht allein zu den Privilegien des Adels, sondern aller - sie wird damit aber zugleich zur Pflicht. Eine pauschale Behandlung zu fordern, wie sie undifferenziert jedem anderen ebenfalls zukommen soll, wäre heutzutage nicht nur unangemessen, sondern keine ernstzunehmende Option mehr.

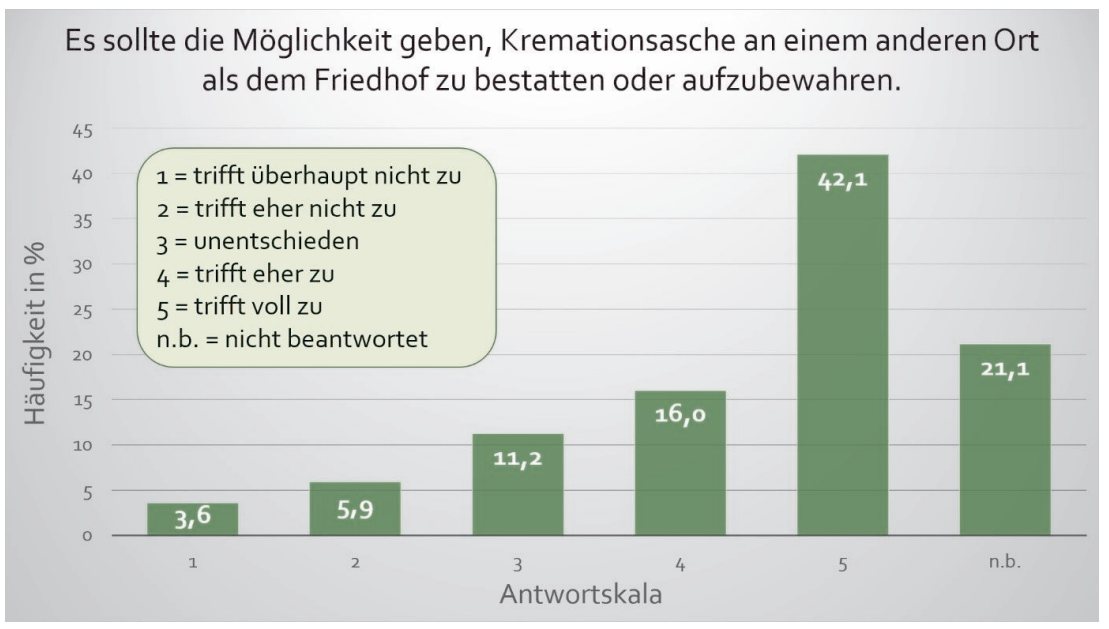

Beispiel für eine Wortmeldung aus der `Nutzerperspektive $<$ - Auszug aus dem Datenmaterial des empirischen Forschungsprojektes zur Pluralisierung des Sepulkralen (Universität Passau, Benkel/Meitzler). Die Teilnehmenden sprechen sich mehrheitlich für einen liberalisierten Umgang mit Kremationsasche aus.

\section{4 | Friedhofsflucht ist reversibel}

Wir haben es hinsichtlich der Entwicklung der Friedhofskultur nicht mit einer einzigen Richtung zu tun. Die Menschen, mit denen wir gesprochen und die sich negativ gegenüber dem Friedhof geäußert bzw. ein alternatives Beisetzungsmodell gewählt haben, sind oftmals Personen, die man potenziell wiedergewinnen kann. Wichtig wird es aus Sicht des Friedhofs sein, den alternativen Bestattungsformen mit eigenen Alternativen zu begegnen - was vielerorts, etwa in Form von Baumgräbern, sogar bereits geschehen ist. ${ }^{1}$

1 Ohnehin darf bezweifelt werden, dass es sich bei Konzepten wie den sogenannten Naturbestattungen tatsächlich um individualisierte Alternativen handelt, schließlich wird auch dort hochgradig kollektiv agiert. 
Friedhofsflucht ist vor allem dann reversibel, wenn das >Angebot $<$ individuell stimmig ist. Und Geld ist dabei, wie unsere Interviews offenbaren, nicht zwingend der zentrale Faktor. Vielmehr stellt sich ein logistisches Problem: Wie kann man individuelle Anliegen im Friedhofsbetrieb überhaupt berücksichtigen? Eine große Herausforderung besteht ja gerade darin, den Wunsch nach Individualität und Selbstbestimmung mit dem Bewahren von Traditionen und der Forderung nach einer geregelten Ordnung in Einklang zu bringen.

Ein Friedhof müsste deshalb idealerweise das eine bieten können, aber auch das andere - sinnvollerweise räumlich getrennt. Eine Mehr-Felder-Strategie, die in unterschiedlichen Arealen unterschiedliche Gestaltungsspielräume eröffnet, würde zwar auf den ersten Blick der Idee einer homogenisierten Friedhofslandschaft widersprechen. Dies wäre jedoch ein kleiner Preis angesichts der damit gewonnenen Möglichkeit, divergierende Gedenkmodelle und Gestaltungsinteressen zu verwirklichen. Im Sinne einer nachhaltigen Friedhofsentwicklung ist aus unserer Sicht eine Heterogenisierung des Friedhofs anzuraten. Damit wollen wir nicht einer vollständigen Beliebigkeit das Wort reden, sondern vielmehr der Pluralität real existierender Einstellungen zu Trauer und Gedenken Rechnung tragen. Die Idee ist natürlich nicht neu; Tendenzen zur Verwirklichung einer sepulkralen Pluralität sind auf Friedhöfen (und anderswo) bereits greifbar, innovative Konzepte deuten sich an, der Geist der Veränderung ist durchaus spürbar. Jedoch nicht überall - und überall wird sich dieses ambitionierte Programm wohl auch nicht realisieren lassen. Eine solche Hegemonie würde unserem Vorschlag auch gar nicht gut tun, denn damit wäre ja wieder ein einziges Gestaltungsschema als das >richtige apostrophiert.

\section{Alternativer Umgang mit Körperresten}

$\mathrm{Ob}$ nun Waldbeisetzung oder Seebestattung, ob Verstreuung in alle Winde oder auf der Rasenfläche, ob Diamant oder Rubin, ob mit Aschepartikeln angereicherte Gemälde, Schallplatten und Glasskulpturen oder andere, erst noch kommende Umgangsweisen mit Kremationsasche: Das Spektrum ist groß und wächst weiter. Wer mit dem Friedhof nichts (mehr) anfangen kann, wird stets alternative Lösungen finden, um den eigenen Traueransprüchen gerecht zu werden (oder dem, was er bzw. sie dafür hält). Kein Zweifel, auch die innovativsten Modellnekropolen werden in $\mathrm{Zu}$ kunft nicht jeden abholen und begeistern können. Mit dieser einfachen Wahrheit sollten Sepulkralexperten sich versöhnen. Die kommende Entwicklung des Umgangs mit Körperüberresten, vorrangig mit Asche, wird alte Fragen in neue Gewänder kleiden - vor allem die Frage, warum manche Konzepte gesellschaftliche Akzeptanz finden und andere sich damit 
schwer tun. Nachforschungen dazu lassen sich nicht lösen von einem ökonomischen Paradoxon. Die Gewinnspannen bei traditionellen Funeralprodukten spielen sich, je nach Anbieter, auf der Bandbreite von fair bis unverschämt ab. Radikale Profitorientierung, die in diesem Bereich fraglos existiert, scheint allerdings nicht die Branche als solche zu beschädigen. Ein wenig in Verruf mögen sepulkrale Dienstleistungen dadurch lokal bzw. temporär geraten; dem steht aber die Tradition des Bestattungshandwerks als etablierte und notwendige Größe und auch seine Funktion als gewissermaßen kulturelles Bollwerk gegenüber. Innovative Trends und neue Ideen hingegen fallen deutlich posttraditional aus und sind daher dem Vorwurf der Kommerzialisierung des Todes stärker ausgesetzt. Die unterschiedlichen Reputationen befinden sich somit nicht im Gleichgewicht - ein Umstand, der sich durch zunehmende Individualisierung und dadurch größere Nachfragen nach mehr funeraler Vielfalt indes langfristig verschieben dürfte.

\section{6 | Faktische bauliche Innovationen}

Materielle Veränderungen der Raumbegebenheiten auf dem Friedhof sind unabdingbar. Häufiger beschworen wird in diesem Kontext beispielsweise die Einrichtung von Spielplätzen in der Nekropole. Wer, wird in diesem Zusammenhang rhetorisch gefragt, würde sich schon postmortal daran stören, dass Kinderlachen um einen herum ertönt? (Nebenbei, in unserer Studie gab es durchaus Gesprächspartner, die dieser Vorstellung wenig abgewinnen können.) Entscheidend ist, dass sich eine Innovation wie der Friedhofsspielplatz nicht mit einem Rückblick auf die Vergangenheit der Bestattungskultur bewerten lässt. Dies würde implizieren, dass das Neue am Alten gemessen wird und nicht an seinem Innovationspotenzial, welches - in manchen Fällen - nun einmal losgelöst von der Tradition sein kann oder sogar sein muss.

Während Spielplätze hier und da bereits Friedhofsrealität sind, verhält es sich im Kontext der Grabsymbiose von Mensch und Tier etwas anders. In Deutschland ist es bislang aus juristischen, für viele aber auch aus moralischen Gründen problematisch, Tierleichen auf Menschenfriedhöfen zu begraben (und vice versa). Die gesetzliche Wirklichkeit entspricht nicht der empirischen: Beide Varianten gibt es bereits. ${ }^{2}$ Unsere Forschungsarbeit hat

2 Beispielsweise wird die Kremationsasche eines Heimtieres oder sogar der Tierleichnam als Ganzes dem Menschen-Erdgrab heimlich einverleibt. Es handelt sich bei dieser illegalen Praxis um eine Art Guerilla-Taktik zur Aneignung des Trauerraums; auch hier nehmen sich die Angehörigen ein autonomes ,Vorrecht gemäß ihrer persönlichen oder der zu Lebzeiten artikulierten Haltung der (menschlichen) Verstor- 
uns an Stätten geführt, an denen Mensch und Tier Seite an Seite ruhen. Manche (Tier-)Friedhofsbetreiber warten nur auf den institutionellen Startschuss, Mensch und Tier ganz offiziell postmortal zu vereinen - in einer Gemeinschaft, die dem lebendigen Alltagsleben von Hund, Katze, Herrchen und Frauchen wenigstens symbolisch entspricht. Eine Art Kompromissmodell wird punktuell bereits angeboten. Dabei wird die tierische Asche zur Grabbeigabe deklariert und gelangt somit in räumliche Nähe zu den Überresten des ehemaligen Tierbesitzers - zumindest theoretisch, die Zahl der faktischen Beisetzungen hält sich bislang nämlich in Grenzen.

Man muss sich, angesichts der sozialen Wandlungsvorgänge im Verhältnis von Mensch und Tier (Preuß 2016; Benkel 2017c; Meitzler 2017c) verdeutlichen, dass solche sepulkralen Interspeziesverbindungen künftig dennoch zunehmen werden.

Das Mensch-Tier-Grab als Hybridform, wenn man es so bezeichnen möchte, ist nur eine von vielen möglichen Ausprägungen. $\mathrm{Zu}$ anderen, die ansatzweise bereits Wirklichkeit sind, gehören Trimm-dich-Pfade, Friedhofscafés und symbolische Bauten (১Schiffsrumpf< im Kindergrabfeld, 'Trauerhaltestelle< usw.). Mit der Veränderung des Angebots geht eine Erweiterung der Funktionalität einher. Zwangsläufig bedeutet dies, dass Vorstellungen darüber, was adäquat ist, `mitwachsen müssen. Entsprechende Anpassungsprozesse fallen Menschen mitunter schwer, was den langsamen Wandel in vielen gesellschaftlichen Bereichen erklärt, nicht nur in der Bestattungskultur. Wir wollen nicht verschweigen, dass inmitten dieser Transformation das Konfliktpotenzial steigt: Je weniger kollektiv die Einstellungen zu Sterben, Tod und Trauer, desto stärker wird künftig darüber gestritten werden.

\section{7 | Interimslösungen}

Ein ganz konkreter Vorschlag betrifft die `Unterbringung` von Ascheresten. Wie oben dargelegt, ist die gegenwärtige Rechtslage in Deutschland diesbezüglich streng. Der Friedhof ist (beinahe) der einzige legitime Ort der Beisetzung. Eben deshalb verdichten sich tiefempfundene Verpflichtungen an die Adresse der Verstorbenen in Handlungen, die von traditionellen Vorschriften abweichen. Restriktive Duldung und abweichendes Verhalten muss man nun aber nicht wie eine Gegenüberstellung von schwarz und weiß behandeln, zumal das eine die Folge des anderen ist. Unser Vorschlag

benen. - Uns ist allerdings auch ein konkreter Fall bekannt, bei dem Menschenasche auf dem Tierfriedhof gezielt beigesetzt wurde, wiederum in Form einer >Nacht-und-Nebel-Aktion<. 
wären Interimslösungen, wie wir sie in Form von Primär-, Sekundär- und Tertiärbestattungen aus vielen Kulturen kennen. Was spricht dagegen, Urnen temporär zuhause, in Kolumbarien, in speziellen Vorrichtungen bei Bestattern oder an anderen Plätzen aufzubewahren? Die Wahl eines sendgültigen Ortes - sei es auf dem klassischen Friedhof oder an anderen, dafür geschaffenen sneutralen`Stätten - wäre dann möglich, wenn die Angehörigen das entsprechende Bedürfnis empfinden und den Wunsch dazu haben. Auch andere Hinterbliebene könnten so Zugang erhalten, da entsprechende Praktiken nicht im Verborgenen stattfinden müssten und eine offene Kommunikation über den Aufbewahrungs- und Beisetzungsort möglich wäre.

Der Vorteil eines solchen Vorgehens, dessen Details natürlich noch näher und vor allem praxisorientiert ausgelotet werden müssten, besteht in der Dynamik. Aus unseren Interviews mit Menschen, die sich die Urne angeeignet haben, wissen wir, dass sich die Haltung zum sterblichen Überrest im Laufe der Zeit ändern kann. Die beschriebene Interimslösung würde den Umgang mit der Asche szwangloser machen. Weder bräuchte man darauf zu verzichten, sie an sich zu nehmen, wenn dies der akuten Trauereinstellung zu entsprechen scheint, noch muss man Kritik oder gar Sanktionen fürchten, wenn man sich nach Monaten oder Jahren doch für eine Beisetzung im traditionellen Sinne entscheidet. ${ }^{3}$

Diese Interimslösung wurde bereits auf verschiedenen Ebenen diskutiert. Auch im Kontext der Novellierung von Bestattungsgesetzen kamen ähnliche Konzepte schon zur Sprache. ${ }^{4}$ Ohne Zweifel gibt es noch andere innovative Modelle; weitere, bislang nicht erahnte Konzepte werden künftig auftauchen. Unser Plädoyer lautet, diese Neuerungen mit Blick auf den sozialen Wandel, der in diesem Buch so prominent in Erscheinung tritt, sachlich zu bewerten und nicht dem unreflektierten Traditionalismus pauschal die Oberhand zu gewähren. Denn sonst entsteht immer wieder aufs Neue jenes Problem, das gegenwärtig an viel zu vielen Orten beklagt wird: dass nämlich die faktischen Umgangsweisen mit Sterben, Tod und Trauer nicht nah genug am Menschen sind - weder am lebenden noch am toten.

3 Wäre die Beisetzung dann auch noch kostenfrei (weil sie bereits pauschal bei der Einäscherung veranschlagt wird oder weil es einen Anspruch auf ein unentgeltliches Grab gibt), gäbe es wenig Anlass zur Befürchtung, dass Urnen im Müll entsorgt werden.

4 Zwei der Autoren des vorliegenden Buches haben in entsprechenden Kontexten aktiv mitgewirkt, so etwa im Bayerischen Landtag (TB) und bei Informationsveranstaltungen für Landtagsabgeordnete (TB/MM) zu Gesetzgebungsverfahren in Brandenburg und Sachsen-Anhalt. 


\section{Online-Offline-Verbindungen}

Das Grab ist nicht alles. Und die Materialität im Trauerzusammenhang, d.h. Körper, Asche, Heimaltar usw., ist ebenfalls nicht der einzige Bezugspunkt, der für eine innovative Sepulkralkultur von Relevanz ist. Wie an anderer Stelle wesentlich ausführlicher dargestellt ist, als dies hier möglich wäre, kann die soziale Welt heute nicht mehr ohne ihr virtuelles Korrelat gedacht werden. Offline trifft in nahezu allen Lebens- und Sterbenslagen auf Online (Benkel 2018c; Benkel/Meitzler 2019c; Stöttner 2018; Offerhaus 2016). Somit ist das Trauer-Ensemble< längst um (Nicht-)Orte erweitert worden (Augé 2014). Dazu gehören nicht nur Online-Referenzen in Traueranzeigen und an Grabstätten (QR-Codes, URLs, Mailadressen, ChatPseudonyme), sondern auch Plattformen für virtuelles Gedenken, Foren des Austauschs und die Umfunktionierung sogenannter sozialer Medien wie Facebook, Youtube oder Twitter.

Auf den ersten Blick scheint es sich um ein noch wenig verbreitetes Phänomen zu handeln, daraus jedoch Rückschlüsse für die Zukunft zu ziehen, wäre naiv. Im Rahmen der erwähnten Untersuchung auf mehr als 1.100 Friedhöfen hat sich gezeigt, dass die Virtualitätsverweise ganz überwiegend im Zusammenhang mit Gräbern und Bestattungsfeiern junger Menschen, also: der digital natives auftreten. Daraus lässt sich für Praktiker im Sepulkralgewerbe eine wichtige Erkenntnis ableiten: Die künftigen Toten werden ein Leben gelebt haben, das mehr und mehr digital vernetzt gewesen ist. Den künftigen Hinterbliebenen wird es genauso gehen, und sie werden bei ihrer Suche nach einem Bestatter, nach Dauergrabpflege, nach Ritualdesignern usf. Online-Angebote durchforsten. Nähe zur Kommunikationstechnik wird in einigen Jahren und Jahrzehnten zu einem bedeutenden symbolischen Element auf Friedhöfen (und anderswo) werden, weil diese Nähe dann längst ein Lebensinhalt ist.

Wie die Kommunikationsmodalitäten künftiger Generationen aussehen werden, kann heute niemand sagen - auch wir besitzen keine Glaskugel. Jedenfalls darf man sich auf durchaus radikal anmutende Traditionsabbrüche gefasst machen. So deutet sich im Internet mittlerweile schon die Möglichkeit an, dass zu Lebzeiten gesammelte biografische Informationen postmortal die verstorbene Person >weiterleben lassen. Sie postet in der Folge weiterhin Tweets, man kann mit ihr chatten, sie hat eine `Meinung $<-$ nicht als Mensch aus Fleisch und Blut, denn der biologische Körper wird dann längst bestattet und somit unsichtbar gemacht sein, sondern als virtuelle Persönlichkeit, deren >Funktionsweiser auf Algorithmen beruht (siehe hierzu ausführlich Seibel 2018). Die virtuelle Identität verspricht Unsterblichkeit; nicht für die Person, aber für ein von ihr geprägtes, ihr ähnelndes, 
zweidimensionales, dafür aber weltweit adressierbares Online-Gegenstück mit gleichem Namen.

Der Friedhof, die Gewerke, Kirchen und andere Institutionen müssen die hinter den beschriebenen Empfehlungen stehenden Entwicklungen wahrnehmen und ihnen gerecht werden, so sie denn langfristig anschlussund konkurrenzfähig bleiben (oder es wieder werden) möchten. Gewiss folgt aus dem Sein nicht das Sollen, d.h. aus aktuellen Entwicklungen ergibt sich nicht, dass diese per se wünschenswert sind. Es wäre jedoch niemandem geholfen, vor diesen Phänomenen von vornherein die Augen zu verschließen. Dies gilt umso mehr, wenn innovative Konzepte die Betroffenen dabei unterstützen, angesichts der gegebenen gesellschaftlichen Rahmenbedingungen und Ansprüche ihre Trauer so zu durchleben, wie es ihnen hilfreich erscheint.

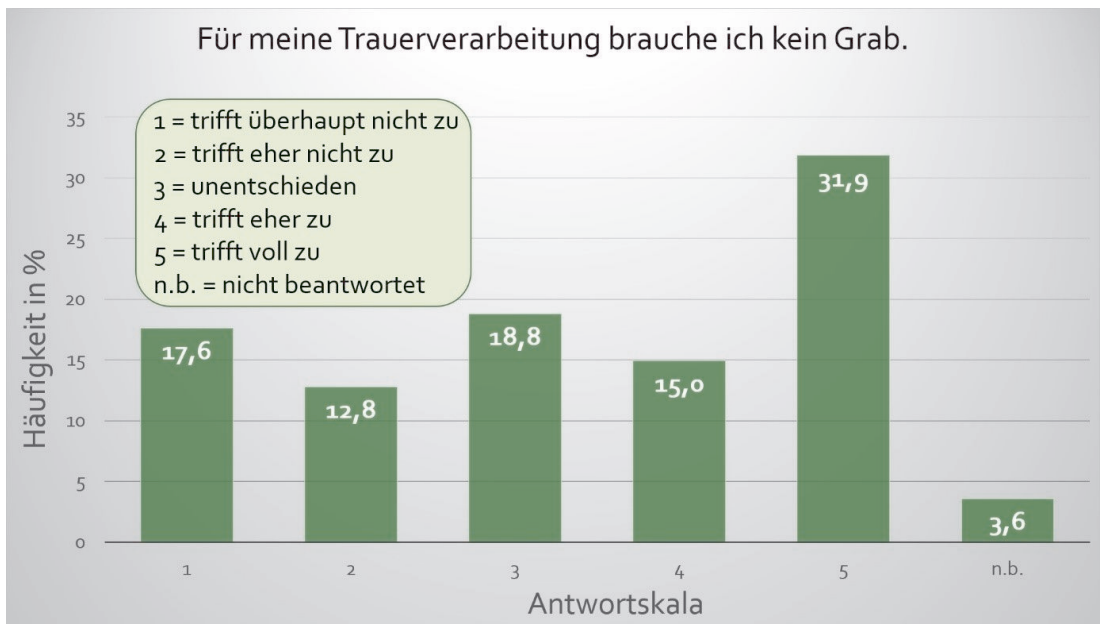

Die Reputation der Grabstätte fällt gemäß unserer Online-Umfrage gegenwärtig ambivalent aus (Stand: November 2018). Über die Notwendigkeit eines klar dem toten Körper zugeordneten Areals gibt es keinen Konsens; vielmehr ist eine leichte Tendenz in Richtung einer Delokalisierung der Trauer zu erkennen. Gemeint ist die Haltung, dass Trauer, losgelöst von einem definierten Ort, überall da stattfinden kann, wo Trauernde sich aufhalten (Universität Passau, Benkel/Meitzler).

Selbstverständlich kann man auf der Einbahnstraße des sozialen Wandels auch Geisterfahrer sein und sich gegen Trends auch dann noch wehren, wenn sie unübersehbar werden. Nachhaltig wird diese Strategie nicht sein. Manchmal mag es den Eindruck erwecken, als habe man, wenn man am Vorherigen festhält, einen festen Standpunkt. Vielleicht ist diese Stabilität 
bei näherem Hinsehen aber doch eher Starrsinn, der letztlich niemandem zum Weiterkommen verhilft.

Unsere Aufgabe als Wissenschaftler kann nicht darin bestehen, Veränderungen in der Gesellschaft aktiv anzuschieben oder sie gar aufzuhalten. Mehrfach sind wir in Tagungs- oder journalistischen Kontexten und auch in unseren eigenen Interviews zu den Möglichkeiten des rakademischen Interventionspotenzials befragt worden, nicht selten mit dem Verweis auf die Dringlichkeit der Mission. So verständlich das Anliegen auch ist, da es an Aktivismus im Dienste der Innovation (oder eben der Tradition) bisweilen zu mangeln scheint: Wir überlassen Steuerungsattitüde lieber jenen gesellschaftlichen Systemen, die darin ihre Existenzberechtigung finden und dafür besser legitimiert sind. Für unseren Teil bevorzugen wir jene Position, die die Wissenschaft einem verleiht - den kritischen und reflexiven Beobachtungsposten.

Die Lektüre dieses Buches verdeutlicht, hoffen wir, dass die Zukunft der Trauer im Zeichen der Pluralisierung steht. Sie entzieht sich nicht dem Zugriff des sozialen Wandels, sondern steht in dessen Zentrum. Auch der Autonomiebegriff kann in westlich geprägten Gesellschaften von den Umstrukturierungen subjektiver Lebenswelten nicht getrennt werden; dies sollte der Fokus auf Trauernde und Hinterbliebene zum Ausdruck bringen. Autonomie bedeutet aber nicht nur Selbstbestimmung gemäß individueller Disposition, sondern kann auch, in einer Wendung des Begriffs, die Autonomie des sterbenden und wohl auch des toten Körpers beschreiben, wenn man eine entsprechende Betrachtungsweise wählt. Dieser spannende Diskurs konnte hier nur angeschnitten werden, steht aber im Mittelpunkt unserer weiteren Forschungsinteressen.

Mit Sterben, Tod und Trauer werden wir uns alle künftig noch auseinandersetzen - als Akademiker, als Praktiker, als Angehörige, schließlich auch als Betroffene. Diese Beschäftigung hat die besondere Note, dass ihr Gegenstand am Ende stets die Oberhand behält. Der Tod wird das Rennen gewinnen; wir werden nur für eine Weile Schritt halten können. Mit dem Ende des Lebens, das gemeinhin auch das Ende aller Produktivität ist, wünschen wir Ihnen und uns selbst noch viele produktive Auseinandersetzungen. 


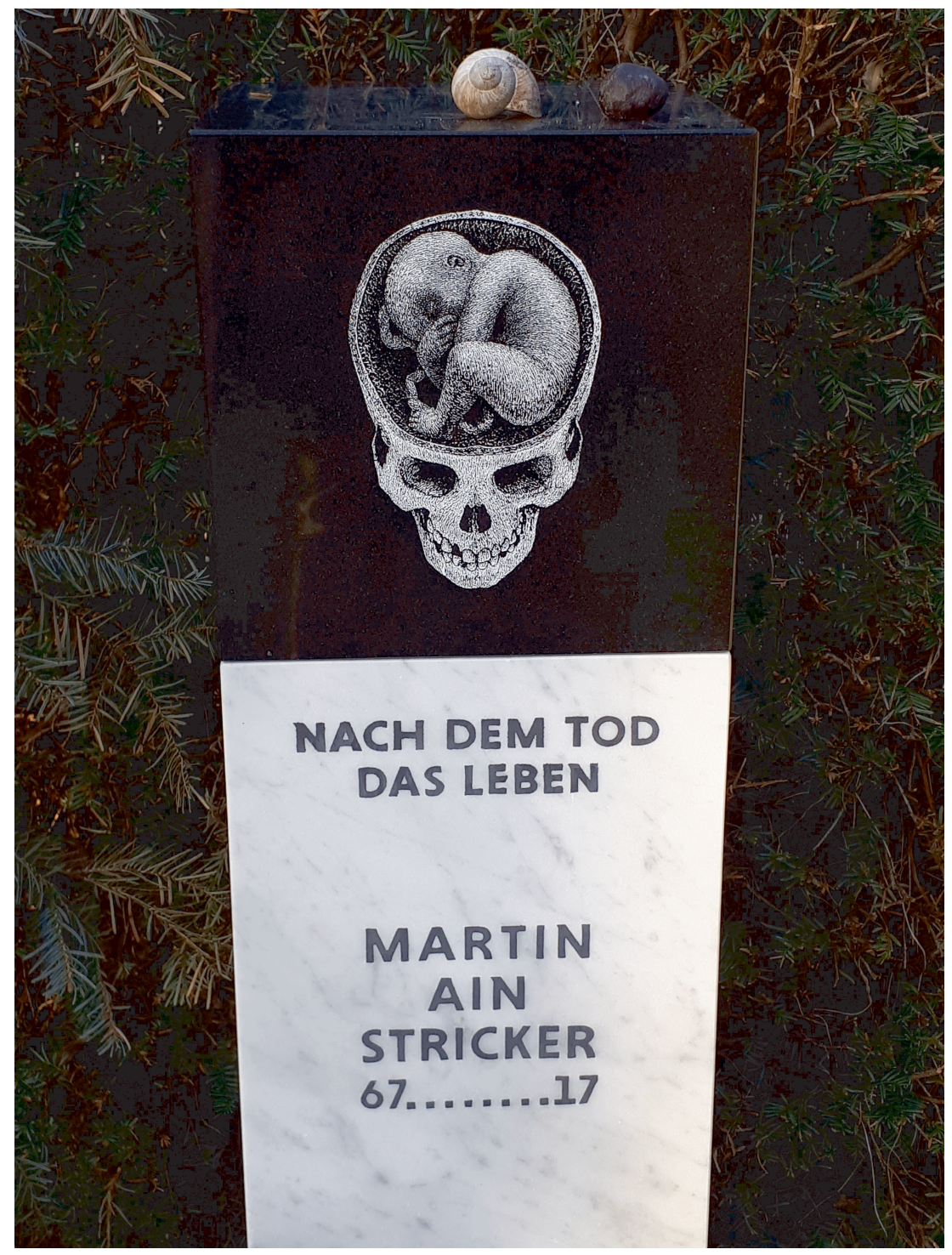




\section{Literaturverzeichnis}

Aeternitas (o.J.): »Geschichte und Zahlen«, Zugriff: www.aeternitas.de/inhalt/bestat ten_beisetzen/themen/bestattungsformen/feuerbestattung/geschichte_zahlen (eingesehen am 15. Juni 2019).

Aeternitas (2001): »Zusammenfassung der Ergebnisse zur Umfrage zum Thema >Urnenbestattungen«", Zugriff: http://www.aeternitas.de/inhalt/marktforschung/mel dungen/2001_friedhofszwang/download1.pdf (eingesehen am 15. Juni 2019).

Aka, Christine (2007): Unfallkreuze. Trauerorte am Straßenrand, Münster.

Ariès, Philippe (2000): Geschichte der Kindheit, München.

Ariès, Philippe (2002): Geschichte des Todes, München.

Assmann, Jan/Maciejewski, Franz/Michaels, Axel (Hg.) (2005): Der Abschied von den Toten. Trauerrituale im Kulturvergleich, Göttingen.

Augé, Marc (2014): Nicht-Orte, München.

Barbalet, Jack M. (2000): »Emotion, Social Theory and Social Structure«, in: Acta Sociologica 43, Heft 3, S. 281-284.

Beauchamp, Tom L./Childress, James F. (2009): Principles of Biomedical Ethics, 6. Aufl. New York/Oxford.

Benkel, Thorsten (2010): »Die Sichtbarkeiten des Frankfurter Bahnhofsviertels. Ein soziologischer Rundgang«, in: ders. (Hg): Das Frankfurter Bahnhofsviertel. Devianz im öffentlichen Raum, Wiesbaden, S. 15-100.

Benkel, Thorsten (2012): Die Verwaltung des Todes. Annäherungen an eine Soziologie des Friedhofs, Berlin.

Benkel, Thorsten (2013): »Fremdes im Schatten der eigenen Kultur«, in: Kriminologisches Journal 45, Heft 2, S. 85-102.

Benkel, Thorsten (2015): »Todesrituale. Zur sozialen Dramaturgie am Ende des Lebens«, in: Gugutzer, Robert/Staack, Michael (Hg.): Körper und Ritual. Sozial- und kulturwissenschaftliche Zugänge und Analysen, Wiesbaden, S. 335-360.

Benkel, Thorsten (2016): »Symbolische Präsenz. Zum Status der Identität nach dem Ende der Identität", in: ders. (Hg.): Die Zukunft des Todes. Heterotopien des Lebensendes, Bielefeld, S. 11-40.

Benkel, Thorsten (2017a): »Erinnerung und Individualisierung «, in: Klie, Thomas/ Sparre, Sieglinde (Hg.): Erinnerungslandschaften, Stuttgart, S. 111-123.

Benkel, Thorsten (2017b): »Strukturen der Sterbenswelt. Über Körperwissen und Todesnähe«, in: Keller, Reiner/Meuser, Michael (Hg.): Alter(n) und vergängliche Körper, Wiesbaden, S. 277-301.

Benkel, Thorsten (2017c): »Riskante Kameradschaft. Der Hund als Kulturgefahr und Hygienedefizit", in: Burzan, Nicole/Hitzler, Ronald (Hg.): Auf den Hund gekommen. Interdisziplinäre Annäherung an ein Verhältnis, Wiesbaden, S. 81-98. 
Benkel, Thorsten (2018a): »Fragwürdig eindeutig. Eine Exkursion in die Schattenzone des Wissens", in: ders./Meitzler, Matthias (Hg.): Zwischen Leben und Tod. Sozialwissenschaftliche Grenzgänge, Wiesbaden, S. 1-27.

Benkel, Thorsten (2018b): »Raum und Vergänglichkeit. Für eine Topologie des personalen Selbst«, in: Stammberger, Birgit/Bühlmann, Lea (Hg.): Das verräumlichte Selbst. Topographien kultureller Identität, Berlin, S. 167-190.

Benkel, Thorsten (2018c): »Gedächtnis - Medien - Rituale. Postmortale Erinnerungs(re)konstruktion im Internet", in: Sebald, Gerd/Döbler, Marie-Kristin (Hg.): (Digitale) Medien und soziale Gedächtnisse, Wiesbaden, S. 169-196.

Benkel, Thorsten (2020): »Kultur beginnt, wenn sie endet. Der Friedhof als Konflikt- und Pluralisierungsraum«, in: Kost, Susanne/Petrow, Constanze (Hg.): Kulturelle Vielfalt in Freiraum und Landschaft. Wahrnebmung, Partizipation, Aneignung und Gestaltung, Wiesbaden (im Erscheinen).

Benkel, Thorsten/Meitzler, Matthias (2013): Sinnbilder und Abschiedsgesten. Soziale Elemente der Bestattungskultur, Hamburg.

Benkel, Thorsten/Meitzler, Matthias (2014a): »Sterbende Blicke, lebende Bilder. Die Fotografie als Erinnerungsmedium im Todeskontext«, in: Medien \& Altern. Zeitschrift für Forschung und Praxis 3, Heft 5, S. 41-56.

Benkel, Thorsten/Meitzler, Matthias (2014b): Gestatten Sie, dass ich liegen bleibe. Ungewöhnliche Grabsteine - eine Reise über die Friedhöfe von heute, Köln.

Benkel, Thorsten/Meitzler, Matthias (2015): »Feldforschung im Feld der Toten. Unterwegs in einer Nische der sozialen Welt", in: Poferl, Angelika/Reichertz, Jo (Hg.): Wege ins Feld. Methodologische Aspekte des Feldzugangs, Essen, S. 234-251.

Benkel, Thorsten/Meitzler, Matthias (2016a): »Die Bildlichkeit des Lebensendes. Zur Dialektik der Totenfotografie«, in: Klie, Thomas/Nord, Ilona (Hg.): Tod und Trauer im Netz. Mediale Kommunikationen in der Bestattungskultur, Stuttgart, S. 117-136.

Benkel, Thorsten/Meitzler, Matthias (2016b): Game over. Neue ungewöhnliche Grabsteine, Köln.

Benkel, Thorsten/Meitzler, Matthias (Hg.) (2018): Zwischen Leben und Tod. Sozialwissenschaftliche Grenzgänge, Wiesbaden.

Benkel, Thorsten/Meitzler, Matthias (2019a): »Vielfalt der Sinnkonstruktionen. Lesarten des Wissensbegriffs diesseits und jenseits der Alltagswelt«, in: Hitzler, Ronald/Reichertz, Jo/Schröer, Norbert (Hg.): Kritik der Hermeneutischen Wissenssoziologie, Weinheim/Basel, S. 258-270.

Benkel, Thorsten/Meitzler, Matthias (2019b): »Materiality and the Body. Explorations at the End of Life«, in: Mortality 24, Heft 2, S. 231-246.

Benkel, Thorsten/Meitzler, Matthias (2019c): »Im Himmel - in der Cloud? Körperlose Gegenwart im virtuellen Raum«, in: Zeitschrift für Bestattungskultur 71, Heft 2, S. 34-37.

Berger, Peter L./Lieban, Richard (1960): »Kulturelle Wertstruktur und Bestattungspraktiken in den Vereinigten Staaten«, in: Kölner Zeitschrift für Soziologie und Sozialpsychologie 12, Heft 2, S. 224-236. 
Berger, Peter L./Luckmann, Thomas (2004): Die gesellschaftliche Konstruktion der Wirklichkeit. Eine Theorie der Wissenssoziologie, Frankfurt am Main.

Bergmann, Jörg R. (1985): »Flüchtigkeit und methodische Fixierung sozialer Wirklichkeit«, in: Bonß, Wolfgang/Hartmann, Heinz (Hg.): Entzauberte Welt. Zur Relativität und Geltung soziologischer Forschung, Göttingen, S. 299-320.

Bergmann, Jörg R./Dausendschön-Gay, Ulrich/Oberzaucher, Frank (Hg.) (2014): Der ,Falk. Studien zur epistemischen Praxis professionellen Handelns, Bielefeld.

Bericat, Eduardo (2016): »The Sociology of Emotions. Four Decades of Progress«, in: Current Sociology 64, Heft 3, S. 491-513.

Birch, Maxine/Miller, Tina (2000): »Inviting Intimacy. The Interview as Therapeutic Opportunity", in: International Journal of Social Research Methodology 3, Heft 3, S. 189-202.

Blumer, Herbert (2013): Symbolischer Interaktionismus. Aufsätze zu einer Wissenschaft der Interpretation, Berlin.

Boehm, Karoline (2012): Praktiken der Polyamorie. Über offene Beziehungen, intime Netzwerke und den Wandel emotionaler Stile, Wien.

Bortz, Jürgen/Döring, Nicola (2006): Forschungsmethoden und Evaluation für $\mathrm{Hu}$ man- und Sozialwissenschaftler, 4. Aufl. Heidelberg.

Bourdieu, Pierre (1993): Sozialer Sinn. Kritik der theoretischen Vernunft, Frankfurt am Main.

Bourdieu, Pierre (2010): »Teilnehmende Objektivierung«, in: ders.: Algerische Skizzen, Berlin, S. 417-440.

Brennan, Michael (2017): „Christopher Hitchens, Public Dying and the Cultural Public Sphere«, in: ders. (Hg.): Theorising the Popular, Newcastle, S. 61-88.

Breuer, Franz (2003): »Subjekthaftigkeit der sozial-/wissenschaftlichen Erkenntnistätigkeit und ihre Reflexion. Epistemologische Fenster, methodische Umsetzungen«, in: Forum Qualitative Sozialforschung 4, Heft 2, Art. 25.

Brüggen, Susanne (2005): Letzte Ratschläge. Der Tod als Problem für Soziologie, Ratgeberliteratur und Expertenwissen, Wiesbaden.

Bude, Heinz (1984): »Der Sozialforscher als Narrationsanimateur. Zur Kritik einer erzähltheoretischen Fundierung der interpretativen Sozialforschung«, in: Kölner Zeitschrift für Soziologie und Sozialpsychologie 37, Heft 2, S. 327-336.

Büsche, Jörg (2006): "Was uns der Kannibale noch mitteilen wollte. Bestattungsrituale im Wandel der Zeit", in: Roland, Oliver (Hg.): Friedhof - ade? Die Bestattungskultur des 21. Jabrhunderts, Mannheim, S. 27-39.

Cantor, Norman L. (2010): After We Die. The Life and Times of the Human Cadaver, Washington.

Caspari, Wilhelm (1914): Erdbestattung oder Feuerbestattung. Der biblische Brauch auf ethnographischem Hintergrund, Berlin.

Cioran, Emile Michel (1988): Von Tränen und von Heiligen, Frankfurt am Main.

Clark, Peter (1998): Zoroastrainism. An Introduction to an Ancient Faith, Brighton.

Coleman, James S. (1995): Grundlagen der Sozialtheorie, Bd. 1: Handlungen und Handlungssysteme, München/Wien. 


\section{Literaturverzeichnis}

Dellwing, Michael/Prus, Robert (2012): Einführung in die interaktionistische Ethnografie. Soziologie im Außendienst, Wiesbaden.

Devereux, Georges (1984): Angst und Methode in den Verhaltenswissenschaften, Frankfurt am Main.

Diaz-Bone, Rainer (2015): »Pretest«, in: ders./Weischer, Christoph (Hg.): MethodenLexikon für die Sozialwissenschaften, Wiesbaden, S. 322.

Diekmann, Andreas (2000): Empirische Sozialforschung. Grundlagen, Methoden, Anwendung, Reinbek.

Dimbath, Oliver (2013): »Visuelle Stimuli in der qualitativen Forschung. Potenziale und Grenzen des fotogestützten Interviews«, in: Soziale Welt 64, Heft 1/2, S. 137-152.

Dreßke, Stefan (2005): Sterben im Hospiz. Der Alltag in einer alternativen Pflegeeinrichtung, Frankfurt am Main.

Durkheim, Emile (1984): Die elementaren Formen des religiösen Lebens, Frankfurt am Main.

Durkheim, Emile (1988): Über soziale Arbeitsteilung, Frankfurt am Main.

Durkheim, Emile (1991): Physik der Sitten und des Rechts. Vorlesungen zur Soziologie der Moral, Frankfurt am Main.

Dürr, Carsten (2018): »Parasozialitätsdynamik. Überlegungen zu unvollständigen Kommunikationen", in: Benkel, Thorsten/Meitzler, Matthias (Hg.): Zwischen Leben und Tod. Sozialwissenschaftliche Grenzgänge, Wiesbaden, S. 145-160.

Ehrenberg, Alain (2012): Das Unbehagen in der Gesellschaft, Berlin.

Elias, Norbert (1984): Über die Zeit, Frankfurt am Main.

Elias, Norbert (1990): Über die Einsamkeit der Sterbenden in unseren Tagen, Frankfurt am Main.

Elias, Norbert (1994): Über den Prozeß der Zivilisation. Soziogenetische und psychogenetische Untersuchungen, 2 Bde., Frankfurt am Main.

Ellis, Carolyn (1995): Final Negotiations. A Story of Love, Loss and Chronic Illness, Philadelphia.

Fachverlag des deutschen Bestattungsgewerbes (Hg.) (2008): Bestattung in Deutschland, 2. Aufl. Düsseldorf.

Feldmann, Klaus (1995): "Leben und Tod im Werk von Talcott Parsons«, in: ders./ Fuchs-Heinritz, Werner (Hg.): Der Tod ist ein Problem der Lebenden. Beiträge zur Soziologie des Todes, Frankfurt am Main, S. 140-172.

Fischer, Joachim (2013): »Helmuth Plessner: Lachen und Weinen«, in: Senge, Konstanze/ Schützeichel, Rainer (Hg.): Hauptwerke der Emotionssoziologie, Wiesbaden, S. 274-279.

Fischer, Norbert (2011): »Neue Inszenierungen des Todes. Über Bestattungs- und Erinnerungskultur im frühen 21. Jahrhundert", in: Groß, Dominik/Tag, Brigitte/Schweikardt, Christoph (Hg.): Who wants to live forever? Postmoderne Formen des Weiterwirkens nach dem Tod, Frankfurt am Main/New York, S. 125-144. 
Fischer, Norbert (2014): „Die Geschichte der modernen Feuerbestattung und Krematorien«, in: Spranger, Tade M./Pasic, Frank/Kriebel, Michael (Hg.): Handbuch des Feuerbestattungswesens, Stuttgart, S. 15-32.

Flam, Helena/Kleres, Jochen (Hg.) (2015): Methods of Exploring Emotions. London/New York.

Flick, Uwe (2006): Qualitative Sozialforschung, Reinbek.

Foucault, Michel (1975): Der Fall Rivière. Materialien zum Verhältnis von Psychiatrie und Strafjustiz, Frankfurt am Main.

Foucault, Michel (2007): Die Anormalen, Frankfurt am Main.

FoWiD - Forschungsgruppe Weltanschauungen in Deutschland (2017): »Religionszugehörigkeiten in Deutschland 2016«, Zugriff: https://fowid.de/meldung/religio nszugehoerigkeiten-deutschland-2016 (eingesehen am 15. Juni 2019).

Fowler, Bridget (2007): The Obituary as Collective Memory, New York/London.

Freud, Sigmund (1982): »Trauer und Melancholie«, in: ders.: Studienausgabe, Bd. 3, Frankfurt am Main, S. 197-212.

Friedrichs, Jürgen (Hg.) (1973): Teilnehmende Beobachtung abweichenden Verhaltens, Stuttgart.

Gennep, Arnold van (2005): Übergangsriten, Frankfurt am Main/New York.

Gerhards, Jürgen (1988): »Die sozialen Bedingungen zur Entstehung von Emotionen«, in: Zeitschrift für Soziologie 17, Heft 3, S. 187-202.

Gläser, Jochen/Laudel, Grit (2010): Experteninterviews und qualitative Inhaltsanalyse, Wiesbaden.

Glinka, Hans-Jürgen (2008): Das narrative Interview in seinen zentralen Analyseschritten, Tübingen.

Goebel, Swantje (2012): Die eigene Sterblichkeit im Blick. Eine biographie-analytische Studie mit Hospizhelfern, München.

Goffman, Erving (2006): Wir alle spielen Theater. Die Selbstdarstellung im Alltag, München.

Goffman, Erving (2009): Das Individuum im öffentlichen Austausch. Mikrostudien zur öfentlichen Ordnung, Frankfurt am Main.

Gorer, Geoffrey (1955): »The Pornography of Death«, in: Encounter 3, Heft 10, S. 49-52.

Götz, Anna-Maria (2013): Die Trauernde. Weibliche Grabplastik und bürgerliche Trauer um 1900, Köln.

Gould, Deborah (2015): „When your Data make you cry«, in: Flam, Helena/Kleres, Jochen (Hg.): Methods of Exploring Emotions, London/New York, S. 163-171.

Granek, Leeat (2010): „Grief as Pathology. The Evolution of Grief Theory in Psychology from Freud to the Present «, in: History of Psychology 13, Heft 1, S. 46-73.

Gröschner, Rolf (1995): Menschenwürde und Sepulkralkultur in der grundgesetzlichen Ordnung. Die kulturstaatlichen Grenzen der Privatisierung im Bestattungsrecht, Stuttgart et al. 
Groß, Dominik/Kaiser, Stephanie/Tag, Brigitte (Hg.) (2016): Leben jenseits des Todes? Transmortalität unter besonderer Berücksichtigung der Organspende, Frankfurt am Main.

Guinebert, Svantje (2018): Hörigkeit als Selbstboykott. Eine philosophische Studie zu Autorität, Selbstkonstitution und Autonomie, Münster.

Guthke, Karl S. (1998): Ist der Tod eine Frau? Geschlecht und Tod in Kunst und Literatur, München.

Happe, Barbara (2012): Der Tod gehört mir. Die Vielfalt der heutigen Bestattungskultur und ihre Ursprünge, Berlin.

Harris, Scott (2015): An Invitation to the Sociology of Emotions, Abingdon/New York.

Hau, Rita et al. (1991): Globalwörterbuch Lateinisch-Deutsch, 2. Aufl. Stuttgart.

Häußler, Michael (2019): Trauerfallgeschichten. Anmerkungen zu Trauer und Bestattung, Darmstadt.

Herodot von Halikarnassos (2001): Das Geschichtswerk, Frankfurt am Main/Leipzig.

Herzog, Markwart (2005): »Trauer- und Bestattungsrituale der Fußballvereinskultur. Totenmemoria - Ahnenbiographien - Stadionbegräbnis - Performance«, in: ders./Fischer, Norbert (Hg.): Nekropolis. Der Friedhof als Ort der Toten und der Lebenden, Stuttgart, S. 181-210.

Hirschauer, Stefan (2001): »Ethnografisches Schreiben und die Schweigsamkeit des Sozialen. Zu einer Methodologie der Beschreibung «, in: Zeitschrift für Soziologie 30, Heft 6, S. 429-451.

Hitzler, Ronald/Eisewicht, Paul (2016): Lebensweltanalytische Ethnographie - im Anschluss an Anne Honer, Weinheim/Basel.

Hockey, Jenny/Katz, Jeanne/Small, Neil (2001): Grief, Mourning and Death Ritual, Buckingham.

Honer, Anne (1993): Lebensweltliche Ethnographie. Ein explorativ-interpretativer Forschungsansatz am Beispiel von Heimwerker-Wissen, Wiesbaden.

Hopf, Christel (1978): »Die Pseudo-Exploration. Überlegungen zur Technik qualitativer Interviews in der Sozialforschung«, in: Zeitschrift für Soziologie 7, Heft 2, S. 97-115.

Höpflinger, Anna-Katharina (2017): »Schwarz, verhüllend, weiblich. Die Inszenierung von Trauer und der Wandel von Gendervorstellungen«, in: Interdisciplinary Journal for Religion and Transformation 3, Heft 2, S. 105-124.

Horn, Eva (1998): Trauer schreiben. Die Toten im Text der Goethezeit, München.

Hörnle, Tatjana (2005): Grob anstößiges Verhalten. Strafrechtlicher Schutz von Moral, Gefüblen und Tabus, Frankfurt am Main.

Husserl, Edmund (1993): Ideen zu einer reinen Phänomenologie und phänomenologischen Philosophie, Tübingen.

Jakoby, Nina (2012): »Trauer als Forschungsgegenstand der Emotionssoziologie«, in: Schnabel, Annette/Schützeichel, Rainer (Hg.): Emotionen, Sozialstruktur und Moderne, Wiesbaden, S. 407-424. 
Jakoby, Nina (2014): »Die Zeit heilt alle Wunden«, in: Dimbath, Oliver/Heinlein, Michael (Hg.): Die Sozialität des Erinnerns. Soziales Gedächtnis, Erinnern und Vergessen, Wiesbaden, S. 183-197.

Jankélévitch, Vladimir (2003): Kann man den Tod denken?, Wien.

Kahler, Waldemar (1935): Das Reichsgesetz über die Feuerbestattung, Berlin.

Kahlert, Heike (2014): »Geschlechterforschung«, in: Endruweit, Günter/Trommsdorff, Gisela/Burzan, Nicole (Hg.): Wörterbuch der Soziologie, 3. Aufl. Konstanz/ München, S. 147-152.

Kamann, Matthias (2009): Todeskämpfe. Die Politik des Jenseits und der Streit um Sterbehilfe, Bielefeld.

Kaschuba, Wolfgang (1999): Einführung in die Europäische Ethnologie, München.

Kast, Verena (1982): Trauern. Phasen und Chancen des psychischen Prozesses, Stuttgart.

Kiening, Christian (2003): »Inszenierte Tode, ritualisierte Texte«, in: ders.: Zwischen Körper und Schrift. Texte vor dem Zeitalter der Literatur, Frankfurt am Main, S. 295-317.

Kieserling, André (1999): Kommunikation unter Abwesenden. Studien über Interaktionssysteme, Frankfurt am Main.

Klaas, Dennis/Nickman, Steven/Silverman, Phyllis R. (Hg.) (1996): Continuing Bonds. New Understandings of Grief, New York/London.

Klein, Uta (2011): »Geschlechtsrolle«, in: Fuchs-Heinritz, Werner et al. (Hg): Lexikon zur Soziologie, 5. Aufl. Wiesbaden, S. 240.

Knoblauch, Hubert (2009): Populäre Religion. Auf dem Weg in eine spirituelle Gesellschaft, Frankfurt am Main/New York.

Knoepffler, Nikolaus (2004): Menschenwürde in der Bioethik, Berlin.

Knoepffler, Nikolaus (2010): Angewandte Ethik, Köln/Weimar/Wien.

Knopke, Ekkehard (2018): »Todesdokumente. Totenscheine und Sterbeurkunden als Inskriptionen der Grenzziehung zwischen Leben und Tod «, in: Benkel, Thorsten/Meitzler, Matthias (Hg.): Zwischen Leben und Tod. Sozialwissenschaftliche Grenzgänge, Wiesbaden, S. 211-224.

Korff, Walter (2006): "Norm«, in: Kasper, Walter et al. (Hg.): Lexikon für Theologie und Kirche, Bd. 7, 3. Aufl. Freiburg/Basel/Wien, S. 907-909.

Küsters, Ivonne (2014): „Das narrative Interview«, in: Baur, Nina/Blasius, Jörg (Hg.): Handbuch der empirischen Sozialforschung, Wiesbaden, S. 799-809.

Lamnek, Siegfried (2005): Qualitative Sozialforschung, 4. Aufl. Weinheim.

Lamnek, Siegfried/Schäfer, Wolfgang J. (1998): »Befragungsmethoden reviewed: face-to-face, telefonisch oder postalisch«, in: Sozialwissenschaften und Berufspraxis 21, Heft 2, S. 162-171.

Lanzerath, Dirk (2014): »Vom Umgang mit dem toten Körper und der Totenasche. Anthropologisch-ethische Aspekte«, in: Spranger, Tade M./Pasic, Frank/Kriebel, Michael (Hg.): Handbuch des Feuerbestattungswesens, Stuttgart, S. 56-69.

Leu, Hans R./Krappmann, Lothar (Hg.) (1999): Zwischen Autonomie und Verbundenheit. Bedingungen und Formen der Behauptung von Subjektivität, Frankfurt am Main. 
Lévi-Strauss, Claude (1979): Traurige Tropen, Frankfurt am Main.

Lévy-Bruhl, Lucien (1956): Die Seele der Primitiven, Düsseldorf/Köln.

Loch, Ulrike/Rosenthal, Gabriele (2002): »Das narrative Interview«, in: Schaeffer, Doris/Müller-Mundt, Gabriele (Hg.): Qualitative Gesundheits- und Pflegeforschung. Programmbereich Gesundheit, Bern, S. 221-232.

Lofland, John/Lofland, Lyn H. (1984): Analyzing Social Settings, 2. Aufl. Belmont.

Lueger, Manfred/Froschauer, Ulrike (2018): Artefaktanalyse. Grundlagen und Verfahren, Wiesbaden.

Luhmann, Niklas (1990): »Paradigm lost. Über die ethische Reflexion der Moral«, in: ders./Spaemann, Robert: Paradigm lost. Über die ethische Reflexion der Moral, Frankfurt am Main, S. 7-48.

Luhmann, Niklas (2002): Das Erziehungssystem der Gesellschaft, Frankfurt am Main.

Macho, Thomas/Marek, Kristin (Hg.) (2007): Die neue Sichtbarkeit des Todes, Paderborn/München.

Malinowski, Bronislaw (1922): Argonauts in Western Pacific, London.

Marquard, Odo (1996): "Zur Diätetik der Sinnerwartung«, in: ders.: Apologie des Zufälligen, Stuttgart, S. 33-53.

Meitzler, Matthias (2010): »Die Wahl der Qual. Schmerz als sexuelle Dienstleistung«, in: Benkel, Thorsten (Hg.): Das Frankfurter Bahnhofsviertel. Devianz im öffentlichen Raum, Wiesbaden, S. 277-305.

Meitzler, Matthias (2016): »Postexistenzielle Existenzbastelei«, in: Benkel, Thorsten (Hg.): Die Zukunft des Todes. Heterotopien des Lebensendes, Bielefeld, S. 133-162.

Meitzler, Matthias (2017a): »Mediatisierung des Todes. Die Leiche zwischen Unsichtbarkeit und Medienpräsenz«, in: Reichertz, Jo/Meitzler, Matthias/Plewnia, Caroline: Wissenssoziologische Medienwirkungsforschung. Zur Mediatisierung des forensischen Feldes, Weinheim/Basel, S. 111-146.

Meitzler, Matthias (2017b): »Forschen bei privaten Unternehmen. Herausforderungen und Potenziale des Feldeinstiegs«, in: Reichertz, Jo/Meitzler, Matthias/Plewnia, Caroline: Wissenssoziologische Medienwirkungsforschung. Zur Mediatisierung des forensischen Feldes, Weinheim/Basel, S. 148-161.

Meitzler, Matthias (2017c): »Hunde, wollt ihr ewig leben? Der tote Vierbeiner - ein Krisentier«, in: Burzan, Nicole/Hitzler, Ronald (Hg.): Auf den Hund gekommen. Interdisziplinäre Annäherung an ein Verbältnis, Wiesbaden, S. 175-200.

Merton, Robert K./Kendall, Patricia (1979): »Das fokussierte Interview«, in: Hopf, Christel/Weingarten, Elmar (Hg.): Qualitative Sozialforschung, Stuttgart, S. 171-204.

Michalski, Mark (1997): Fremdwahrnehmung und Mitsein. Zur Grundlegung der Sozialphilosophie im Denken Max Schelers und Martin Heideggers, Bonn.

Mielke, Leonie (2007): Hospiz im Wohlfahrtsstaat. Gesellschaftliche Antworten auf Sterben und Tod. Eine soziologische Bestandsaufnahme in Deutschland, Ludwigsburg.

Misoch, Sabina (2015): Qualitative Interviews, Berlin/München/Boston.

Möller, Petra (2009): Todesanzeigen. Eine Gattungsanalyse, Diss. Univ. Gießen. 
Nassehi, Armin (2003): Geschlossenheit und Offenheit. Studien zur Theorie der modernen Gesellschaft, Frankfurt am Main.

Offerhaus, Anke (2016): »Begraben im Cyberspace. Virtuelle Friedhöfe als Räume mediatisierter Trauer und Erinnerung«, in: Benkel, Thorsten (Hg.): Die Zukunft des Todes. Heterotopien des Lebensendes, Bielefeld, S. 339-364.

Ogawa, Tadashi (1991): »Die Vorstruktur des Bewußtseins bei Husserl. Eine Rekonstruktion in strukturaler Sicht", in: Phänomenologische Forschungen 24/25, S. 76-91.

Opdenakker, Raymond (2006): »Advantages and Disadvantages of Four Interview Techniques in Qualitative Research", in: Forum Qualitative Sozialforschung 7, Heft 4, Art. 11.

Pauen, Michael/Welzer, Harald (2015): Autonomie. Eine Verteidigung, Frankfurt am Main.

Petersen, Anders/Jacobsen, Michael H. (2019): „Grief. The Painfulness of Permanent Human Absence«, in: Jacobsen, Michael H. (Hg.): Emotions, Everyday Life and Sociology, Abingdon/New York, S. 191-208.

Planert, Ute/Süß, Dietmar (2015): »Nichts ist umsonst. Anmerkungen zur Sozialgeschichte des Todes«, in: Planert, Ute/Süß, Dietmar/Woyke, Meik (Hg.): Sterben, Töten, Gedenken. Zur Sozialgeschichte des Todes, Bonn, S. 7-22.

Plessner, Helmuth (1950): Lachen und Weinen. Eine Untersuchung nach den Grenzen des menschlichen Verhaltens, München.

Ploder, Andrea/Stadlbauer, Johanna (2016): »Strong Reflexivity and its Critics. Responses to Autoethnography in the German-Speaking Cultural and Social Sciences", in: Qualitative Inquiry 22, Heft 9, S. 753-765.

Pollack, Detlef/Rosta, Gergely (2015): Religion in der Moderne. Ein internationaler Vergleich, Frankfurt am Main/New York.

Popitz, Heinrich (2006): Soziale Normen, Frankfurt am Main.

Preuß, Dirk (2008): »Body Worlds. Looking back and looking ahead «, in: Annals of Anatomy 190, Heft 1, S. 23-32.

Preuß, Dirk (2011): »Pietät in der Rechtsmedizin. Autopsie eines Begriffs«, in: Zeitschrift für Rechtsmedizin 21, Heft 4, S. 286-290.

Preuß, Dirk (2014): »Kremation in theologischer Perspektive«, in: Spranger, Tade M./Pasic, Frank/Kriebel, Michael (Hg.): Handbuch des Feuerbestattungswesens, Stuttgart, S. 33-55.

Preuß, Dirk (2015): »Pietät - eine Rekonstruktion in moralphilosophischer Perspektive«, in: ders./Hönings, Lara/Spranger, Tade M. (Hg.): Facetten der Pietät, München, S. 141-334.

Preuß, Dirk (2016): »Zeus(') Platz. Die Zukunft des toten Heimtieres«, in: Benkel, Thorsten (Hg.): Die Zukunft des Todes. Heterotopien des Lebensendes, Bielefeld, S. 181-211.

Przyborski, Aglaja/Wohlrab-Sahr, Monika (2014): Qualitative Sozialforschung, 4. Aufl. München.

Quante, Michael (2006): Einführung in die Allgemeine Ethik, 2. Aufl. Darmstadt. 


\section{Literaturverzeichnis}

Quante, Michael (2014): Menschenwürde und personale Autonomie, Hamburg.

Reichertz, Jo (2012): " Das ist ein Geben und Nehmen<. Mit einem privaten Newsmacher unterwegs. Methodische Probleme bei der Analyse von Feldaufenthalten und erste Überlegungen zum Zusammenspiel von Videojournalisten und Polizisten/Feuerwehrleuten", in: Bidlo, Oliver/Englert, Carina J./Reichertz, Jo: Tat-Ort Medien. Die Medien als Akteure und unterhaltsame Aktivierer, Wiesbaden, S. 7-31.

Reichertz, Jo (2015): »Die Bedeutung der Subjektivität in der Forschung«, in: Forum Qualitative Sozialforschung 16, Heft 3, Art. 33.

Reichertz, Jo (2016): Qualitative und interpretative Sozialforschung. Eine Einladung, Wiesbaden.

Reuband, Karl-Heinz/Blasius, Jörg (1996): »Face-to-face, telefonische und postalische Befragungen. Ausschöpfungsquoten und Antwortmuster in einer Großstadt-Studie«, in: Kölner Zeitschrift für Soziologie und Sozialpsychologie 48, Heft 2, S. 296-318.

Rhan, Felicitas (2016): »Was vom Dandy übrig blieb«, in: Frankfurter Allgemeine Zeitung, 27. August 2016, S. 11.

Ritter, Falko/Keldenich, Christoph (2010): Friedhofspflicht für Totenasche zeitgemäß? Zur Notwendigkeit einer Überprüfung der gegenwärtigen Rechtslage, Königswinter.

Roethlisberger, Fritz J./Dickson, William J. (1964): Management and the Worker, Cambridge.

Rosenthal, Gabriele (2014): Interpretative Sozialforschung, 4. Aufl. Weinheim/Basel.

Rossetto, Kelly R. (2014): »Qualitative Research Interviews. Assessing the Therapeutic Value and Challenges«, in: Journal of Social and Personal Relationships 31, Heft 4, S. 482-489.

Rössler, Beate (2017): Autonomie. Ein Versuch über das gelungene Leben, Berlin.

Russell Hochschild, Arlie (2006): Das gekaufte Herz. Zur Kommerzialisierung der Gefüble, Frankfurt am Main/New York.

Sachmerda-Schulz, Nicole (2017): Selbstbestimmt bis nach dem Tod. Zur Ausbreitung und Normalisierung der anonymen Bestattung, Wiesbaden.

Schlich, Thomas/Wiesemann, Claudia (Hg.) (2001): Hirntod. Zur Kulturgeschichte der Todesfeststellung, Frankfurt am Main.

Schmied, Gerhard (1985): Sterben und Trauern in der modernen Gesellschaft, Opladen.

Schmied, Gerhard (2002): Friedhofsgespräche. Untersuchungen zum ,Wohnort der Toten`, Opladen.

Schneider, Norbert (2010): »Zeig mir das Spiel vom Tod. Sterben, Tote und Tod im Fernsehen und in ausgewählten Kinofilmen «, in: Graf, Friedrich W./Meier, Heinrich (Hg.): Der Tod im Leben. Ein Symposium, 5. Aufl. München, S. 101-124.

Scholz, Sebastian (2006): »Bestattung: IV. Kirchengeschichte«, in: Kasper, Walter et al. (Hg.): Lexikon für Theologie und Kirche, Bd. 2, 3. Aufl. Freiburg/Basel/Wien, S. 323-324.

Scholz, Werner (2000): Hinduismus, Köln. 
Schulz, Felix R. (2013): Death in East Germany 1945-1990, New York/Oxford.

Schulz, Marlen/Ruddat, Michael (2012): »'Let's talk about Sex! Über die Eignung von Telefoninterviews in der qualitativen Sozialforschung «, in: Forum Qualitative Sozialforschung 13, Heft 3, Art. 2.

Schulz Meinen, Haimo (2009): Das Grab im eigenen Garten. Private Friedhöfe in Deutschland?, Frankfurt am Main.

Schütte, Miriam/Schmies, Tobias (2014): »Befragung von speziellen Populationen«, in: Baur, Nina/Blasius, Jörg (Hg.): Handbuch der empirischen Sozialforschung, Wiesbaden, S. 799-809.

Schütz, Alfred (1971a): "Symbol, Wirklichkeit und Gesellschaft«, in: ders.: Gesammelte Aufsätze, Bd. 1: Das Problem der sozialen Wirklichkeit, Den Haag, S. 331-411.

Schütz, Alfred (1971b): »Über die mannigfaltigen Wirklichkeiten«, in: ders.: Gesammelte Aufsätze, Bd. 1: Das Problem der sozialen Wirklichkeit, Den Haag, S. 237-298.

Schütz, Alfred (1971c): »Wissenschaftliche Interpretation und Alltagsverständnis menschlichen Handelns", in: ders.: Gesammelte Aufsätze, Bd. 1: Das Problem der sozialen Wirklichkeit, Den Haag, S. 3-54.

Schütz, Alfred (1971d): »Begriffs- und Theoriebildung in den Sozialwissenschaften «, in: ders.: Gesammelte Aufsätze, Bd. 1: Das Problem der sozialen Wirklichkeit, Den Haag, S. 55-76.

Schütz, Alfred (1972): „Die soziale Welt und die Theorie der sozialen Handlung«, in: ders.: Gesammelte Aufsätze, Bd. 2: Studien zur soziologischen Theorie, Den Haag, S. 3-21.

Schütz, Alfred (1974): Der sinnhafte Aufbau der sozialen Welt, Frankfurt am Main.

Schütz, Alfred/Luckmann, Thomas (2003): Strukturen der Lebenswelt, Konstanz.

Schütze, Fritz (1987): Das narrative Interview in Interaktionsfeldstudien, Hagen.

Schützeichel, Rainer (Hg.) (2006): Emotionen und Sozialtheorie. Disziplinäre Ansätze, Frankfurt am Main/New York.

Schützeichel, Rainer (2017): »Sinnwelten des Trauerns. Eine Analyse der Professionalisierung von Trauerarbeit«, in: Jakoby, Nina/Thönnes, Michaela (Hg.): Zur Soziologie des Sterbens. Aktuelle theoretische und empirische Beiträge, Wiesbaden, S. 113-134.

Seeck, Francis (2017): Recht auf Trauer. Bestattungen aus machtkritischer Perspektive, Münster.

Seibel, Constanze (2018): »Tod im Leben - Leben im Tod. Paradoxien des sozialen Miteinanders", in: Benkel, Thorsten/Meitzler, Matthias (Hg.): Zwischen Leben und Tod. Sozialwissenschaftliche Grenzgänge, Wiesbaden, S. 161-184.

Senge, Konstanze/Schützeichel, Rainer (Hg.) (2013): Hauptwerke der Emotionssoziologie, Wiesbaden.

Simmel, Georg (1999): Soziologie. Untersuchungen über die Formen der Vergesellschaftung, Frankfurt am Main.

Sörries, Reiner (2008): Alternative Bestattungen. Formen und Folgen, Frankfurt am Main.

Sörries, Reiner (2009): Ruhe sanft. Kulturgeschichte des Friedhofs, Kevelaer. 
Sörries, Reiner (2012): Herzliches Beileid. Eine Kulturgeschichte der Trauer, Darmstadt. Sörries, Reiner (2016): Stirbt der Friedhof? Über das Dahinsiechen traditioneller Begräbniskultur, Frankfurt am Main.

Spranger, Tade M. (2000): »Plädoyer für die Aufhebung des Friedhofszwangs bei Feuerbestattungen«, in: Verwaltungsrundschau 46, Heft 5, S. 158-160.

Spranger, Tade M. (2006): »Die Zukunft der Bestattung«, in: Roland, Oliver (Hg.): Friedhof-ade? Die Bestattungskultur des 21. Jahrhunderts, Mannheim, S. 173-178.

Spranger, Tade M. (2014a): »Verfassungsrechtliche Grundlagen«, in: ders./Pasic, Frank/Kriebel, Michael (Hg.): Handbuch des Feuerbestattungswesens, Stuttgart, S. 79-88.

Spranger, Tade M. (2014b): »Landesrechtliche Vorgaben«, in: ders./Pasic, Frank/ Kriebel, Michael (Hg.): Handbuch des Feuerbestattungswesens, Stuttgart, S. 90-111.

Spranger, Tade M. (2014c): »Beisetzung, Urnenzwang, Friedhofszwang«, in: ders./ Pasic, Frank/Kriebel, Michael (Hg.): Handbuch des Feuerbestattungswesens, Stuttgart, S. 235-251.

Spranger, Tade M./Hönings, Lara (2014): »Der strafrechtliche Schutz der Totenasche«, in: Spranger, Tade M./Pasic, Frank/Kriebel, Michael (Hg.): Handbuch des Feuerbestattungswesens, Stuttgart, S. 303-307.

Spranger, Tade M./Pasic, Frank/Kriebel, Michael (Hg.) (2014): Handbuch des Feuerbestattungswesens, Stuttgart.

Stegmann, Michael/Bieber, Ulrich (2012): "Alters- und Renteneinkommen von Witwen und Witwern in Deutschland: Ein Überblick über die Leistungen der GRV und empirische Ergebnisse", in: Deutsche Rentenversicherung, Heft 1/2012, S. 45-68.

Stets, Jan E./Turner, Jonathan H. (Hg.) (2007/2014): Handbook of the Sociology of Emotions, Bd. 1/2, New York.

Stöttner, Carina (2018): „Digitales Jenseits? Virtuelle Identität im postmortalen Stadium«, in: Benkel, Thorsten/Meitzler, Matthias (Hg.): Zwischen Leben und Tod. Sozialwissenschaftliche Grenzgänge, Wiesbaden, S. 185-209.

Thimm, Caja/Nehls, Patrick (2017): »Sharing Grief and Mourning on Instagram. Digital Patterns of Family Memories«, in: Communications 42, Heft 3, S. 327-349.

Tönnies, Ferdinand (2017): Gemeinschaft und Gesellschaft. Grundbegriffe der reinen Soziologie, München.

Turner, Jonathan H./Stets, Jan E. (2005): The Sociology of Emotions, Cambridge.

Wagner, Birgit (2016): »Wann ist Trauer eine psychische Erkrankung? Trauer als diagnostisches Kriterium in der ICD-11 und im DSM-5«, in: Psychotherapeutenjournal 15, Heft 3, S. 250-255.

Wagner, Pia/Hering, Linda (2014): »Online-Befragung«, in: Baur, Nina/Blasius, Jörg (Hg.): Handbuch der empirischen Sozialforschung, Wiesbaden, S. 661-673.

Walter, Tony (1994): The Revival of Death, London/New York.

Weber, Max (1976): Wirtschaft und Gesellschaft. Grundriß der Verstehenden Soziologie, 5. Aufl. Tübingen. 
Weber, Max (1988): »Die >Objektivität`sozialwissenschaftlicher und sozialpolitischer Erkenntnis«, in: ders.: Gesammelte Aufsätze zur Wissenschaftslehre, Tübingen, S. 146-214.

Weissman, Arlene N./Steer, Robert A./Lipton, Douglas S. (1986): »Estimating Illicit Drug Use Through Telephone Interviews and the Randomized Response Technique«, in: Drug and Alcohol Dependence 18, Heft 3, S. 225-233.

Winkel, Heidemarie (2002): 'Trauer ist doch ein großes Gefühl... Zur biographiegenerierenden Funktion von Verlusterfahrungen und der Codierung von Trauerkommunikation, Konstanz.

Winkel, Heidemarie (2008): »Trauer als Biographiegenerator«, in: Forum Qualitative Sozialforschung 9, Heft 1, Art. 50.

Wissert, Michael (2013): „Wirkungen von Trauerbegleitung im Rahmen der emotionalen und sozialen Bewältigung von tiefgehenden und komplizierten Trauerprozessen«, Zugriff: http://www.projekt-trauerleben.de/index.html (eingesehen am 15. Juni 2019).

Worden, J. William (2011): Beratung und Therapie in Trauerfällen. Ein Handbuch, 4. Aufl. Bern. 


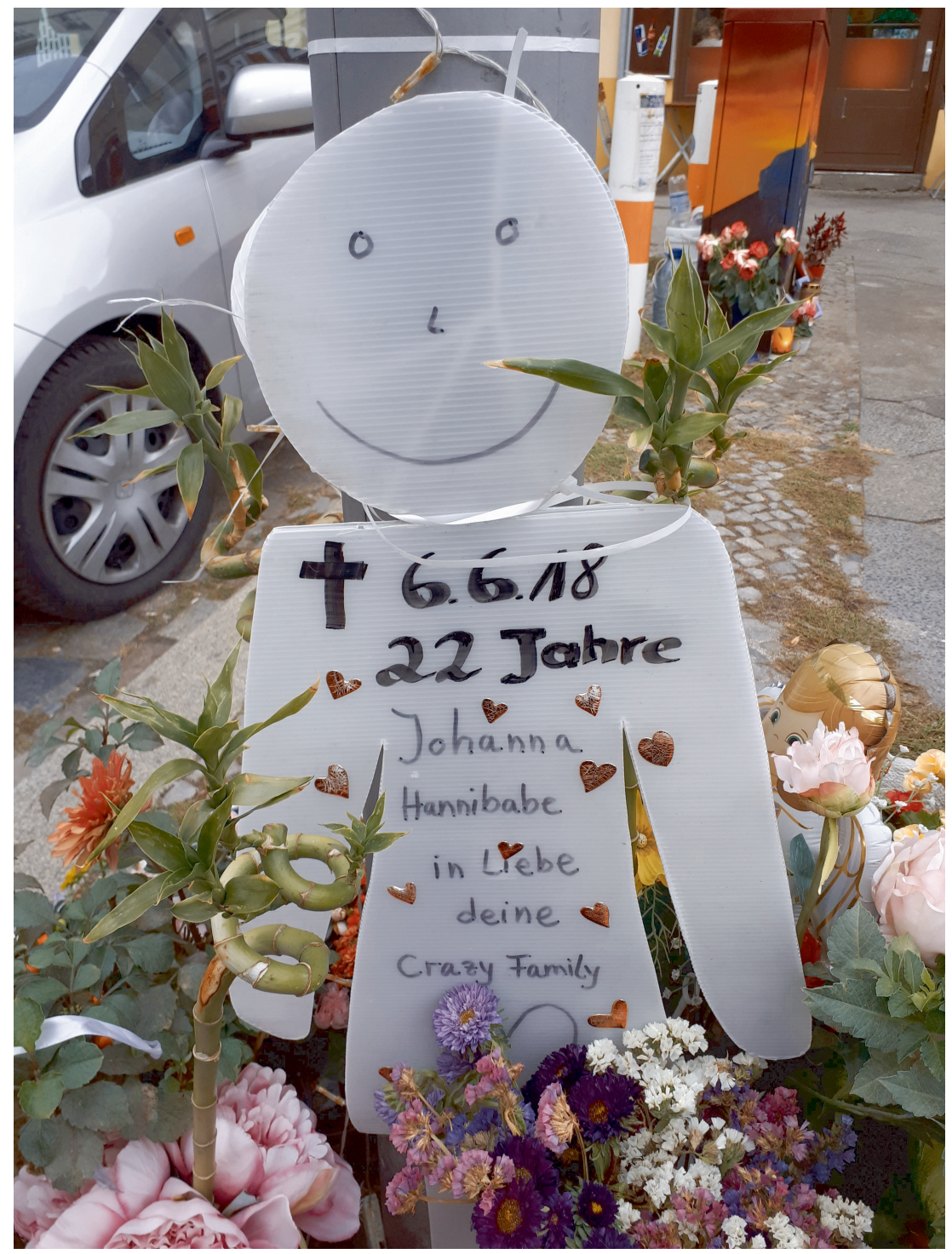




\section{Die Autoren}

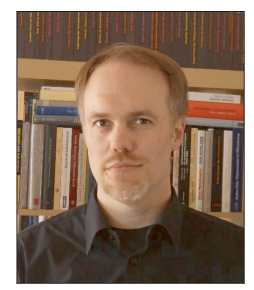

Dr. Thorsten Benkel, geb. in Kaiserslautern. Akademischer Rat für Soziologie an der Universität Passau. Leiter mehrerer Forschungsprojekte im Kontext von Sterben, Tod und Trauer. Ethnografische Arbeit u.a. im Kontext von Privatreligionen, Sepulkralkultur, Drogenszene, Prostitutionsmilieu, Obduktion und Gefängnis. Studium der Soziologie, Philosophie, Psychologie und Literaturwissenschaft. Promotion in Frankfurt am Main über das Wirklichkeitsverständnis der Soziologie. Schwerpunkte: Qualitative Sozialforschung, Mikrosoziologie, Soziologie des Wissens, der Medizin, des Körpers und des Rechts.

Thorsten.Benkel@uni-passau.de

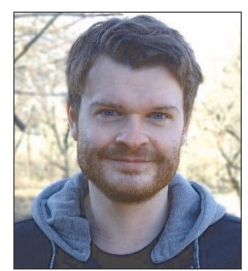

Matthias Meitzler M.A., geb. in Groß-Umstadt. Wissenschaftlicher Mitarbeiter und Lehrbeauftragter an der Universität Passau. Promotionsprojekt zur postmortalen Individualisierung an der Universität Bayreuth. Feldforschung u.a. im Hospiz bzw. im Krankenhaus, auf dem Friedhof und im SM-Kontext. Studium der Soziologie, Geschichte und Psychoanalyse an der Goethe-Universität Frankfurt am Main sowie Zweitstudium der Psychologie an der Universität Hagen. Schwerpunkte: Qualitative Sozialforschung, Wissens- und Thanatosoziologie, Mediatisierungsforschung, Mensch-Tier-Beziehungen.

Matthias.Meitzler@uni-passau.de

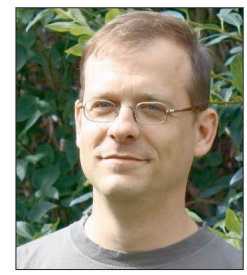

Dr. Dr. Dirk Preuß, geb. in Nürnberg. Wissenschaftlicher Mitarbeiter an der Tierärztlichen Hochschule Hannover. Studium der Biologie und der Katholischen Theologie. Promotionen in der Wissenschaftsgeschichte zur Anthropologie im 20. Jahrhundert sowie in Angewandter Ethik zum Begriff der Pietät. Schwerpunkte: Tier- und Medizinethik, Wissenschaftsgeschichte, Sepulkralkultur.

Dirk.Preuss@tibo-hannover.de 


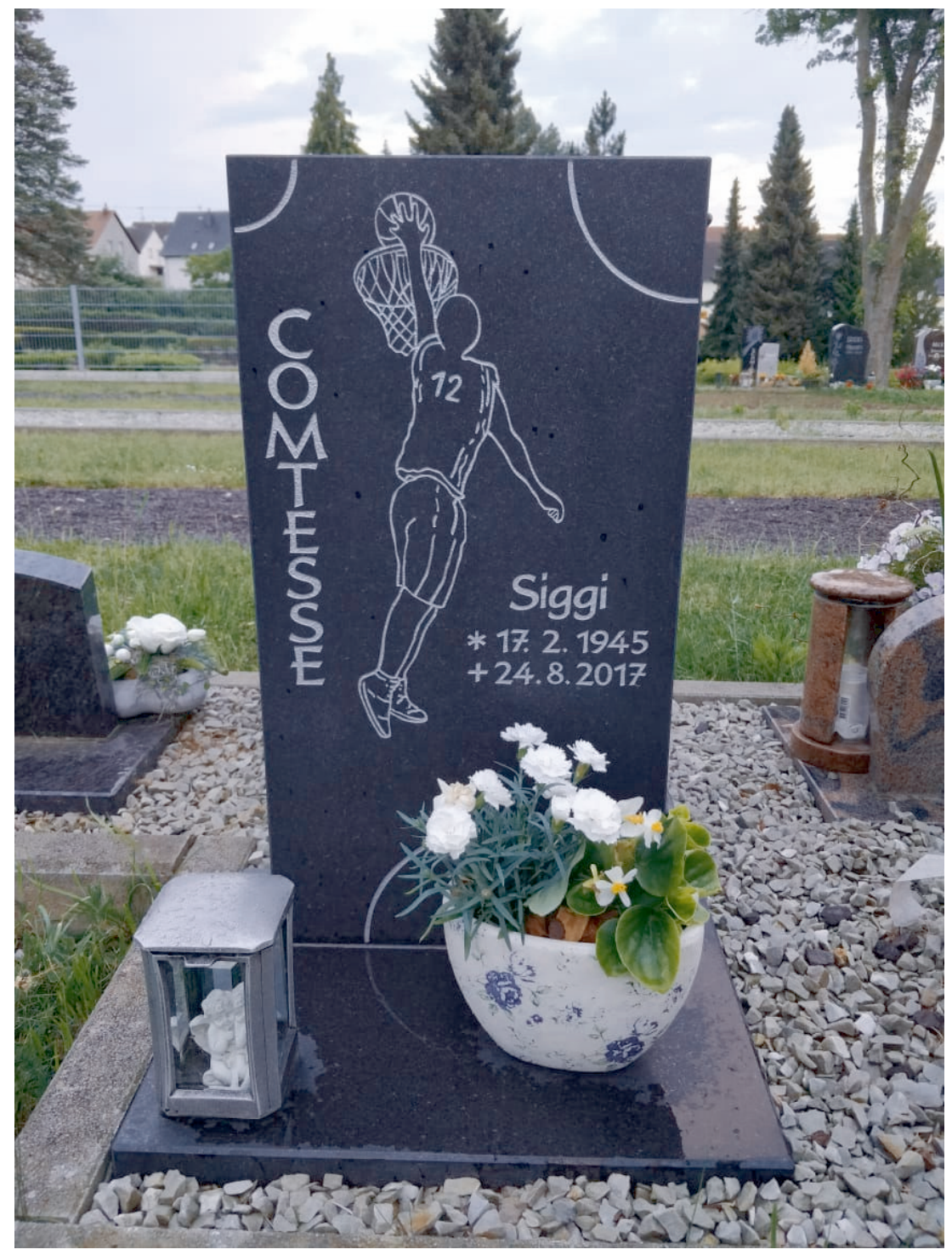




\section{Abbildungen}

$\begin{array}{rll}\text { Seite } & \text { Abbildung } & \text { Quelle } \\ & & \\ 6 & \text { 'Trauerautomat‘ auf einem Friedhof } & \text { Benkel/Meitzler } \\ 9 & \text { Gesichter im Oval } & \text { Benkel/Meitzler } \\ 36 & \text { Hinterbliebene vor einer Urnenwand } & \text { Benkel/Meitzler } \\ 53 & \text { Adressierung am Grab } & \text { Benkel/Meitzler } \\ 83 & \text { Verrätselung post mortem } & \text { Benkel/Meitzler } \\ 95 & \text { Worte zwischen Intimität und Öffentlichkeit } & \text { Benkel/Meitzler } \\ 105 & \text { Steinerne Trauer } & \text { Benkel/Meitzler } \\ 120 & \text { Pinocchios Tränen } & \text { Benkel/Meitzler } \\ 126 & \text { Eine improvisierte Trauerstätte: } & \text { Benkel/Meitzler } \\ & \text { Das Loveparade-Gelände in Duisburg } & \\ 164 & \text { Quo vadis, Friedhof? } & \text { Benkel/Meitzler } \\ 175 & \text { Urnenstelen auf niederländischem Friedhof } & \text { Benkel/Meitzler } \\ 185 & \text { Grabstätte als Motivationsquelle } & \text { Benkel/Meitzler } \\ 188 & \text { Pietätvoller Hinweis im Straßenverkehr } & \text { Benkel/Meitzler } \\ 190 & \text { Colemans Badewanne } & \text { Bearbeitete } \\ & & \text { Darstellung } \\ 194 & \text { Umfragegrafik 1: Beisetzung von Asche } & \text { Benkel/Meitzler } \\ 200 & \text { Umfragegrafik 2: Bedeutung der Grabanlage } & \text { Benkel/Meitzler } \\ 202 & \text { Geburt und Tod symbolisch vereint } & \text { Benkel/Meitzler } \\ 216 & \text { Der Unfallort als Trauerort: } & \text { Benkel/Meitzler } \\ & \text { Aneignung im öffentlichen Raum } & \\ 217 & \text { Autorenfotos } & \text { Benkel/Meitzler/ } \\ & \text { Rückblick auf eine Lebenswelt } & \text { Preuß } \\ 218 & \text { Benkel/Meitzler } \\ 220 & \text { Sepulkrale Umbaumaßnahmen } & \text { Benkel/Meitzler }\end{array}$




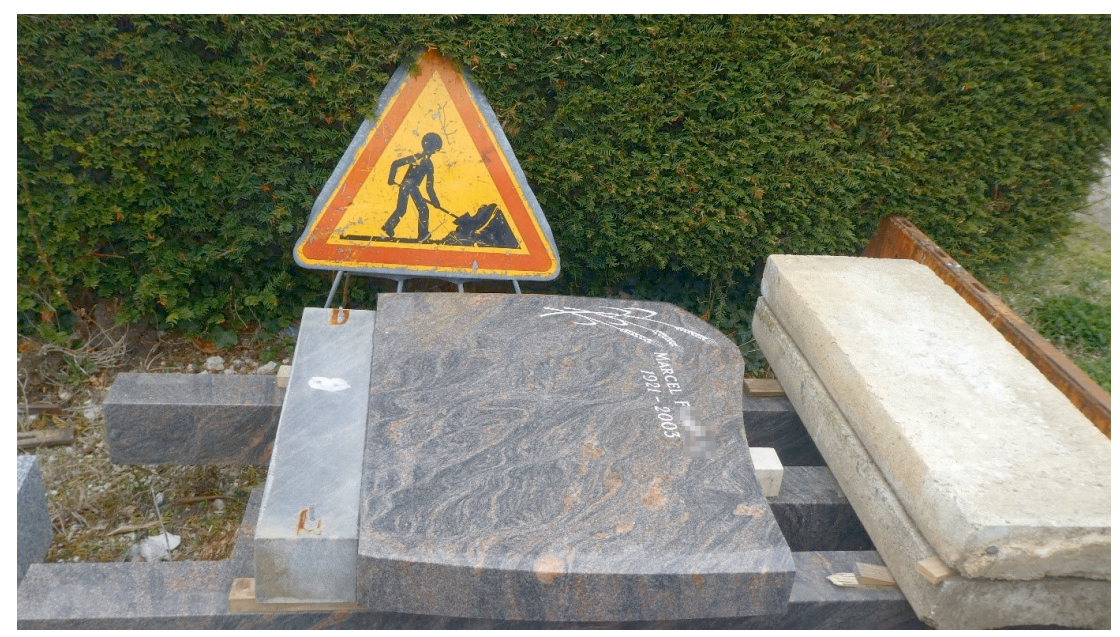

